\title{
Planform Characterization of a High Lift, Low Speed, Ground Effect Glider
}

Meagan L. Hubbell

West Virginia University

Follow this and additional works at: https://researchrepository.wvu.edu/etd

\section{Recommended Citation}

Hubbell, Meagan L., "Planform Characterization of a High Lift, Low Speed, Ground Effect Glider" (2012). Graduate Theses, Dissertations, and Problem Reports. 4869.

https://researchrepository.wvu.edu/etd/4869

This Dissertation is protected by copyright and/or related rights. It has been brought to you by the The Research Repository @ WVU with permission from the rights-holder(s). You are free to use this Dissertation in any way that is permitted by the copyright and related rights legislation that applies to your use. For other uses you must obtain permission from the rights-holder(s) directly, unless additional rights are indicated by a Creative Commons license in the record and/ or on the work itself. This Dissertation has been accepted for inclusion in WVU Graduate Theses, Dissertations, and Problem Reports collection by an authorized administrator of The Research Repository @ WVU.

For more information, please contact researchrepository@mail.wvu.edu. 


\title{
Planform Characterization of a High Lift, Low Speed, Ground Effect Glider
}

\author{
Meagan L. Hubbell \\ Dissertation submitted to the \\ College of Engineering and Mineral Resources \\ at West Virginia University \\ in partial fulfillment of the requirements \\ for the degree of \\ Doctor of Philosophy \\ in \\ Aerospace Engineering
}

Dr. James Smith, PhD., Committee Chair

Dr. Gerald Angle, PhD.

Dr. MaryAnn Clarke, PhD.

Dr. Eric Johnson, $\mathrm{PhD}$.

Dr. John Kuhlman, PhD.

Department of Mechanical and Aerospace Engineering

Morgantown, West Virginia

2012

Keywords: Ground Effect, Low Speed, Spanwise Wing Curvature

Copyright 2012 Meagan L. Hubbell 


\section{Abstract \\ Planform Characterization of a High Lift, Low Speed, Ground Effect Glider Meagan L. Hubbell}

The main objective of this research was to design and develop a planform shape for a single passenger, unpowered, subsonic glider that relies on gravitational forces for momentum. The wing structure and aerodynamic shape optimized the benefits of near-ground flight (i.e. the increased lift and decreased induced drag), and as a result reduced the overall aircraft weight and wingspan, and enhanced the maneuverability of the craft.

The design faced many challenges as a result of flight in the ground effect regime. There were natural instabilities, primarily in the longitudinal direction that caused the glider to pitch up. In addition, the wing size needed to be minimized in order to contain flight to the ground effect regime while maintaining enough lift to generate flight for a given rider.

An initial straight wing design was developed to determine if a ground effect vehicle without specialty aerodynamic features (such as wingtips, dihedral, twist, etc) could be created. As a result, a basic glider was designed that had a $10.6 \mathrm{ft}$ root chord length with a wing span of $18 \mathrm{ft}$; this design accommodated the physical requirements of a pilot while maintaining acceptable but limited maneuverability.

In an effort to enhance aerodynamic performance, above that achieved by a straight wing design, variations in the planform shape were examined computationally in ground effect. These changes were inspired by the wing structures of birds that utilize ground effect for a large portion of their flight regime such as seagulls and pelicans. The modifications include twisting and curving the wings in an effort to vary the frontal areas and arc the wings towards the ground plane. The optimal design configurations were then tested experimentally in the subsonic wind 
tunnel, at reduced Reynolds number, to verify the performance characteristic trends and compared with the predicted CFD and analytical results.

Results indicated that $10 \%$ twisted wings produced the greatest improvement in the lift profile as compared to the baseline straight wing design of the glider while in ground effect. This allowed for a reduction in the overall size of the glider by $4.5 \%$ which allows for an overall reduction in weight and a decrease in the wing span allowing for an increasing in the banking angle and thus an increase in the maneuverability. 


\section{Table of Contents}

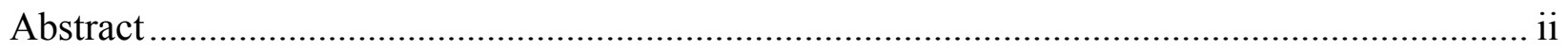

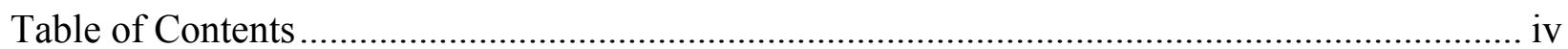

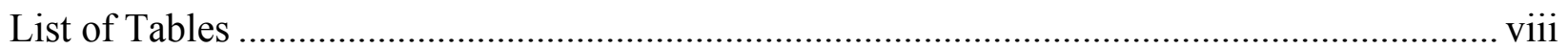

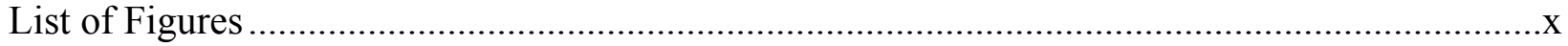

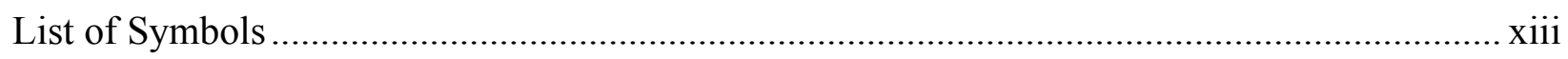

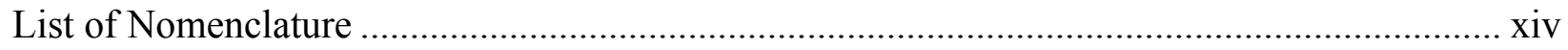

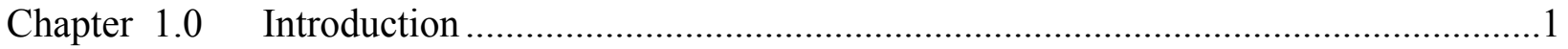

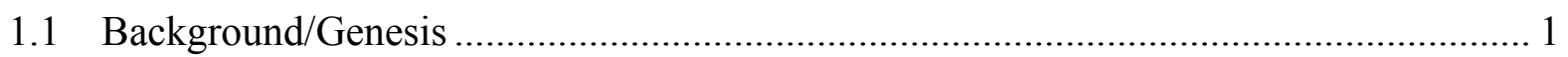

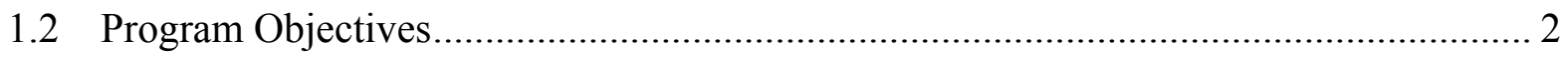

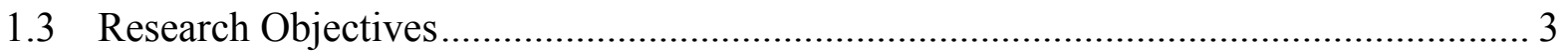

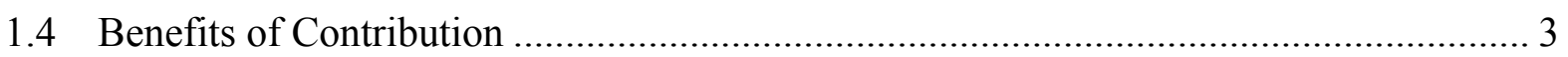

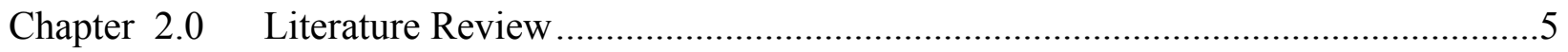

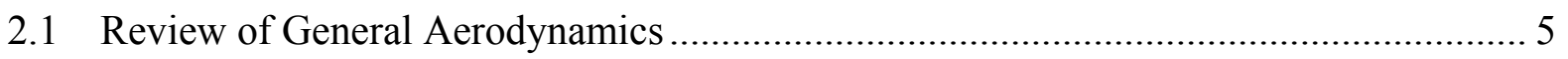

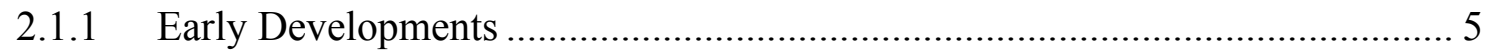

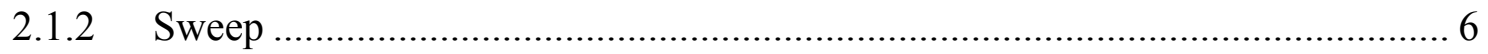

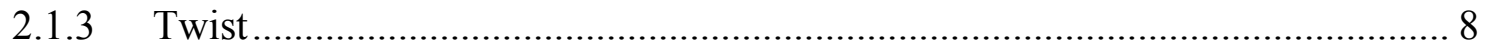

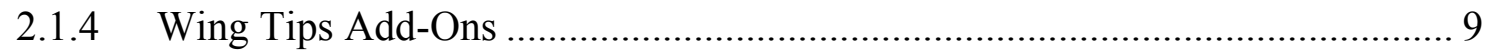

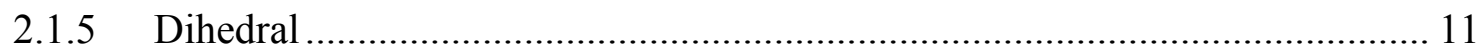

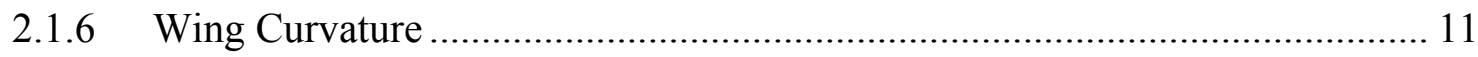

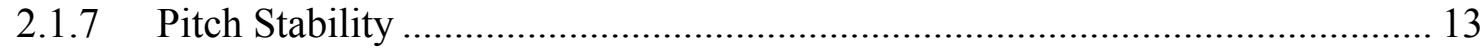

2.2 Aerodynamic Ground Effect Research ....................................................................... 13

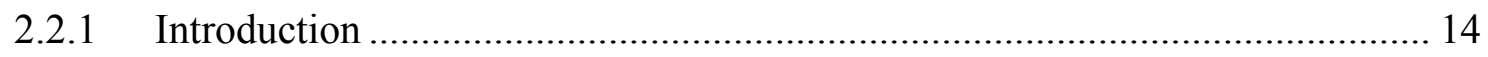

2.2.2 Historical Overview .............................................................................. 14

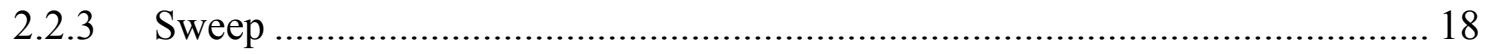

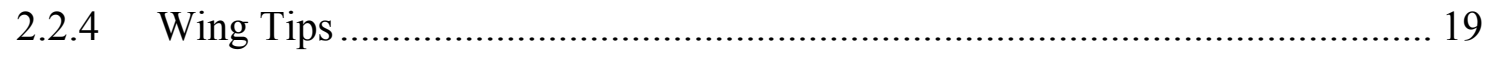

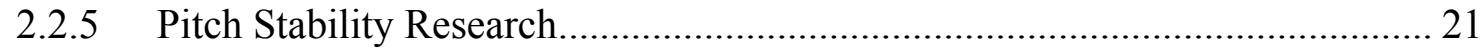

2.2.6 Numerical Wing-in-Ground Effect Research............................................... 21

2.2.7 Computational Wing-in-Ground Effect Research ............................................ 22

2.2.8 Experimental Wing-in-Ground Effect Research ............................................. 23

2.2.9 Ekranoplan Design Problems ...................................................................... 26

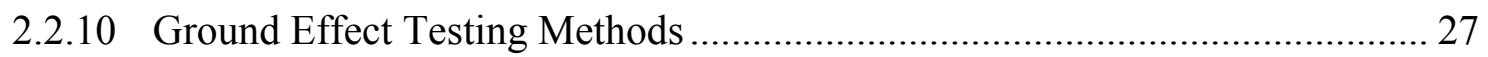




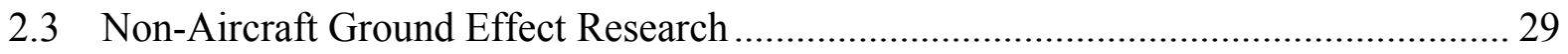

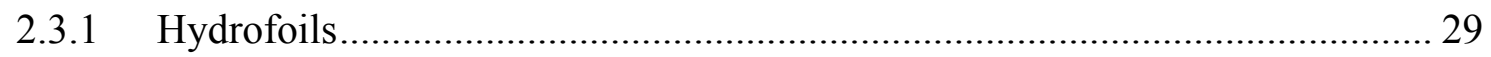

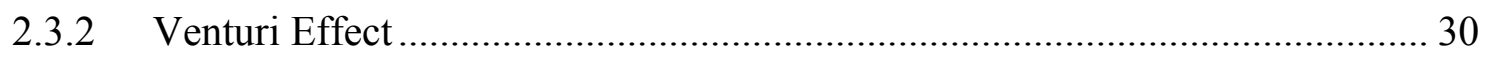

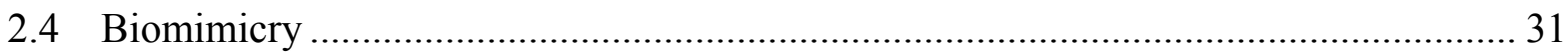

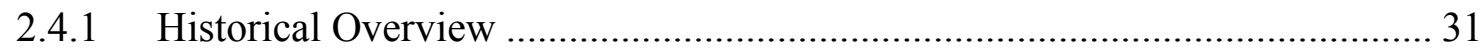

2.4.2 Morphing Wing Research ...................................................................... 32

2.4.3 Physiology of Birds in Flight ……………………................................... 33

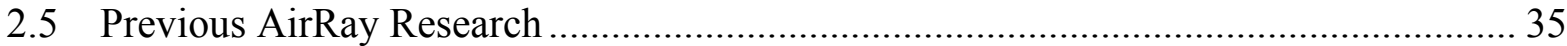

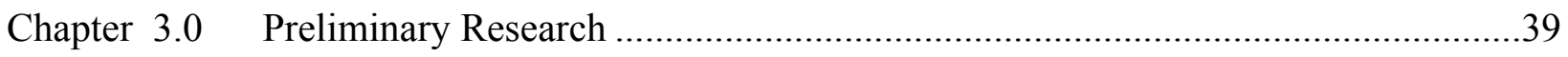

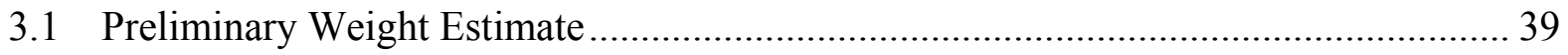

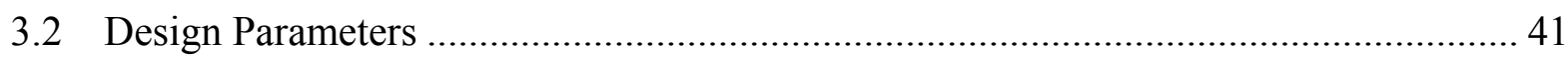

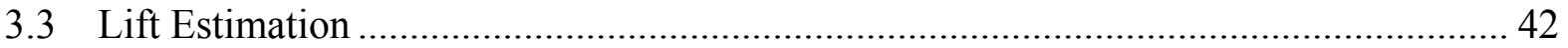

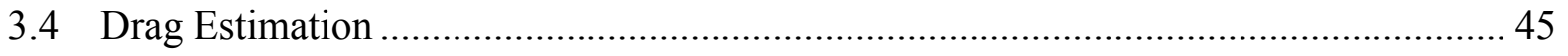

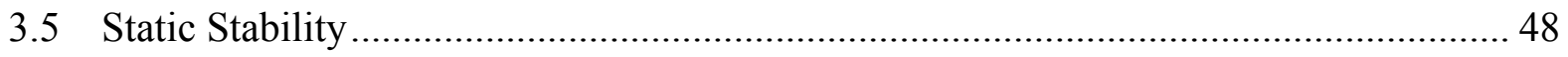

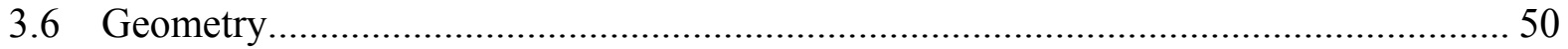

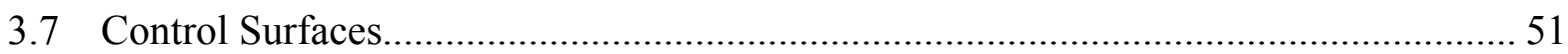

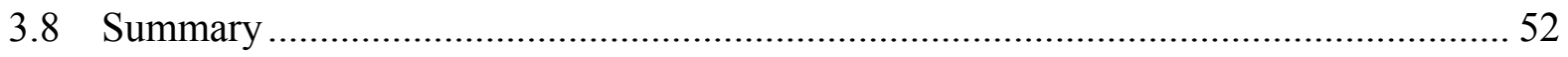

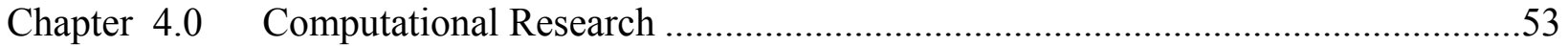

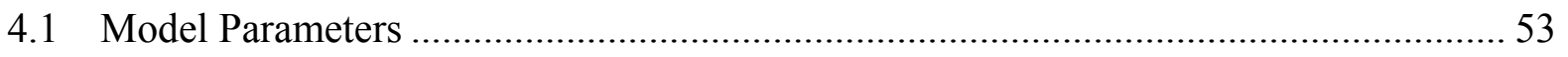

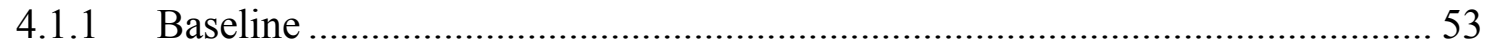

4.1.2 Spanwise Wing Curvature …………………….................................... 54

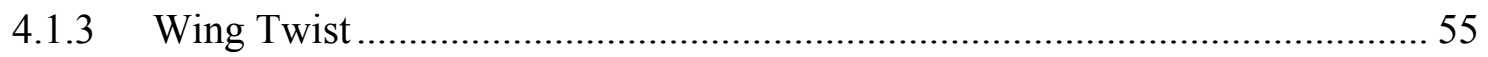

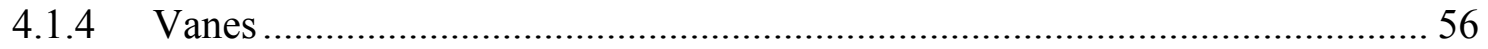

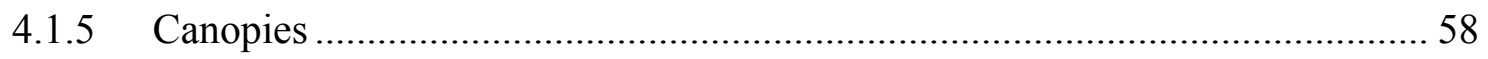

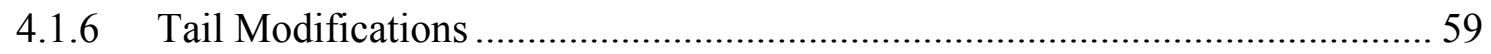

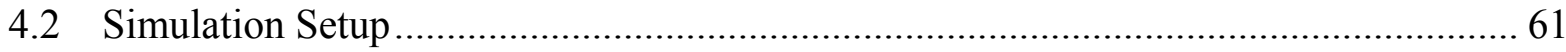

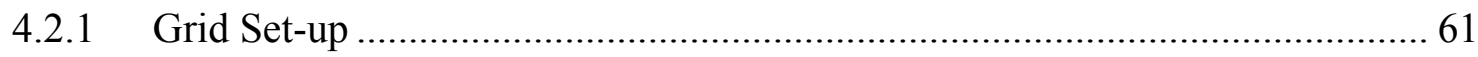

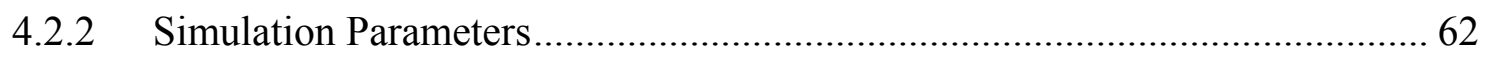

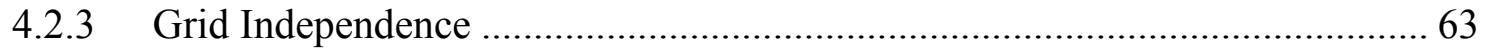

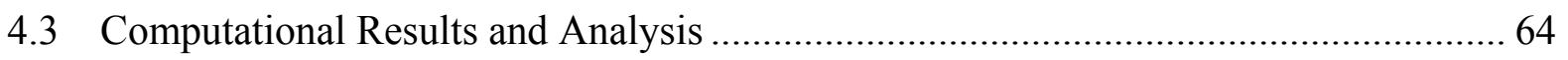

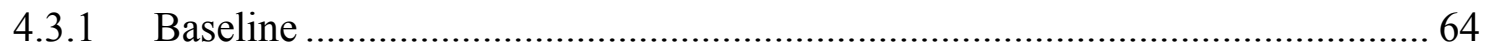




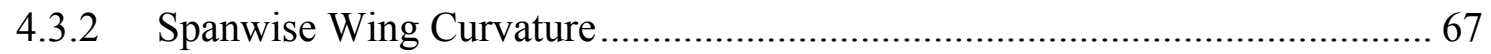

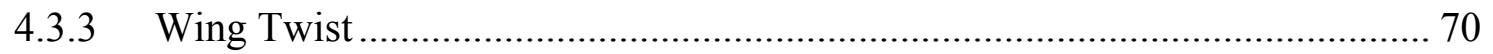

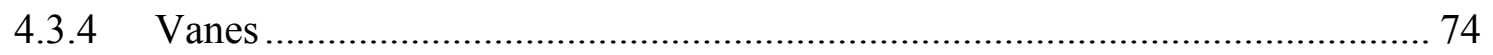

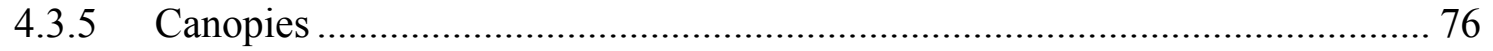

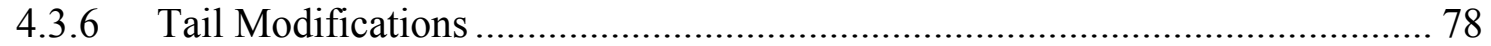

4.3.7 Assessment of Computational Research .......................................................... 80

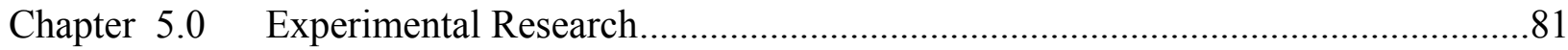

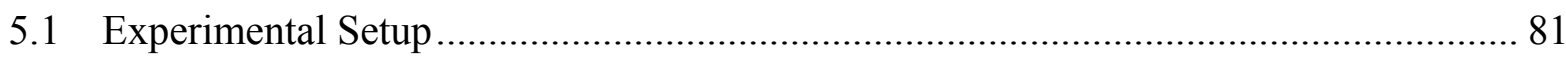

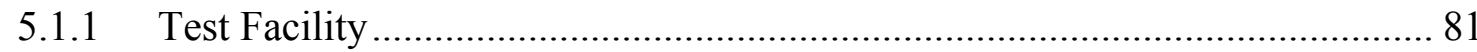

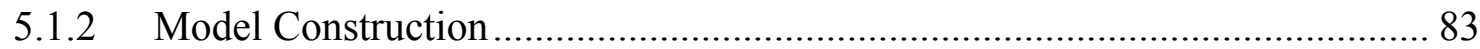

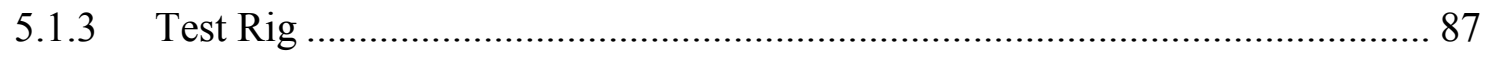

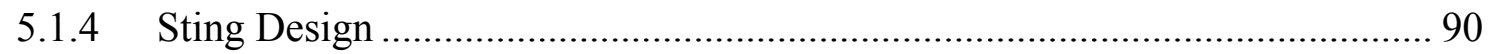

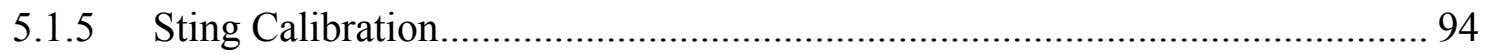

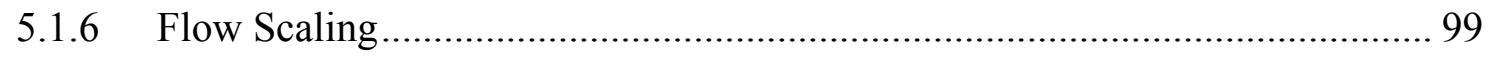

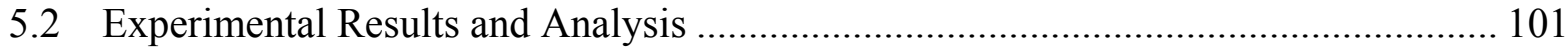

5.2.1 Reynolds Number Comparison ................................................................ 101

5.2.2 Boundary Layer Trip Analysis .................................................................... 103

5.2.3 Baseline Model Testing ........................................................................ 116

5.2.4 Twisted Model Testing............................................................................ 118

5.2.5 Spanwise Curvature Model Testing ............................................................... 123

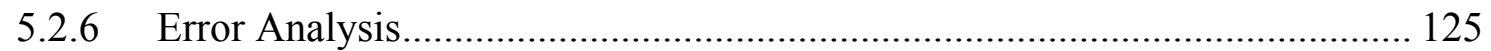

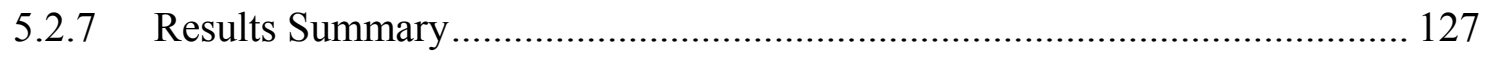

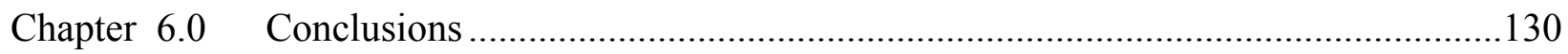

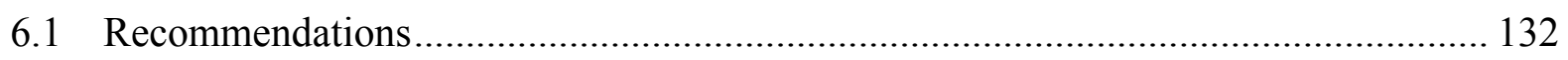

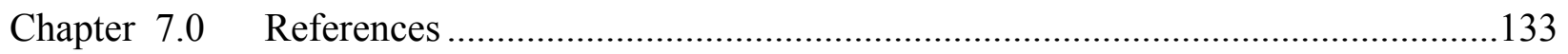

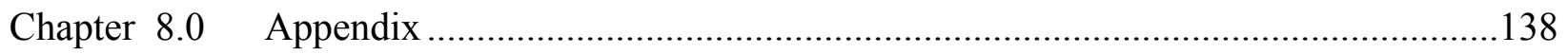

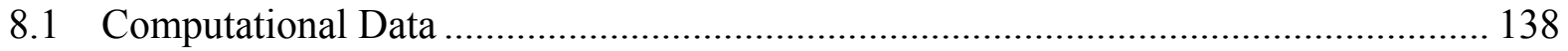

8.2 Experimental Data - Freestream Model (not-in-ground effect) ................................. 140

8.3 Experimental Data - Baseline Model (in-ground effect)........................................... 142

8.4 Experimental Data - 6\% Twist (in-ground effect) ………………............................ 144

8.5 Experimental Data - 10\% Twist (in-ground effect) ………........................................ 147

8.6 Experimental Data - 10\% Spanwise Curve (in-ground effect) ……………………... 150 
8.7 Experimental Data Variance. 


\section{List of Tables}

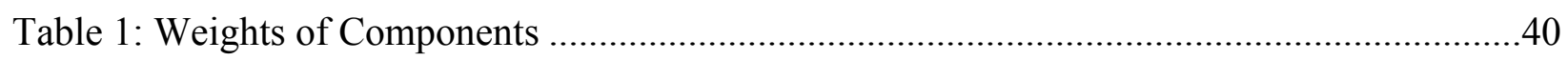

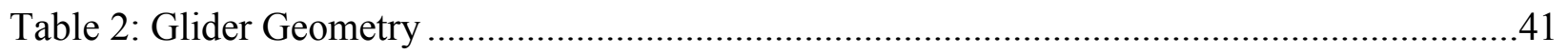

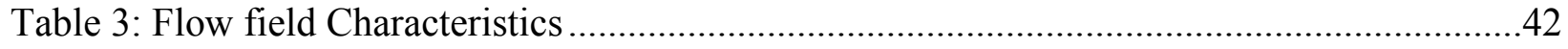

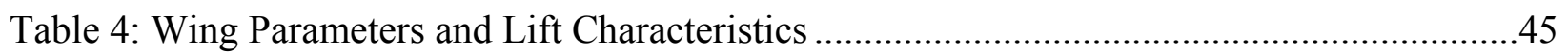

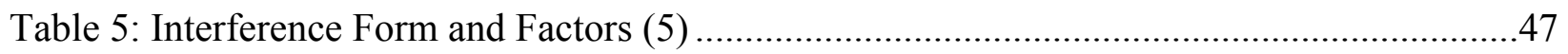

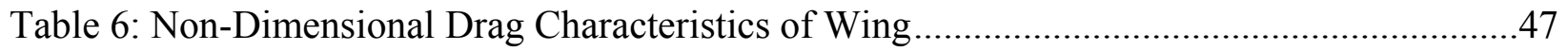

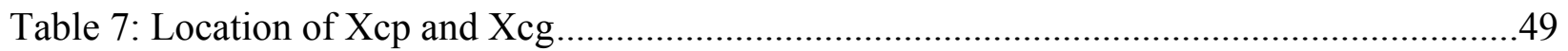

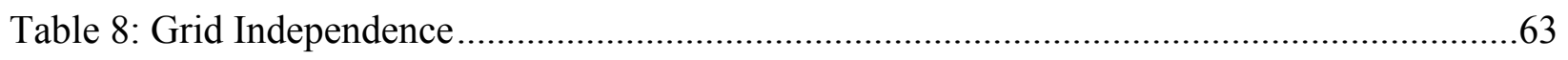

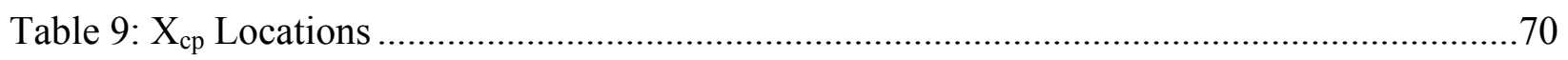

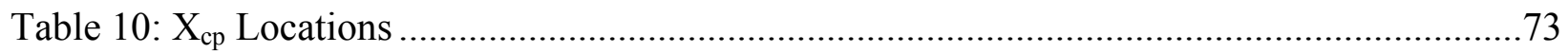

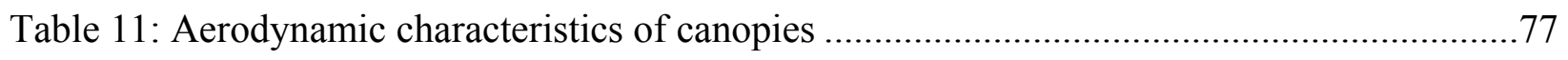

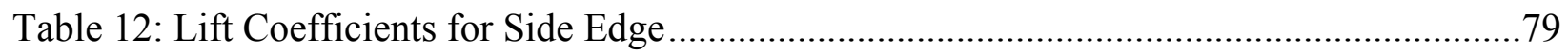

Table 13: Lift and Drag Coefficients for Front Edge ……....................................................79

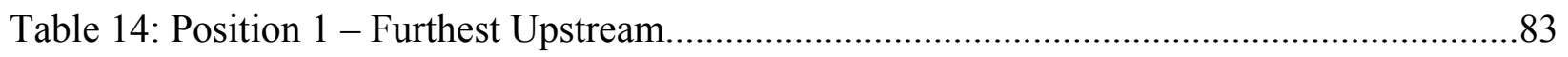

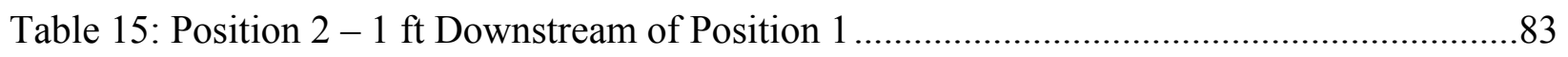

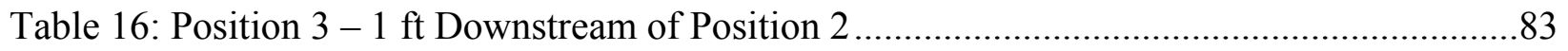

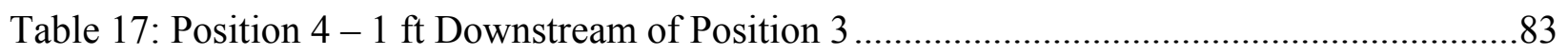

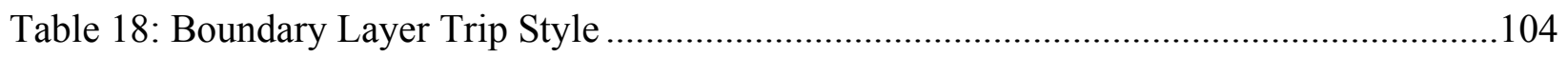

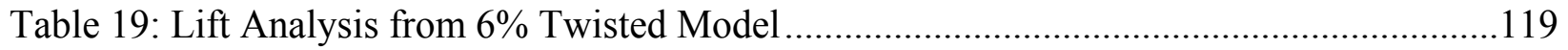

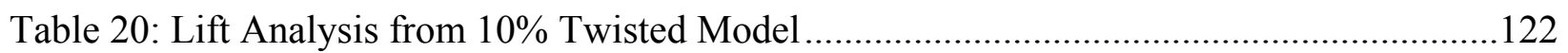

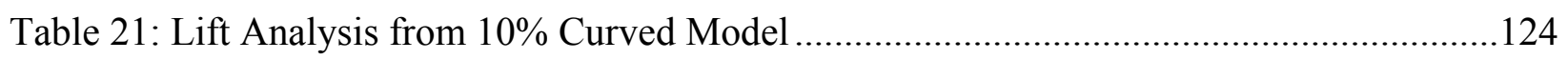

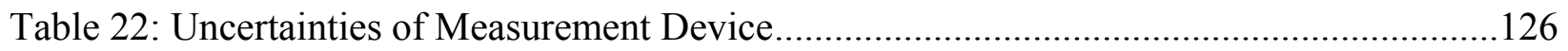

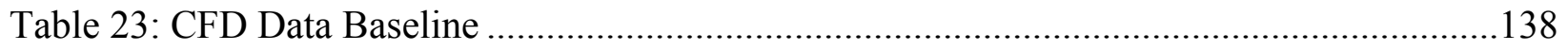

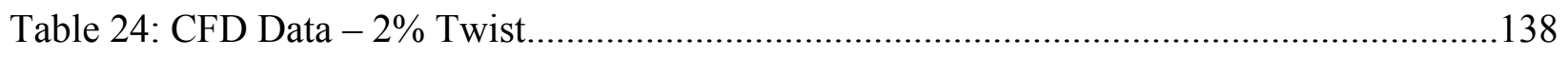

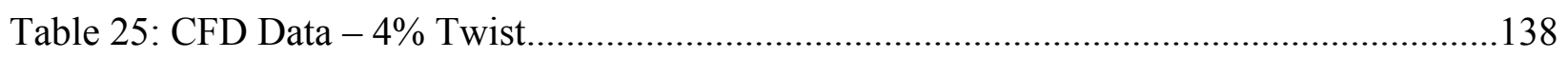

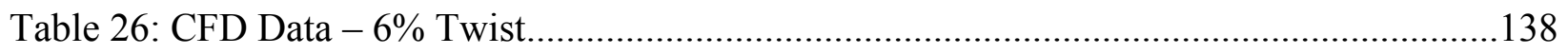

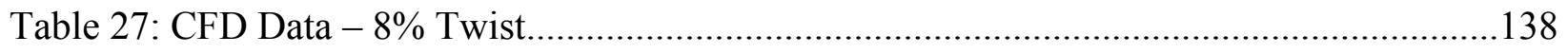

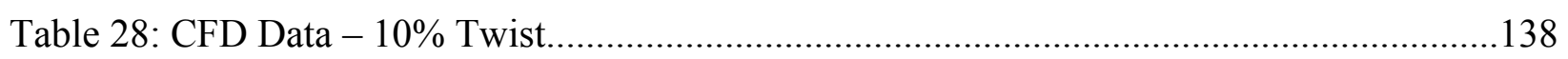

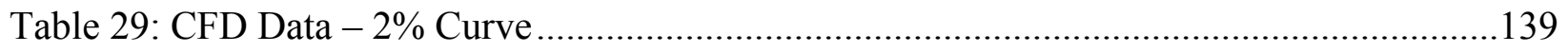

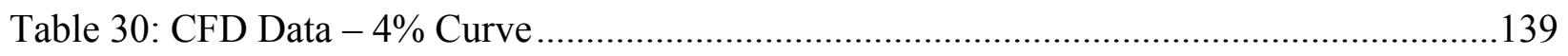

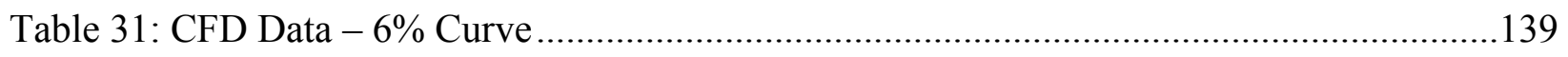

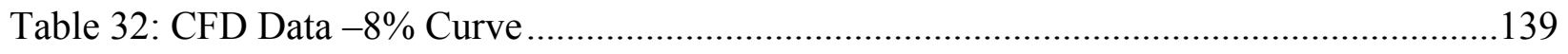

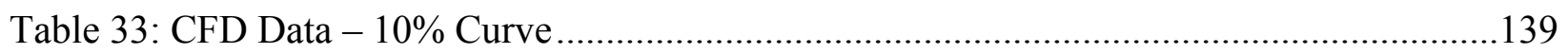

Table 34: Experimental Data Runs - Baseline Model (OGE) - $0^{\circ}$ Angle of Attack .....................140

Table 35: Experimental Data Runs - Baseline Model (OGE) - $5^{\circ}$ Angle of Attack .....................140

Table 36: Experimental Data Runs - Baseline Model (OGE) - $10^{\circ}$ Angle of Attack ..................141 
Table 37: Experimental Data Runs - Baseline Model (OGE) - $15^{\circ}$ Angle of Attack 141

Table 38: Experimental Data Runs - Baseline Model (IGE) - $0^{\circ}$ Angle of Attack. 142

Table 39: Experimental Data Runs - Baseline Model (IGE) - $5^{\circ}$ Angle of Attack. 142

Table 40: Experimental Data Runs - Baseline Model (IGE) - $10^{\circ}$ Angle of Attack .143

Table 41: Experimental Data Runs - Baseline Model (IGE) - $15^{\circ}$ Angle of Attack .143

Table 42: Experimental Data Runs $-6 \%$ Twist Model (IGE) $-(-5)^{\circ}$ Angle of Attack 144

Table 43: Experimental Data Runs $-6 \%$ Twist Model (IGE) - $0^{\circ}$ Angle of Attack 144

Table 44: Experimental Data Runs - 6\% Twist Model (IGE) - $5^{\circ}$ Angle of Attack 145

Table 45: Experimental Data Runs - 6\% Twist Model (IGE) - $10^{\circ}$ Angle of Attack 145

Table 46: Experimental Data Runs - 6\% Twist Model (IGE) - $15^{\circ}$ Angle of Attack 146

Table 47: Experimental Data Runs - 10\% Twist Model (IGE) - (-5) ${ }^{\circ}$ Angle of Attack 147

Table 48: Experimental Data Runs - 10\% Twist Model (IGE) - $0^{\circ}$ Angle of Attack 147

Table 49: Experimental Data Runs - 10\% Twist Model (IGE) - $5^{\circ}$ Angle of Attack 148

Table 50: Experimental Data Runs - 10\% Twist Model (IGE) - $10^{\circ}$ Angle of Attack 148

Table 51: Experimental Data Runs - 10\% Twist Model (IGE) - $15^{\circ}$ Angle of Attack

Table 52: Experimental Data Runs - 10\% Spanwise Curve Model (IGE) - $0^{\circ}$ Angle of Attack150 Table 53: Experimental Data Runs - 10\% Spanwise Curve Model (IGE) - $5^{\circ}$ Angle of Attack 150 Table 54: Experimental Data Runs - 10\% Spanwise Curve Model (IGE) - $10^{\circ}$ Angle of Attack 151 Table 55: Experimental Data Runs - 10\% Spanwise Curve Model (IGE) - $15^{\circ}$ Angle of Attack151 Table 56: Variation in the Experimental Data Set across Test Runs 152

Table 57: Standard Deviation in the Experimental Data Set across Test Runs .152 


\section{List of Figures}

Figure 1: Concept Design of AirRay (1) ...............................................................................

Figure 2: Spanwise Curvature (left), Twist (right) .................................................................

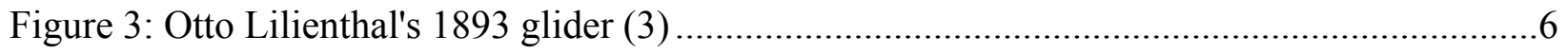

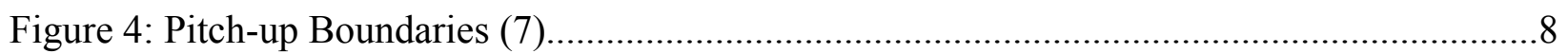

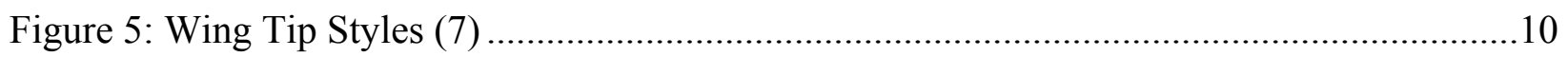

Figure 6: Spanwise curvature (9) (left) and planform curvature (10) (right) ............................12

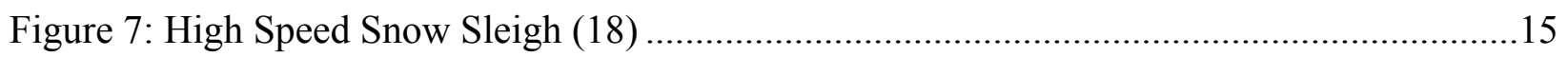

Figure 8: Collection of Russian Ekranoplan Designs (14) ...................................................... 16

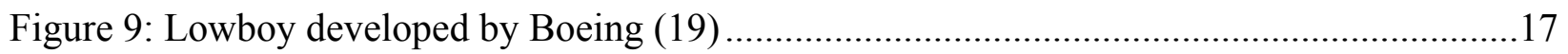

Figure 10: Large Weilandcraft developed by Weiland (19) ....................................................17

Figure 11: Boeing Pelican by Phantom Works (20) .............................................................17

Figure 12: Theoretical Effect of Aspect Ratio and Sweep Angle on Lift-Curve Slope (21)........19

Figure 13: Aerodynamic Configuration of Prototype CM-2 (2) .............................................20

Figure 14: Concept design by De Divitiis (24) ...................................................................21

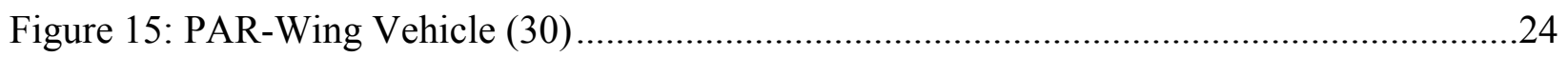

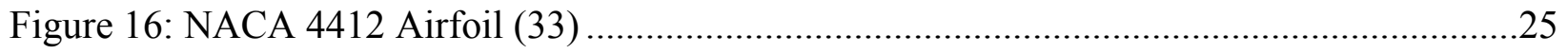

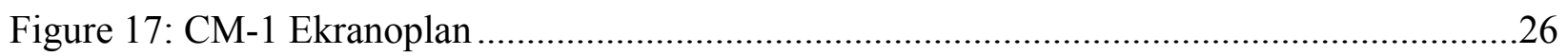

Figure 18: Composite Wing Ekranoplan (2)...................................................................27

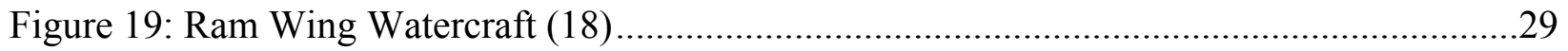

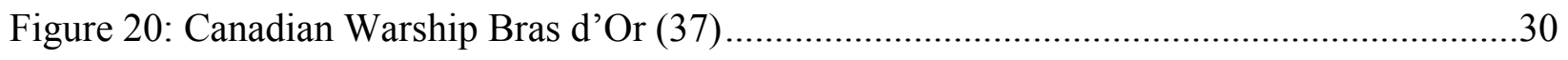

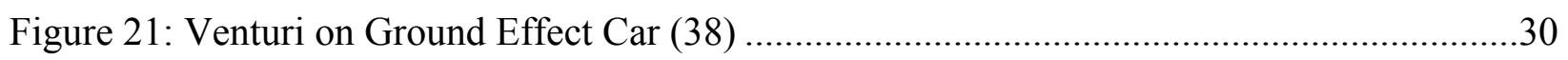

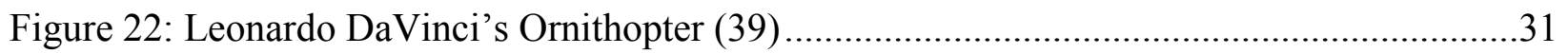

Figure 23: Robotic fly designed by Harvard University team (40) ..........................................32

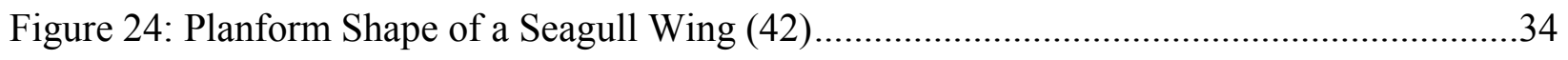

Figure 25: Spanwise Distribution of the Twist of a Seagull Wing (42) ....................................34

Figure 26: Front Profile of a Flapping Seagull Wing (42) ......................................................35

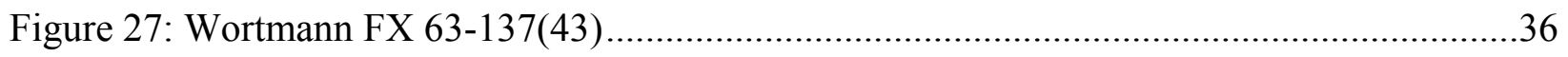

Figure 28: Wortmann FX 63-137 Lift versus Angle of Attack (44) .........................................36

Figure 29: Wortmann FX 63-137 Drag versus Lift (44).......................................................... 37

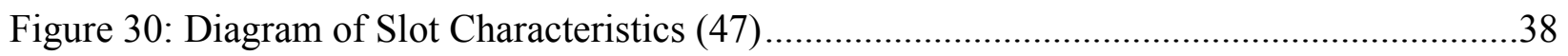

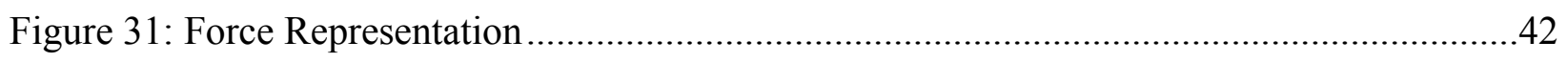

Figure 32: 3-D Lift Slope of Wortmann FX 63-137 .......................................................44

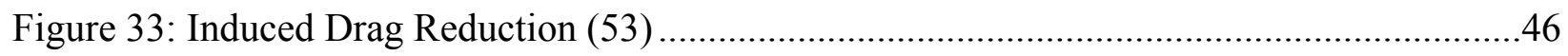

Figure 34: Concept Drawing of Proposed Straight Wing Design............................................50

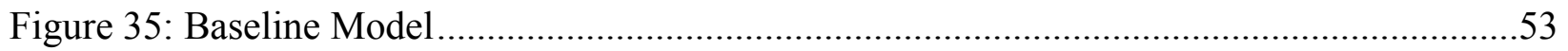

Figure 36: Concept Drawing of Proposed Wing Curvature....................................................54 
Figure 37: Concept Drawing of Proposed Wing Twist ......................................................55

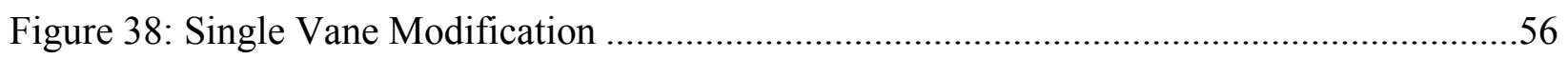

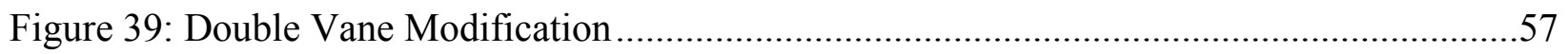

Figure 40: Canopy Design: 5 inch Maximum Height............................................................58

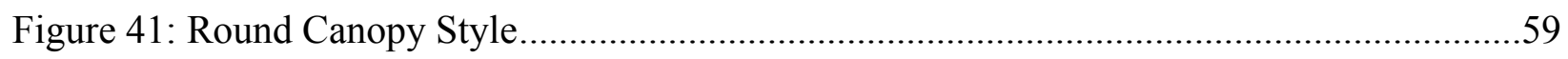

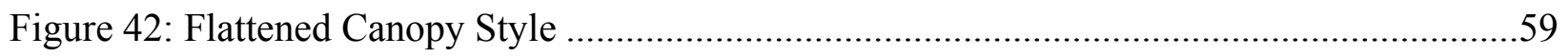

Figure 43: Tail Section with Highlighted Areas of Interest...................................................60

Figure 44: Tail Section with Split Tail ...........................................................................61

Figure 45: Lift Coefficient Comparison of Baseline Configuration Data ..................................65

Figure 46: Drag Coefficient Comparison of Baseline Configuration Data ................................66

Figure 47: Lift Coefficients for Spanwise Curved Wings .....................................................67

Figure 48: Drag Coefficients for Spanwise Curved Wing .......................................................68

Figure 49: Moment Coefficient for Spanwise Wing Curvature versus Angle of Attack..............69

Figure 50: Lift Coefficients for Twisted Wing ..................................................................... 71

Figure 51: Drag Coefficients for Twisted Wing ........................................................................ 72

Figure 52: Moment Coefficient for Wing Twist versus Angle of Attack..................................73

Figure 53: Velocity Profile of Baseline Model Demonstrating Wake.......................................74

Figure 54: Baseline Model with Single Vane ....................................................................75

Figure 55: Baseline Model with Double Vanes .........................................................................76

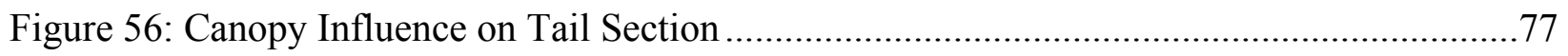

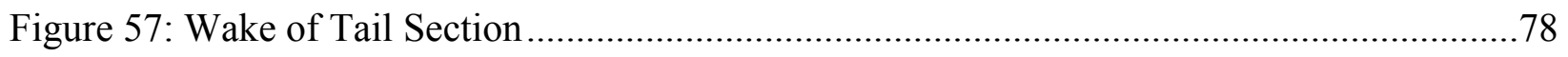

Figure 58: WVU Subsonic Closed Loop Wind Tunnel (57) ..................................................81

Figure 59: Wind Tunnel Top View with Vane and Wall Placement ........................................82

Figure 60: Balsa Wood Cross-Section of Wing......................................................................84

Figure 61: Balsa Wood Cross-Section of Wing with Styrofoam Inlay .....................................85

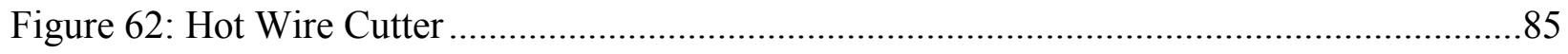

Figure 63: Econocoat Covered Wing Form for Baseline Configuration ....................................86

Figure 64: Complete Model of Baseline Geometry ..............................................................8

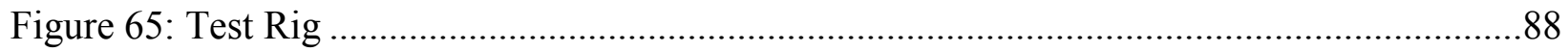

Figure 66: Symmetric Models Mounted to Test Rig .............................................................89

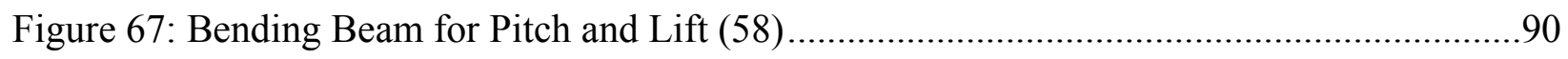

Figure 68: Wheatstone Bridges for Lift and Pitch (58) ........................................................91

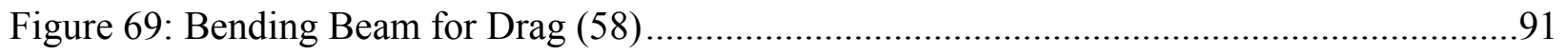

Figure 70: Wheatstone Bridge for Drag (58) ................................................................. 92

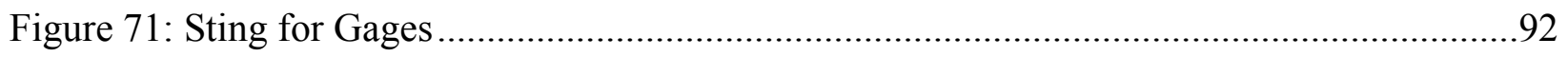

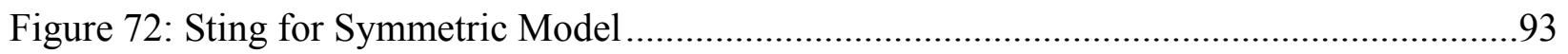

Figure 73: Representation of Ground Plane through Mirror Imaging ....................................93

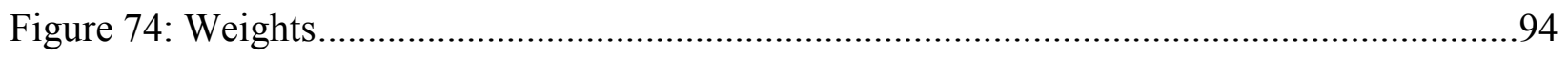




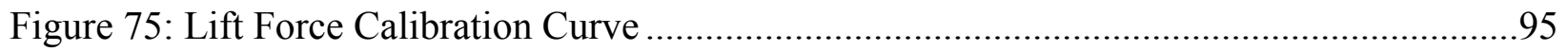

Figure 76: Interference Caused by Lift at $0^{\circ}$ Angle of Attack..................................................96

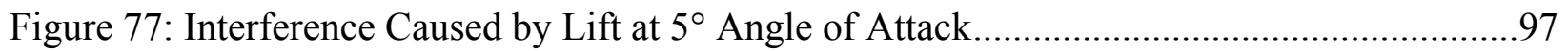

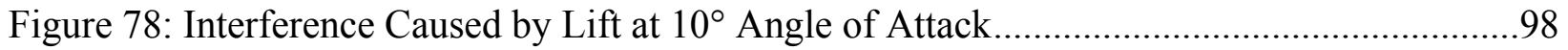

Figure 79: Interference Caused by Lift at $15^{\circ}$ Angle of Attack.................................................99

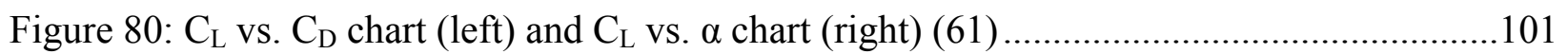

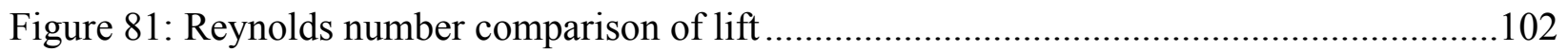

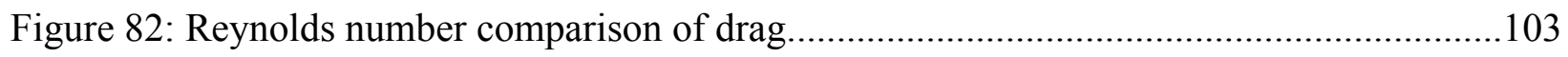

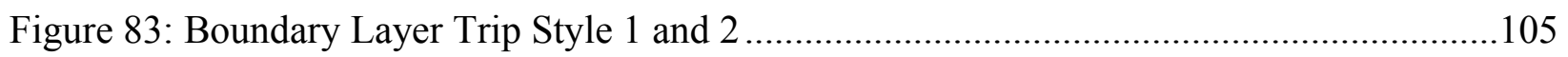

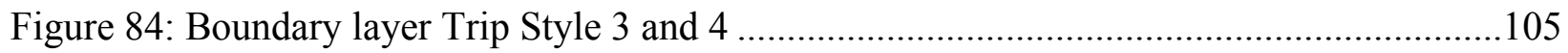

Figure 85: Boundary Layer Trip Lift Comparison (Experimental) ...........................................106

Figure 86: Boundary Layer Trip Drag Comparison (Experimental) ……………………….......107

Figure 87: Ineffective Boundary Layer Trips - Lift Coefficients (Experimental) ......................108

Figure 88: Ineffective Boundary Layer Trips - Drag Coefficients (Experimental) .....................109

Figure 89: Boundary Layer Trips with Increasing Effectiveness - Lift Coefficients

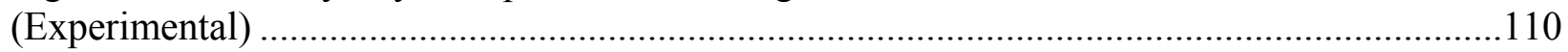

Figure 90: Boundary Layer Trips with Increasing Effectiveness - Drag Coefficients

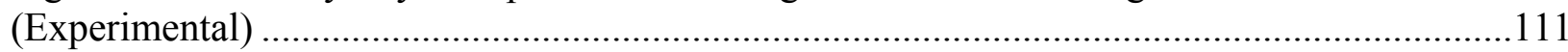

Figure 91: Boundary Layer Trips with Decreasing Effectiveness - Lift Coefficients

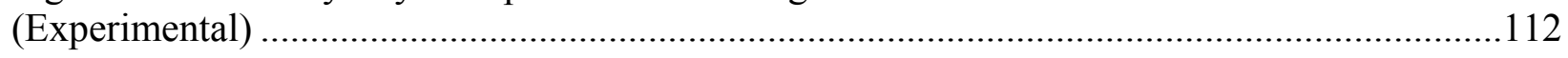

Figure 92: Boundary Layer Trips with Decreasing Effectiveness - Drag Coefficients

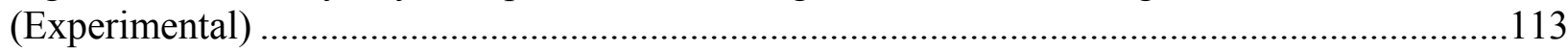

Figure 93: Most Effective Trip - Lift Coefficient (Experimental) ...........................................114

Figure 94: Most Effective Trip - Drag Coefficient (Experimental) …………………...............115

Figure 95: Lift Coefficient Comparison for Baseline Configuration.........................................116

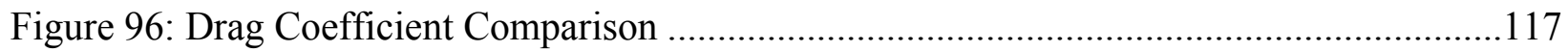

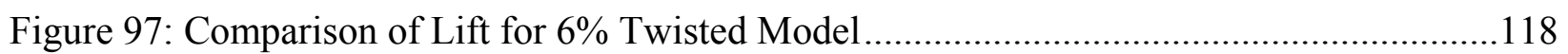

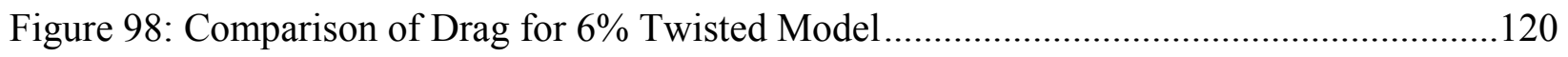

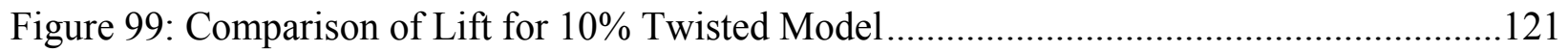

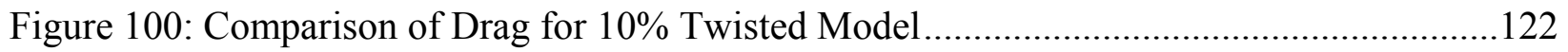

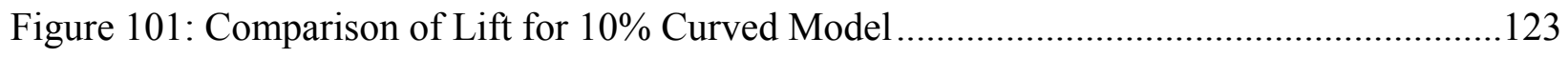

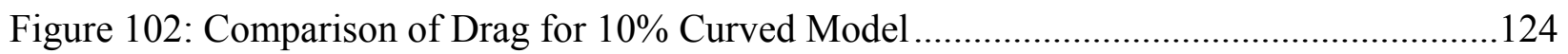

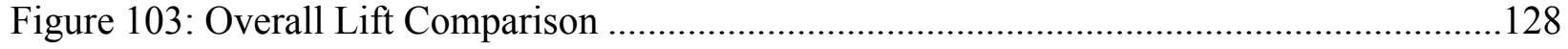

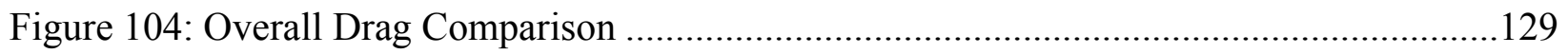

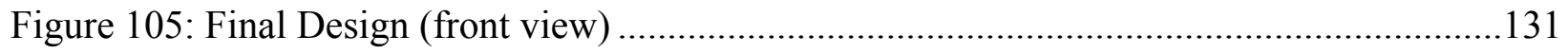

Figure 106: Final Design (back view) .............................................................................131 


\section{List of Symbols}

\begin{tabular}{|c|c|}
\hline$V$ & Velocity \\
\hline$\mu$ & Viscosity \\
\hline$\rho$ & Density \\
\hline$\Lambda$ & Sweep Angle \\
\hline$\Lambda_{\mathrm{LE}}$ & Sweep Angle at Leading Edge \\
\hline$\Lambda_{\mathrm{t} / \mathrm{c}}$ & Sweep Angle at Maximum Thickness Line \\
\hline$\lambda$ & Taper \\
\hline$\alpha$ & Angle of Attack \\
\hline$\delta$ & Boundary Layer Height \\
\hline$a$ & Slope \\
\hline$b$ & Span \\
\hline$k$ & Constant \\
\hline $\mathrm{c}$ & Chord \\
\hline $\mathrm{c}_{\mathrm{r}}$ & Root Chord \\
\hline $\mathrm{c}_{\mathrm{t}}$ & Tip Chord \\
\hline$\overline{\mathrm{c}}$ & Standard Mean Chord \\
\hline e & Oswald's Efficiency \\
\hline$t$ & Thickness \\
\hline$t / c$ & Thickness to Chord Ratio \\
\hline$x / c$ & Chord-wise Location of Maximum Thickness Point \\
\hline$x_{\mathrm{cp}}$ & Position of Center-of-Pressure \\
\hline$x_{\mathrm{cg}}$ & Position of Center-of-Gravity \\
\hline$x_{\mathrm{L}}$ & Root Chord Length \\
\hline$x_{\text {pay }}$ & Position of Payload \\
\hline$l_{V T}$ & Distance between quarter chord of main wing and vertical tail \\
\hline$W_{\text {fus }}$ & Weight of Fuselage \\
\hline$W_{\text {sys }}$ & Weight of System \\
\hline$W_{\text {tail }}$ & Weight of Tail \\
\hline$W_{\text {pay }}$ & Weight of Payload \\
\hline$W_{\text {wing }}$ & Weight of Wing \\
\hline$W_{\text {total }}$ & Total Weight \\
\hline
\end{tabular}




\section{List of Nomenclature}

\begin{tabular}{|c|c|}
\hline $\mathrm{AOA}$ & Angle of Attack \\
\hline AR & Aspect Ratio \\
\hline CAD & Computer Aided Design \\
\hline $\mathrm{C}_{\mathrm{d}}$ & 2-D Coefficient of Drag \\
\hline $\mathrm{C}_{\mathrm{D}}$ & 3-D Coefficient of Drag \\
\hline $\mathrm{C}_{1}$ & 2-D Coefficient of Lift \\
\hline $\mathrm{C}_{\mathrm{L}}$ & 3-D Coefficient of Lift \\
\hline CFD & Computational Fluid Dynamics \\
\hline CIRA & Center for Industrial Research Applications \\
\hline $\mathrm{D}$ & Drag \\
\hline $\mathrm{F}$ & Form Factor \\
\hline$F_{f}$ & Viscous Drag \\
\hline $\mathrm{F}_{\mathrm{x}}$ & Force in $\mathrm{x}$-direction \\
\hline $\mathrm{F}_{\mathrm{y}}$ & Force in y-direction \\
\hline GE & Ground Effect \\
\hline $\mathrm{H}$ & Height \\
\hline IGE & In-Ground Effect \\
\hline $\mathrm{L}$ & Lift \\
\hline M & Mach \\
\hline M & Moment \\
\hline m.a.c & Mean Aerodynamic Chord \\
\hline NACA & National Advisory Committee for Aeronautics \\
\hline OGE & Out-of-Ground Effect \\
\hline PAR & Power Augmented Ram \\
\hline Q & Interference Factor \\
\hline $\operatorname{Re}$ & Reynolds Number \\
\hline $\operatorname{Re}_{\text {eff }}$ & Effective Reynolds Number \\
\hline $\mathrm{S}$ & Wing Area \\
\hline $\mathrm{S}_{\mathrm{wet}}$ & Surface Area \\
\hline S.M. & Static Margin \\
\hline WIG & Wing in Ground Effect \\
\hline
\end{tabular}




\section{Chapter 1.0 Introduction}

This chapter discusses the objectives of this research and includes both the goals and a description of the steps necessary to achieve them. In addition it will cover the origins of the concept as well as the benefits of this research.

\subsection{Background/Genesis}

This new ground effect, gravity propelled aircraft referred to as AirRay was initially conceptualized through observations of low flying sea birds that would curve their wings when flying close to the surface of the water as a way of capturing the updrafts at a wave's edge. This style of biomimicry resulted in the development of the conceptual design shown in Figure 1.

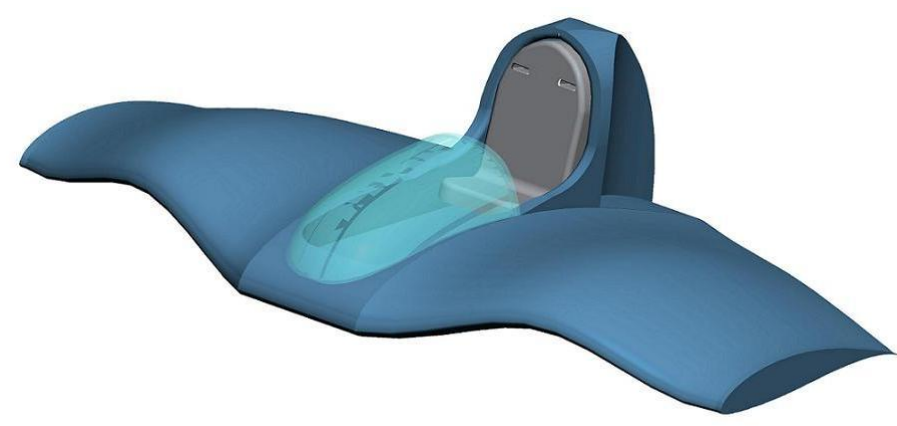

Figure 1: Concept Design of AirRay (1)

This aircraft, as initially conceptualized, would be a small, unpowered, low speed $(<30$ $\mathrm{mph}$ ), single passenger, recreational vehicle which would operate on downhill slopes and fly in ground effect. Historically, ground effect aircraft have been powered, capable of carrying anywhere from four to a couple hundred people and fly at velocities upwards of $60 \mathrm{mph}$. AirRay, as a glider, is substantially different from historical ground effect vehicles. The concepts and techniques developed, and utilized in maintaining flight for such a unique vehicle, could have 
widespread application to ground effect aircraft and enhance the field for ground effect flight in this regime.

\subsection{Program Objectives}

The main objective of this program is to design and develop the aerodynamics for a small, single passenger, unpowered, subsonic glider that relies on gravitational forces for momentum. In order to do so, the geometry of AirRay was designed to optimize the benefits of ground effect (i.e. the increased lift and decreased induced drag). In addition, the design of AirRay will attempt to minimize the overall weight and wingspan thus maximizing maneuverability. It is desirable to obtain a final design that is light enough to be carried by one person and small enough to be easily maneuverable in flight.

A basic straight wing was initially designed to determine the capabilities of a glider without the influence of twist (Figure 2), wing extensions, dihedral, or spanwise wing curvature (Figure 2). A preliminary literature search indicated that some of these features have only been loosely examined in ground effect, while others have yet to be examined. This research applied some of these features individually such as twist and spanwise wing curvature to the design computationally to determine the impact they had on the lift and drag effects as well as their ability to enhance stability and maximize maneuverability, and then to validated these findings experimentally at reduced Reynolds numbers.

Wingtips and endplates have been examined since the 1960's for their effects on aircraft flying in ground effect and have a known influence on straight wings (2). Dihedral and spanwise wing curvature have been neglected as to their influence on lift in ground effect, but have been studied for their impact on lateral stability in free flow. Twist has also been scrutinized for its effect on delaying stall in free flow, but has not been applied for its impact in ground effect. 
Both twist and curvature have the capability to structurally create a curved surface on the underside of the wing. This could allow for a recirculation of flow that has the potential to increase lift as a result of the proximity to the ground above that of the straight wings. This was partially demonstrated in the 1960's with the Russian development of one-sided endplates that were turned down as a way to increase the size and modify the shape of the capture area (2). This has also been demonstrated in nature since many birds have a tendency to cup their wings when approaching the ground to take advantage of updrafts and/or to increase the capture area.

\subsection{Research Objectives}

This research analyzed the effects of wing curvature through two methods. The first method incorporated a twist in the wing originating from a point along the trailing edge so that the leading edge rises up as shown in Figure 2 on the right. The root and chord remained unaltered while the maximum twist occurred in the center of the wing. The second method involved spanwise curvature so that the wing saw both a dihedral and anhedral arc that returned the tip to the horizontal plane at the root as shown in Figure 2 on the left. This is similar to the twisting method, however, both the leading and trailing edge was curved instead of just the leading edge.
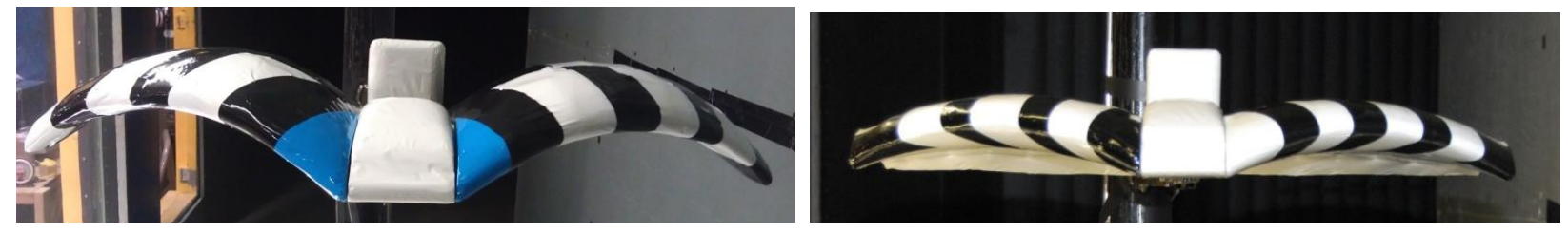

Figure 2: Spanwise Curvature (left), Twist (right)

\subsection{Benefits of Contribution}

The concept of ground effect is not new; however, its application to such a small, low speed, unpowered glider is unique. For decades the inherent problems associated with ground 
effect have challenged designers of new and improved aircraft concepts. The use of arc dihedral/anhedral and twist as a way of modifying the capture area to be curved on a ground effect aircraft in order to generate more lift is also novel. This research can be applied in the future not only to AirRay as a gravity propelled aircraft, but to any powered aircraft that operates in ground proximity flight. This could lead to new avenues of low-speed, single or multi, rider aircraft that could have commercial and military applications as scout vehicles, border patrol over untamed landscape, or for towing vehicles which are capable of flying over minefields. 


\section{Chapter 2.0 Literature Review}

This chapter discusses research that has been performed by previous researchers in the field of ground effect as well as general aerodynamic concepts that apply to the current proposed research.

\subsection{Review of General Aerodynamics}

This section discusses early development of aircraft and the aerodynamic geometries that were utilized in order to understand the impact each of these geometries have on the proposed aircraft's flight capabilities.

\subsubsection{Early Developments}

The concept of flight has fascinated mankind since the time of ancient civilization. Almost every culture in the world has a myth about the concept of flight and the foolish attempts that were made to achieve it. Through the years, there were many that speculated about the ability to fly and potential methods to achieve this goal. Among these men was the $13^{\text {th }}$ century philosopher, Roger Bacon, who was convinced of the possibility of human flight and its eventual development. Later, the $15^{\text {th }}$ century scientist Leonardo DaVinci speculated on the potential of human flight and developed concepts that could achieve it. Eventually, with the age of enlightenment came the birth of aviation from the "father of aeronautics", Sir George Cayley. The English baronet spent his entire life combining the basic principles of flight into working models including one that achieved human flight. From his efforts, new ideas and technologies began to emerge including the hot air balloon which became prominent in the late 1700's as a military weapon. In the mid-1800's a few brave men attempted flight with prototype monoplanes. While they were able to take-off and land relatively safely, no stable flight was achieved. 
In 1893, Otto Lilienthal became the first real aviator when he managed to achieve sustained flight in what is called an Ostandardo glider (3). This monoplane had cambered wings and a tail, and was capable of gliding up to 300 feet as shown in Figure 3. He continued to research in the area of aviation until his death during an experimental flight in 1896.

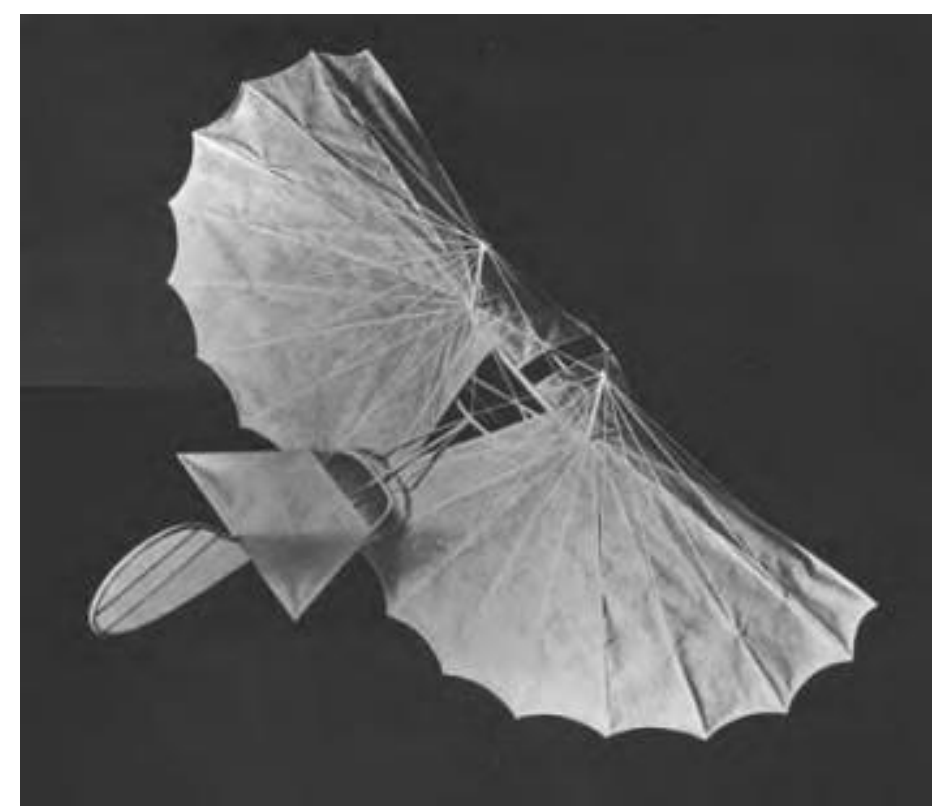

Figure 3: Otto Lilienthal's 1893 glider (3)

As the turn of the new century began, the Wright brothers would come forward as the next contenders in modern flight development. By December of 1903, the Wright brothers had created and successfully flown the world's first manned, powered, flight sustainable aircraft to the amazement of the world and for the future of aviation. (3)

\subsubsection{Sweep}

The concept of swept wings was first developed in 1935 by Adolf Busemann, a German engineer, and revealed to the world during the $5^{\text {th }}$ Volta Conference in Rome, Italy (4). The conference was held to discuss the potential for flying faster than the sound barrier and engineers came from across the globe with their research in an effort to further the field of aviation. One 
year after the conference, the concept of swept wing aircraft was being used by the German military for classified research and development. This lead to the first swept wing jet airplane, the ME 262, which made an appearance in Germany during World War II (4).

Wing sweep is defined as the angle between the line perpendicular to the aircraft centerline and a line parallel to the leading edge or a line parallel to the maximum thickness point along the span of the wing. Swept back wings have been used on a variety of aircraft for many years and can have many advantages such as increasing the critical Mach number and relocating the center of pressure. However there are also disadvantages to using swept wings in that there is a lower effective dynamic pressure and an increase in wing weight (5). (5)Also, there can be an increase in drag due to lift, a greater tendency towards tip stalling, and a reduction in the effectiveness of high-lift devices (6).

From a control standpoint, wing sweep enhances the stability of an aircraft by creating a natural dihedral (7). This dihedral invokes increased lateral stability and is also noticeable during sideslip when a rolling moment is applied. This may or may not be desirable and can be corrected with a negative dihedral. Approximately $1^{\circ}$ of effective dihedral is produced for about every $10^{\circ}$ of sweep (7).

Some additional benefits of wing sweep are the increase in pitch stability as a result of moving the center of gravity forward to compensate for the wing sweep. The tail section usually will become more effective as well due to its relocation behind the tip of the wings. A disadvantage is that wing sweep and the additional consideration of aspect ratio greatly influence an effect known as "pitch-up." This is an uncontrollable rise in angle of attack when approaching stall. As seen in Figure 4, as the sweep of the wing increases and as the aspect ratio increases, the probability of pitch-up increases. 


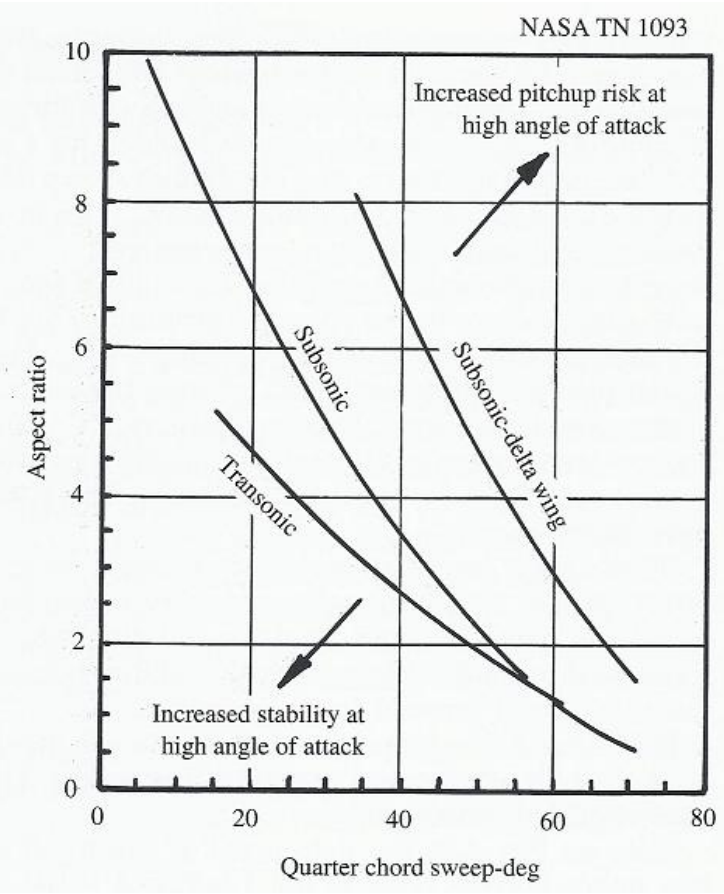

Figure 4: Pitch-up Boundaries (7)

\subsubsection{Twist}

There are two main types of twist: aerodynamic and geometric. Aerodynamic twist is when the angle between the zero-lift angle at the root, is different than the zero-lift angle at the tip (7). This occurs when there are different airfoil shapes present at each end of the wing such as a highly cambered airfoil at the root and an uncambered airfoil at the tip. Geometric twist occurs when the chord lines of the spanwise airfoil sections do not all lie in the same plane. This creates a varying geometric angle of incidence for the wing. "Wash out" is when the incidence angle decreases as the tip approaches (which is common on many aircraft) to control boundary layer separation and local stall onset. "Wash in" is when the incidence angle increases as the tip approaches. (6)

The benefits of wing twist include a means to achieve an optimized lift distribution, which is only occurs at one lift coefficient for one wing geometry, and the prevention of stall at 
the wing tips. Regardless of the method, both achieve the same purpose of changing the spanwise lift distribution often to appear more elliptical.

\subsubsection{Wing Tips Add-Ons}

The need to increase the efficiency of aircraft flight resulted in research on the effects of varying wing tip designs. The most popular wing tip designs include the addition of an endplate or winglet. Wing additions were first developed in the late 1800's by an English engineer, Frederick W. Lanchester, who determined theoretically and experimentally that vertical surfaces located at the wingtips could significantly reduce induced drag. He later patented the use of endplates for this purpose in 1897. (8)

During the early stages of aircraft development the tip of the wing was usually rounded which allowed the air to easily flow around it and shed. However around the 1970's the use of wingtip additions, which were more blunt, began to gain popularity in order to reduce the induced drag (8). This prevents the airflow from easily shedding thus allowing for greater spacing between the vortices and hence a reduction in overall strength (6). Figure 5 shows examples of a variety of wing tip styles. 


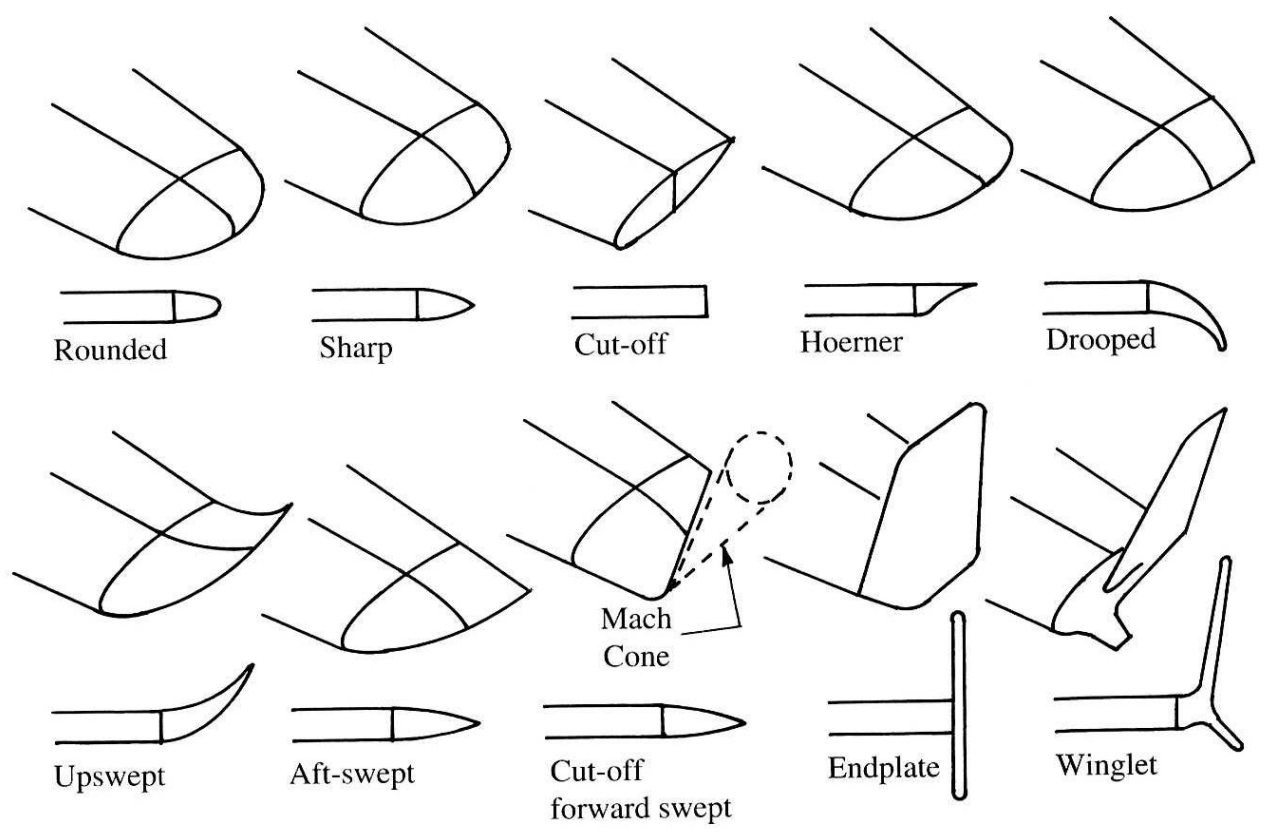

Figure 5: Wing Tip Styles (7)

The most widely used wing tip, the Hoerner, was created by S. Hoerner around 1965 and its popularity is a result of its ability to maximize the effective span of the wing compared to other available wing tips. The drooped and upswept wing tips are very similar to the Hoerner but the effective span and drag reductions are less. Drag can further be reduced on select wing tip styles by sweeping the tip aft thus increasing the trailing edge span. (7)

Endplates and winglets are another form of wing tip additions that change the way in which air flows around the tips. Endplates, as mentioned before, have been around in concept since the late 1800's but have seen little practical application even though they offer an increase in the effective span. Their disuse is mainly a result of the endplates themselves creating additional drag in the flow field (7). Winglets are a newer construct, which were developed by Richard Whitcomb in the 1970's. Whitcomb determined that a vertical, cambered and angled surface above or below the tip, if properly designed, could reduce the strength of the trailing vortex and hence reduce the induced drag (8). This new style of wing tip design became very 
popular in the aviation industry since it could not only increase the effective span but also reduce drag. It is now used predominately by many large airliners, as well as on most business jets.

\subsubsection{Dihedral}

Dihedral is the upwards (positive) angle of the wing reference plane from the horizontal plane, whose origin is located at the root chord, at which the wings sit when examined from the front. Anhedral is the opposite in which it is the downwards (negative) angle.

Commonly, dihedral is used for stability purposes and helps adjust for rolling and sideslip maneuvers. When an aircraft banks, a wing with dihedral will roll the aircraft level again as a result of the lowered wing gaining lift when banked. The amount of rolling moment is proportional to the dihedral angle (7). Excessive dihedral will cause a dutch-roll maneuver to occur in which the aircraft will roll and yaw simultaneously. This can be counteracted by the use of a larger tail or anhedral, which is the downwards (negative) angle of the wing reference plane from the horizontal plane.

\subsubsection{Wing Curvature}

Wing curvature research has been broken down into two categories defined by the direction of influence. The first type of curvature is applied in the spanwise direction and arcs the wing toward the ground. The second type of curvature is applied in the planform direction which causes the leading and trailing edge of the wing to curve into a crescent shape. 

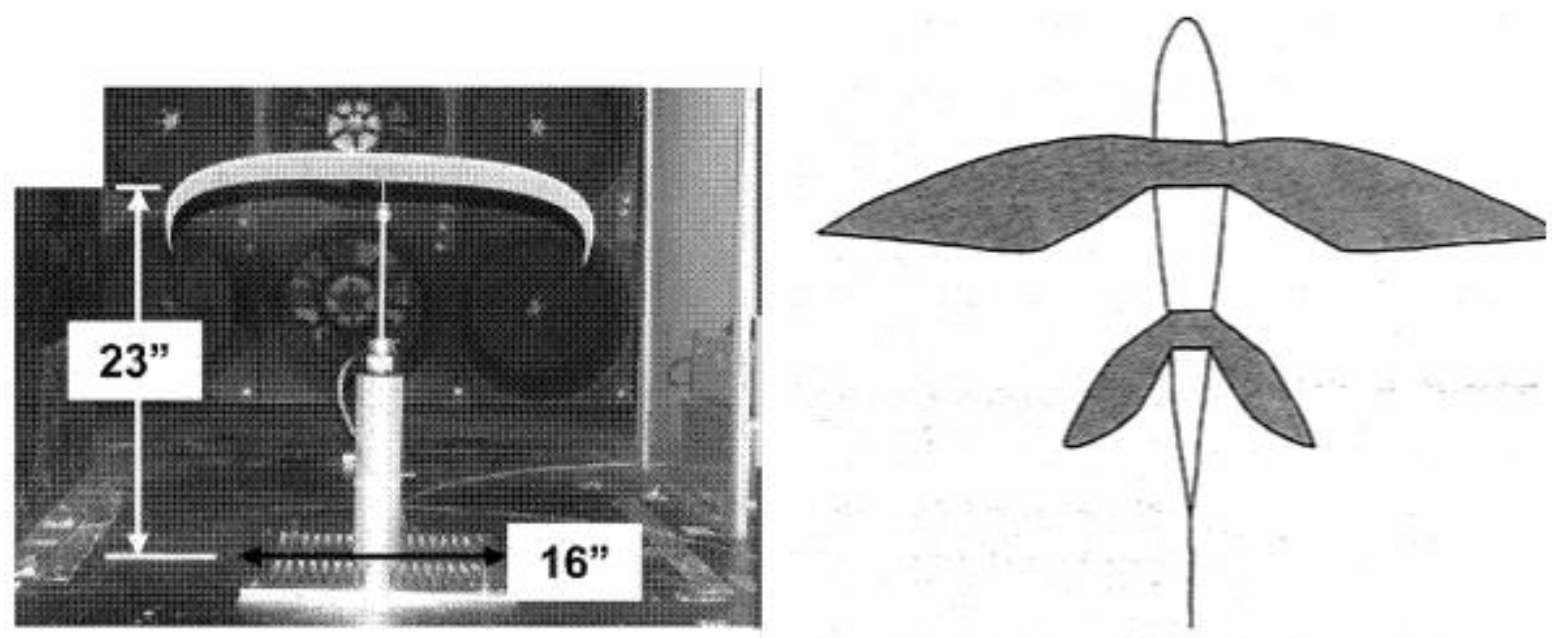

Figure 6: Spanwise curvature (9) (left) and planform curvature (10) (right)

Spanwise wing curvature research has a variety of applications. Paragliders for instance are interested in determining the effects of curved surfaces in a flow field and quite often have to adapt airplane aerodynamics to gliding parachutes.

Spanwise and planform wing curvature have also become more popular in recent years as a result of the interest in the physiology of birds and fish. Since many migratory birds have curved wings as a result of years in the evolutionary process, a re-examination of the efficiency of such a structure has emerged in a field called biomimetics. Biomimicry and more specifically biophysical aerodynamics is the study of the environment and in this case flying mammals as a method for solving human problems. In order to take into account the complexity of such a wing structure, researchers have been moving away from the classical approach of Prandtl's lifting line theory and closer to panel methods. Research in planform wing curvature has shown that there exists an increase in the efficiency, which is the ratio of lift and induced drag, as compared to straight wings (11). 


\subsubsection{Pitch Stability}

Since the beginning of aircraft development, it has been apparent that longitudinal stability is vitally important to the success of controlled flight; this was one of the key achievements of the Wright brothers which enabled their success. Various techniques have been used in order to correct the natural instabilities as the angle of attack varies. Much of the previous research was focused in the area of supersonic flight, specifically for use with missiles. There are two main methods for stabilizing the pitch on missiles. The first is with the use of nose mounted canards and nose flaps which can be very stable at higher Mach numbers (12). The second method utilizes the location of the fins that extend from body slots to affect the longitudinal stability. The second method is effective only at angles of attack higher than 15 degrees (13).

Aside from missiles, avoiding pitch-up is a major design concern when developing anything from a fighter to a general aviation aircraft. Computer systems are used today on some current fighter aircraft which are naturally unstable in order to reduce the potential for dangerous maneuvers. For instance, the F-16 has an angle of attack limiter to prevent it from pitching up beyond 25 degrees (7). In most cases, the maneuverability of a fighter is key, so stability is achieved by adjusting the sweep angle or aspect ratio to restrict the potential for pitch-up as shown by Figure 4 in Section 2.1.2.

\subsection{Aerodynamic Ground Effect Research}

This section will present an overview of previous research that has been performed on the subject of ground effect. This will include aerodynamic features such as sweep, wing tips, etc, that were researched for their advantages in the ground effect regime, and begin with an 
overview of historical ground effect vehicles and their development problems. The goal is to determine areas where information is lacking and show the need for the further research.

\subsubsection{Introduction}

Ground effect is defined as an increase in the lift-to-drag ratio developed by a lifting surface such as a wing when moving in close proximity to the ground (14). While ground effect research did not begin until the 1930's, its effects were thought to have been utilized in the Wright brothers' experiments in order for them to achieve flight (15). Purposeful application to modern technology however did not occur until much later.

Ground effect is categorized by the direction of influence, either span dominated or chord dominated. Span dominated ground effect is utilized with wings that have a large aspect ratio in which the chord and ground clearance of the wing are significantly less than the span. As a result of span dominated ground effect, induced drag is reduced. Chord dominated ground effect occurs with smaller aspect ratios and results in a stagnation of airflow underneath the wing. This leads to an increase in the pressure under a moving body while in close proximity to the ground (16). As a result of the increase in pressure underneath the moving body, moments of sudden pitch-up can occur in addition to the increased lift. This problem is inherent in all ground effect vehicles and needs to be corrected before safe flight characteristics can be achieved.

\subsubsection{Historical Overview}

While ground effect had a major influence on the success of early airplanes, it did so without any realization of its participation. It wasn't until the 1930's that the phenomenon of ground effect began to be recognized for what it was. During long trans-Atlantic service flights of the Dornier DO-X, pilots would fly close to the surface of the water allowing them to extend 
the range of their aircraft (14). Coincidentally, this reduction in fuel consumption also resulted in an increase in their payload potential.

During the 1930's, investigation began into ground effect machines, however the experimental testing capabilities of the time limited the research possibilities. Experimental testing was restricted to ground boards that were fixed near the model of an airfoil inside a wind tunnel (17). Even with an understanding of the general phenomenon, there were few practical applications for ground effect technology during that time. The most notable of these designs was a high speed snow sleigh developed in Sweden by Toivo Kaario as shown in Figure 7 (15).

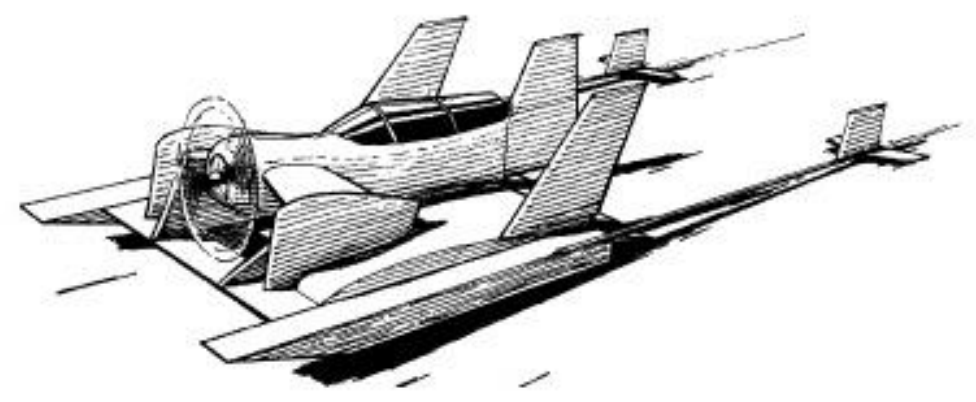

Figure 7: High Speed Snow Sleigh (18)

Progressive research was deterred until the 1950's and 60's when a revival of ground effect occurred largely in part due to Rostislav Alexeiev, a Russian engineer. His interest in this area led to the development of ekranoplans at the Central Design Bureau of Hydrofoils which is still in operation today. Ekranoplans are defined as vehicles that are heavier than air and contain at least one engine, that are capable of flying close to an underlying surface for utilization of ground effect (14). The design of ekranoplans ranged from two seater personal aircraft to large double deck military transports. Many of these concept designs can be seen in Figure 8, some of which were developed into working prototypes. 

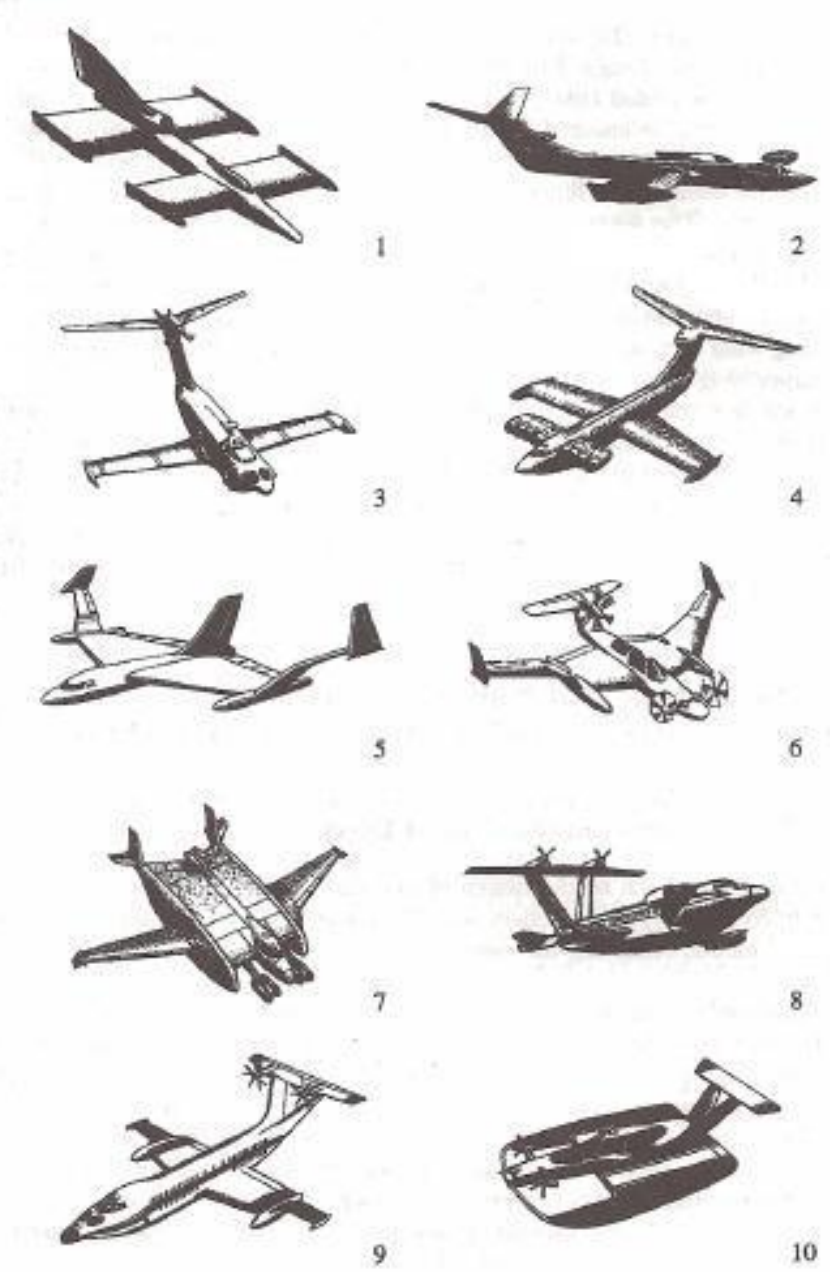

Figure 8: Collection of Russian Ekranoplan Designs (14)

Many of the designs have reoccurring features including power augmented ram units and tails that are elevated in an attempt to remove them from the ground effect regime. As a result of shifting the tail placement and allowing for special profiling of the wing sections, the pitch instability which is inherent in ground effect vehicles was addressed and resolved (14).

As a result of the Soviet Union being a leader in the ekranoplan field and the onset of the Cold War, the United States began its own research and development of ground effect aircraft. They developed planes such as the "Lowboy" designed by Boeing, shown in Figure 9, and the "Large Weilandcraft" designed by Weiland, shown in Figure 10 (19). 


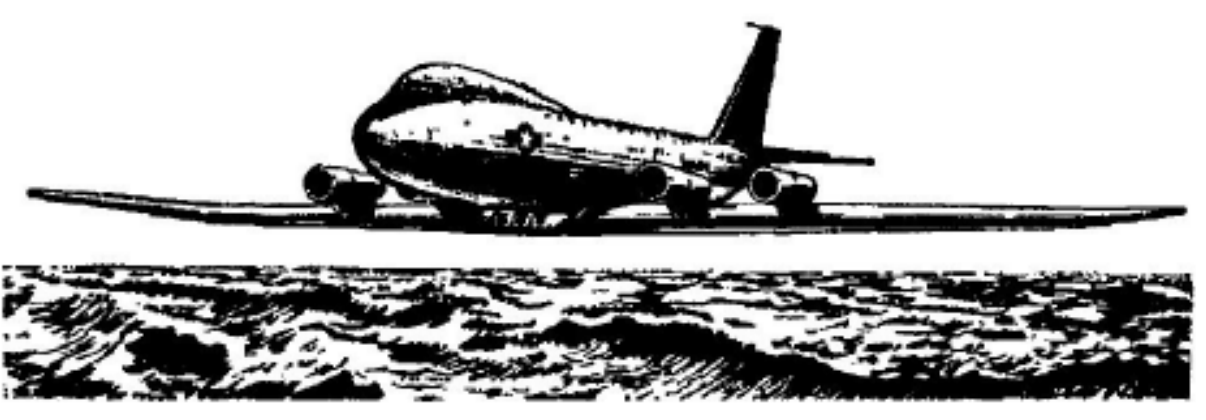

Figure 9: Lowboy developed by Boeing (19)

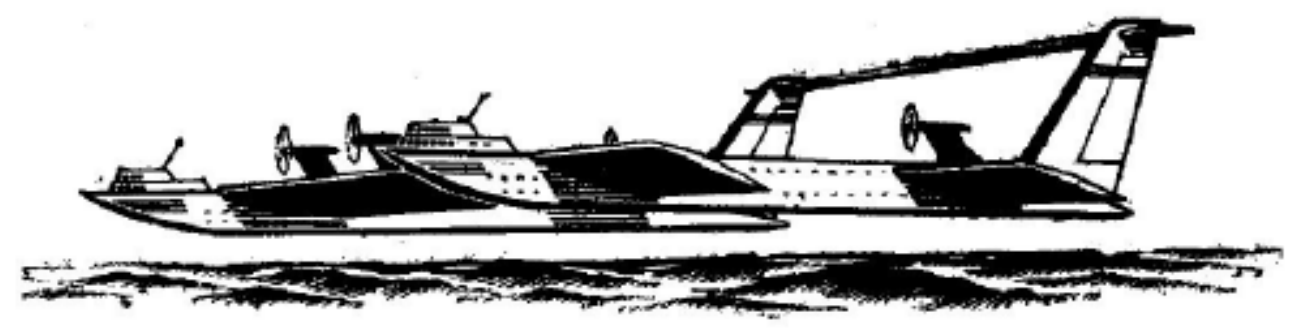

Figure 10: Large Weilandcraft developed by Weiland (19)

Shortly after the end of the Cold War, development in this field waned. This was largely a result of the collapse of the Soviet Union and decline and death of Alexeiev in the 1980's. It was not until recently that ground effect research has seen a resurgence of interest with the design of the Boeing "Pelican" by Phantom Works shown in Figure 11 (20).

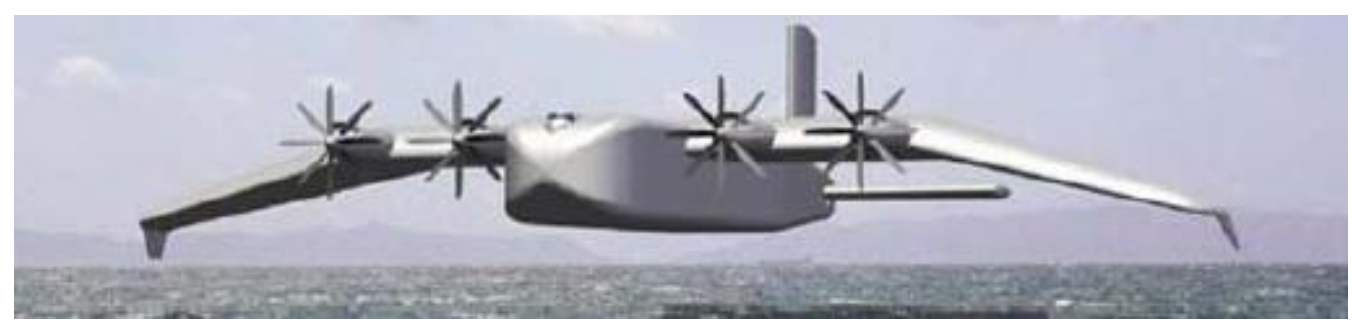

Figure 11: Boeing Pelican by Phantom Works (20) 
This aircraft is designed to have a wing span that is approximately 500 feet which is about twice the size of the C-5A Galaxy, the US military's largest aircraft. The Pelican is designed to operate as a long range, transoceanic transport, flying within $20 \mathrm{ft}$ of the water's surface and capable of carrying 1400 tons of cargo, approximately 10 times more than the Galaxy (20).

\subsubsection{Sweep}

In the 1970's NASA began research on a span-distributed-load airplane that would allow for a payload to be dispersed evenly in the wings as a way of enhancing the efficiency of the airplane. The plane featured a long wing span and a high sweep angle. However as a result of the design, traditional landing methods of flaring and de-crabbing were not feasible and an alternate method of using ground effect to slow the descent was developed (21). De-crabbing is a maneuvering technique during touchdown in which the aircraft partially flies into a crosswind in order to compensate for drift and then just before landing corrects the maneuver with the rudder. This maneuver is designed to ensure a correct alignment with the runway and to maintain level wings during touchdown (22).

As a result, researchers examined the effects of aspect ratio and leading edge sweep angle on aircraft performance at varying ground effect heights. Before this time, little had been done in this area. It was found that as the aspect ratio decreased, the lift coefficients would also decrease. Also, the base drag increased as the aspect ratio decreased inside of the ground effect regime but decreased as the sweep angle increased. This, however, was expected because the influence of the aspect ratio diminishes as sweep angle increases. It should also be noted that as sweep angle increases, the pitching moment at a given flap deflection is reduced making it less effective. The 
effects of sweep and aspect ratio can be seen in Figure 12 with respect to the amount of lift slope increase, for in-ground effect to out-of-ground effect flight (21).

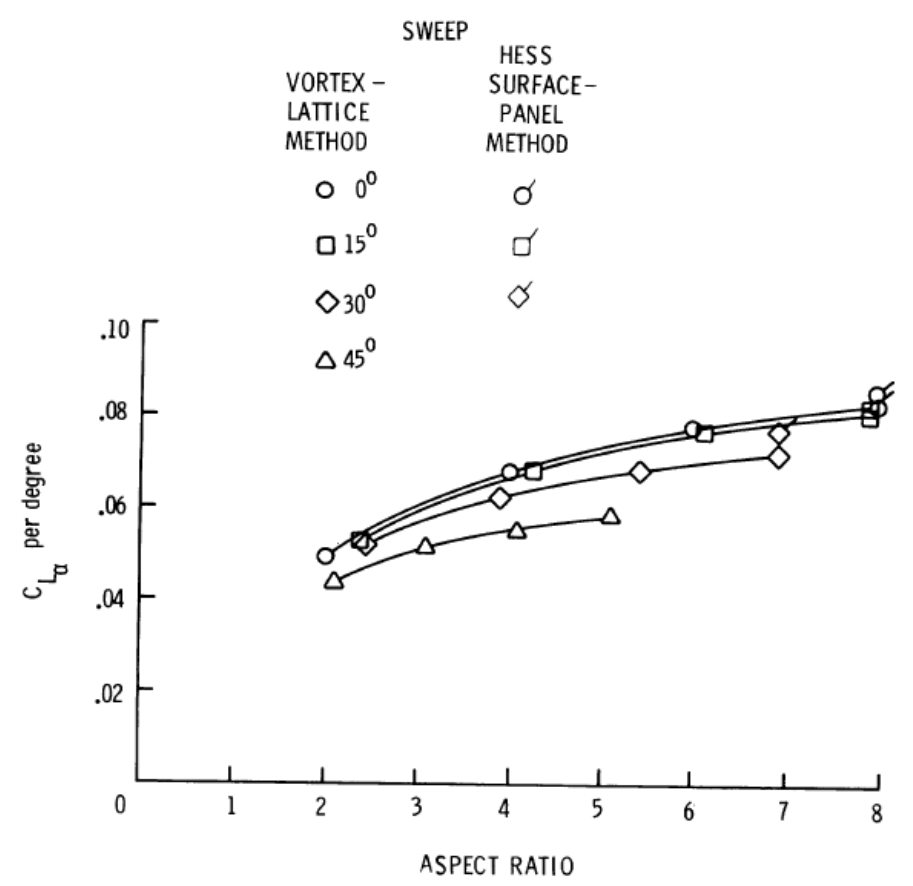

Figure 12: Theoretical Effect of Aspect Ratio and Sweep Angle on Lift-Curve Slope (21)

\subsubsection{Wing Tips}

The advantages of endplates and winglets outside of the ground effect regime have been identified and characterized since the 1890's. With the development of Russian ekranoplans in the 1960's came new avenues of research for a historic field. In an effort to make ekranoplans more efficient and to solve some of their aerodynamic problems, Russian researchers utilized one-sided, downward pointing endplates. In particular, the endplates decreased losses that occur due to the flow from the high pressure underside to the lower pressure upperside of the wing (2). The one-sided endplates were pointed in the downward direction as seen in Figure 13, which also resulted in the creation of a dynamic air cushion under the wing. It should be noted that the lower the aspect ratio, the more efficient the endplates become while in ground effect (18). 

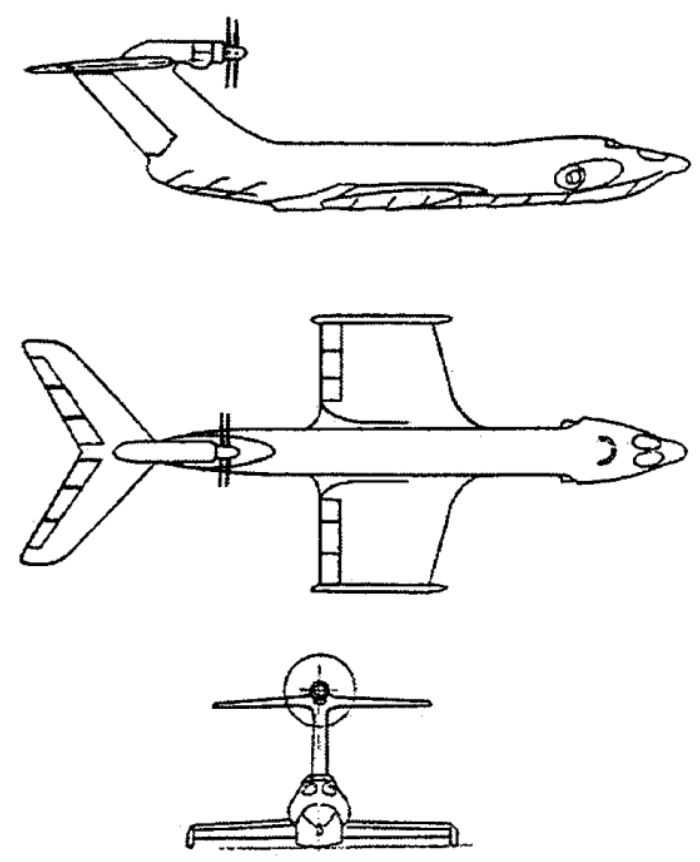

Figure 13: Aerodynamic Configuration of Prototype CM-2 (2)

Later, researchers experimentally tested a variety of winglet configurations both in the upwards and downwards direction. These experiments characterized the effectiveness of each style in terms of lift and drag characteristics as compared to a straight wing design. While every winglet design showed an advantage over a straight wing, the greatest advantage came from an upwards directed winglet that was $1 / 5^{\text {th }}$ the size of the span. This was a result of the tip vortices being furthest from the wing and thus decreasing any downwash effect. It was also determined that the range of effectiveness of the winglets lies below approximately 8 degrees angle of attack. Outside of this range, winglets were shown to be more effective in freestream than in the ground effect regime (23). 


\subsubsection{Pitch Stability Research}

While pitch stability has been studied in relation to the proximity of the ground, solutions to resolve any aerodynamic instabilities introduced have not been evaluated while taking the aircraft out of ground effect. A design by De Divitiis, shown in Figure 14, incorporated a high positioned tail on a ground effect aircraft. This high tail, located outside of the ground effect regime, as predicted to effectively restore a balanced aerodynamic moment (24).

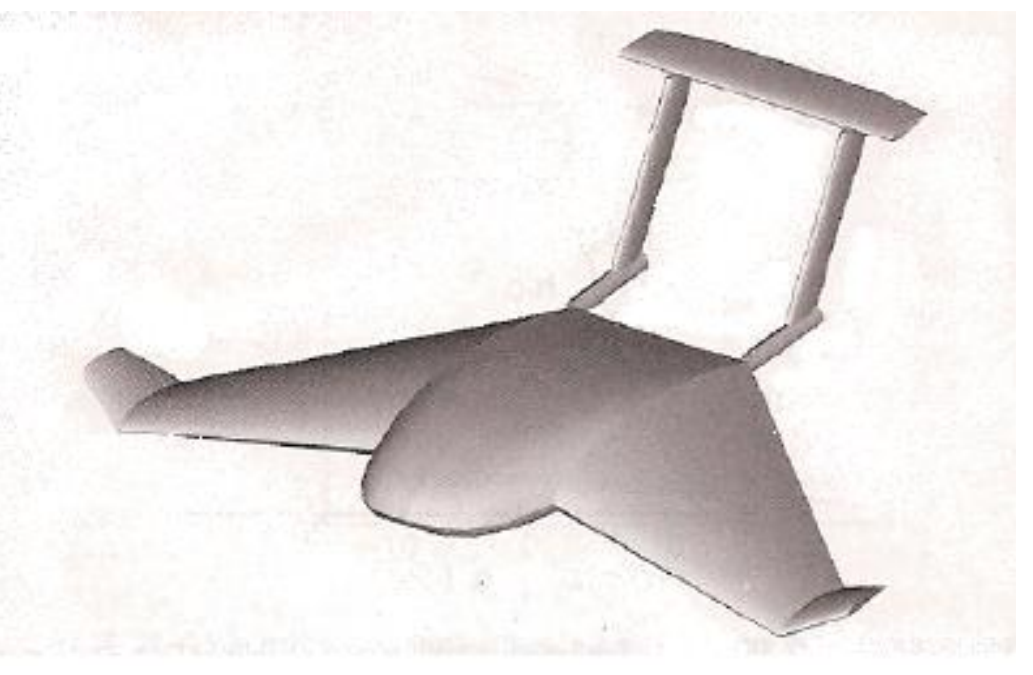

Figure 14: Concept design by De Divitiis (24)

\subsubsection{Numerical Wing-in-Ground Effect Research}

In the 1920's and 1930's, simplified numerical models were developed and used to predict the aerodynamic forces necessary for flight. In order to manage these complex calculations, many classical problems were assumed to have inviscid, incompressible, and irrotational flow.

Dr. C. Wieselsberger was one of the first researchers in the area of ground effect. In 1922 he placed an image of a lifting surface below the ground plane which effectively simulated the effect of the ground. This was done through satisfying the no-penetration boundary condition of the ground plane. Eleven years later Tomotika obtained an exact solution for flow past a flat 
plate while in close proximity to the ground by using conformal mapping methods. During the 1940 's a variety of non-planar shapes were examined for their interaction with the ground effect regime, including circular-arc and Joukowski airfoils.

Then, there was a lapse of interest in ground effect research until the 1950's, and it wasn't until the 1980's when the concept of extreme ground effect began to appear (25). The region that is primarily expressed as being extreme is located within approximately $10 \%$ of the chord length from the ground. This region primarily sees further enhancement of aerodynamic characteristics over the rest of the ground effect regime (14). Primarily, the benefits of ground effect increase exponentially as the proximity to the ground increases (16).

In the past twenty years, many improvements have been made with regards to modeling techniques; consequently this has allowed for a broader range of complex geometries to be studied. These include zero thickness surfaces (akin to those studied in the automotive industry) and three-dimensional airfoils that provide a more realistic representation of the flow in ground effect (25).

\subsubsection{Computational Wing-in-Ground Effect Research}

Computational modeling has only begun to be applied to ground effect research in the past fifteen years. Research began in the early 1990's when Steinback and Jacob produced high Reynolds number data for airfoils in ground effect (26). The main objective of this research was to determine viscous effects as the ground plane was approached.

In 1996, Hsiun and Chen began research into the effect of Reynolds number on the aerodynamic characteristics of a NACA 4412 airfoil during ground effect (27). Their models were simulated in a turbulent regime with a SIMPLE, k-epsilon RANS solver. From these simulations, it was found that both the lift coefficient and the lift-to-drag ratios increase with 
Reynolds number. In addition, it was found that the pressure distribution on the leading edge was more strongly influenced at lower Reynolds numbers. It was also noted that with a decrease in the ground clearance, lift coefficient increases (27). This is consistent with the results found by Chawla, Edwards, and Franke's on a similar airfoil in wind tunnel testing (28).

In the late 1990's, questions arose about the validity of computational and experimental testing that uses fixed ground plane methods, implying that for accurate results, the ground plane must be in motion. In 2003, Chun and Chang clarified the 2D ground effect characteristics for both the moving and fixed ground boundary layers in turbulent flow using the NACA 4412 airfoil. The results indicated that the change in lift and pitching moment between the two techniques was minimal but drag was smaller for the fixed plane than for the moving plane (29).

\subsubsection{Experimental Wing-in-Ground Effect Research}

As stated earlier, in the 1930 's, research into the area of ground effect began; however, researchers were finding they had limited abilities to perform ground effect testing as a result of the lack of efficient and accurate experimental methods. Therefore, the primary method used for testing ground effect was through a ground board that was fixed underneath the model. This was done with the intent to simulate the experience of being in close proximity to the ground. It was found early on through experimental testing that the ground effect phenomenon occurs only in a region that is less than a chord length of the wing from the ground. The most advantageous range of ground clearances however, tends to exist below $25 \%$ of the chord (14).

During the tension of the Cold War, research into advanced ground effect applications came to the forefront of development. One such advancement included the ram-lift device which was utilized with the PAR-wing vehicle, as shown in Figure 15. The ram-lift technology is comparable to a power plant which was located on the nose of the aircraft and designed to 
provide additional lift under the wings. This device would assist with generating airflow at startup in order to provide artificial ground effect until the aircraft got under way. This made it possible for the PAR-wing vehicle to take-off while having little to no forward thrust (30). A PAR-wing vehicle is the same concept as a wing-in-ground effect vehicle but has the addition of a ram-lift device. Ailor and Eberle examined the lift and pressure distribution that would accompany ram-lift using a multitude of geometries. Through a series of 2-D and 3-D testing, they determined that some geometries were capable of generating additional lift during ground effect (31).

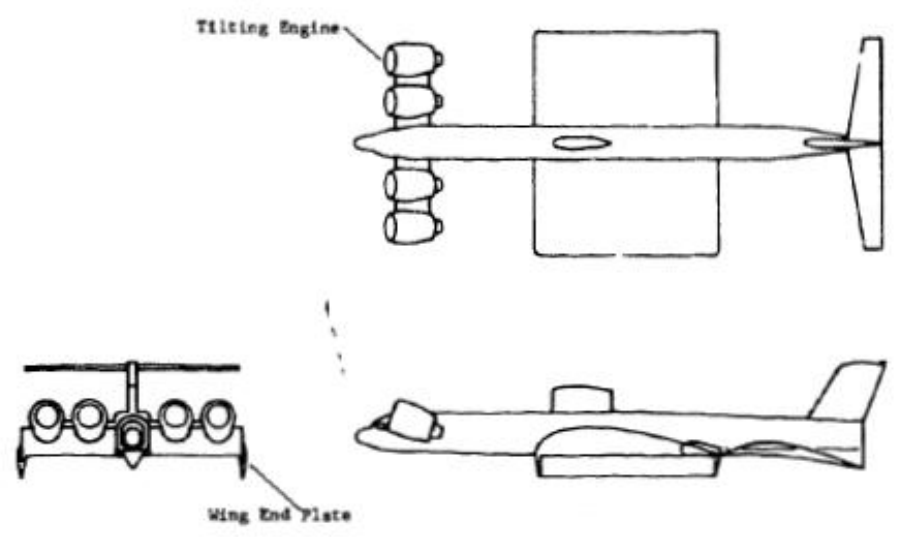

Figure 15: PAR-Wing Vehicle (30)

It was not until the 1990s when research was renewed on par-wing technology, this time for use in a launcher. The technology was adapted to assist space flight vehicles in an attempt to create a conventional horizontal take-off to orbit vehicle. This research involved more complex models than those used in the earlier studies. The NACA 4415 airfoil was tested at various parameters such as angle of attack, flap angle, height from ground, and end plates. Fixed board testing techniques were utilized during the research and from the data it was found that both the lift and drag coefficients increased with proximity to the ground plane (28). 
In 1996 ground effect research once again became important, but not to the aircraft industry, this time the race car industry was interested in the performance of a NACA 4412 airfoil, shown in Figure 16. They used ground board testing to examine the occurrence of force reduction with decreasing ground clearance (32). Through this research effort, it was determined that the force reversal phenomena is a result of boundary layers merging together as the ground plane approaches which occurs at higher height locations for cambered airfoils than for symmetric airfoils (32).

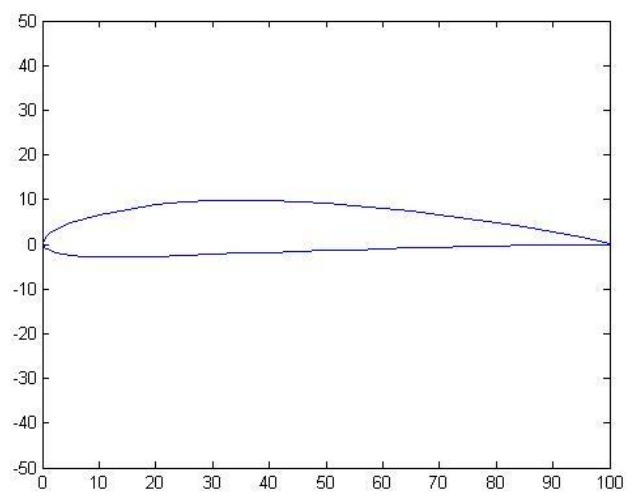

Figure 16: NACA 4412 Airfoil (33)

In 2007 the NACA 4412 airfoil was examined by Ahmed, Takasaki, and Kohama through the use of moving ground testing techniques (34). Specifically, angles of attack and ground clearances were examined to determine the impact on aerodynamic characteristics. When in extreme ground effect, it was found that there is a significant drop in lift force. This is not the case however while in the normal ground effect region, above an $\mathrm{h} / \mathrm{c}$ value of 0.1 . Lift forces actually increase as the ground approaches. It was also found that drag forces have a tendency to be increased for all angles of attack, closer to the ground (34). 


\subsubsection{Ekranoplan Design Problems}

In the 1960's Russian researchers under the direction of R.E. Alekseev began development of a new style of high-speed aircraft called ekranoplans. These were some of the first working technologies to utilize ground effect concepts. During development many obstacles were overcome as a result of inherent problems that occur while operating in ground effect.

Many of the original concept ekranoplans were modeled and experimentally tested in order to determine the advantages and disadvantages to each design. One of the first prototypes to prove the capability of stable flight while in ground effect was the CM-1 ekranoplan as shown in Figure 17.

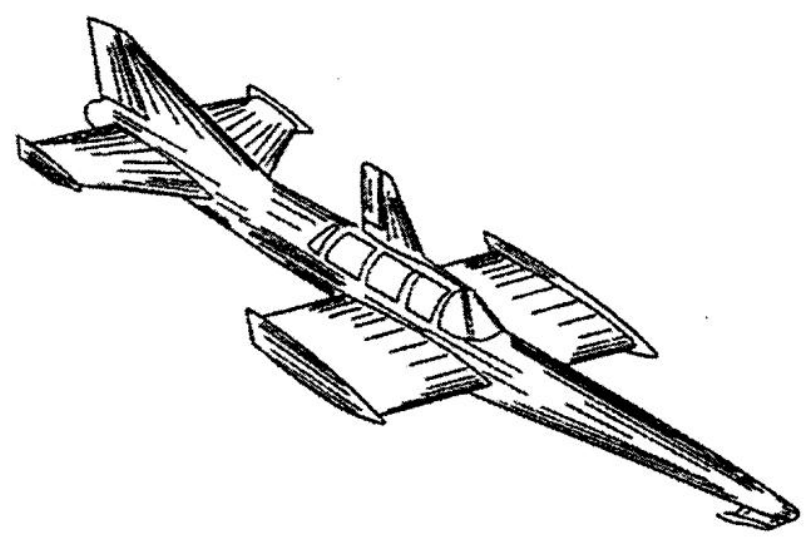

Figure 17: CM-1 Ekranoplan

As a result of the testing of this ekranoplan, configuration changes were found to be necessary. Alekseev developed the idea of high tails to control stability once removed from the ground effect regime. In addition it was also determined that under-wing jets could reduce the required landing and take-off speeds. These concepts were integrated into the CM-2 ekranoplan which also included the use of one-sided end plates. The end plates were unique in that they were capable of reducing losses that occurred from the high pressure to the low pressure side of the airfoil. In addition they assisted in creating an efficient air cushion under the wing. This styling 
became the model for future generations of ekranoplan development which lasted until the 1970's when attempts were made to improve the economic and seaworthy effectiveness of the devices (2).

Unfortunately, Alekseev was unable to complete this phase of the design, therefore development was passed into the hands of Sinitsyn. Under his guidance, composite wing forms were examined as a method for combining the functions of varying wing styles as shown in Figure 18. This method of wing construction allowed for greater wing efficiency while decreasing the tail area.

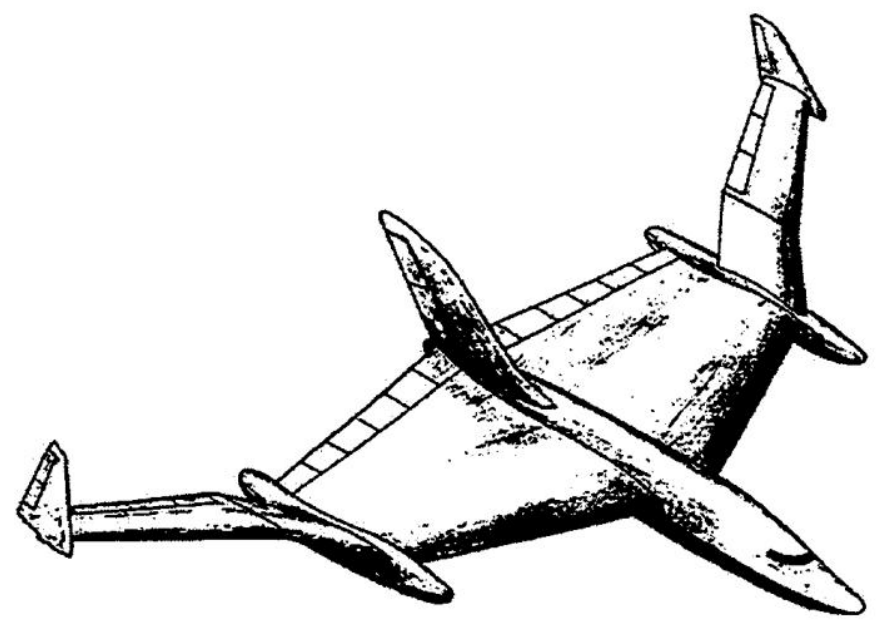

Figure 18: Composite Wing Ekranoplan (2)

\subsubsection{Ground Effect Testing Methods}

There are four types of possible modeling techniques for evaluating ground effect: mirror-image, slip condition, stationary ground, and moving ground. Three of these techniques are used with experimental testing whereas the slip-condition method is for use when computationally testing ground effect. Slip condition is a setting applied to the ground wall when constructing a computational model and surrounding environment that mimics the interaction with a moving ground. Of the three experimental techniques, the most accurate is the moving 
ground in which a ground plane, usually simulated with a rotating belt, moves at the same speed as the air flow generated in the wind tunnel. This technique is representative of a body moving over the ground with no additional wind other than that caused by the motion of the body through the environment (35).

When ground effect testing began, the primary method for testing was through the use of a ground board that was fixed underneath the model, i.e. a stationary ground plane. This was done with the intent to simulate a proximity to the ground. The problem with this method is that the board is stationary with respect to the airfoil during the experiment, whereas in the real world, the ground moves with respect to the wing. While this method is still used today, it is not as accurate as more recently developed methods which include using a mirror-image or a moving ground plane. The mirror-image technique replicates ground effect through placing duplicate models in a mirror-image position equal distance apart. The plane of symmetry between the models then represents the ground effect plane, since the normal flow components cancel at this location. For this method, the forces are typically only read for one of the models and not its mirror image. This method was found to be of more value to early researchers than the stationary ground plane (17).

The moving ground plane was first developed for the automotive industry and replicates ground effect by mimicking the natural environment in which ground effect occurs. This system can be complex and expensive but allows for a simple solution to accurately test in ground effect. The entire system is similar to a wind tunnel but with a moving belt for the ground plane with the simultaneous utility of a suction system upstream of the belt to avoid problems with the wind tunnel's inner boundary layer (36). 


\subsection{Non-Aircraft Ground Effect Research}

This section discusses research that has been performed in the field of ground effect but does not necessarily directly apply to flight applications.

\subsubsection{Hydrofoils}

Hydrofoils are essentially aerodynamic shapes that are mounted on watercraft and are shallowly submerged. These foils provide additional lift and result in lifting sections of the hull up out of the water. They have been applied to a variety of watercraft in order to provide stability and/or to reduce drag, an example of which is shown in Figure 19. This concept of a ram wing watercraft was developed in the 1930's and the hydrofoil used for longitudinal stability during cruise can be seen in the center of the trailing edge (18).

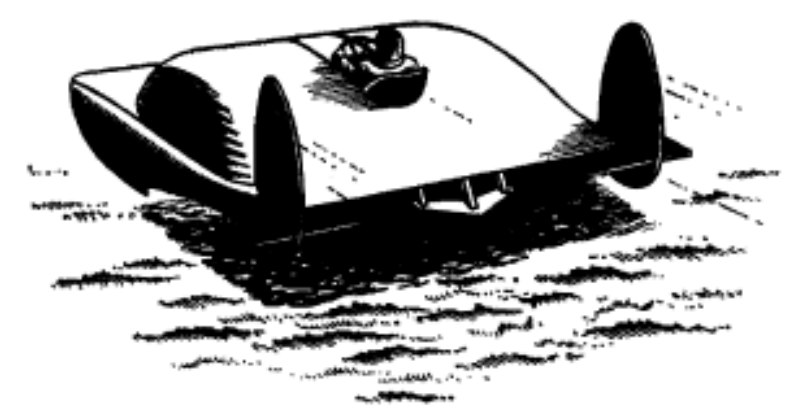

Figure 19: Ram Wing Watercraft (18)

More modern examples of hydrofoil usage can be seen on the Canadian warship, Bras d'Or, shown in Figure 20. This ship was designed and developed in Canada during the 1960's and used hydrofoils to make it one of the fastest warships of its time. The hydrofoils were placed at both the bow and aft of the hull in order to lift it from the water during cruise. 


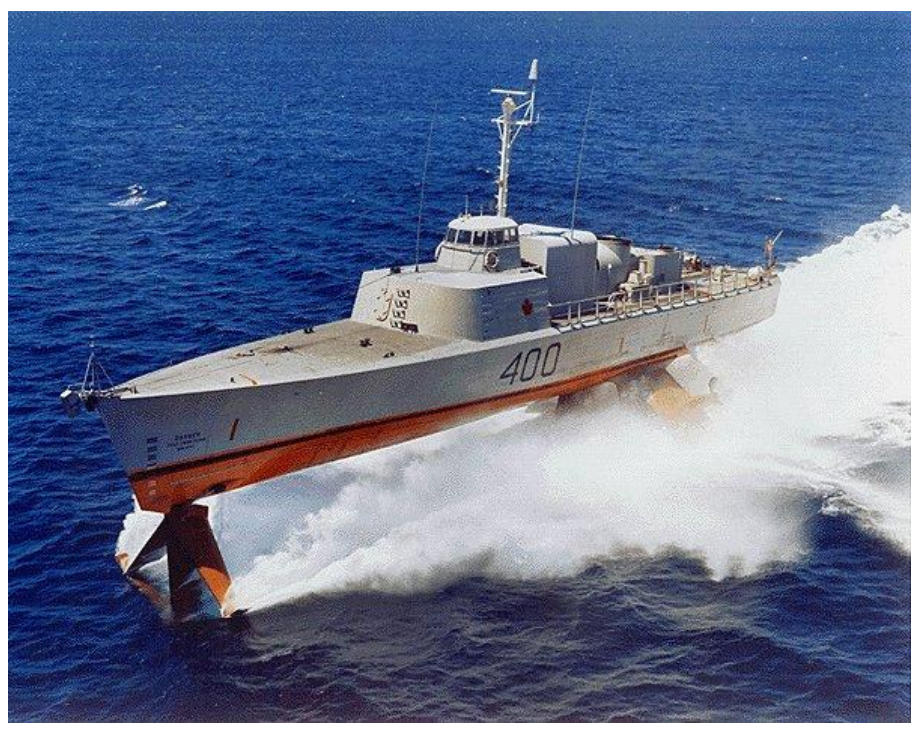

Figure 20: Canadian Warship Bras d'Or (37)

\subsubsection{Venturi Effect}

The Venturi is a tunnel or nozzle-like geometry that causes fluid speed to increase as a result of the fluid being forced through a narrow or constricted area. The increased speed causes a reduction of pressure (38). An example of a Venturi can be seen in Figure 21 on a ground effect car.

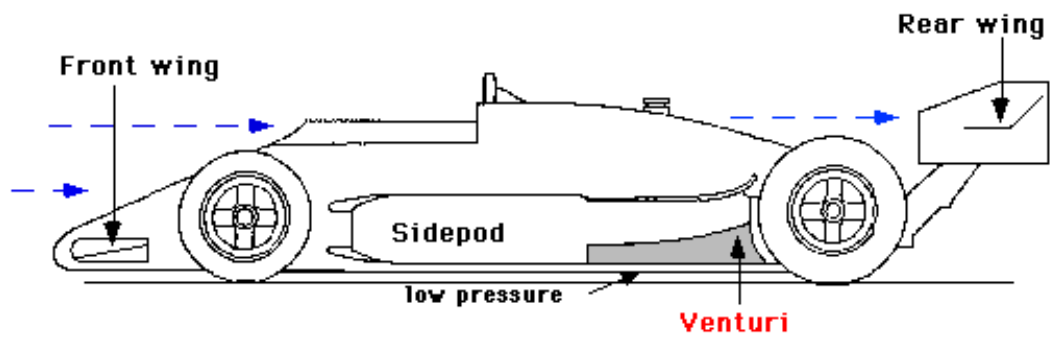

Figure 21: Venturi on Ground Effect Car (38)

In the case of the ground effect car, the front and rear wings create a down force which pushes the car to the track. The underbody Venturi tunnel creates a low pressure area between the chassis and the ground which also draws the car toward the track (38). 


\subsection{Biomimicry}

This section discusses the field of biomimicry, from its origins to its utilization in aerodynamics research today. Biomimicry is the imitation of nature: its models, systems, and/or elements, to solve human problems.

\subsubsection{Historical Overview}

The idea of flight has always fascinated mankind and even early inventors such a Leonardo DaVinci tried to mimic the flying abilities of birds and bats. He designed the ornithopter shown in Figure 22 around 1490 which was designed to create flight through flapping of its wings (39).

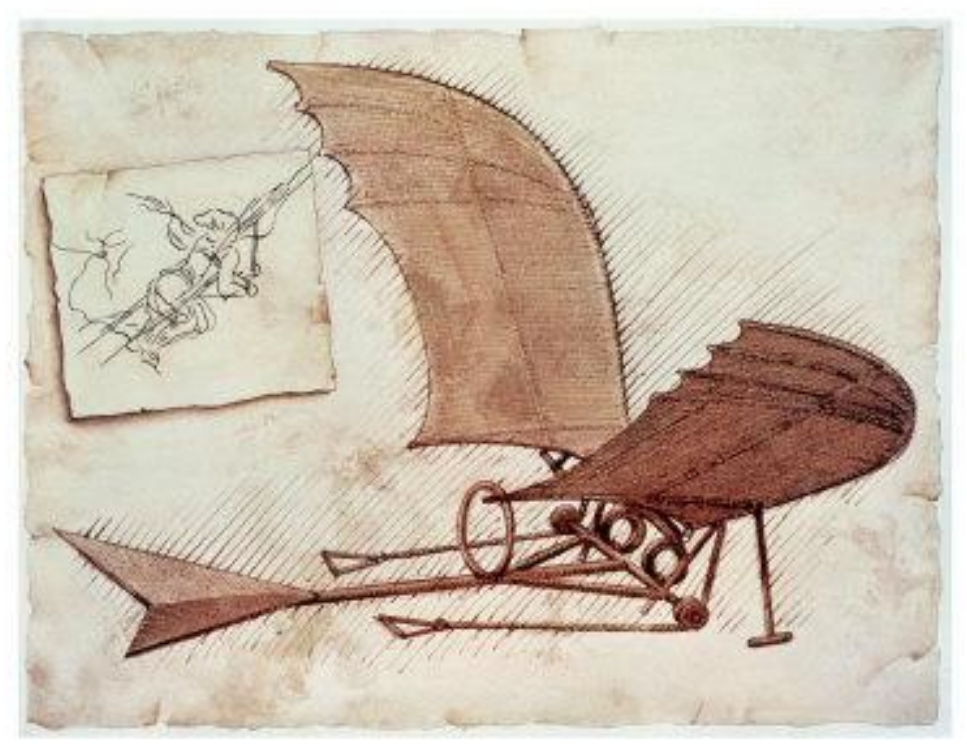

Figure 22: Leonardo DaVinci’s Ornithopter (39)

While the mimicry of animals has been examined many times before with little to show in working applications, new research into the field could prove to be more beneficial. Currently researchers from a variety of institutions are examining the flying styles of insects and birds. Applications vary from micro-UAV's that resemble flying insects developed for military 
purposes (as shown in Figure 23) to crawling insects designed by the Jet Propulsion Laboratory, JPL, for use on extra-terrestrial worlds.

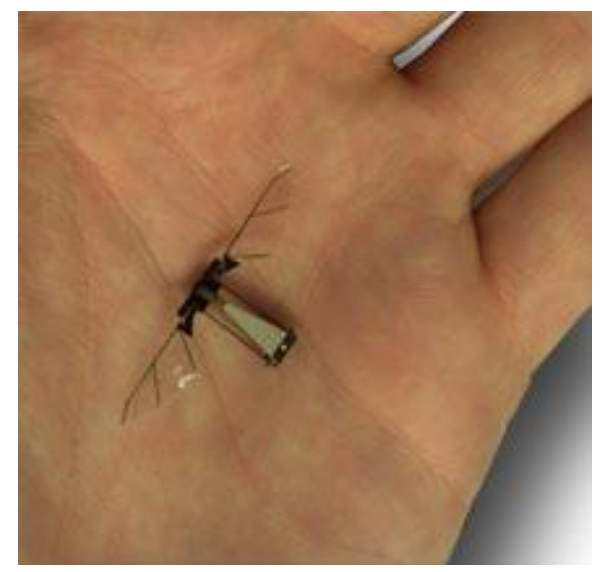

Figure 23: Robotic fly designed by Harvard University team (40)

\subsubsection{Morphing Wing Research}

In recent years, morphing wing technology has also become an increasingly popular research topic. The benefit of morphing wing technology is its ability to adapt the aerodynamic characteristics of the wing to suit necessary flight requirements. A morphing aircraft is one that is capable of controlling substantial shape changes while flying, with the intent of increasing its performance in such areas as efficiency and versatility (41). While preliminary solutions were developed by Birnbaum in 1924 for incompressible flow past a flapping airfoil, the application to modern technology has only recently begun to be possible with the development of smart materials. The military has been in the forefront with their Mission Adaptive Program, pushing development of aircraft that excel in a multitude of capabilities through morphing wing parameters.

In 2007, Wickenheiser and Garcia combined the extended lifting line theory with real airfoil data in order to determine the effects of various wing geometries on the lift-to-drag ratio as well as the center-of-pressure location in freestream (41). Their wing geometries included 
planform curvature or forward and aft swept wing sections. This research showed that morphing wings into crescent shapes was beneficial in acquiring a lift reduction at higher flight speeds. This would be useful in high-speed dives to avoid enemy engagement. In addition the center-ofpressure was capable of being manipulated forward and aft of its standard operating position with the assistance of wing twisting. It is important to note that this type of wing curvature shows a reduction in the lift and hence the efficiency.(41)

\subsubsection{Physiology of Birds in Flight}

With a resurgence of interest in biomimicry comes the necessity to overview the flying population and determine what makes them really fly. A variety of studies were conducted in the 1980's which were recently reviewed and republished. One study presented in 2006 examined avian wing geometry with a laser scanner and presented findings about aspects such as camber line, thickness distribution, planform shape, and twist distribution. One bird in particular of interest in the study was the Seagull.

The Seagull is primarily a coastal bird that commonly flies over incoming waves using their updrafts to soar in the air. As a result, they have developed wing features suited to this flight style. Figure 24 (42) shows the planform shape of the Seagull wing which reveals a leading edge sweep that begins at approximately a third of the wing span with a less dramatic sweep along the trailing edge. 


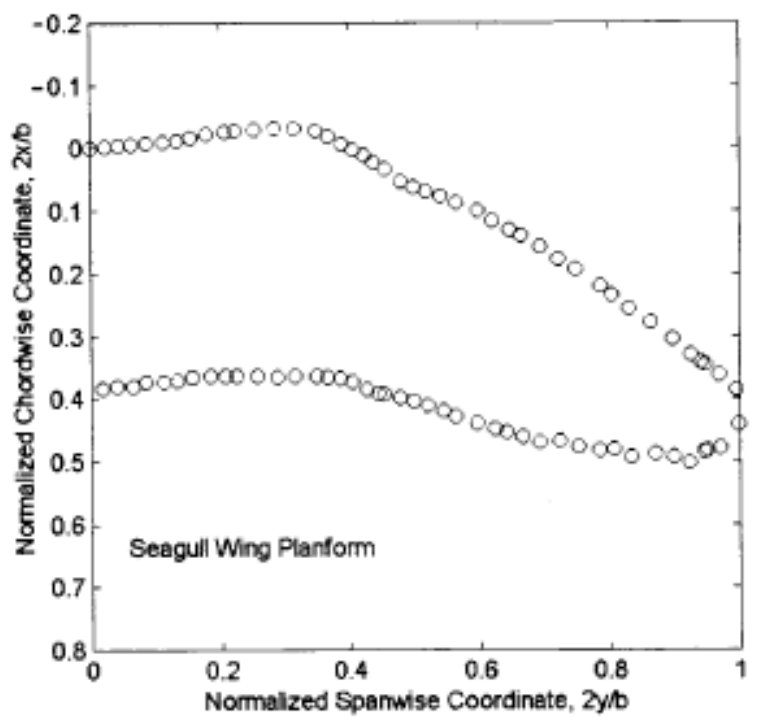

Figure 24: Planform Shape of a Seagull Wing (42)

The twist of the Seagull wing was examined along the spanwise direction, shown in Figure 25, and reveals that the angle of twist ranges from zero degrees to approximately 8 degrees. The maximum twist in this range occurs at approximately two-thirds the distance from the root chord.

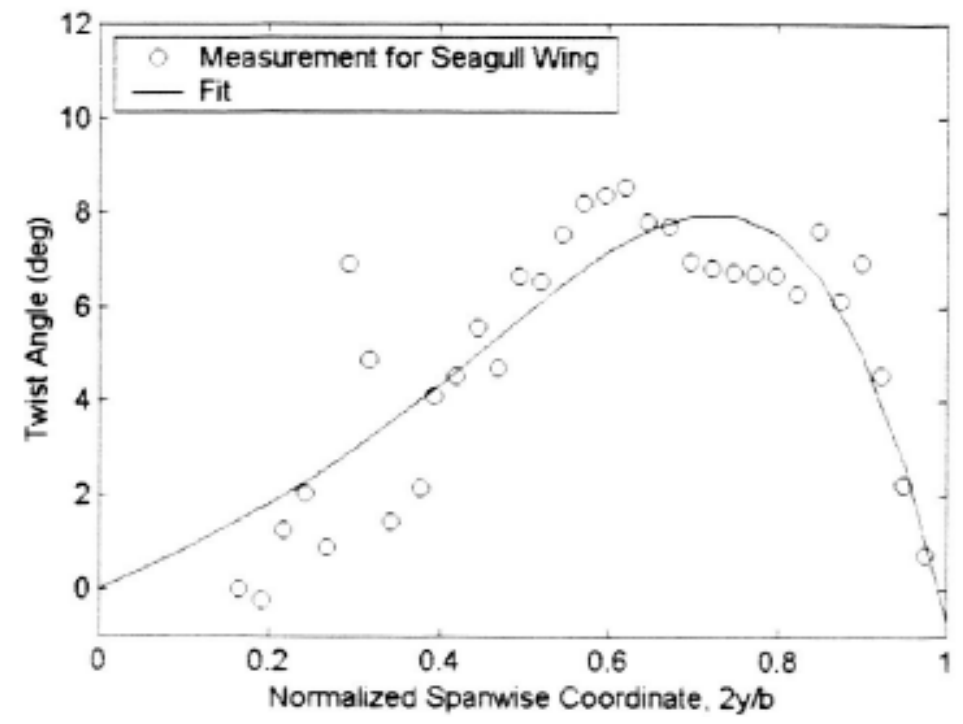

Figure 25: Spanwise Distribution of the Twist of a Seagull Wing (42) 
Aside from the twist, the Seagull wing itself will have a tendency to curve during the normal flapping motion of flight. Figure 26 shows the motion of the Seagull wing along the spanwise direction, with respect to its vertical position, in free space during flight. During this motion the Seagull wing will curve along various points of the span. One such position creates a curvature where the maximum vertical coordinate occurs in the center of the semi-span with the root and tip remaining on the same horizontal plane. This position creates a curve whose apex occurs at a location that is approximately $20 \%$ of its span.

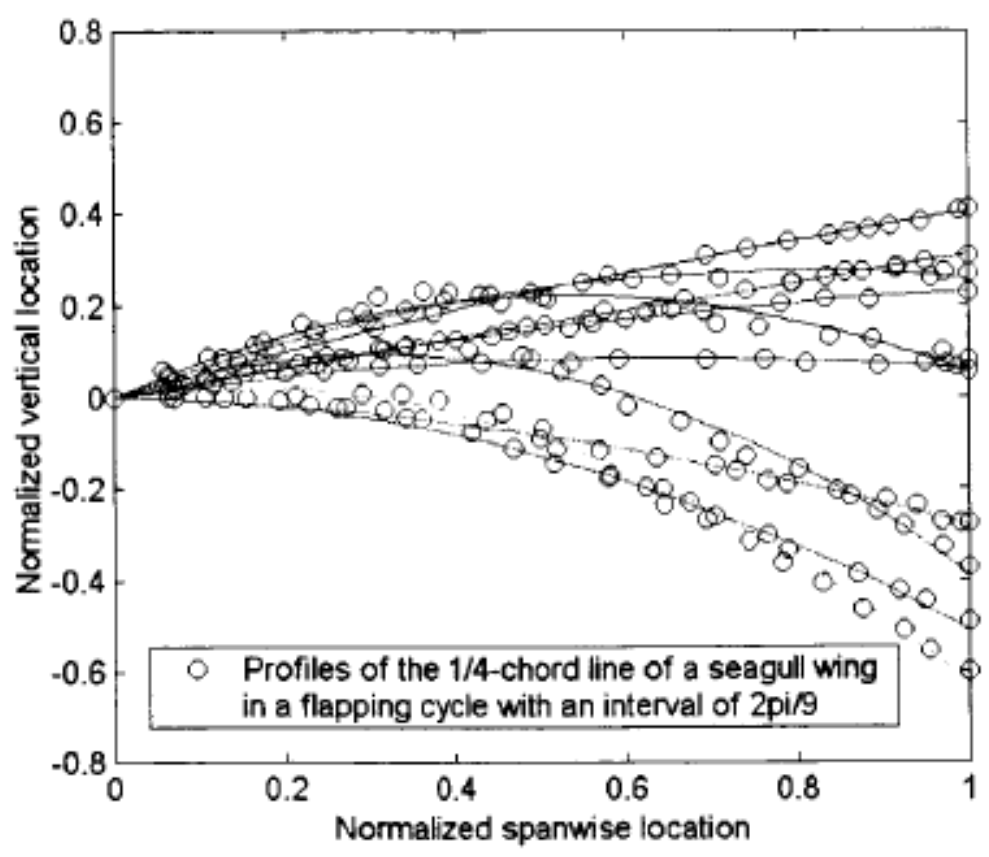

Figure 26: Front Profile of a Flapping Seagull Wing (42)

\subsection{Previous AirRay Research}

For the initial conceptual research on AirRay, the Wortmann FX 63-137 airfoil, seen in Figure 27, was chosen because of the availability of low speed wind tunnel data, the previous usage of this airfoil with low speed applications, and the reasonably high lift coefficients at varying angles of attack. 


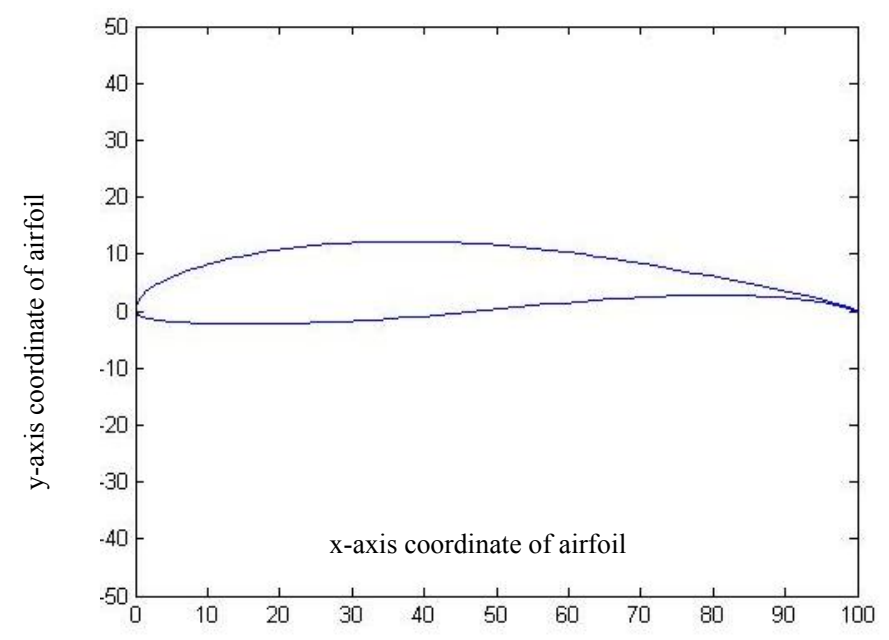

Figure 27: Wortmann FX 63-137(43)

The analytical aerodynamic data of the Wortmann airfoil can be found in Figure 28, lift versus angle of attack, and Figure 29, drag versus lift. This particular airfoil is commonly used on sailplanes which have similar flight objectives as ground effect vehicles.

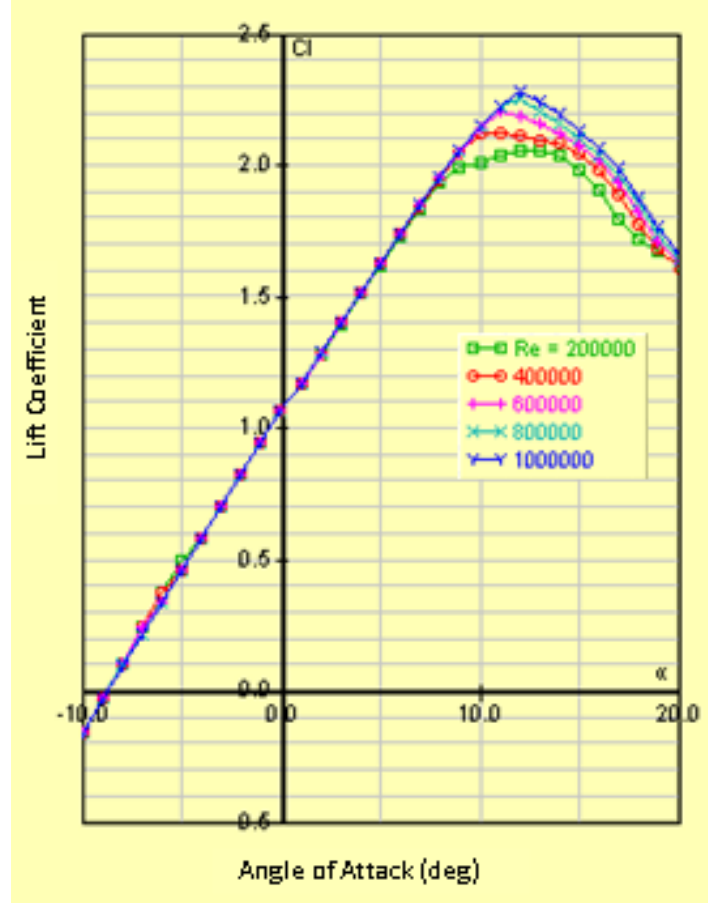

Figure 28: Wortmann FX 63-137 Lift versus Angle of Attack (44) 


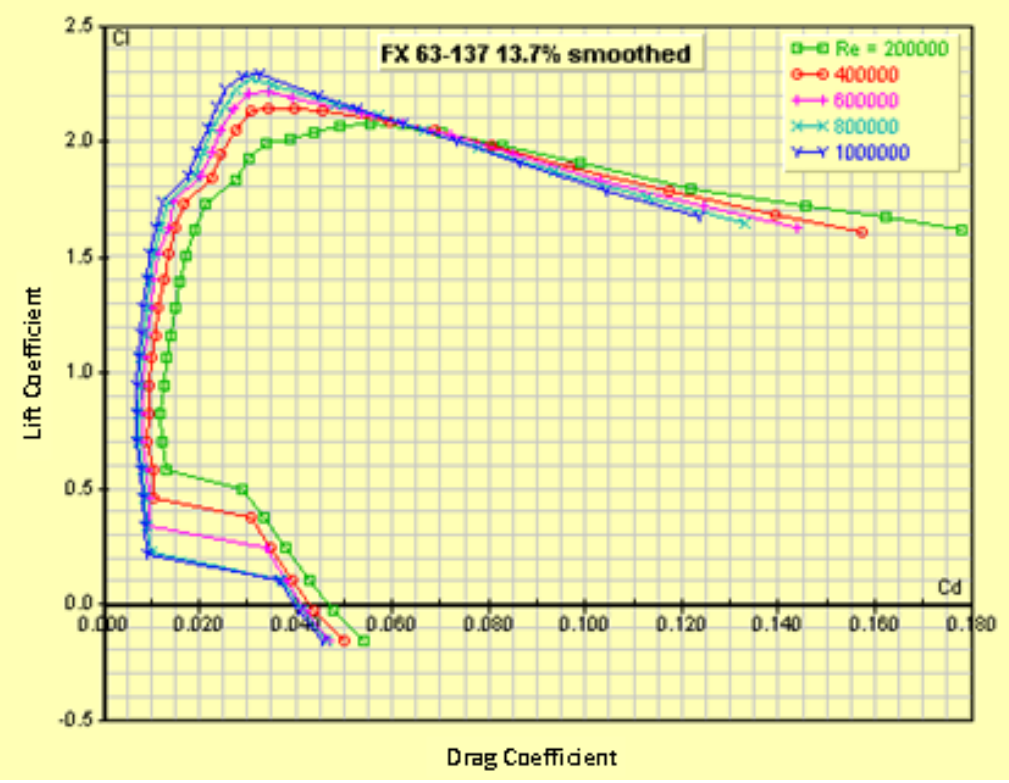

Figure 29: Wortmann FX 63-137 Drag versus Lift (44)

Computational analysis has been performed on the Wortmann FX 63-137 to determine the extent of lift enhancement during ground effect as well as the change in the center-ofpressure locations at varying angles of attack (45). The lift was found to increase $30 \%$ over that experienced by a moving body not located in the ground effect regime. The center-of-pressure was found to have traveled a maximum of $16 \%$ of the chord length (45). These results were found through analyzing a series of CFD simulations which were validated by comparison to a known flat plate airfoil in ground effect (45). These results were found for a range of angle-ofattack from -3 to 15 degrees and for various height-to-chord ratios.

Similar to previous theoretical research, the lift on the airfoil was found to increase as proximity to the ground increased (45). In addition, the drag forces were reduced as the airfoil approached the ground. The center-of-pressure was found to maintain a nominal travel distance as long as the angle-of-attack remained constant (45). However, with a changing angle-of-attack, 
the travel of the center-of-pressure can become significant. This research was performed at a Reynolds number of $1.25 \times 10^{6}$.

This result led to research on a method that would restrict the movement of the center-ofpressure (46) (47). By creating airfoils that had an angled slot cut into the main body as shown in Figure 30, the path of the air around the airfoil could be changed as the angle of attack increased.

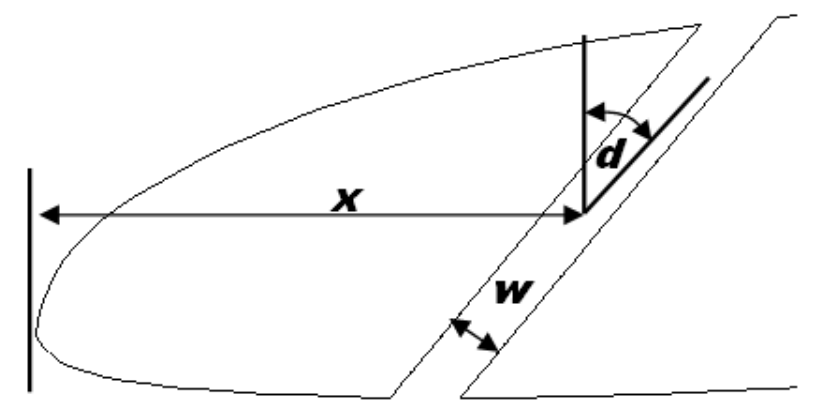

Figure 30: Diagram of Slot Characteristics (47)

Usually in ground effect, there is an unstable moment whereupon the airfoil will pitch-up; through the use of a ducted airfoil the airflow that would cause this effect is reduced as the angle of attack increases. This action limits the movement of the center-of-pressure by reducing the lift capabilities of the airfoil at higher angles of attack. A slot that is located a distance, $\mathrm{x}$, at $20 \%$ of the chord length from the leading edge, with a width, $w$, that is $2 \%$ of the chord length and at an angle, $\mathrm{d}$, that is 40 degrees from the vertical was found to have the greatest impact on reducing the movement of the center of pressure across a range of angles of attack from -3 to 15 degrees (46). The Reynolds number for this research was $1.23 \times 10^{6}$. 


\section{Chapter 3.0 Preliminary Research}

This section discusses the basic design of the proposed glider and provides a starting place in order to determine the capabilities and aerodynamic additions necessary in order to meet the overall project design objectives.

\subsection{Preliminary Weight Estimate}

A weight estimate is necessary when designing the aerodynamic characteristics of any aircraft. It affects not only the capability for flight but the ability to maintain stability. For this reason an analysis of weights was performed, where any unknown weights were estimated.

For this study, AirRay is considered to be a small, low speed, single passenger ground effect glider. Therefore for preliminary design purposes an average rider was assumed to weigh approximately 185 lbs; this assumption is based on a National Statistics Report written by the Center for Disease Control, CDC (48). The internal components of AirRay: controls, harness and seat, were estimated to weigh a total of $40 \mathrm{lbs}$ as shown in Table 1 . The weights of the items in the table were based on the amount of material and components necessary to make the basic framework for those parts. From the known weights and the glider geometry, the amount of material necessary to build the structure and its subsequent weight could be estimated. It should be noted that since the glider weight is dependent upon the required wing geometry and that geometry takes into account overall weight with respect to lift, the process of calculating the glider weight is iterative.

First the total weight of the rider and all internal/safety components were determined. Table 1 is comprised of all the internal and safety components in addition to the corresponding weights. These values were estimated based on commercially available parts and the projected amounts of required material. 
Table 1: Weights of Components

\begin{tabular}{|l|c|c|}
\hline Main landing gear & 20 & $\mathrm{lbs}$ \\
\hline Nose landing gear & 10 & $\mathrm{lbs}$ \\
\hline Internal linkages & 5 & $\mathrm{lbs}$ \\
\hline Safety roll bars & 10 & $\mathrm{lbs}$ \\
\hline Harness & 5 & $\mathrm{lbs}$ \\
\hline
\end{tabular}

Since it is desired to construct the glider out of a lightweight plastic or composite material, an average density was derived from a variety of polyethylene plastics. These plastics are among some of the most common plastics used in manufacturing recreational vehicles today. The average density of plastic was found to be $0.035 \mathrm{lb} / \mathrm{in}^{3}(49)$.

In order to calculate the weight, an appropriate skin thickness was determined. Most high speed airplanes have an average skin thickness of $1 / 16$ inch which is approximately $1.5 \mathrm{~mm}$. This is a result of lightening strike requirements and the necessary thickness to sink rivets into the aluminum. Low speed aircraft have a tendency to have skin thickness as low as 0.016 inch which is about $0.4 \mathrm{~mm}$ since these aircraft will experience lighter loads (50). Commercial aircraft are commonly built with aluminum or composite materials, but AirRay is designed for plastic material. Since a lightweight frame is desirable but strength needs to maintained, a skin thickness of $1 \mathrm{~mm}$ was estimated for usage. This thickness will later be structurally analyzed to determine whether or not it can withstand the stresses applied to it during normal operation. If necessary the skin thickness will be redesigned at that time to account for any additional requirements.

Once all of these components have been indentified or calculated then it is possible to determine the weight to the glider through multiplying the geometric surface area (both of the top and bottom surfaces) by the skin thickness and by the density of plastic. The resultant empty weight of the structure is estimated to be approximately $100 \mathrm{lbs}$ of plastic. The geometric parameters of the glider are shown in Table 2. 
Table 2: Glider Geometry

\begin{tabular}{|l|c|c|}
\hline S (wing area) & 161.5 & $\mathrm{ft}^{2}$ \\
\hline Seat Width & 2.1 & $\mathrm{ft}$ \\
\hline Seat Hight & 3.7 & $\mathrm{ft}$ \\
\hline $\mathrm{b}$ (span) & 18.0 & $\mathrm{ft}$ \\
\hline ct (tip) & 6.9 & $\mathrm{ft}$ \\
\hline Cr (root) & 10.6 & $\mathrm{ft}$ \\
\hline Cbar (std mean chord) & 9.0 & $\mathrm{ft}$ \\
\hline mac (aero mean chord) & 9.1 & $\mathrm{ft}$ \\
\hline$\lambda$ (taper) & 0.7 & - \\
\hline AR (aspect ratio) & 2.0 & - \\
\hline$\Lambda$ LE (sweep angle - LE) & 26.0 & $\mathrm{deg}$ \\
\hline Lt/c (sweep angle - max thick line) & 20.1 & $\mathrm{deg}$ \\
\hline e (Oswald's coeff) & 0.8 & - \\
\hline $\mathrm{k}$ (constant) & 0.2 & - \\
\hline
\end{tabular}

\subsection{Design Parameters}

Certain design parameters had to be determined before further design decisions could commence. Since the glider is being designed for application on a downhill slope as a recreational device, it was felt that the speed of the glider needs to be comparable to other activities commonly found in those environments. From a study conducted in 2005, winter sport participants of activities including skiing and snowboarding have an average speed of $26.7 \mathrm{mph}$ with a $7.0 \mathrm{mph}$ standard deviation (51). As a result, it was decided that AirRay should fly at approximately $30 \mathrm{mph}$ to make it comparable to current speeds of similar modern sporting activities. Comparatively, this should mean that the pilot has the capability of controlling the glider with the same ease and safety as these other activities. From this parameter the Mach number and Reynolds number of the craft could be determined as shown in Table 3. This is useful in categorizing the type of flow which in this case is considered incompressible, subsonic, turbulent flow. The characteristic length for the Reynolds number calculation is the root chord of $10.6 \mathrm{ft}$. 


Table 3: Flow field Characteristics
\begin{tabular}{|l|c|c|}
\hline$V_{\max }$ & 44.12 & $\mathrm{ft} / \mathrm{s}$ \\
\hline$V_{\text {terminal }}$ & 41.07 & $\mathrm{ft} / \mathrm{s}$ \\
\hline Mach \# & 0.039 & - \\
\hline Re & $2.6 \mathrm{E}+06$ & - \\
\hline
\end{tabular}

The slope of the hill also ties into the performance of the glider. Most slopes available are those designed for ski resorts which have a tendency to range between 8 degrees for a novice slope to 18 degrees for an advanced slope (52). Since the intermediate slopes range between 1015 degrees, the basic design will account for a minimum 10 degree slope. It should be noted that the slope affects the force balance on the glider as shown schematically in Figure 31.

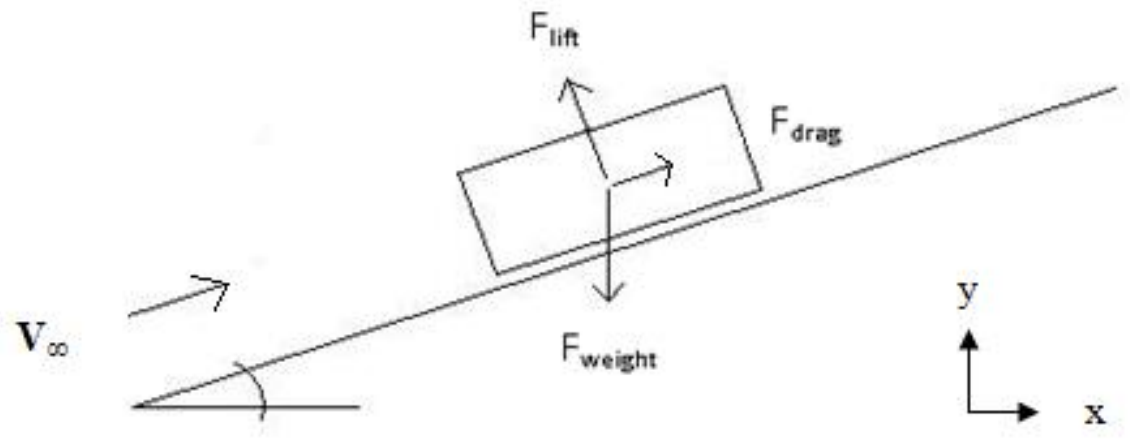

Figure 31: Force Representation

As a result, the lift is a function of the y-component of weight and the drag is influenced by the x-component of weight. The slope will also impact the terminal velocity of the glider. The terminal velocity will be limited by the seat back of the glider which will act as a drag device.

\subsection{Lift Estimation}

In order to design a properly sized aircraft, it was necessary to know the aerodynamic characteristics such as lift, drag and pitching moment, of the 2-D airfoil selected for use. The 2-D experimental lift curve for the Wortmann airfoil is shown in Figure 28. 
In order to assess accurate lift characteristics of a wing, the lift-curve needed to be recalculated to accommodate for 3-D effects. This was done by adjusting the slope with a variation of Prantl's lifting line equation developed by Helmbold and modified by Kuchemann. The slope equation, shown by Equation 1, takes into account both aspect ratio, AR, and sweep angle, $\Lambda$, and is accurate for aspect ratios less than 4 (4).

$$
a=\frac{a_{0} \cos \Lambda_{c / 2}}{\left[1+\left(\frac{a_{0} \cos \Lambda_{c / 2}}{\pi A R}\right)^{2}\right]^{1 / 2}+\frac{a_{0} \cos \Lambda_{c / 2}}{\pi A R}}
$$

This equation empirically adjusts the linear range of the 2-D lift curve, which has an original slope, $a_{0}[1 / \mathrm{rad}]$. It should also be noted that the sweep angle is taken from a location at half the chord length.

The 3-D lift-curve slope, once determined, was then used to calculate the lift coefficients at particular angles of attack through the use of Equation 2 (4). The slope calculated in Equation 1 is in radians and was converted to degrees for comparison purposes.

$$
C_{L}=a\left(\alpha-\alpha_{L=0}\right)
$$

Equation 2

Equation 2 is essentially a modified point slope formula in which $\alpha_{L=0}$ is the angle of attack at lift equal to zero and $\alpha$ is the current angle-of-attack. This produces the linear range of the lift curve as shown in Figure 32 for an AR of approximately 2, and a value of $\alpha_{L=0}=0.46$. 


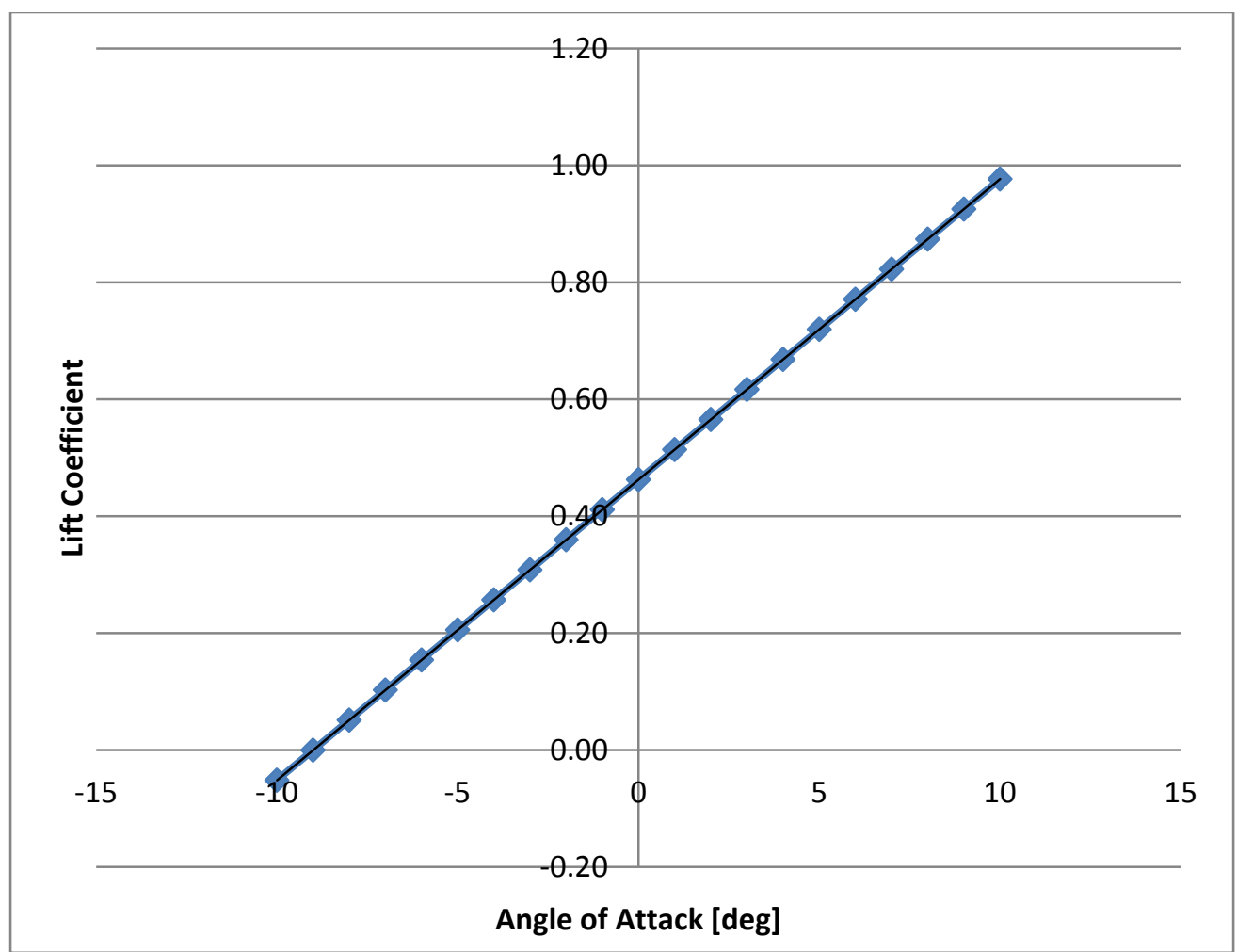

Figure 32: 3-D Lift Slope of Wortmann FX 63-137

When designing a fixed wing aircraft, the angle of attack of the wing may not be the same as that of the body. The difference between the wing angle and the longitudinal axis of the aircraft is called the angle of incidence (4). This angle defines the amount of lift, through the lift coefficient, achievable without modification of the wing. AirRay is designed to have a $5^{\circ}$ angle of incidence for cruise at $30 \mathrm{mph}$ to increase its capabilities without approaching stall which begins to occur around $10^{\circ}-12^{\circ}$ according to the 2-D data found in Figure 28. The 3-D lift coefficient taken at $\alpha=5^{\circ}$ is 0.73 which can be increased by a maximum of $20 \%$ to accommodate for the potential influence of ground effect resulting in a lift coefficient of 0.88 as shown in Table 4. 
Table 4: Wing Parameters and Lift Characteristics

\begin{tabular}{|l|c|c|}
\hline Thickness & 0.137 & - \\
\hline Max Thick Location & 0.297 & - \\
\hline$\alpha$ (zero lift) & -9 & deg \\
\hline Max $C_{I}$ & 2 & - \\
\hline$C_{I}(\alpha=5$ deg) & 1.6 & - \\
\hline$C_{I}(\alpha=5$ deg $+\mathrm{GE}(20 \%))$ & 1.92 & - \\
\hline$C_{L}(\alpha=5$ deg$)$ & 0.73 & - \\
\hline$C_{L}(\alpha=5$ deg $+\mathrm{GE}(20 \%))$ & 0.88 & - \\
\hline
\end{tabular}

The overall lift can then be calculated utilizing the modified lift coefficient found in Equation 3 (4).

$$
\mathrm{L}=\frac{1}{2} \rho \mathrm{V}^{2} \mathrm{AC}_{\mathrm{L}}
$$

Equation 3

This equation takes into account dynamic pressure, $1 / 2 \rho \mathrm{V}^{2}$, wing area, $\mathrm{A}$, and the lift coefficient, $\mathrm{C}_{\mathrm{L}}$, resulting in a lifting force of approximately $285 \mathrm{lbs}$ at the assumed flight velocity of $30 \mathrm{mph}$ for a wing span of $17 \mathrm{ft}$ and a chord of $10 \mathrm{ft}$.

\subsection{Drag Estimation}

Drag estimation was divided into two parts: the drag associated with the wing planform and the drag associated with the frontal area of the fuselage section and pilot station. The drag bucket of the Wortmann airfoil, shown previously in Figure 29, demonstrates that for a range of 2-D lift coefficients between 0.5 and 1.5, the 2-D base drag coefficient, $\mathrm{C}_{\mathrm{do}}$, does not exceed 0.02 .

There is additional drag placed on the wing as a result of induced drag. Induced drag is the drag that is a resultant of the generation of lift. In ground effect there is an approximate $10 \%$ decrease in the induced drag due to ground effect at a height-to-span ratio of 0.5 as shown in Figure 33. 


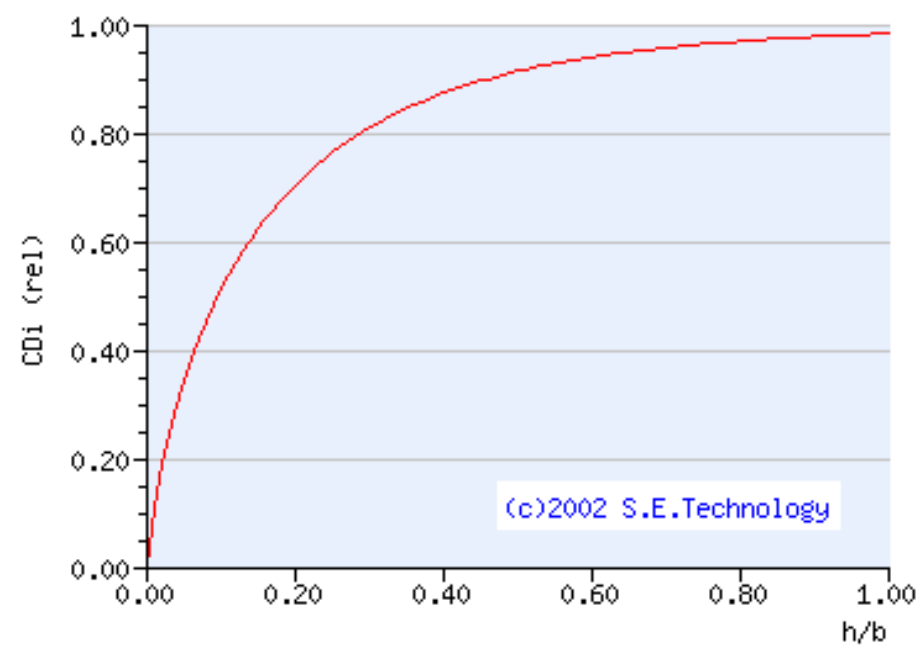

Figure 33: Induced Drag Reduction (53)

Like the lift coefficient, it is necessary to have 3-D drag coefficients, which can be calculated through the use of Equation 4. (5)

$$
\mathrm{C}_{\mathrm{D}_{\mathrm{o}}}=\mathrm{C}_{\mathrm{f}} \mathrm{FQ}\left(\mathrm{S}_{\mathrm{wet}} / \mathrm{S}\right)
$$

Equation 4

This equation takes into account the form factor, $F$, the interference factor, $Q$, and the ratio between surface area, $S_{\text {wet, }}$ and wing area, $S$. The form factor is defined through Equation 5 and evaluates the shape of the wing as part of the base drag. (5)

$$
\mathrm{F}=\left[1+\frac{0.6}{(\mathrm{x} / \mathrm{c})_{\mathrm{m}}}+100\left(\frac{\mathrm{t}}{\mathrm{c}}\right)^{4}\right]\left[1.34 \mathrm{M}^{0.18} \cos \left(\Lambda_{\frac{\mathrm{t}}{\mathrm{max}}}\right)^{0.28}\right]
$$

The form factor was calculated to be approximately 1.06. The interference factors can be found in a lookup table such as the one shown in Table 5, and are based on the style of connection the body has with the wing or structural additions like missiles that would cause interference. For this design, the well filleted low wing factor was used. 


Table 5: Interference Form and Factors
\begin{tabular}{|l|r|}
\hline Interference Form & Factor \\
\hline wing mounted nacelle & 1.5 \\
\hline wing tip missle & 1.25 \\
\hline high wing, mid wing & 1 \\
\hline well filleted low wing & 1 \\
\hline unfilleted low wing & 1.25 \\
\hline
\end{tabular}

This results in a base drag of 0.02 , found through the use of a wing area of $161.5 \mathrm{ft}^{2}$ and a surface wing area of $330.8 \mathrm{ft}^{2}$. Once a 3-D base drag has been calculated, the overall drag coefficient for the wings could be determined through Equation 6 .

$$
\mathrm{C}_{\mathrm{D}}=\mathrm{C}_{\mathrm{D}_{\mathrm{o}}}+\mathrm{kC}_{\mathrm{L}}^{2}
$$

Equation 6

This drag equation is broken into two parts, the base drag coefficient and the induced drag. The induced drag is a function of the constant $\mathrm{k}$, which takes into account the aspect ratio and Oswald's efficiency, e, as shown in Equation 7.

$$
\mathrm{k}=\frac{1}{\pi \mathrm{AR} e}
$$

Equation 7

The constant $\mathrm{k}$, resulted in a value of approximately 0.198 , found from an Oswald's efficiency of 0.8 and an AR of 2. The results of the 3-D drag estimation can be found in Table 6 which shows the 2-D drag coefficient, $\mathrm{C}_{\mathrm{do}}$, the 3 -D base drag, $\mathrm{C}_{\mathrm{Do}}$, the overall drag outside of ground effect, $C_{D \text { AoA }}=5$ deg and the overall drag inside of ground effect, $C_{D A o A}=5 \operatorname{deg}-G E(10 \%$ Ind).

Table 6: Non-Dimensional Drag Characteristics of Wing

\begin{tabular}{|l|c|}
\hline Cdo & 0.02 \\
\hline CDo & 0.018 \\
\hline$C D(\alpha=5$ deg $)$ & 0.167 \\
\hline$C D(\alpha=5$ deg - GE $(10 \%$ Ind $))$ & 0.152 \\
\hline
\end{tabular}


The drag coefficient for the fuselage area was calculated apart from the wing, because the backrest of the passenger acts effectively like a flat plate perpendicular to the flow. This was done as a way of producing drag that limited the terminal velocity especially in the advent of higher angled slopes, higher than the original design. The 3-D drag coefficient for a flat plate is 2.0 (4). In-ground-effect, a potential $10 \%$ reduction in induced drag can be assumed, resulting in a $C_{D}=1.8$.

\subsection{Static Stability}

One of the major criteria for the success of any design is its ability to maintain stable controlled flight. In a static state an aircraft needs to be balanced longitudinally in order to sustain flight; this is known as static stability. It is a comparison between the relative positions of the center-of-pressure, $x_{c p}$, and the center-of-gravity, $x_{c g}$, with respect to the overall chord of the aircraft, $x_{L}$, as shown in Equation 8.

$$
\text { S.M. }=\frac{x_{c p}-x_{c g}}{x_{L}}
$$

Equation 8

The difference between the two positions is known as the static margin, S.M., and must be positive to demonstrate longitudinal stability.

The center-of-gravity is determined by the weight distribution of all the components of the glider including the position of the rider. For some aspects of the design, the components have been estimated but not finalized, such as the landing gear, harnesses, and control linkages. In these cases, an estimated weight has been given as presented in Section 3.1 and the location of these components was based on historical placement. The assumptions are listed below(54):

1. The wing weight is located, $W_{\text {wing }}$, at $0.1(\overline{\mathrm{c}})$ behind a quarter of the m.a.c.

2. The fuselage weight, $W_{f u}$, is located at $0.45(x)$ behind the nose. 
3. The tail weight is located, $W_{\text {tail }}$, at $0.9(x)$ behind the nose.

4. The main landing gear weight is located $1.1\left(x_{\mathrm{cg}}\right)$ behind the nose.

From these assumptions of weight distribution, an estimation of the overall center-ofgravity location can be determined as shown in Equation 9 (54).

$$
\frac{x_{c g}}{x}=\frac{0.45\left(W_{\text {fus }}+W_{\text {sys }}+2 * W_{\text {tail }}\right)+0.006 W_{\text {total }}+\left(W_{\text {pay }} x_{\text {pay }}+0.1 W_{\text {wing }} \overline{\mathrm{c}}\right) / x}{\left[0.960 W_{\text {total }}-W_{\text {wing }}\right]} \quad \text { Equation } 9
$$

It should be noted that the payload $\left(\mathrm{W}_{\text {pay }}\right)$ in Equation 9 is the weight of the rider, the location of which was finitely adjustable during the design process as a way to balance the glider with different wing geometries. It should be noted that for a sitting person, the natural center of gravity is going to be different than that of a standing individual. This means that a sitting person's main body mass will be approximately 1 foot behind their actual center of gravity. This is based on the dimensions of an average American male.

The center-of-pressure is determined as a function of the mean aerodynamic chord, which is an average of the chord length over the entire wing. For this particular airfoil, the center-ofpressure was estimated to be at $30 \%$ of the mean aerodynamic chord based on the mean aerodynamic center and the leading edge sweep. The locations of the center-of-pressure and the center-of-gravity along with the S.M. can be found in Table 7.

Table 7: Location of Xcp and Xcg

\begin{tabular}{|l|c|c|}
\hline Xperson & 3.5 & $\mathrm{ft}$ \\
\hline$X c g$ & 4.33 & $\mathrm{ft}$ \\
\hline$X c p$ & 5.17 & $\mathrm{ft}$ \\
\hline S.M. & 0.063 & - \\
\hline
\end{tabular}




\subsection{Geometry}

The process of wing development is iterative. The weight is affected by the overall size of the glider which changes based on the weight distribution. The lift capabilities of the wing are influenced by the amount of sweep and aspect ratio, which in turn stabilize the glider by counterbalancing the force defined by the weight distribution. Through this process a low weight glider that minimizes the wing span for maneuverability while maintaining stability can be designed. The basic geometries were shown previously in Table 2 and the preliminary, straight wing model of the glider is shown in Figure 34 .

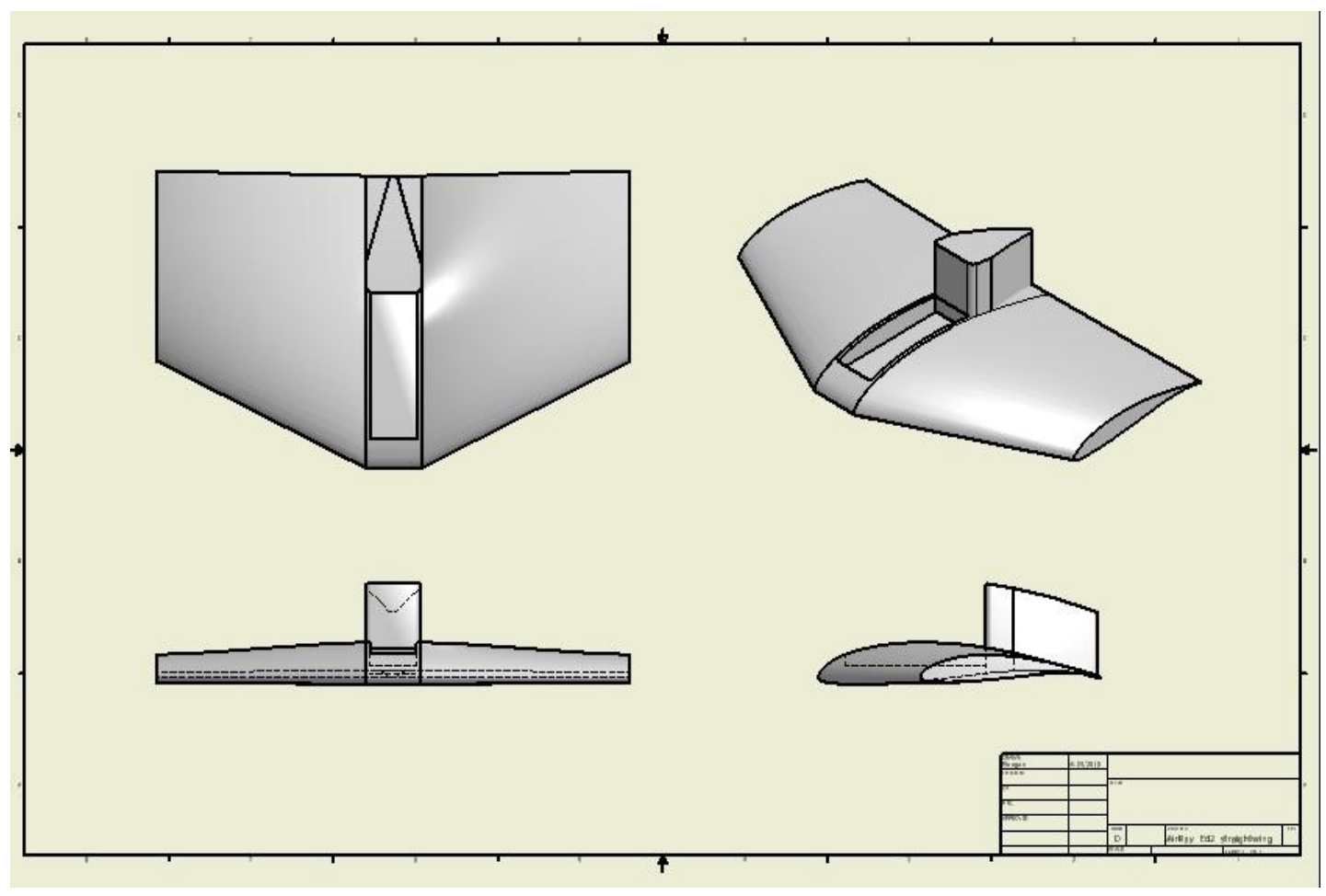

Figure 34: Concept Drawing of Proposed Straight Wing Design 


\subsection{Control Surfaces}

While the main focus of this research was to design a planform for the main wing that successfully enhances the lift characteristics while providing stability, basic control surfaces were also designed as part of the overall goals of the project.

Due to the wing-in-body nature of the design, control surfaces were placed on the trailing edge of the wing which would act as a horizontal stabilizer and behind the seat back of the glider, acting as a vertical tail. The vertical tail was designed through use of Equation 10 (5).

$$
S_{V T}=C_{V T} \frac{b_{W} S_{W}}{l_{V T}}
$$

The area of the vertical tail is determined through a relationship between the areas on the main wing, $S_{w}$, the span of the main wing, $b_{w}$, the distance between the quarter chord of the wing and the quarter chord of the tail, $l_{V T}$, and the vertical tail coefficient, $C_{V T}$. This resulted in a vertical tail area of $3.5 \mathrm{ft}^{2}$, which allowed for a vertical tail 24 in tall by 21 inch deep.

Flaperons were placed on the trailing edge of the wing and act in part as a pitch stabilizer and in part as a control device for turning the glider. Also, in the event of emergency braking, the flaperons will deploy and act as a drag device to retard the craft. Typically flaperons, like ailerons, are sized between $15 \%$ and $25 \%$ of the wing chord. For this case, the flaperons will be approximated at $15 \%$ of the wing chord and will be located between $50 \%$ and $90 \%$ of the semispan (7). This resulted in a flaperon on each wing that is $1.5 \mathrm{ft}$ deep by $3 \mathrm{ft}$ long.

The impact of the spanwise wing curvature and twist were not examined with regards to the control surfaces as this is outside the scope of the project. 


\subsection{Summary}

While these are the minimal design features that can be created through the use of a straight wing, the potential to further reduce the wing span is present. The addition of twist and/or wing curvature could enhance the lift to adequately reduce the span to a more manageable size. If these methods are insufficient in decreasing the span, then the use of one-sided endplates will be examined in combination with curve and twist to test their effectiveness when not applied to a straight wing. 


\section{Chapter 4.0 Computational Research}

This chapter discusses the meshing setup and simulation of the Computational Fluid Dynamic (CFD) models in Fluent and subsequent results.

\subsection{Model Parameters}

This section will provide an overview of the styles of wing and body geometries that were computationally examined for their effects on the aerodynamic characteristics in the ground effect regime.

\subsubsection{Baseline}

To create a point of reference, a baseline model was created for comparison during the analysis. The baseline model was analyzed analytically so that the computational data can be accessed for accuracy. This model is a straight wing design with a $26^{\circ}$ leading edge sweep as shown in Figure 35.

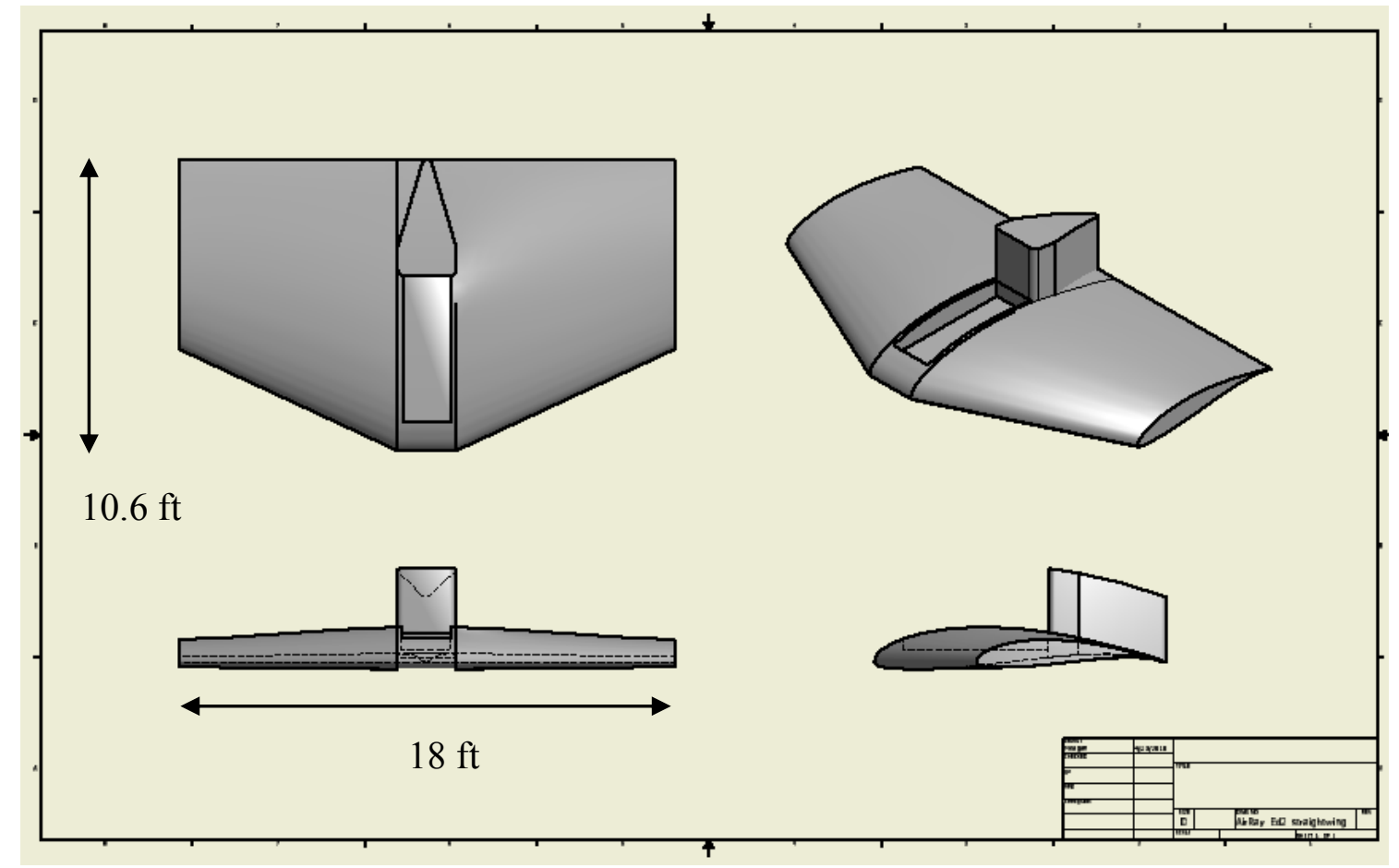

Figure 35: Baseline Model 


\subsubsection{Spanwise Wing Curvature}

For the purpose of this research, spanwise wing curvature was analyzed as shown in Figure 36. This geometry has the same wing span and wing tip and root chord as the baseline model shown in Figure 35.

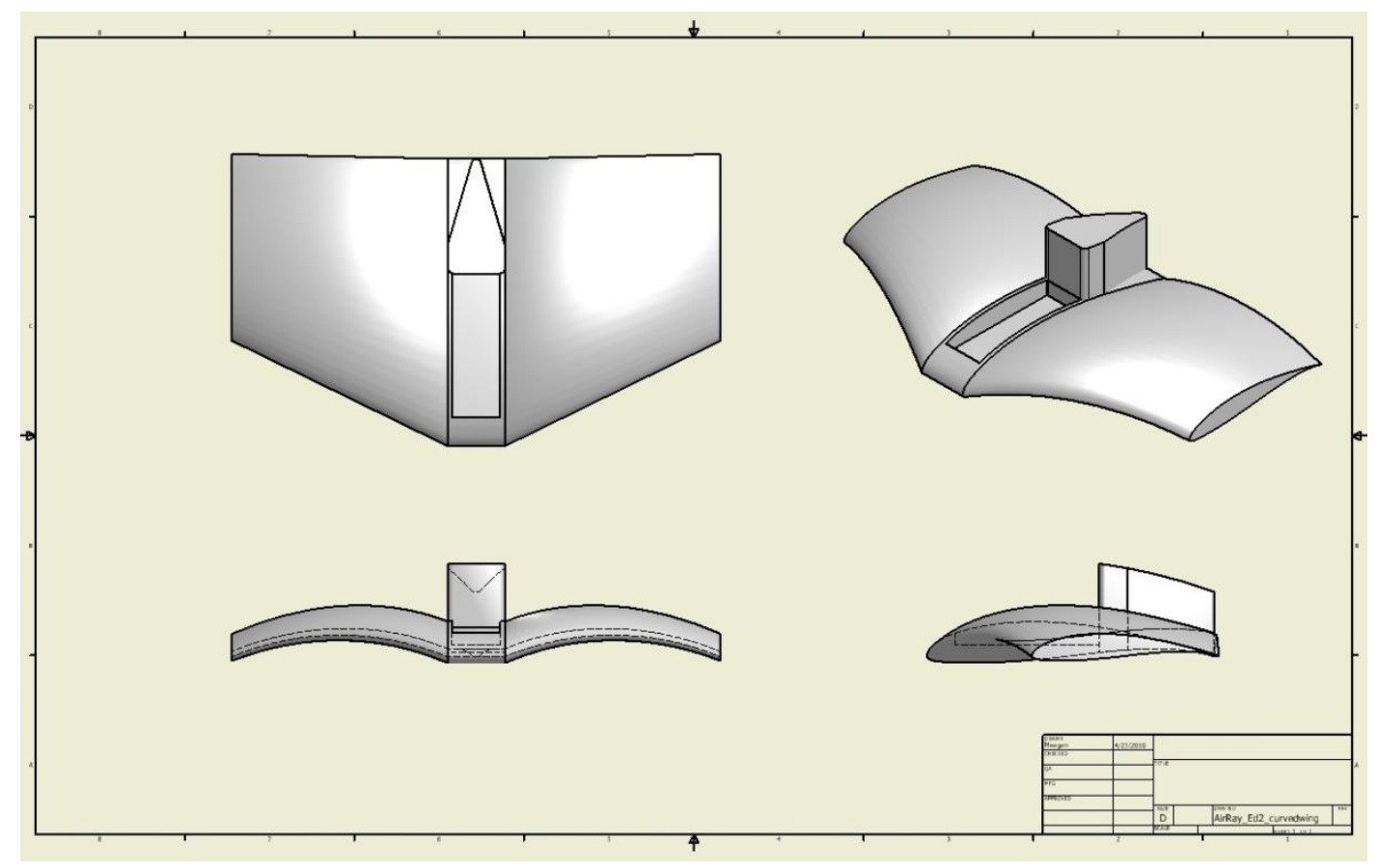

Figure 36: Concept Drawing of Proposed Wing Curvature

The apex of the arc will occur in the center of the wing and has radii of curvature ranging from zero to $10 \%$ of the span at increments of $2 \%$. The spanwise wing curvature is symmetric along both the leading and trailing edge creating a uniform curve. In addition, the root and tip chords remain on the same horizontal plane and only the center of the wing will change. This spanwise wing curvature was chosen to reflect the type of wing structure that occurs as part of the flapping cycle of a seagull shown previously in Section 2.4.3. This method will be compared to the straight wing computationally in order to obtain a trend for the analysis which will then be validated experimentally. 


\subsubsection{Wing Twist}

Wing twist can be applied to wings in a variety of ways. The most common is when it is applied linearly across the wing from root-to-tip where the tip is usually pointed up or down. For this research the twist was applied across the center of the wing so that the root and tip maintain the original angle of incidence, as shown in Figure 37.

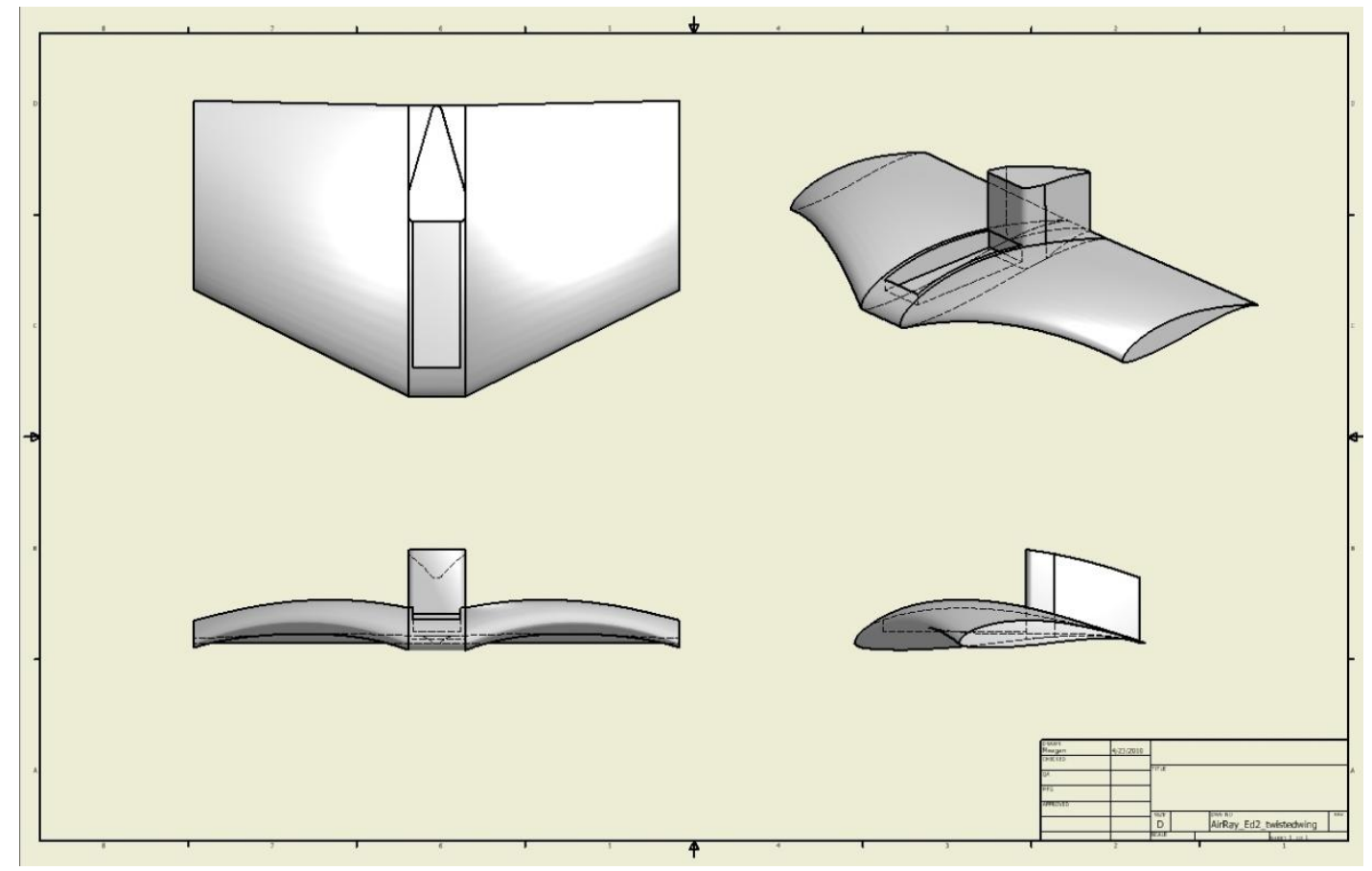

Figure 37: Concept Drawing of Proposed Wing Twist

The twist was applied at the trailing edge tip so that the trailing edge will continue to lie along the horizontal plane created by the root chord. In this manner a cupped surface was created similar to that of the spanwise wing curvature method, but as a result of a flat trailing edge, a wing larger frontal area was created for capturing the air flow. The amount of twist was adjusted to match the range of curvature in the aforementioned spanwise wing curvature analysis, which was approximately 10 degrees of twist. This was so an accurate comparison could be drawn. The twist method was also analyzed computationally to determine the trend effects of twist on the 
wing characteristics as compared to a straight wing and a spanwise curved wing. Select parameters of twist were then experimentally validated.

\subsubsection{Vanes}

After the initial computational analysis was performed, there were irregularities in the flow that were created from the rider location and the tail section. The flow was shedding from the front of the tail causing a wake to occur over the wing and resulting in a loss of lift in that section, and minimizing controllability of the surfaces on the vertical tail. Modifications to the surface of the wing were made in the form of vanes in an attempt to redirect the flow back to the tail section and reconnect the flow. The vanes were placed next to the tail section as shown in Figure 38 . Note that this is only a semi-span model divided along the center chord line. This was done in an effort to reduce computational space and time by performing symmetric modeling across the centerline.

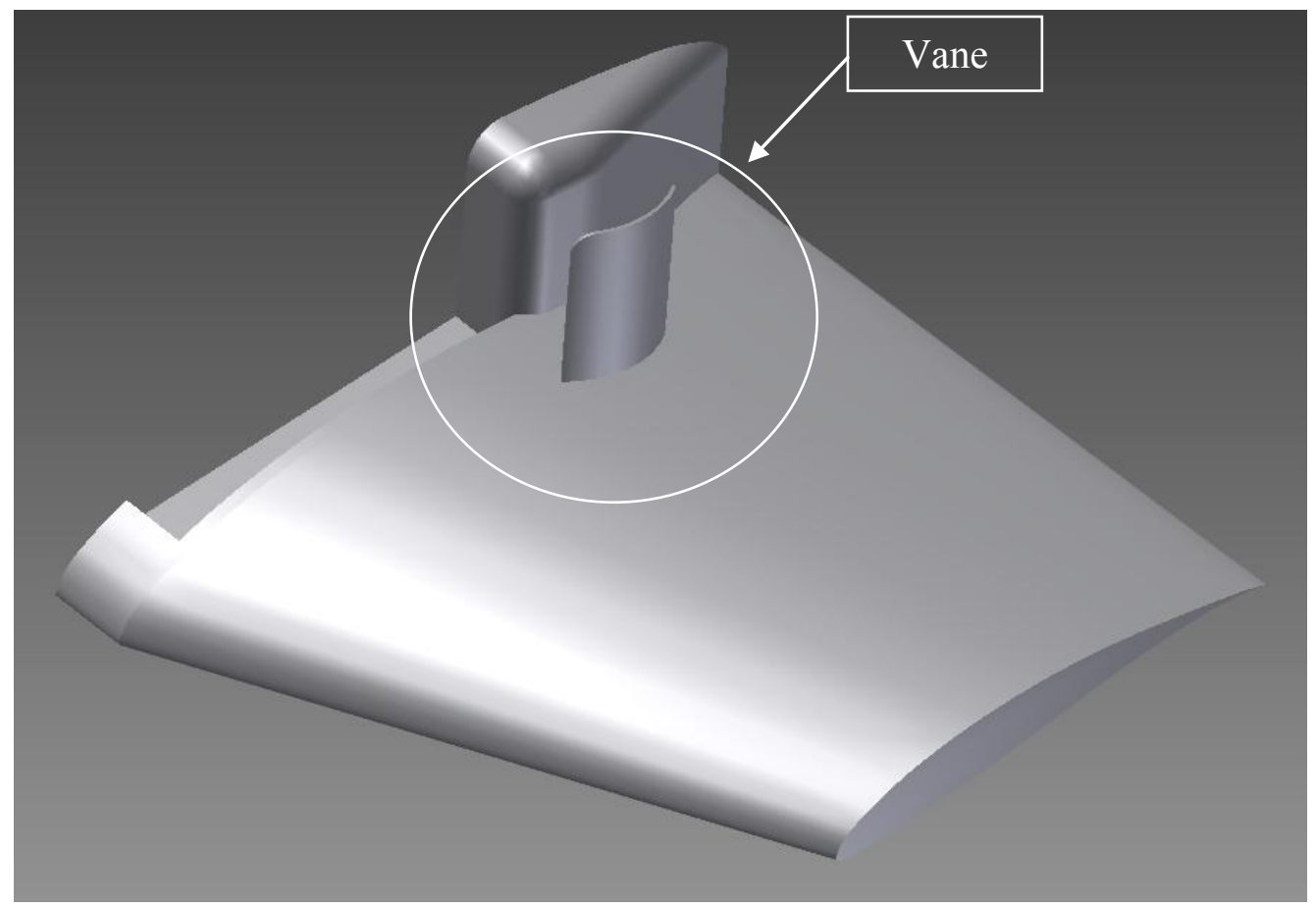

Figure 38: Single Vane Modification 
Twelve variations of vanes were examined, including modifications to the height, the length, the distance from the tail section along the span, the placement along the chord, and the number of vanes. The most efficient of which was the double vane as shown in Figure 39. The double vanes, shown in the figure, are the same height as the tail section, approximately 3 feet. These vanes are location within a $1 \mathrm{ft}$ distance from the tail section.

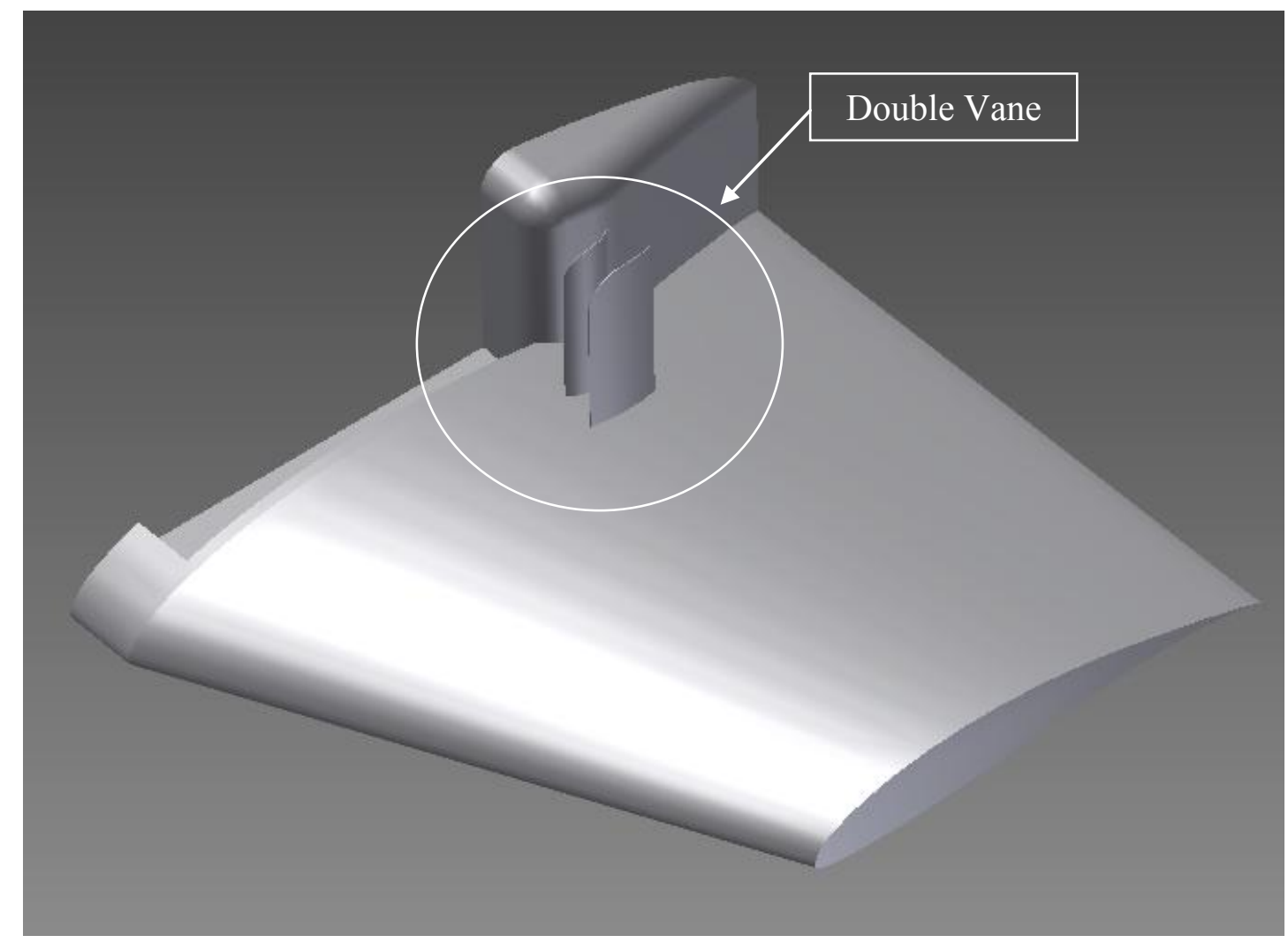

Figure 39: Double Vane Modification

This design technique, while useful in correcting the flow, was later assessed to be aesthetically unappealing to the design and was not implemented. Instead, modifications were made to both the canopies and the tail section in an effort to reduce the wake generated by the center section. 


\subsubsection{Canopies}

The design for the glider was originally created with a void in the center section that would allow for the placement of a rider. This however caused flow irregularities and did not provide any protection to the rider, so a canopy section was deemed necessary. This design feature would assist in correcting the flow irregularities as well as providing protection to the rider. The canopy was designed to start at the nose and gradually slope upward to a maximum height. Three heights were tested: 5, 6.5 and 8 inches. These heights were picked in an attempt to direct the air flow over the top of the tail section in order to generate additional lift. An example of the canopy styling can be seen in Figure 40.

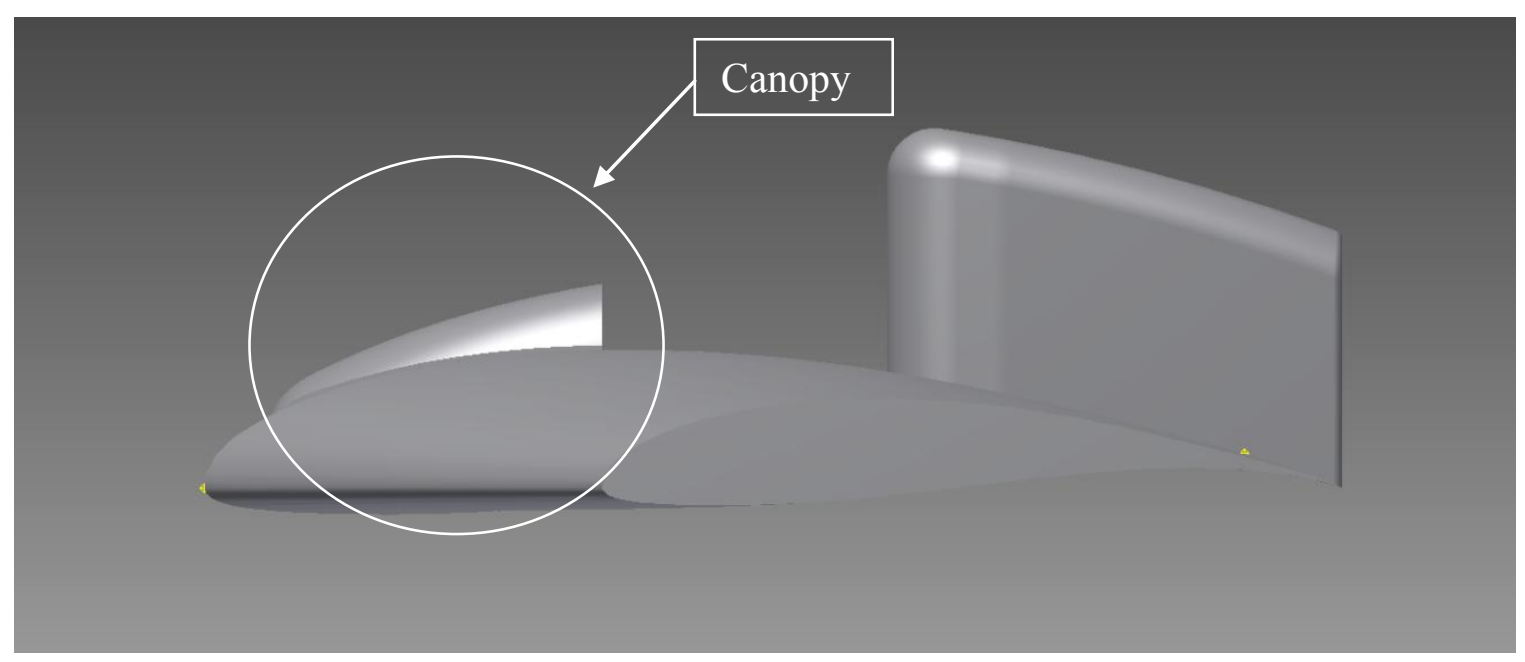

Figure 40: Canopy Design: 5 inch Maximum Height

In order to maximize the amount of air flow directed over the tail section, the canopy top was eventually flattened out to prevent shedding over the sides of the canopy. An example of the front of the original canopy is shown in Figure 41. This style had a peak in the arc at the center of the glider. This was later flattened to be more elliptical as shown in Figure 42. 


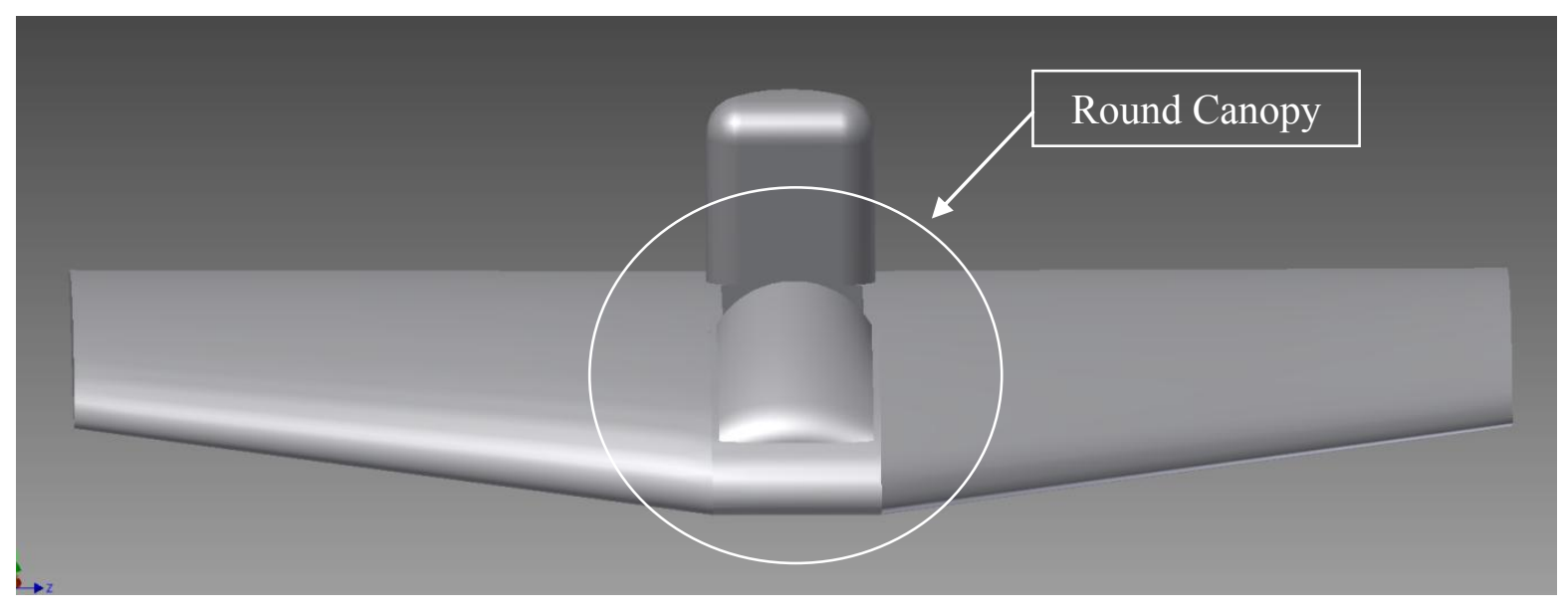

Figure 41: Round Canopy Style

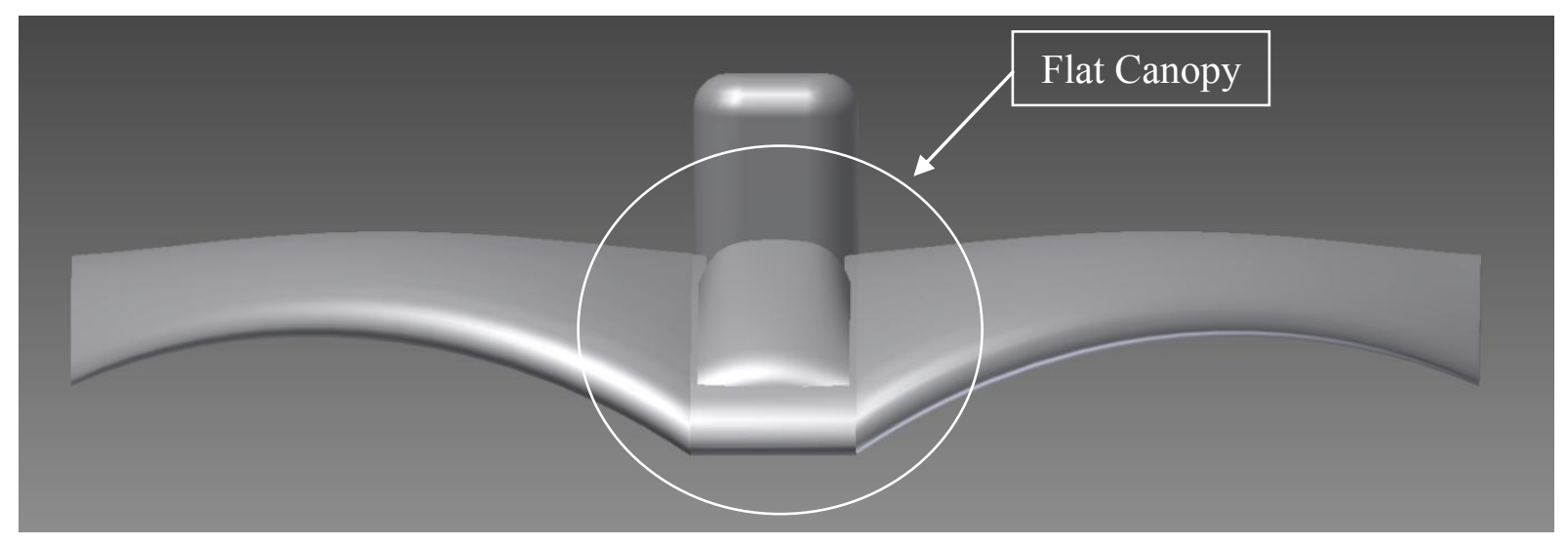

Figure 42: Flattened Canopy Style

\subsubsection{Tail Modifications}

The addition of the canopy led to improved lift capabilities, but limited separation still occurred along the tail section as a result of the sharpness of the seat back and an $18.5^{\circ}$ bend aft of the seat back. The modifications to the tail were broken up into two sections as shown in Figure 43. 


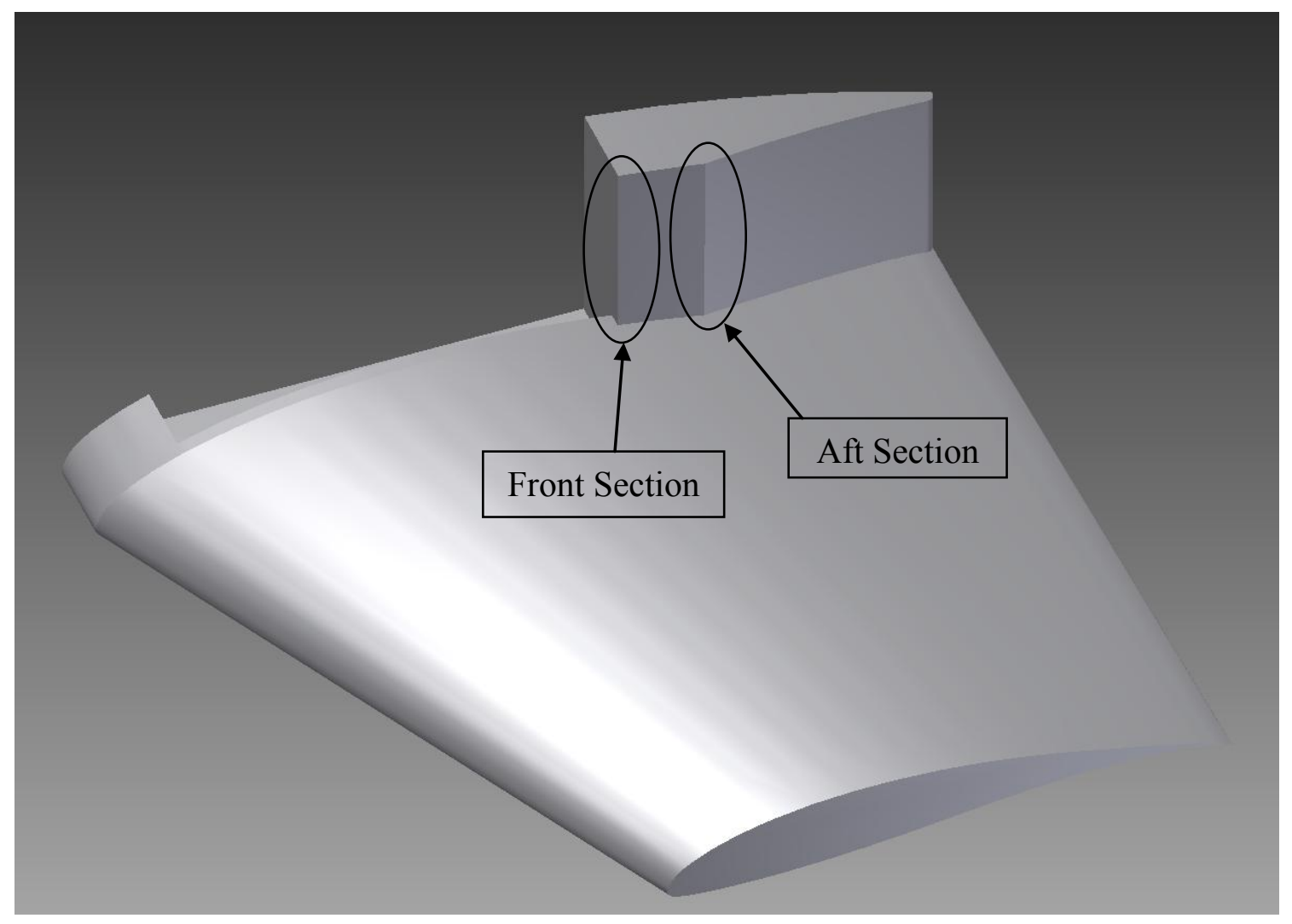

Figure 43: Tail Section with Highlighted Areas of Interest

The first section that was examined for modification was the frontal area of the tail section otherwise known as the seat back region for the passenger. This area adjoins the tail at a $90^{\circ}$ angle creating a potential location for flow separation. The angle was therefore varied across a range of three radii: $5,7.5$ and 10 inches.

The second section that was examined is aft of the seat where the tail angles back $18.5^{\circ}$ to connect to the trailing edge. This angle was gradually reduced to $15^{\circ}$ and $10^{\circ}$ to examine the effects of the flow separation. Since the angle reduction causes the tail to become increasingly thicker, the tail was eventually split as shown in Figure 44. 


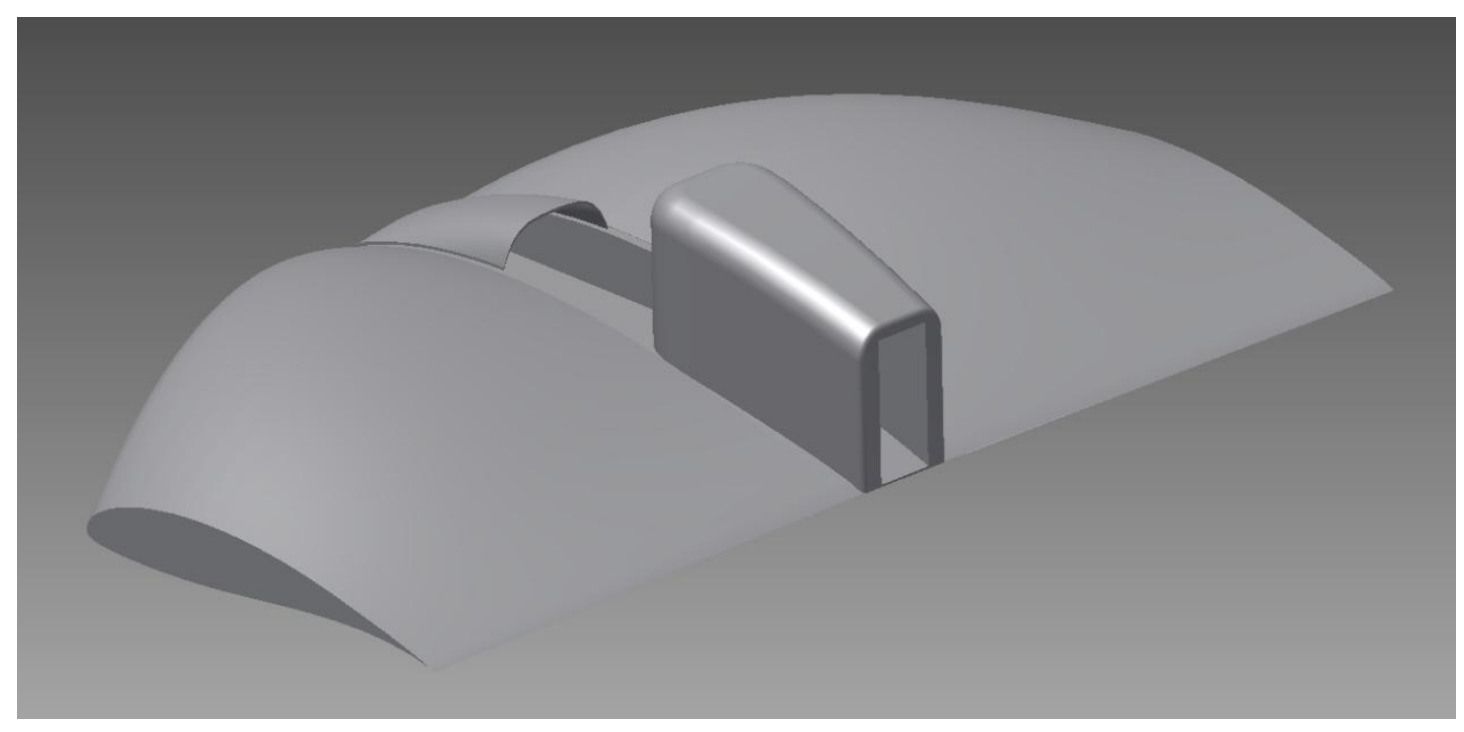

Figure 44: Tail Section with Split Tail

While not explicitly shown, the tail section would have two movable panels on either side of the tail that would be separate from the top of the tail, but covered by it, in order to allow for the lifting surface on the top to remain. The tail panels would work together and act as a rudder for the glider.

\subsection{Simulation Setup}

The models were initially created in Autodesk Inventor, a 3D CAD program. The models were then transferred into Gambit, which was chosen to create the grid meshes necessary for computational simulation. Fluent was then used to simulate the computational fluid dynamics for the $3 \mathrm{D}$ models.

\subsubsection{Grid Set-up}

The models were first imported into Gambit after being created in Inventor. In order to reduce the model size during simulation, the models were split in half along the center line. 
These semi-span models were placed along a symmetric plane which would simulate a fullmodel without requiring additional space inside the simulation.

The semi-span models were placed inside two control volumes of different sizes, which allowed for varying grid sizes to be used. The inner control volume, referred to as the model volume, has dimensions that are 2 chord lengths in the chordwise direction, $3 / 4$ chord in the spanwise direction, and $3 / 4$ chord in the vertical direction. The outer control volume has dimensions 7 chord lengths in the chordwise direction, 3.5 semi-span lengths in the spanwise direction and $1 / 2$ span +2 chord lengths in the vertical direction.

The grid meshing was started by creating a line mesh along the trailing edge with a constant spacing of 1. A size function was used to grow the line mesh along the surface of the model with a growth rate of 1.1 and a maximum cell size of 3 . Once the surface mesh was created a size function was once again used to grow the surface mesh to the model volume with a growth rate of 1.1 and a maximum cell size of 9 . The meshed surfaces of the model volume were then used as a source to grow the control volume mesh. The growth rate and maximum cell size used were 1.2 and 18 . The model volume has a smaller cell count than the control volume to allow for refinement of the simulation closest to the model surface.

\subsubsection{Simulation Parameters}

Once the mesh was complete, it was imported into Fluent for simulation. The full scale design is low speed, operating at $30 \mathrm{mph}$, but has a Reynolds number of $2.34 \times 10^{6}$, indicating turbulent flow. Turbulent flow occurs at a Reynolds number $1.5 \times 10^{6}$ and higher for flow over a surface (6). As a result, the computational analysis utilized turbulent flow equations and parameters. A k-epsilon RNG viscous turbulent model with enhanced wall treatment and 
pressure gradient effects was chosen for use based on documentation in the Fluent User's Guide (55). Second order pressure and power law momentum solution methods were also utilized for convergence. Convergence occurred at a minimum of $1 \mathrm{e}-3$, however most criteria converged around 1e-6 due to the length of time it took continuity to converge.

Within the analysis, a moving body was simulated by generating a translational ground plane. When the translational speed is set to be the same velocity as the flow field, it mimics the movement of a body through the air.

\subsubsection{Grid Independence}

The straight wing was modeled first and used to establish the parameters for grid independence. The numerical uncertainty in a fine-grid solution is a maximum of $2.2 \%$ (56). Three grid meshes were tested to determine the most suitable mesh for simulation. The first mesh contained 760,972 cells, the second mesh 953,766 cells, and the third mesh 2,680,907 cells. The results of the grid independence study are shown in Table 8.

Table 8: Grid Independence

\begin{tabular}{|l|r|l|l|l|}
\hline & \multicolumn{1}{|l|}{$C_{L}$} & \% Diff & \multicolumn{1}{l|}{$C_{D}$} & \% Diff \\
\hline Mesh 1 & 0.3045 & - & 0.0943 & - \\
\hline Mesh 2 & 0.3120 & $2.40 \%$ & 0.0905 & $4.20 \%$ \\
\hline Mesh 3 & 0.3100 & $0.65 \%$ & 0.0900 & $0.56 \%$ \\
\hline
\end{tabular}

The percent difference between the lift of the first and second mesh was $2.4 \%$ which means that the first mesh was not refined enough for grid independence. This was also supported by the difference in the drag coefficient being $4.2 \%$ which is higher than the allowable uncertainty of $2.2 \%$. Hence, the first mesh was unacceptable to use and a more refined mesh had to be created. Mesh 3 was thus created to compare against Mesh 2 to assess its refinement. The third mesh showed only a $0.65 \%$ difference in the lift coefficient from the second mesh and a 
$0.56 \%$ difference in the drag coefficient. This indicated that the second mesh was grid independent since Mesh 3 did not show a significant improvement in results.

\subsection{Computational Results and Analysis}

This section discusses the results that were generated from the computational simulations and analyzed the results based on predicted performance. While some aspects of the modifications may not be used on AirRay, they still provide valuable insight into the effects they have on ground effect vehicles for future applications.

\subsubsection{Baseline}

The straight wing was modeled in ground effect and compared to the analytical results from the basic design calculations in order to assess the validity of the computational results. The computational data is broken into two groups, the original tail that the initial analysis was performed with and the modified split tail which will be discussed later. The analytical results are for a baseline straight wing case out-of-ground effect. These results can be expected to increase up to a maximum of $20 \%$ in ground effect. Therefore the computational results should be greater than the analytical results out-ground-effect and preferably greater than the analytical results in-ground-effect. The comparison of lift results for the baseline geometry is shown in Figure 45. Note: The nomenclature of IGE represents in-ground effect and the nomenclature of OGE represents out-of-ground effect. 


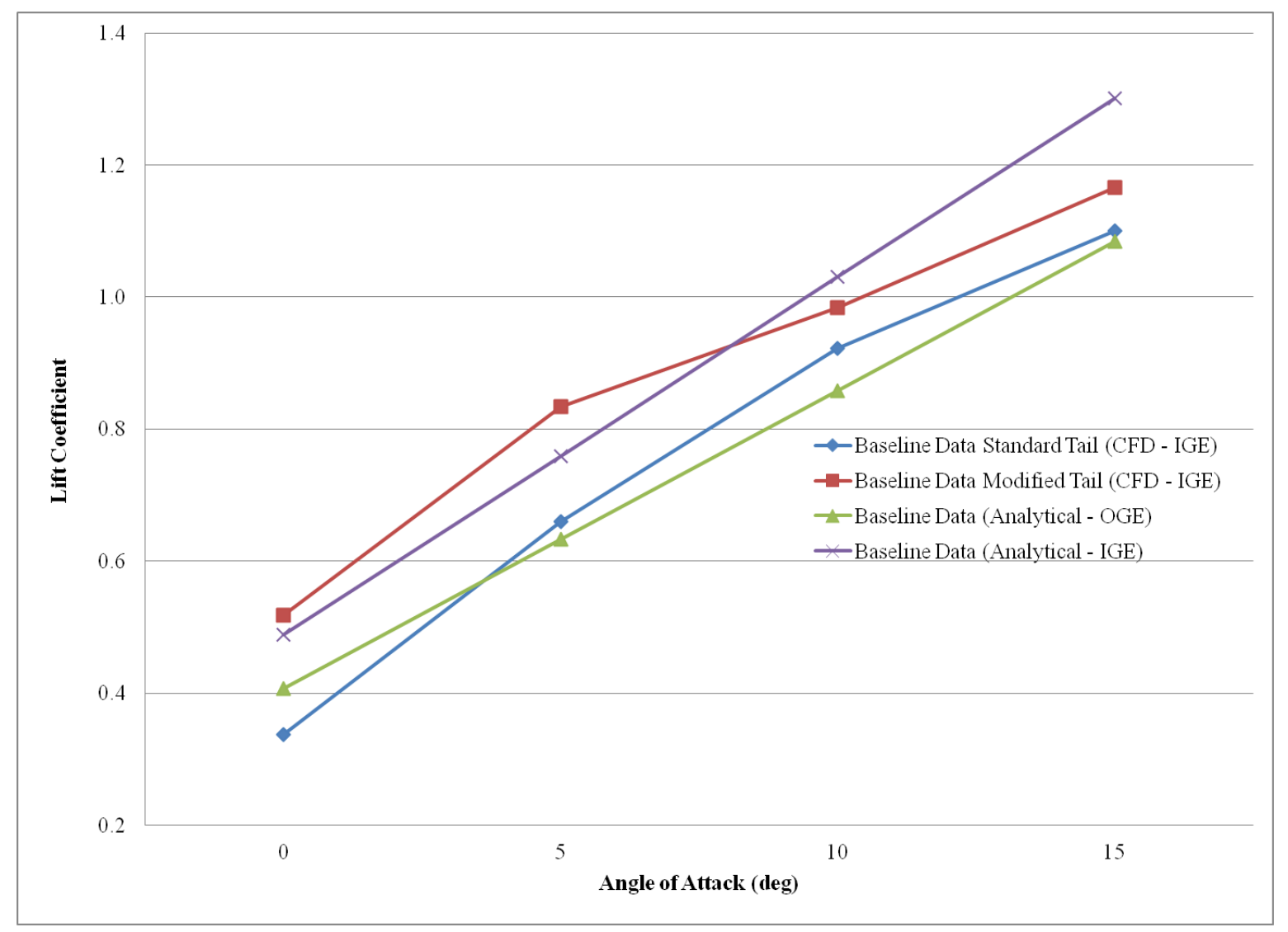

Figure 45: Lift Coefficient Comparison of Baseline Configuration Data

In Figure 45 the standard tail model only performs marginally better than the model would out-of-ground effect at an angle of attack larger than zero. The model with a modified split tail performs significantly better than what was originally expected for any ground effect case at low angles of attack (around $5^{\circ}$ or less) and reasonably well at high angles of attack.

The analytical baseline data has been calculated from 2-D data found in the literature for the Wortmann FX 63-137 airfoil. The 3D data was determined by Equation 11 (7).

$$
C_{L_{\alpha}}=\frac{2 \pi A}{2+\sqrt{4+\frac{A^{2} \beta^{2}}{\eta^{2}}\left(1+\frac{\tan ^{2} \Lambda_{\max t}}{\beta^{2}}\right)}}\left(\frac{S_{\text {exposed }}}{S_{\text {ref }}}\right)(F) \quad \text { Equation } 11
$$

This method of converting data from $2 \mathrm{D}$ to $3 \mathrm{D}$ data was verified by another method shown in Equation $12(5)$. 


$$
C_{L}=\left(\frac{2 \pi A}{2+\sqrt{4+(A \beta)^{2}\left(1+\frac{\tan ^{2}\left(\Lambda_{t / c}\right)}{\beta^{2}}\right)}}\right) \alpha+C_{L_{\alpha=0}}
$$

Equation 12

The baseline drag data, shown in Figure 46, demonstrates that a drag reduction occurs with the modifications to the tail configuration in-ground effect. This aligns the drag curve of the modified tail in-ground effect very closely with the drag curve expected analytically out-ofground effect.

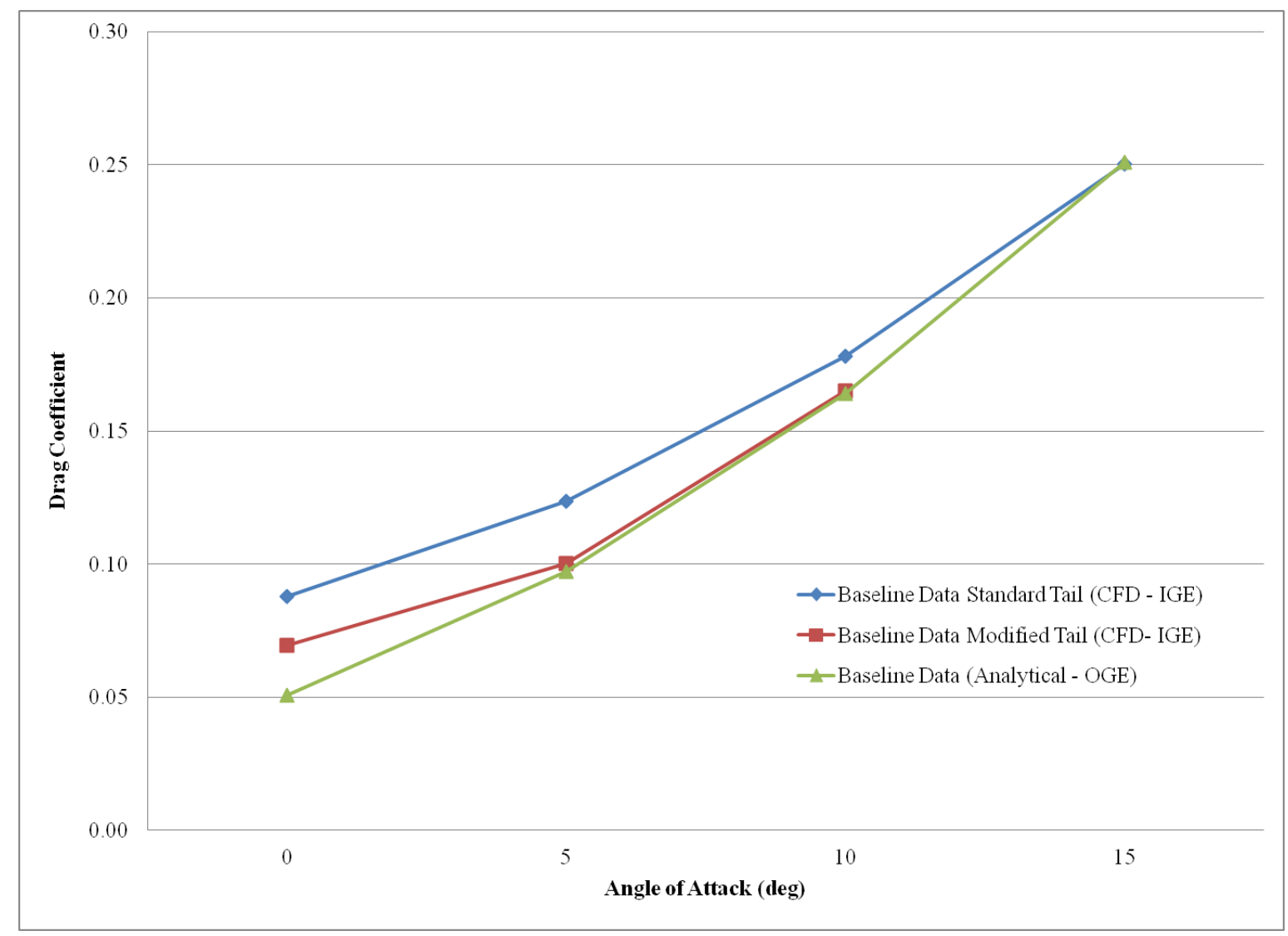

Figure 46: Drag Coefficient Comparison of Baseline Configuration Data 


\subsubsection{Spanwise Wing Curvature}

For this research, the spanwise wing curvature was symmetrically applied to the wingspan where the root and tip remained on the same plane and the crest of the curve occurred in the center of the span. The impact of the maximum curvature on the lift coeffcieint versus angle of attack, was examined over a range of $0 \%-10 \%$ of the span as shown in Figure 47.

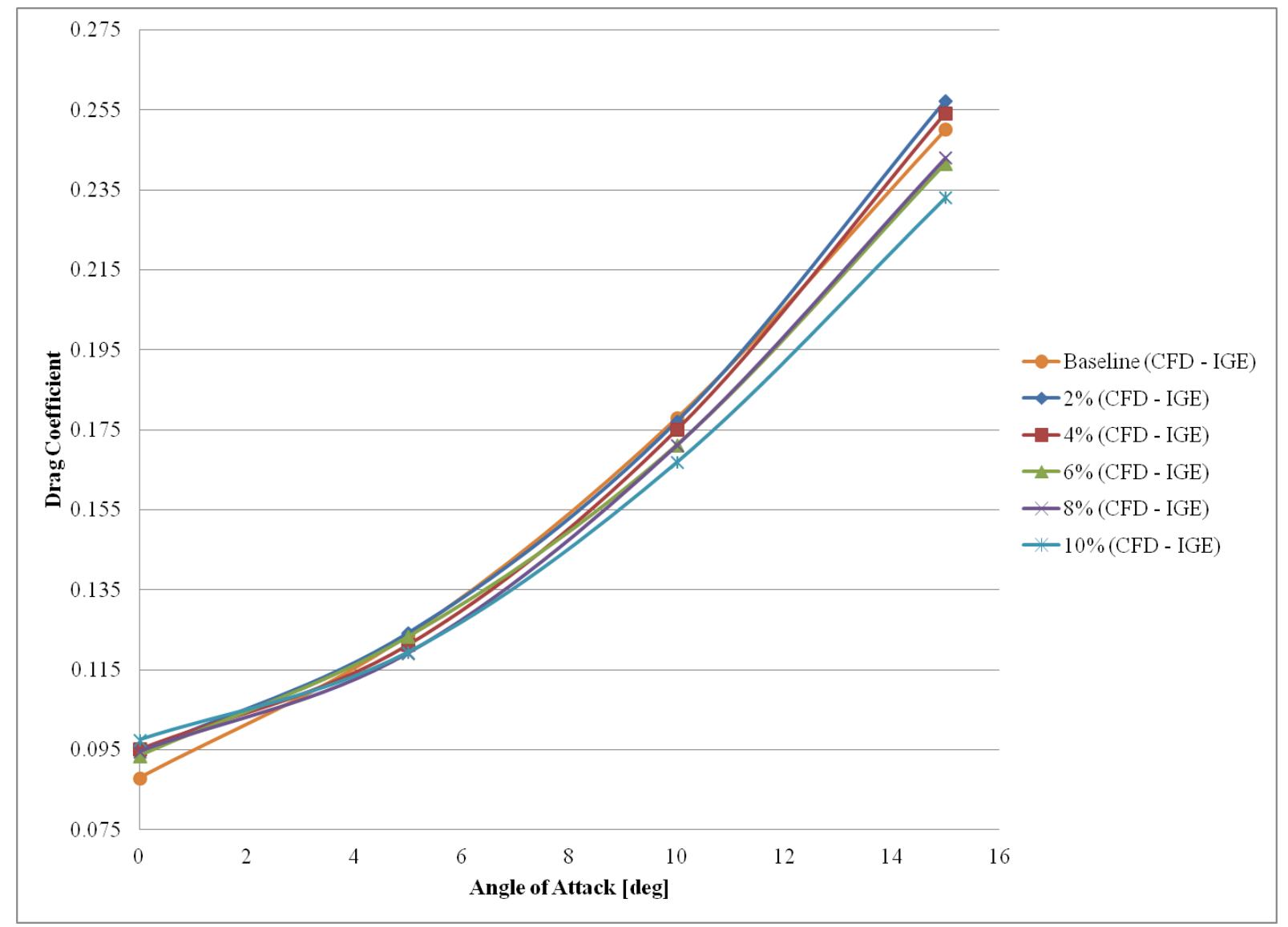

Figure 47: Lift Coefficients for Spanwise Curved Wings

The data shown in Figure 47 revealed that the lift capabilities of spanwise curved wings diminished as the amount of spanwise curvature increased. With the exception of the $4 \%$ case at 
10 degrees angle of attack, this trend is consistent throughout the data. There was also mixed performance in the predicted drag coefficient data as shown in Figure 48.

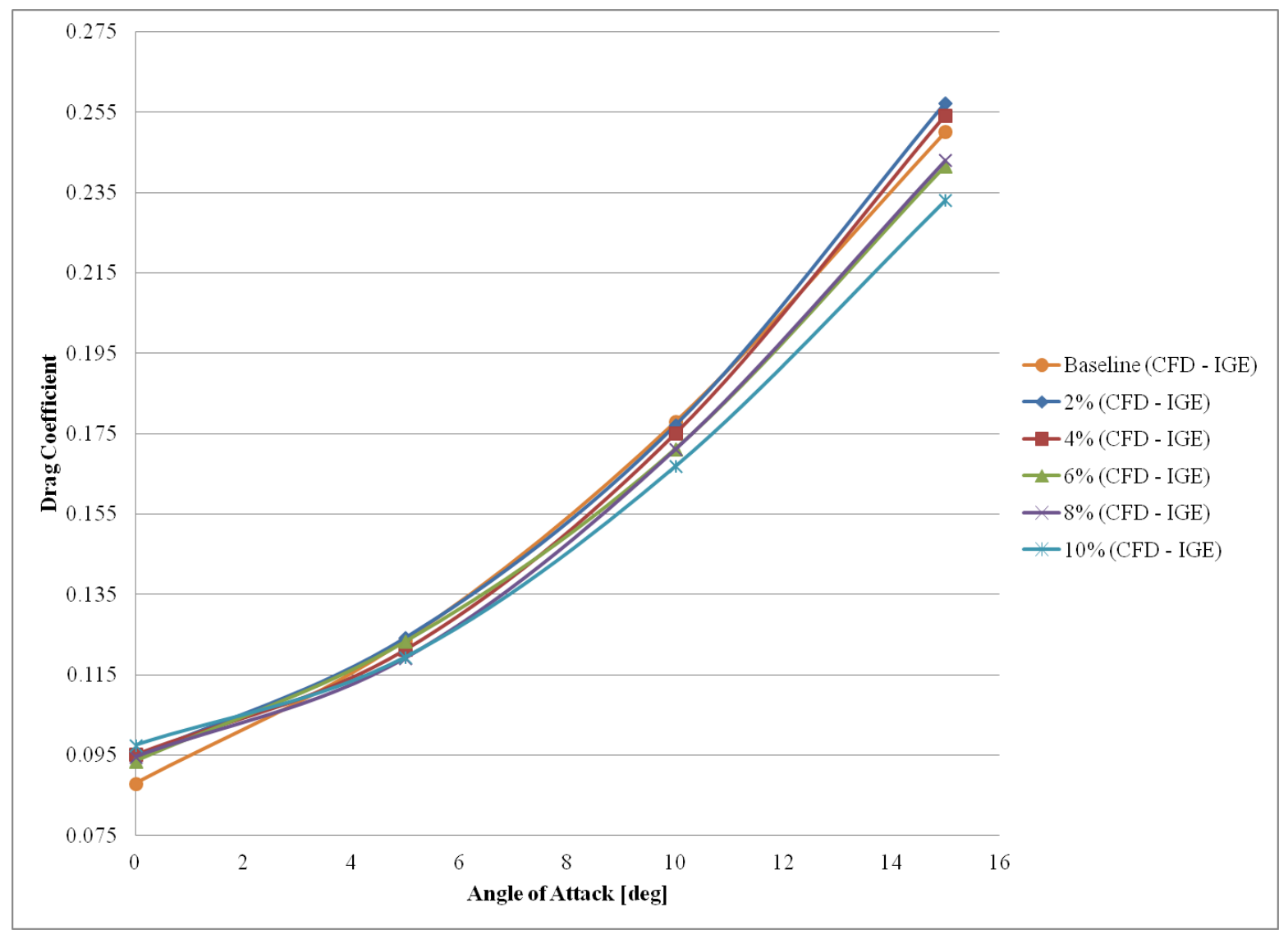

Figure 48: Drag Coefficients for Spanwise Curved Wing

At low angles of attack, the drag coefficient increased as the amount of curvature was increased. At high angles of attack however, the drag coefficient was reduced for the higher amounts of curvature but not for those under $5 \%$. This is an unexpected result, but leaves little to be desired from the application of spanwise curvature.

The moment coefficients at the leading edge were also examined in order to determine the center of pressure location as shown in Figure 49. As the amount of applied spanwise curvature increased, a slight decrease in the moment coefficient occurred. This was compared 
against 2-D moment coefficients from a secondary source as a reference case (44). The slopes predicted by the CFD spanwise curvature models are similar to the slope which appears in the reference case at higher angles of attack.

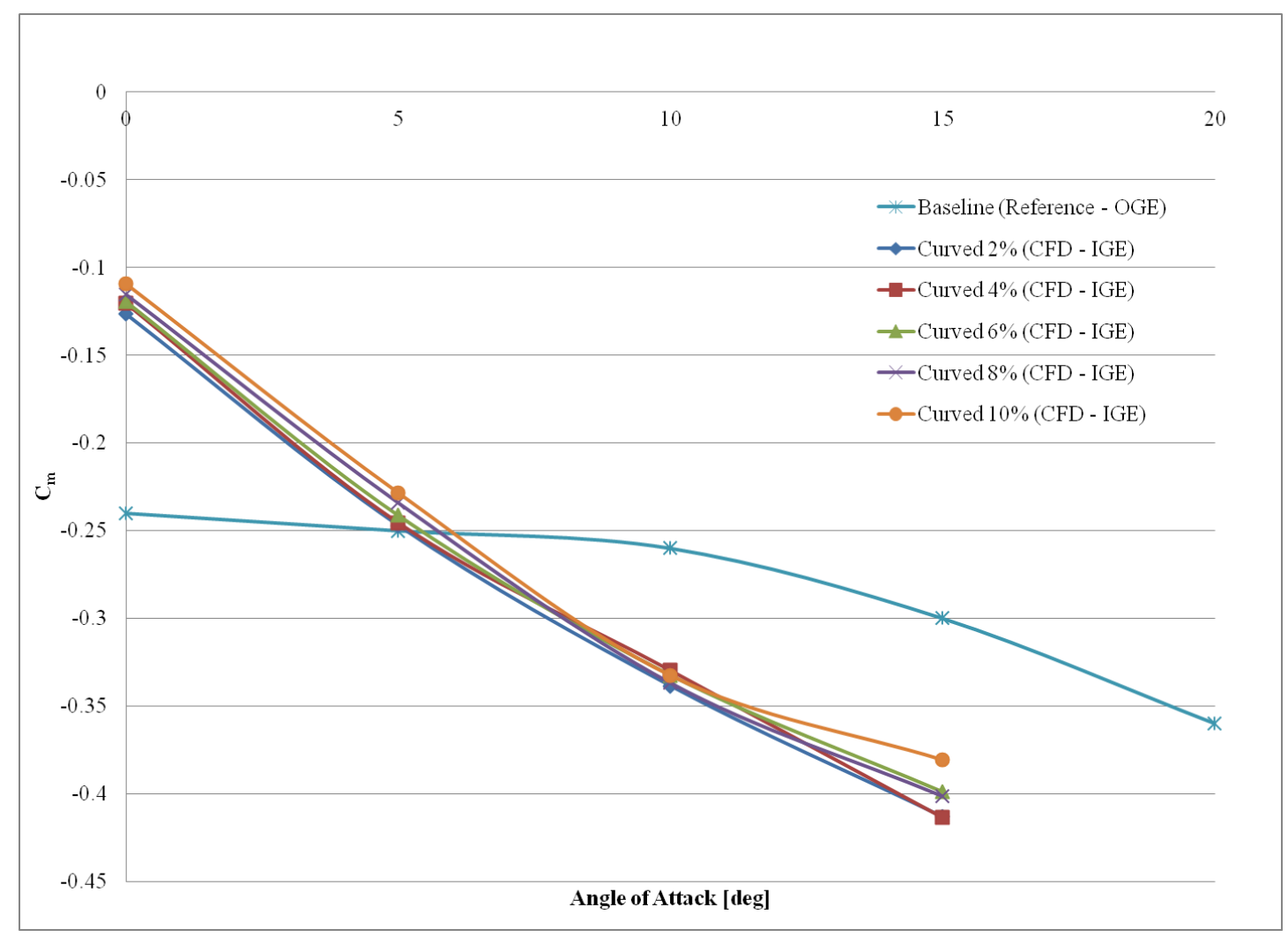

Figure 49: Moment Coefficient for Spanwise Wing Curvature versus Angle of Attack

The centers of pressure locations, $X c p$, are calculated from the moment coefficients and lift coefficients as shown in Equation 13.

$$
X_{c p}=\frac{-M_{L E}}{L}=\frac{-C_{m, L E} C}{C_{L}}
$$

Equation 13

These locations are represented in Table 9 with the percentage of variation across angles of attack noted at the bottom. As a result of increasing the spanwise curvature, there is an increasing change in the movement of the center of pressure. This movement is minimal in the twisted wing 
styles, as will be shown later. By comparison, this type of wing structure does not provide any benefit to the application.

Table 9: $\mathrm{X}_{\mathrm{cp}}$ Locations

\begin{tabular}{|c|c|c|c|c|c|}
\hline & $2 \%$ & $4 \%$ & $6 \%$ & $8 \%$ & $10 \%$ \\
\hline 0 & 4.08 & 4.18 & 4.19 & 4.26 & 4.34 \\
\hline 5 & 3.99 & 4.01 & 4.06 & 4.09 & 4.13 \\
\hline 10 & 3.97 & 4.01 & 4.04 & 4.07 & 4.09 \\
\hline 15 & 3.91 & 3.95 & 3.99 & 4.01 & 3.86 \\
\hline$\%$ Change & $1.71 \%$ & $2.22 \%$ & $2.02 \%$ & $2.52 \%$ & $4.81 \%$ \\
\hline
\end{tabular}

\subsubsection{Wing Twist}

Wing twist is the application of curve to the leading edge only, where the trailing edge remains on the same plane. In this manner, the airfoil cross-section is twisted up from a single point of reference, in this case the trailing edge. The root and tip remain on the same plane and the maximum twist occurs in the center of the span. The maximum amount of twist coincides with the maximum amount of spanwise curvature that was used in the previous section in order to create a fair comparison between the two. The predicted lift coefficients for the twisted wings are shown in Figure 50. 


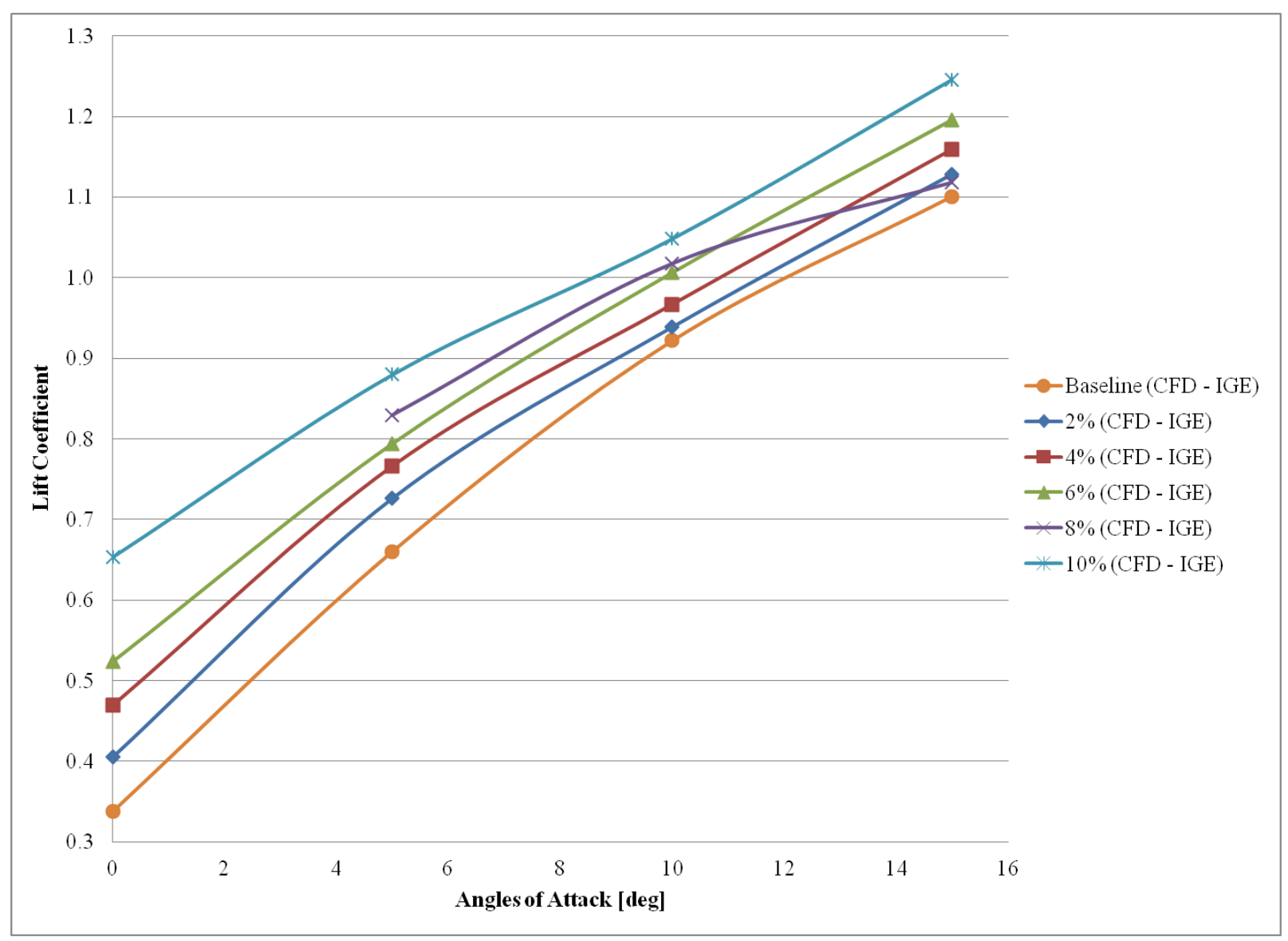

Figure 50: Lift Coefficients for Twisted Wing

A data point for the $8 \%$ twist at the zero degree angle of attack has been omitted from the data set as a result of an inability to properly converge the solution. In addition, the $8 \%$ data point at 15 degrees angle of attack shows signs of being inconsistent and potentially incorrect when compared to the overall data set. In general, as the twist is increased the lift coefficients are shown to increase as well. This indicates that the benefit comes from the increase in the capture area, not the spanwise curvature of the surface. While the lift coefficients have shown an increase as the amount of twist increases, the drag coefficients have also revealed an increase as shown in Figure 51. 


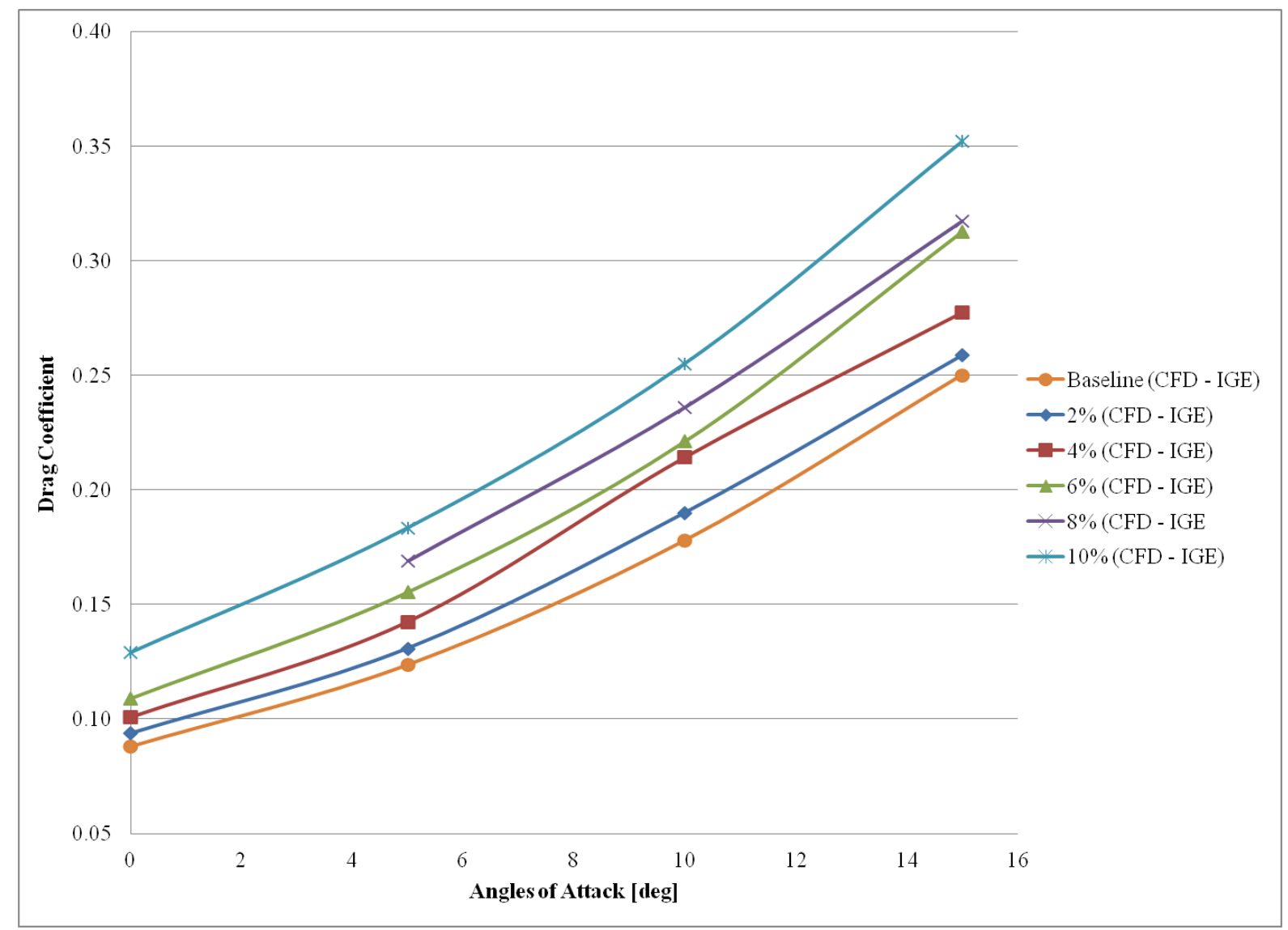

Figure 51: Drag Coefficients for Twisted Wing

While the drag does increases with the amount of twist applied, in this particular application, the increase in drag is not a significant cause for concern. AirRay is for use on downhill slopes, so a certain amount of drag is required to restrict the maximum velocity to $30 \mathrm{mph}$.

The moment coefficients were also examined for the twist style models as shown in Figure 52. As the amount of applied twist increased, there was an increase in the moment coefficient that occurred. This is opposite of the effects that occurred with the spanwise curvature models. This prediction was compared against 2-D moment coefficients from a secondary source (44). The slopes predicted by the CFD spanwise curvature models are similar to the slope which appears in the reference case but at much higher angles of attack. 


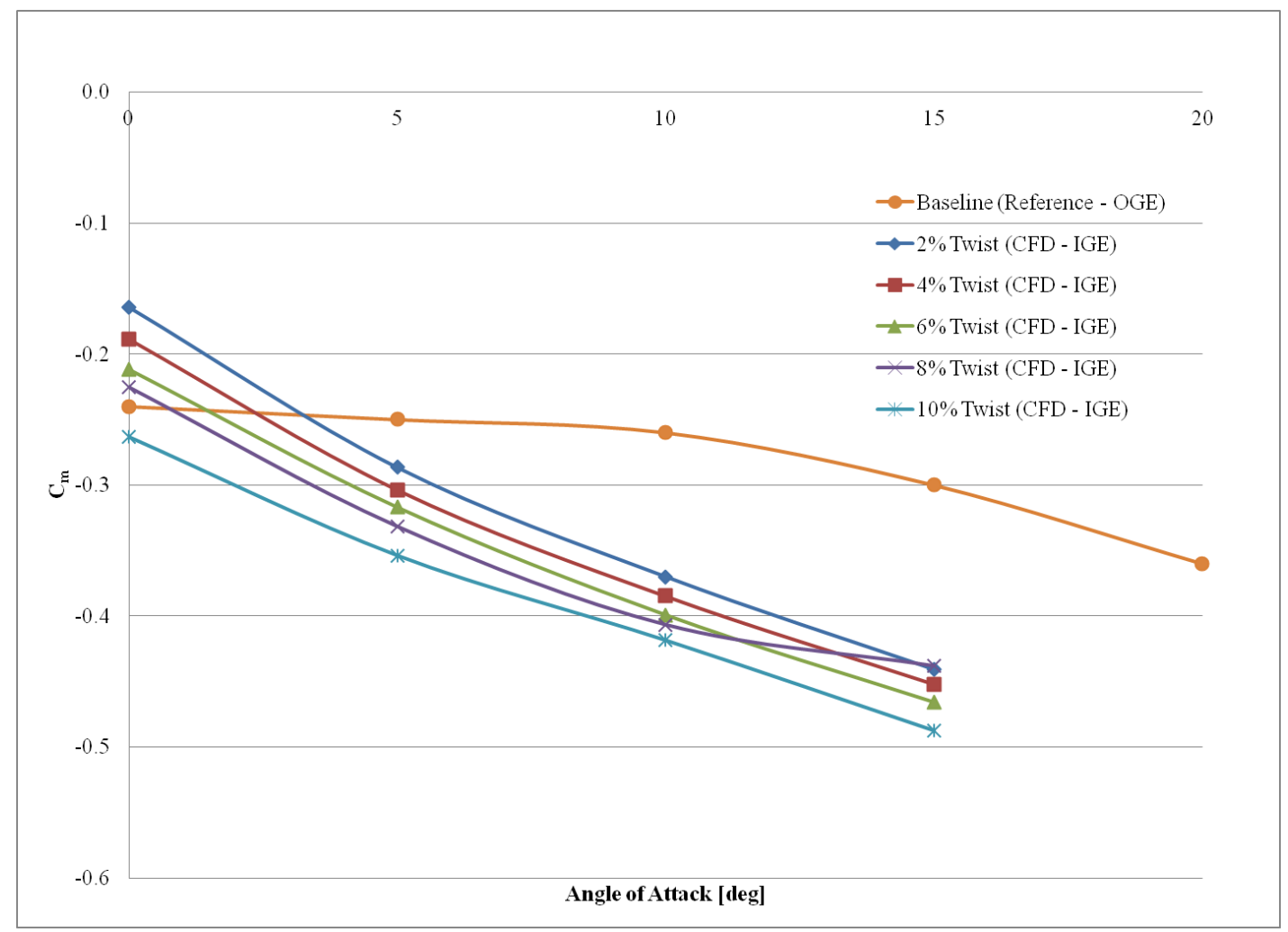

Figure 52: Moment Coefficient for Wing Twist versus Angle of Attack

The centers of pressure locations, $X c p$, were calculated from the moment coefficients and lift coefficients as shown previously in Equation 13. These locations are represented in Table 10 with the percentage of variation across angles of attack noted at the bottom. There is minimal variation in the movement in the center of pressure that occurs as a result of varying the twist parameters which demonstrates longitudinal stability with a twisted wing.

Table 10: $\mathrm{X}_{\mathrm{cp}}$ Locations

\begin{tabular}{|c|c|c|c|c|c|}
\hline & $2 \%$ & $4 \%$ & $6 \%$ & $8 \%$ & $10 \%$ \\
\hline 0 & 4.05 & 4.02 & 4.04 & 4.09 & 4.02 \\
\hline 5 & 3.94 & 3.96 & 3.99 & 4.00 & 4.02 \\
\hline 10 & 3.94 & 3.98 & 3.96 & 4.00 & 3.99 \\
\hline 15 & 3.91 & 3.90 & 3.89 & 3.92 & 3.91 \\
\hline$\%$ Change & $1.37 \%$ & $1.16 \%$ & $1.50 \%$ & $1.73 \%$ & $1.10 \%$ \\
\hline
\end{tabular}




\subsubsection{Vanes}

One of the greatest concerns with the simulations was an occurrence of flow shedding that appeared near the tail section and created a wake that spread over a small area of the wing, and decrease the flow over the vertical tail. Since this phenomena is common to all the models regardless of the style of wing, a common solution was attempted to resolve this undersirable flow characteristic. The separated wake can be seen in Figure 53 and is indicated within the circle.

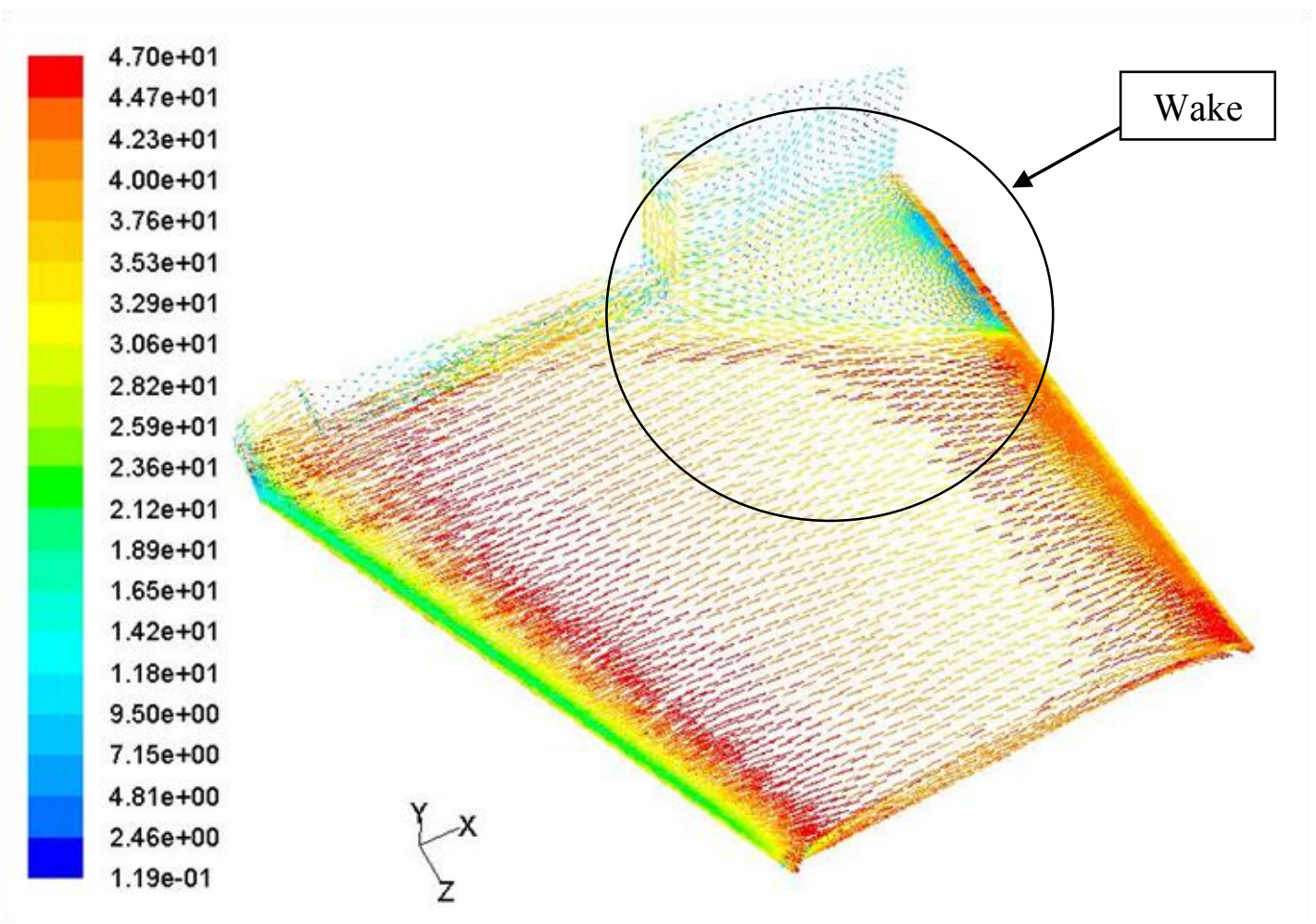

Figure 53: Velocity Profile of Baseline Model Demonstrating Wake

A variety of vanes were employed in an attempt to correct the flow. The initial vanes were low profile, standing only $1 / 2$ inch above the surface of the body. These vanes did not adequately impact the flow since the problem occurred along the entire height of the tail section. 
The vanes were redesigned to be the height of the tail section however this resulted in causing a wake of its own as shown in Figure 54.

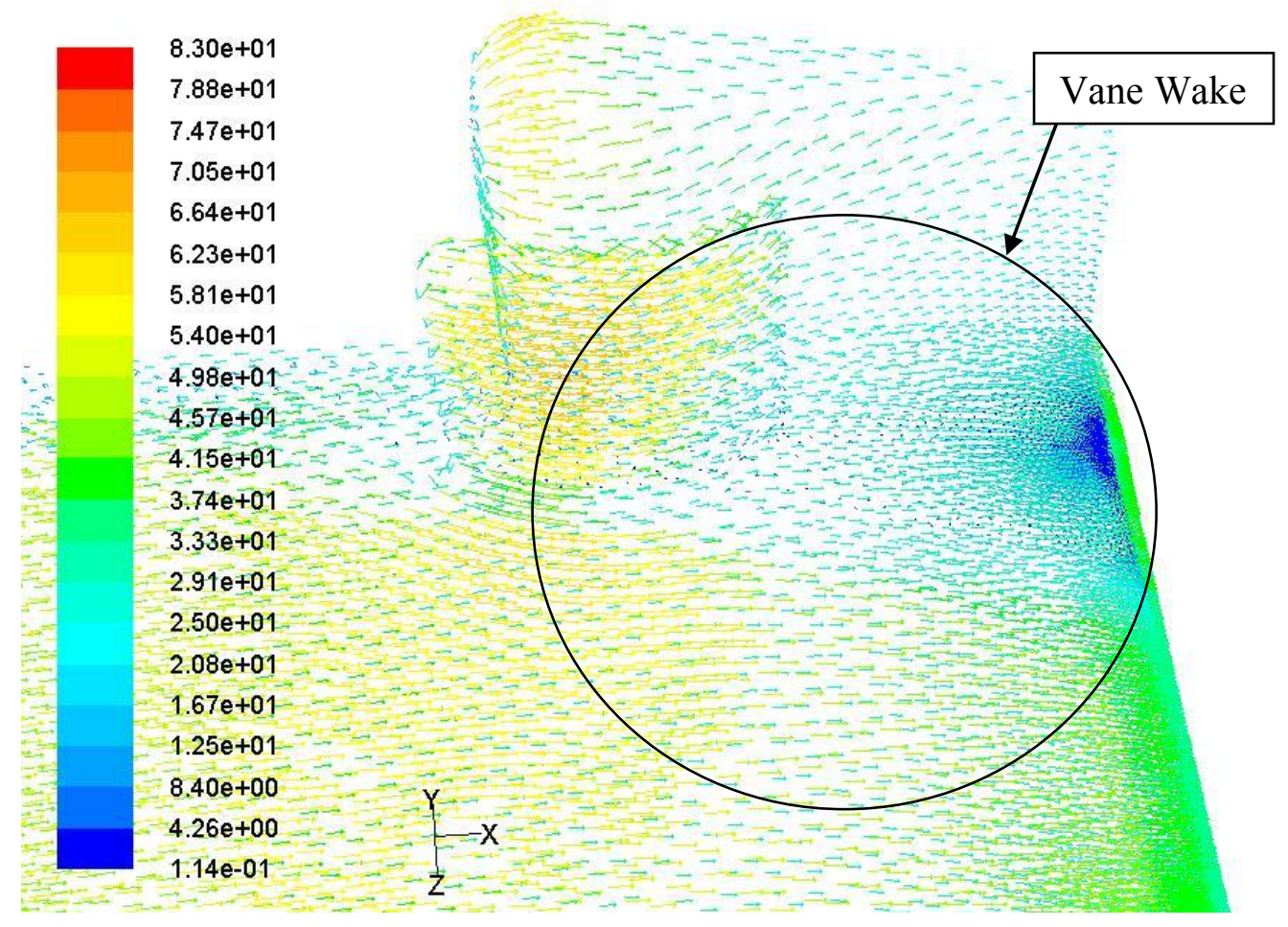

Figure 54: Baseline Model with Single Vane

This single vane system was modified over several iterations to adjust the length and curve of the vane. While the shedding flow from the seat was channeled back onto the tail section, the vane itself created a wake that needed to be corrected. This was resolved by creating a two vane system, slightly staggered from each other as shown in Figure 55. 


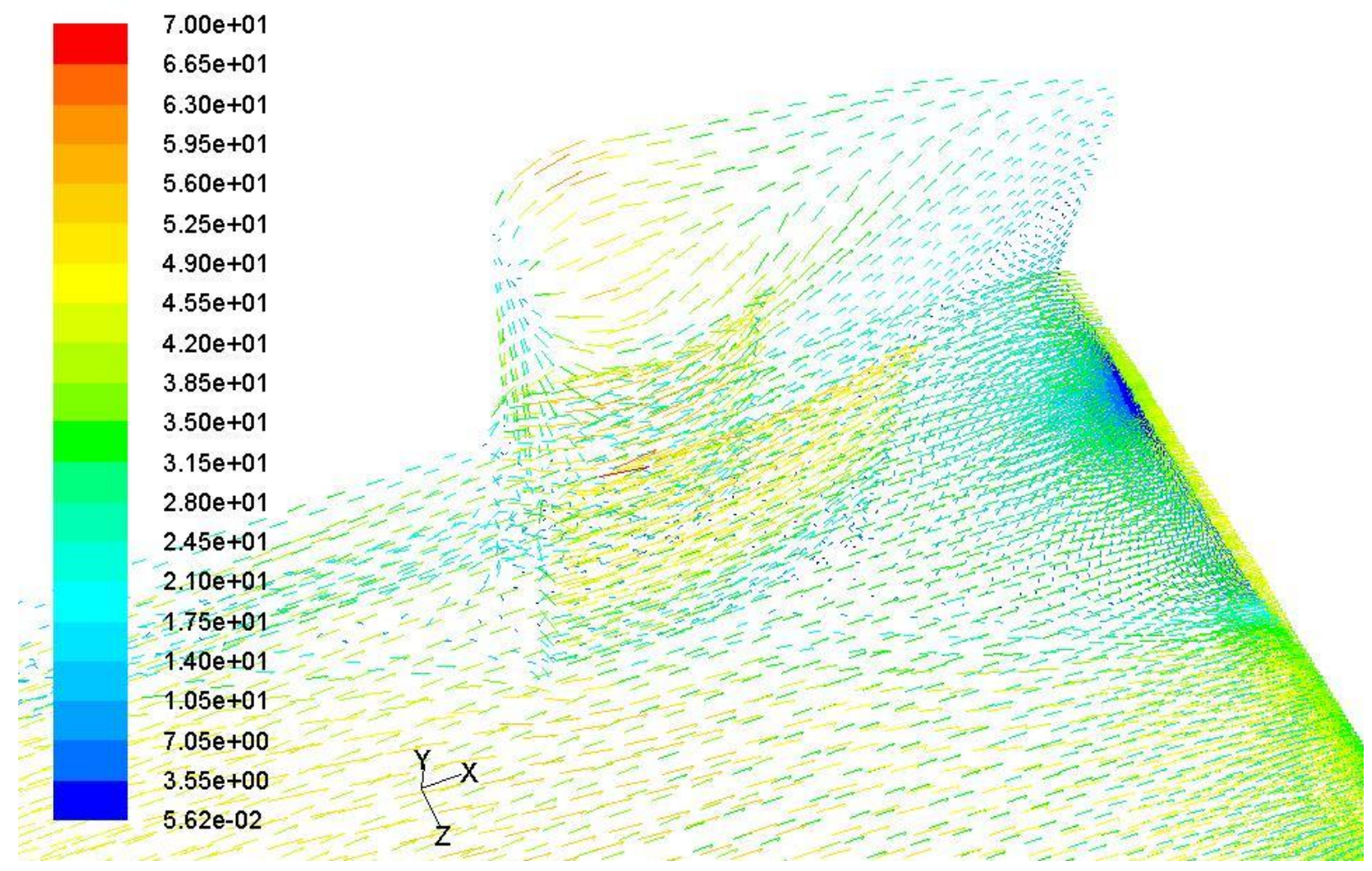

Figure 55: Baseline Model with Double Vanes

The inner vane reconnected the flow diverging from the seat back and the outer vane reshaped the flow shedding from the inner vane with little wake generation itself. Through varying the length, curvature, and distance between the vanes, a combination was created that increases the baseline, zero angle of attack lift coefficient by $25 \%$ and decreases the drag coefficient by $2.3 \%$. This solution resolved the flow irregularities, however this method was deemed not aesthetically pleasing so a secondary solution was devised, as will be discussed below.

\subsubsection{Canopies}

Three canopies were tested for their effects on correcting the irregularities in the flow around the center section. These canopies vary in height from 5 in to 8 inches. 
Table 11: Aerodynamic characteristics of canopies

\begin{tabular}{|l|c|c|}
\hline & $\mathrm{CL}$ & $\mathrm{CD}$ \\
\hline Canopy 1 & 0.428 & 0.061 \\
\hline Canopy 2 & 0.434 & 0.067 \\
\hline Canopy 3 & 0.416 & 0.073 \\
\hline
\end{tabular}

The results of the three canopy heights are shown in Table 11. The second canopy geometry, with a max height of 6.5 in, demonstrated an increase in the lift coefficient compared to the other canopy geometries. The height of this canopy allowed air flow to hit the seat at an angle that allowed it to join with the upward airflow already present on the seat back. This resulted in an increase in the airflow that passed over the top of the tail section as shown in Figure 56.

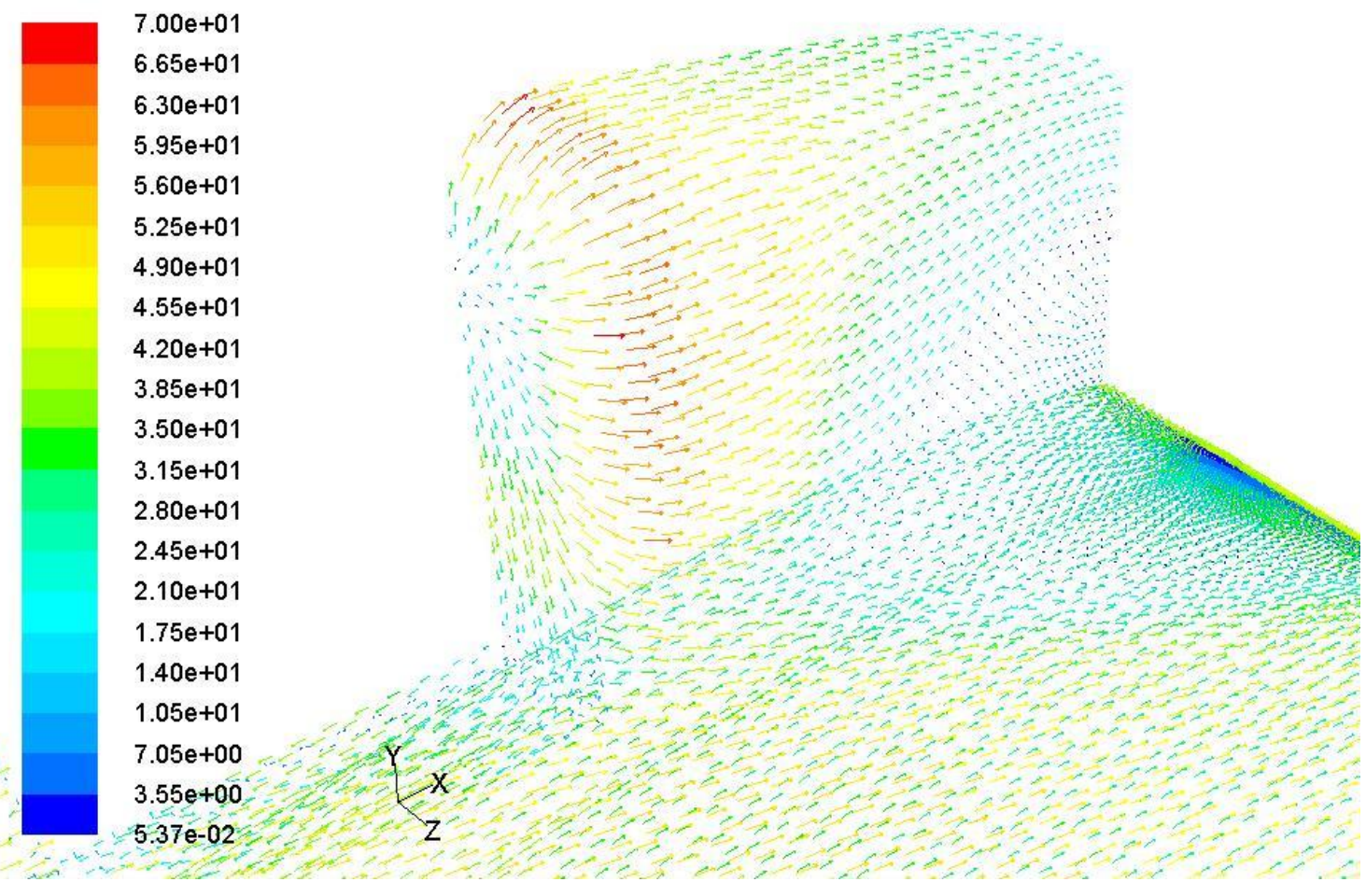

Figure 56: Canopy Influence on Tail Section 
These three canopies were semi-circular which led to a high point in the center to the canopy which allowed airflow to shed over the sides and downward to join back with the wings. Canopy 2 was modified to be flatter on top creating an elliptically shaped canopy instead of a semi-circular shape. This allowed more airflow to stay attached to the top of the canopy thus increasing the airflow over the tail section and also increasing the aircraft's overall lift coefficient from 0.43 to 0.47 . The flattening of the canopy also allowed for a drag reduction to occur, lowering the $\mathrm{C}_{\mathrm{D}}$ from 0.067 to 0.0542 .

\subsubsection{Tail Modifications}

The addition of the canopy minimized the turbulent regions from forming before the tail section. Thus the majority of the remaining wake that was created was formed not by the passenger seating area but by the tail section entirely. This means that the tail section needed to be modified to eliminate the remaining wake as shown in Figure 57.

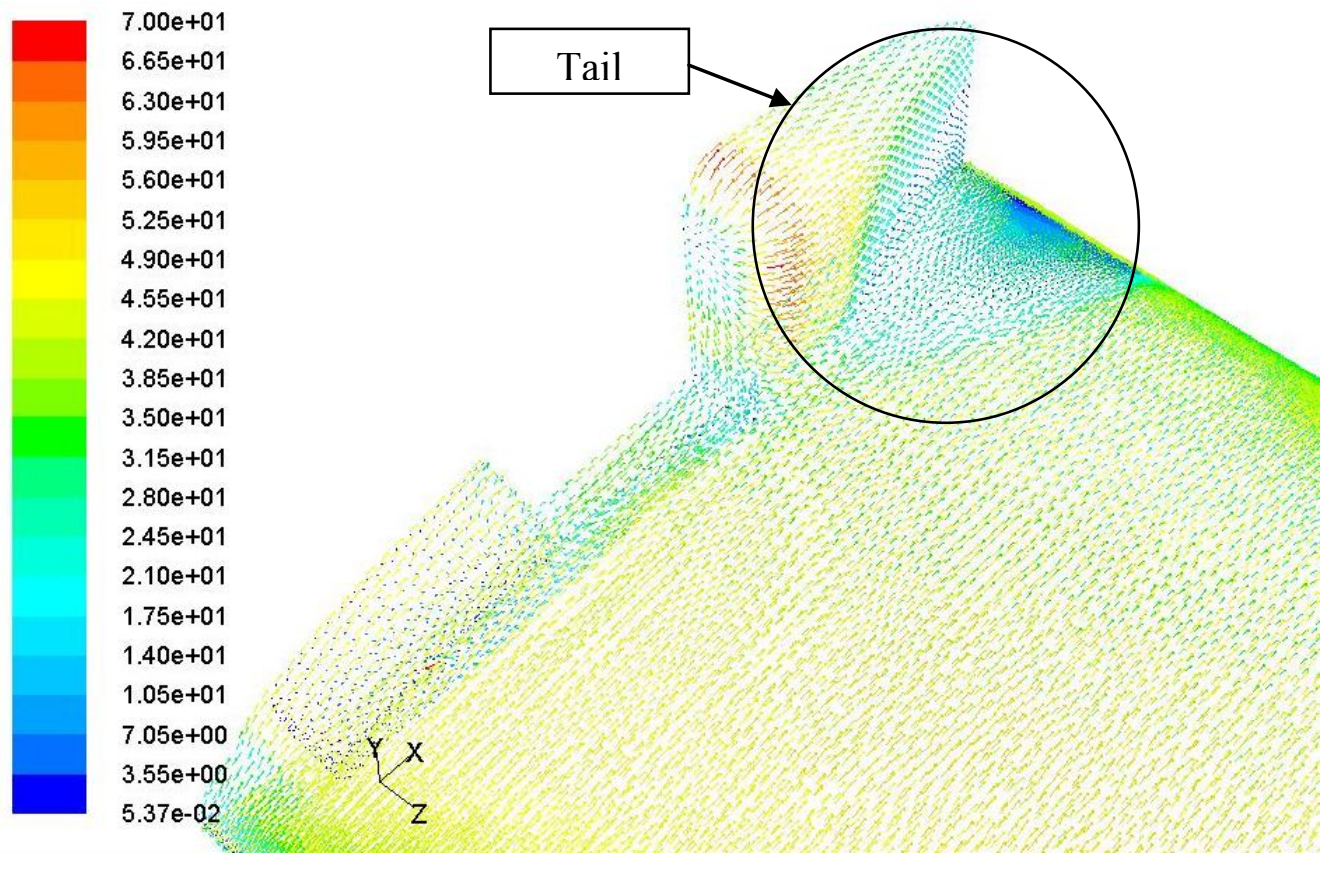

Figure 57: Wake of Tail Section 
The first section that was examined was the bend in the aft section of the tail. This bend was originally $18.5^{\circ}$ and was gradually reduced to $15^{\circ}$ and then $10^{\circ}$. The results of the decrease in the angle are shown in Table 12. As the angle was reduced, the wake reduced allowing for flow over that area of the wing and subsequently the lift characteristics increased. The reduction in tail angle also allowed for a reduction in the drag coefficient.

Table 12: Lift Coefficients for Side Edge

\begin{tabular}{|c|c|c|}
\hline Degree & $C_{L}$ & $C_{D}$ \\
\hline 18.5 & 0.4347 & 0.0673 \\
\hline 15 & 0.4554 & 0.0529 \\
\hline 10 & 0.4925 & 0.0481 \\
\hline
\end{tabular}

The draw-back to decreasing the side angle to correct the flow was that the tail increased significantly in thickness and was not practical as a single control surface. To reduce the thickness of the tail without changing the angles of the edges, required that the tail be split in two. This would allow ease of movement for a rudder will still keeping to the aerodynamic necessity of the tail shape. An example of the split tail was shown previously in Figure 44. One side effect of the split tail concept is that more airflow can be allowed over the rider as air can be released between the tails, if the increased profile drag becomes excessive.

The second section that was focused upon was the connection point between the seat back and the front of the tail section. This connection was varied to have a radius of $5,7.5$, and 10 inches while maintaining a constant side angle of $10^{\circ}$. For the zero angle of attack baseline case, the lift coefficients resulted as shown in Table 13.

Table 13: Lift and Drag Coefficients for Front Edge

\begin{tabular}{|c|c|c|}
\hline Radius [ in] & $C_{L}$ & $C_{D}$ \\
\hline 5 & 0.485 & 0.573 \\
\hline 7.5 & 0.4925 & 0.608 \\
\hline 10 & 0.4907 & 0.0649 \\
\hline
\end{tabular}


The mid-range radius allowed the flow to remain attached to the tail surface more efficiently than the other radius options. This was reflected in the lift coefficients produced by the range of radii.

\subsubsection{Assessment of Computational Research}

The different elements explored during the computational portion of this research effort provided unique benefits to the design. Unfortunately, not all of these elements could be incorporated due to the astatically unappealing nature of the variations. Selected planform shapes were then tested experimentally, with an emphasis on the twisted wings as discussed in the next chapter. These shapes provided the most lift benefit which would allow for a reduction in wing size and thus weight.

The canopy section is a requirement for passenger safety and the second canopy, with a maximum height of 6.5 inches above the surface of the wing, placed in front of the passenger is enough to angle the air flow up over the rider and on top of the tail section providing additional lift.

The modification of the tail section to incorporate rounded edges and a split tail prevents the separated wake from forming and shedding over the wing. Without the interference of this wake, an improvement in the lift capabilities was seen in the baseline and a marginal reduction in the drag coefficient was seen as well. Since this section is common to all the models, the increase in lift capability can be expected on the twisted and spanwise curved wing variants as well. 


\section{Chapter 5.0 Experimental Research}

\section{$5.1 \quad$ Experimental Setup}

This section covers preliminary tasks that were completed for experimentation, which includes the model construction, test rig, instrumentation, and flow scaling in order to create a working test environment.

\subsubsection{Test Facility}

The WVU Subsonic Closed Loop Wind Tunnel was used as the testing facility for this experiment. The tunnel, built in 1945, is comprised of 2 test sections, the high speed test section and the low speed test section a shown in Figure 58 (57). The models will be tested on the low speed side, as it is significantly larger measuring $4 \mathrm{ft}$ by $6 \mathrm{ft}$ with the interior walls in place.
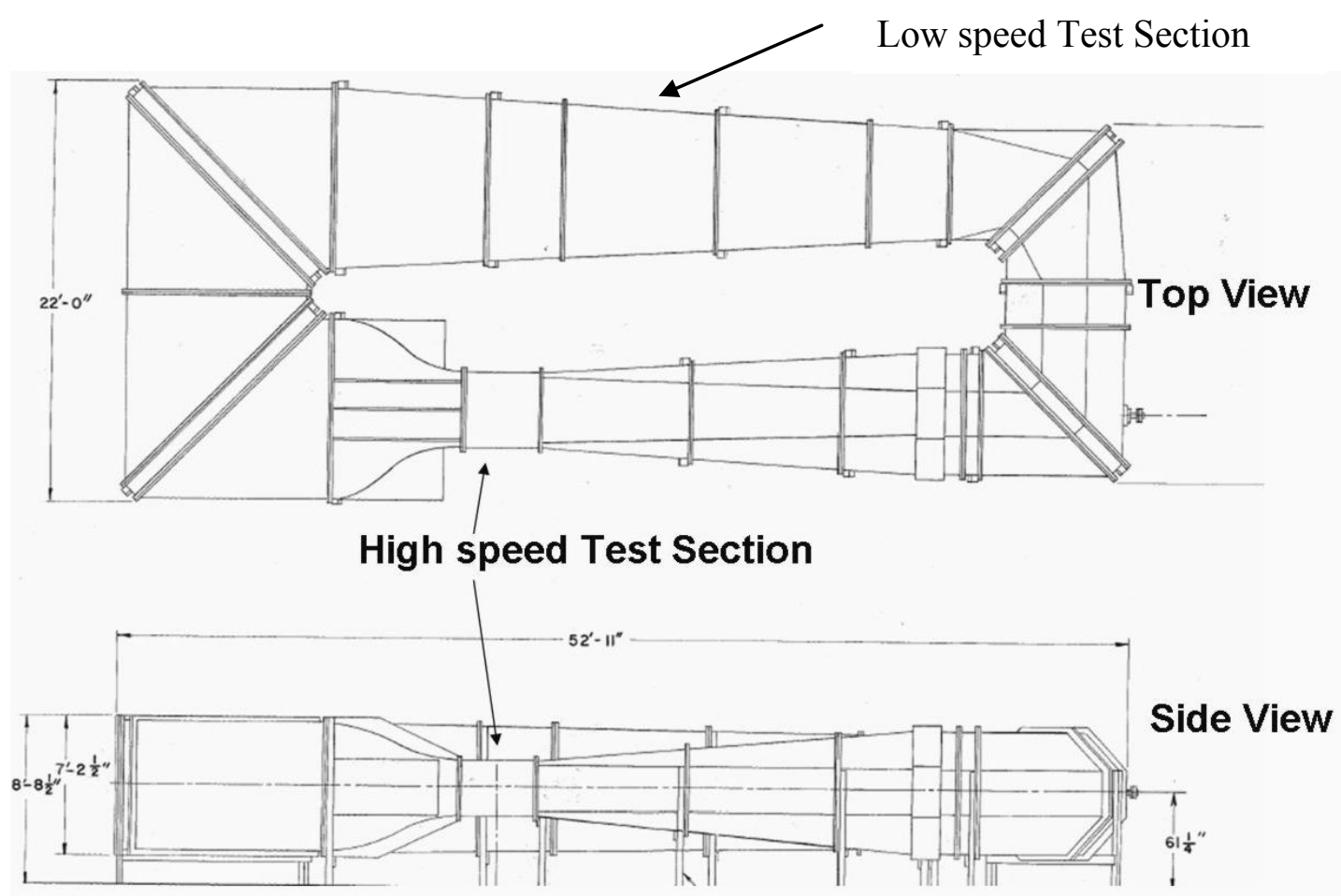

Figure 58: WVU Subsonic Closed Loop Wind Tunnel (57) 
Before a test was conducted, a basic flow examination was performed to assess the type of in the large test section of the wind tunnel. It was found that the flow was impinged along the inner wall of the tunnel, upstream of the test section by the turning vanes. This flow situation was resolved with the placement of a wall just downstream of the vanes in order to divert the flow back to the center of the tunnel as shown in Figure 59.

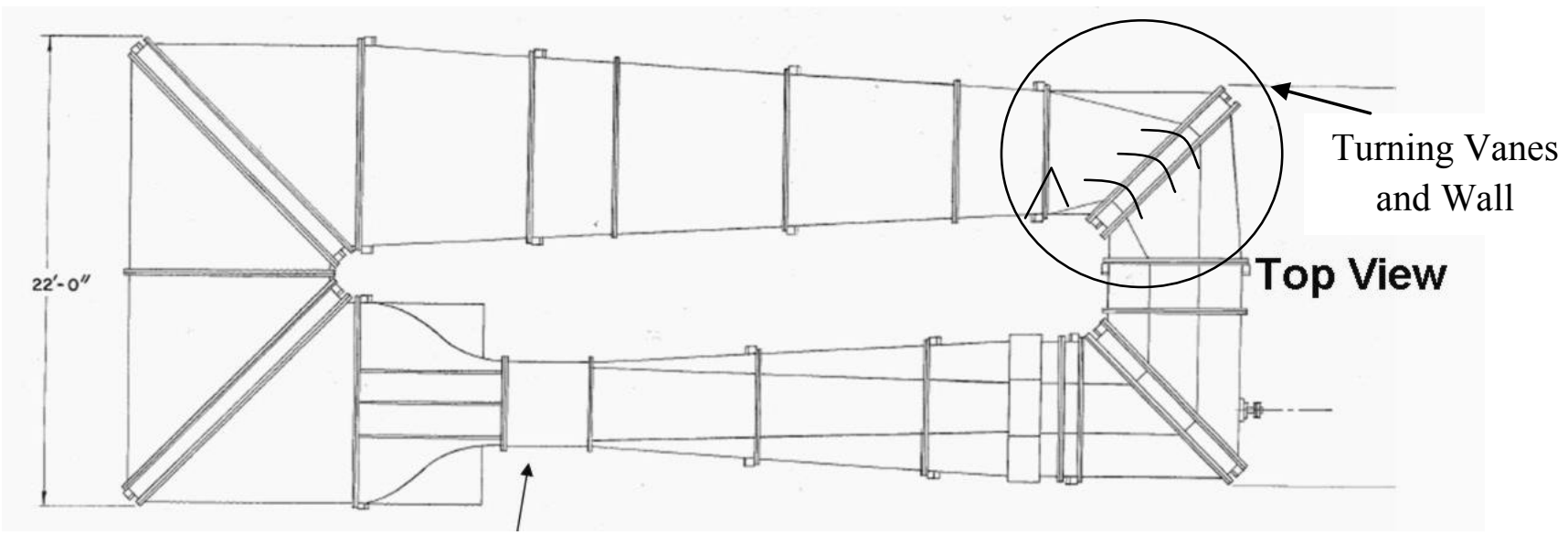

Figure 59: Wind Tunnel Top View with Vane and Wall Placement

The flow was then examined with a manometer to assess the variations of flow speed at different locations along the length of the test section and an inside $3 \mathrm{ft}$ cross-sectional window. Four locations down the length of the tunnel were tested, $1 \mathrm{ft}$ apart, beginning furthest upstream and moving downstream along the length of the tunnel. At any given location along the length of the tunnel, five additional locations were test vertically (32 in to 44 in above the floor) and three locations horizontally (center, $1.5 \mathrm{ft}$ left and $1.5 \mathrm{ft}$ right) to comprise a 2-D window of semiuniform velocity. The velocities of the flow are shown in Table 14 to Table 17 with the change in the overall velocity shown in the far right column. 
Table 14: Position 1 - Furthest Upstream

\begin{tabular}{|l|l|l|l|r|}
\hline & \multicolumn{3}{|c|}{ Velocity [ft/s] } & \\
\hline P1 & Left & Middle & Right & $\Delta$ Vel \\
\hline 44 & 14.34 & 17.24 & 14.34 & 2.90 \\
\hline 41 & 15.12 & 16.56 & 16.56 & 1.44 \\
\hline 38 & 14.02 & 15.12 & 15.86 & 1.84 \\
\hline 35 & 14.34 & 15.12 & 15.86 & 1.51 \\
\hline 32 & 14.34 & 15.86 & 15.12 & 1.51 \\
\hline
\end{tabular}

Table 15: Position 2 - $1 \mathrm{ft}$ Downstream of Position 1

\begin{tabular}{|l|l|c|c|r|}
\hline & \multicolumn{3}{|c|}{ Velocity [ft/s] } & \\
\hline P1 & Left & Middle & Right & $\Delta$ Vel \\
\hline 44 & 15.12 & 17.24 & 16.56 & 2.12 \\
\hline 41 & 15.86 & 17.24 & 15.86 & 1.38 \\
\hline 38 & 15.86 & 16.97 & 15.86 & 1.11 \\
\hline 35 & 15.12 & 16.91 & 16.91 & 1.78 \\
\hline 32 & 15.12 & 16.56 & 15.86 & 1.44 \\
\hline
\end{tabular}

Table 16: Position 3 - $1 \mathrm{ft}$ Downstream of Position 2

\begin{tabular}{|c|c|c|c|r|}
\hline & \multicolumn{3}{|c|}{ Velocity [ft/s] } & \\
\hline P1 & Left & Middle & Right & \multicolumn{1}{c|}{$\Delta$ Vel } \\
\hline 44 & 15.12 & 15.86 & 15.86 & 0.74 \\
\hline 41 & 15.12 & 15.12 & 15.12 & 0.00 \\
\hline 38 & 14.81 & 15.57 & 15.12 & 0.75 \\
\hline 35 & 14.34 & 15.42 & 15.86 & 1.51 \\
\hline 32 & 14.34 & 15.12 & 15.57 & 1.22 \\
\hline
\end{tabular}

Table 17: Position 4 - $1 \mathrm{ft}$ Downstream of Position 3

\begin{tabular}{|c|c|c|c|r|}
\hline & \multicolumn{3}{|c|}{ Velocity [ft/s] } & \\
\hline P1 & Left & Middle & Right & \multicolumn{1}{c|}{$\Delta$ Vel } \\
\hline 44 & 14.81 & 15.86 & 15.57 & 1.04 \\
\hline 41 & 14.34 & 15.12 & 15.12 & 0.78 \\
\hline 38 & 14.34 & 15.12 & 15.12 & 0.78 \\
\hline 35 & 14.02 & 14.34 & 14.66 & 0.64 \\
\hline 32 & 13.18 & 14.34 & 14.66 & 1.48 \\
\hline
\end{tabular}

\subsubsection{Model Construction}

Four sets of models were created for experimental testing. Sets of models are necessary as two are required to utilize the plane approach, to simulate a moving ground plane under the 
craft. Two sets of models were created with twisted wings, one pair with curvature and the last pair were baseline models with straight wings, for a total of four pairs of wing models. The wings of the models were constructed of balsa wood cross sections, supported by carved Styrofoam along the leading and trailing edges, overlaid with Monocoat for a skin. The cross sections of the wing can be seen in Figure 60, assembled together to form a wing.

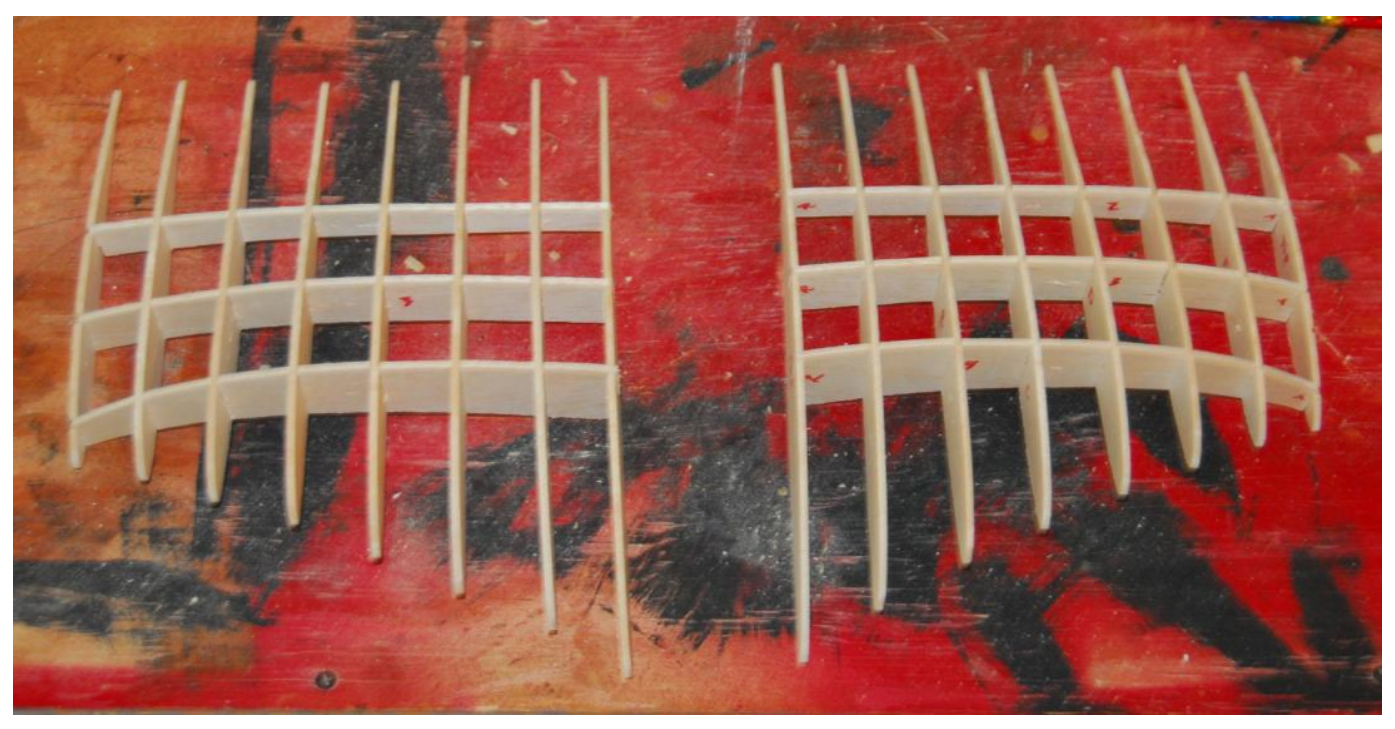

Figure 60: Balsa Wood Cross-Section of Wing 


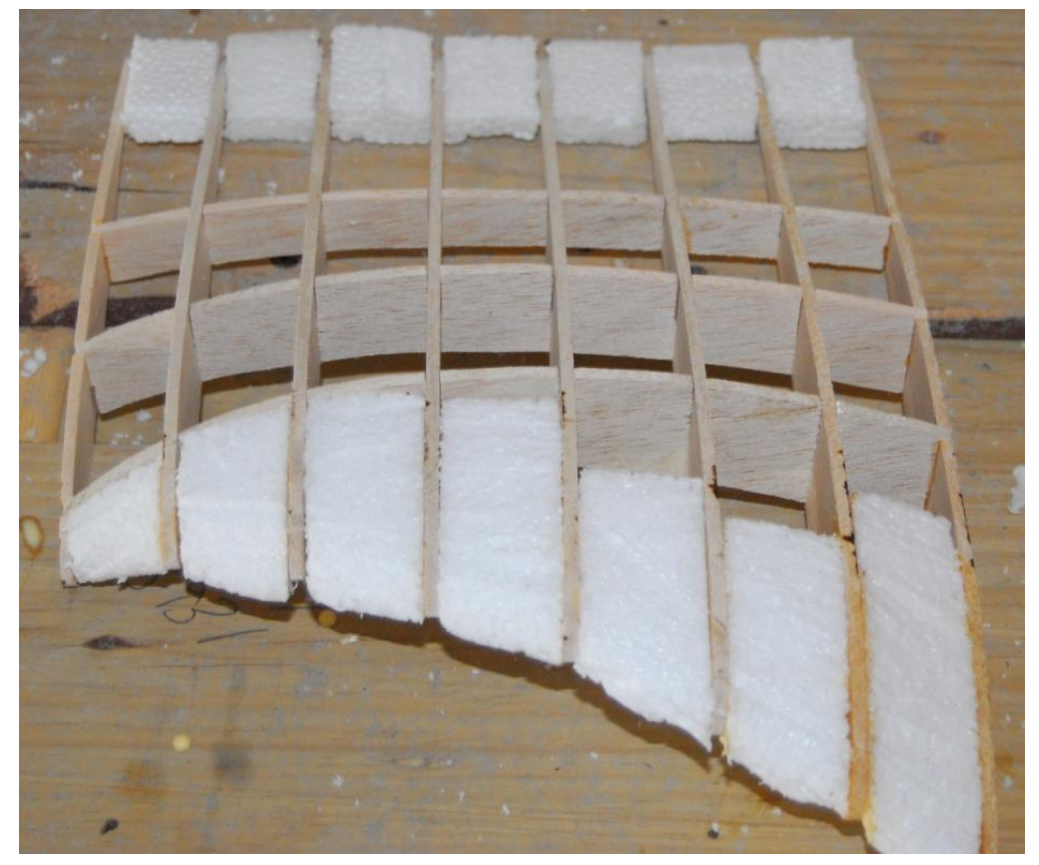

Figure 61: Balsa Wood Cross-Section of Wing with Styrofoam Inlay

Styrofoam was glued into the leading and trailing edge and was cut to fit the curvature of the wing as shown in Figure 61. A home-made hot wire cutter was used to cut the Styrofoam as seen in Figure 62.

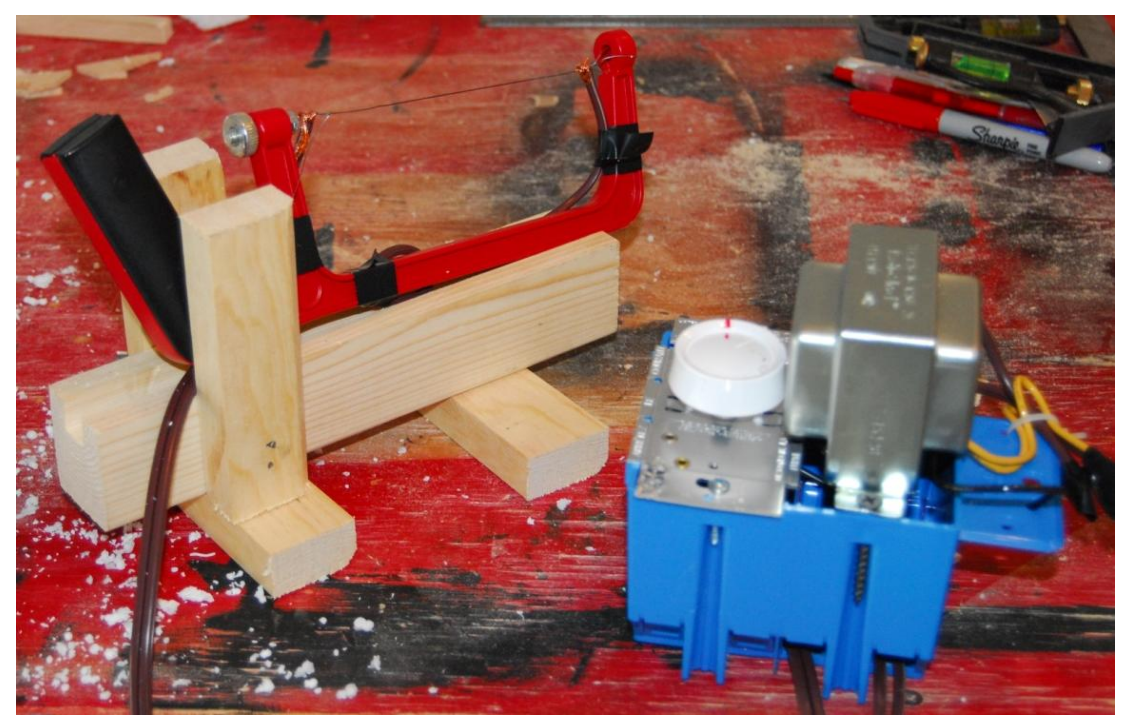

Figure 62: Hot Wire Cutter 
To cover the surface of the wing, a plastic, low heat material called Econocoat was used. This material can be heated to stick to itself with an iron and then heated with a heat gun to shrink the material to mold tightly to the wing form as shown in Figure 63.

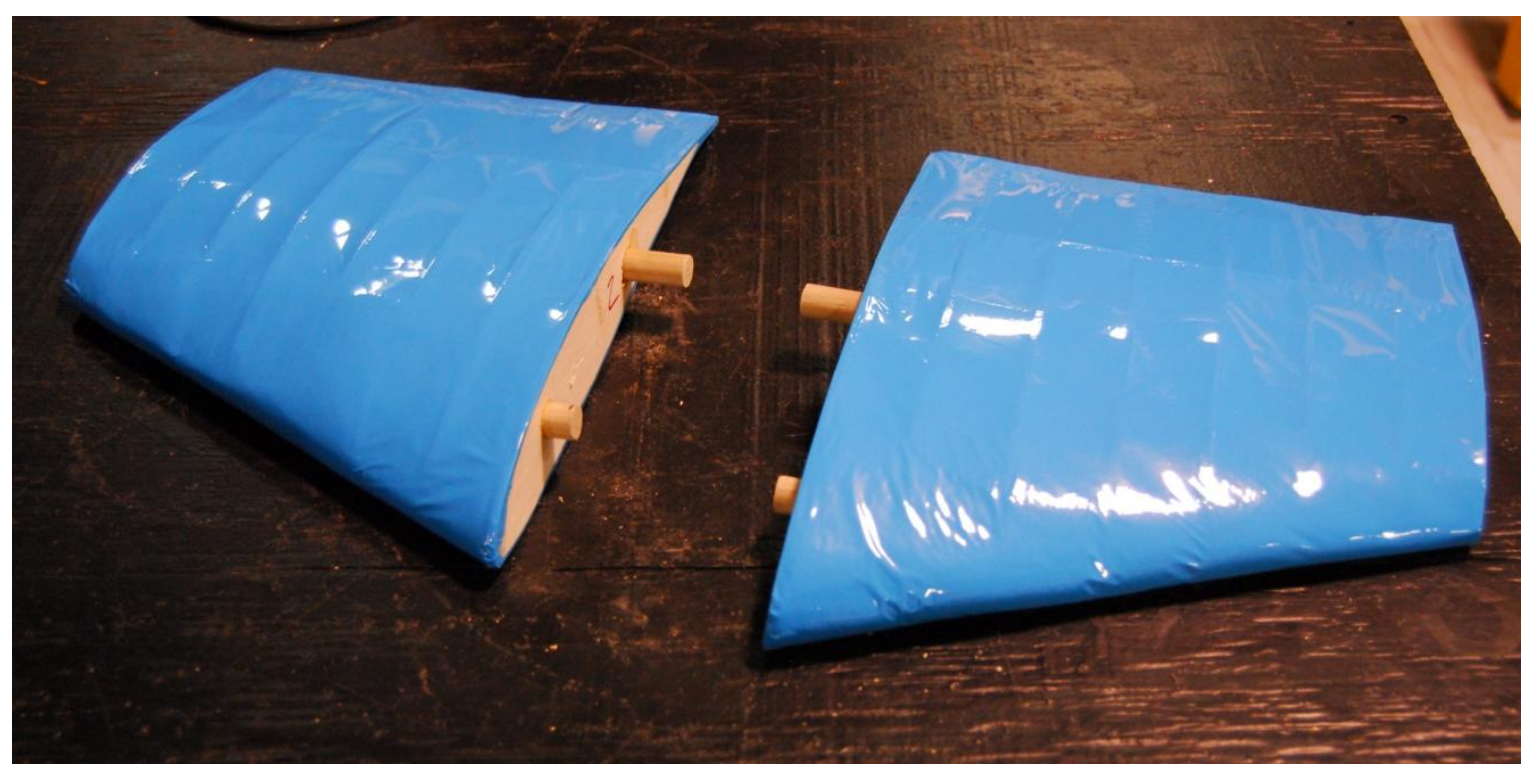

Figure 63: Econocoat Covered Wing Form for Baseline Configuration

The center body of the glider was made of solid balsa wood, hand-carved to match the specifications of the CFD model. This was also covered in Monocoat to assist in removing surface roughness similar to the wings. A complete model can be seen in Figure 64 . 


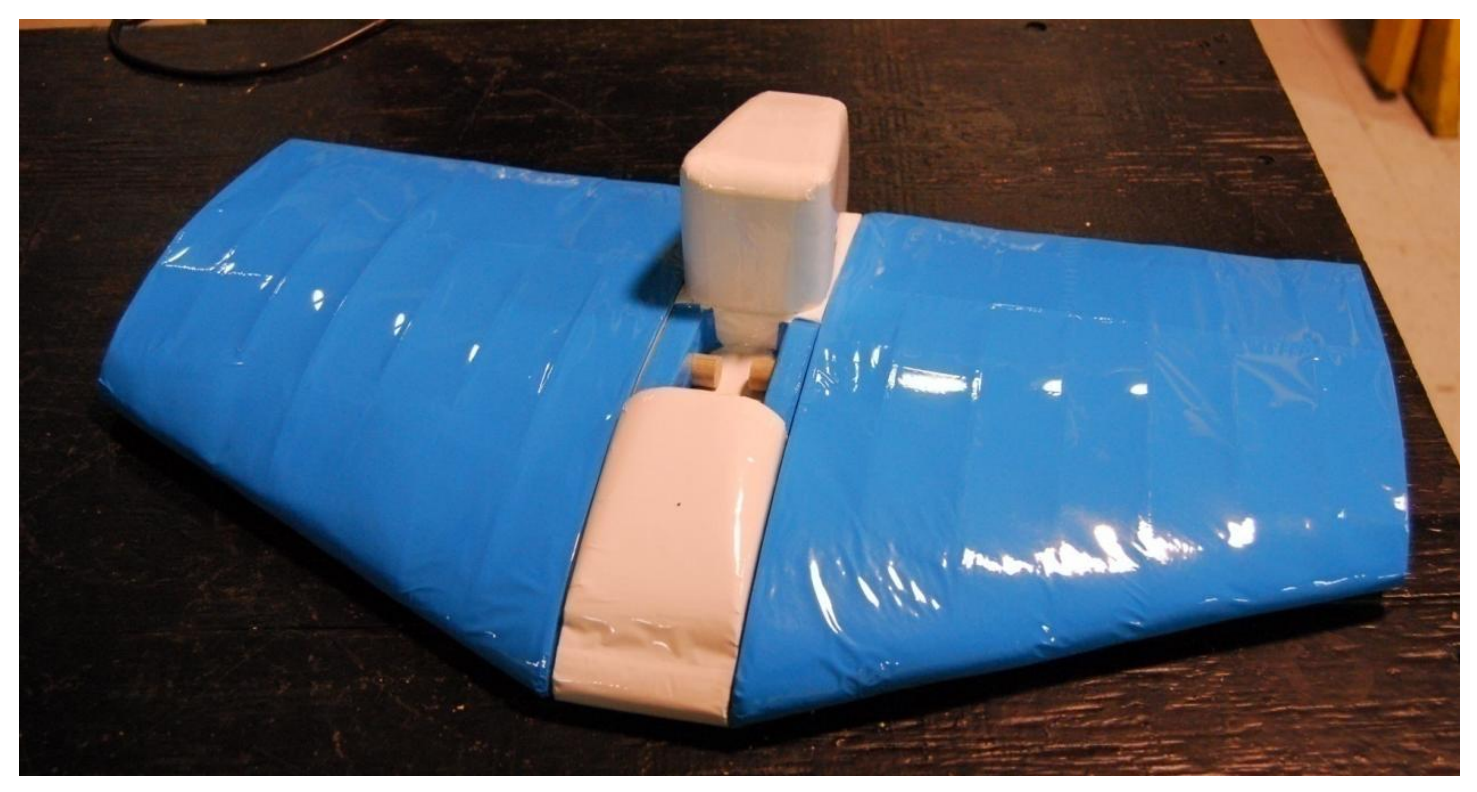

Figure 64: Complete Model of Baseline Geometry

\subsubsection{Test Rig}

In order to perform wind tunnel testing, a test apparatus had to be designed and constructed that would hold both the models and the sting containing any instrumentation that would be used to take and record data. There were some initial concerns about vibrations from the wind tunnel interfering with the readings from the instrumentation, so it was decided that the test rig needed to be hard mounted to the concrete floor beneath the wind tunnel. Therefore a design was created of a freestanding pipe on a stable t-shaped platform as shown in Figure 65 that was drilled through the floor of the tunnel and mounted into the floor using concrete anchors. 


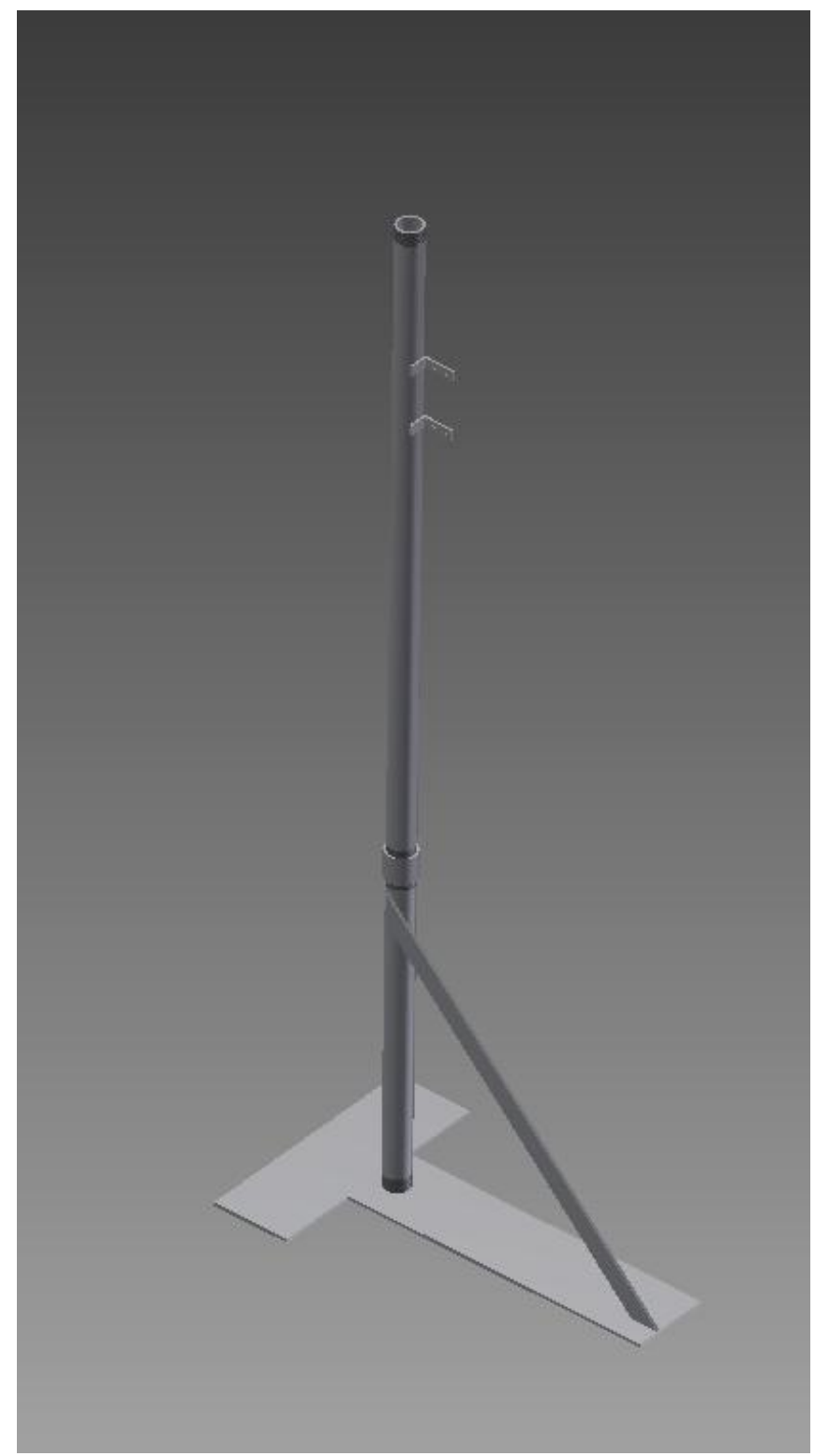

Figure 65: Test Rig

The test rig was designed in two sections, a bottom section that would fit under the tunnel and top section that could be attached from inside the wind tunnel to the bottom section. As mentioned before the bottom section had four anchors points which were mounted into the concrete floor with 4 in bolts. The top section consisted of schedule 80,2 in steel pipe that connected to the bottom section with a threaded coupling. This meant of course that a small hole 
was drilled in the wind tunnel floor to allow for the connection to occur. This opening was kept minimal to prevent flow issues around the spacing. The top of the test rig was fitted with brackets that were welded in place which were used for mounting the two stings needed to hold the models as shown in Figure 66.

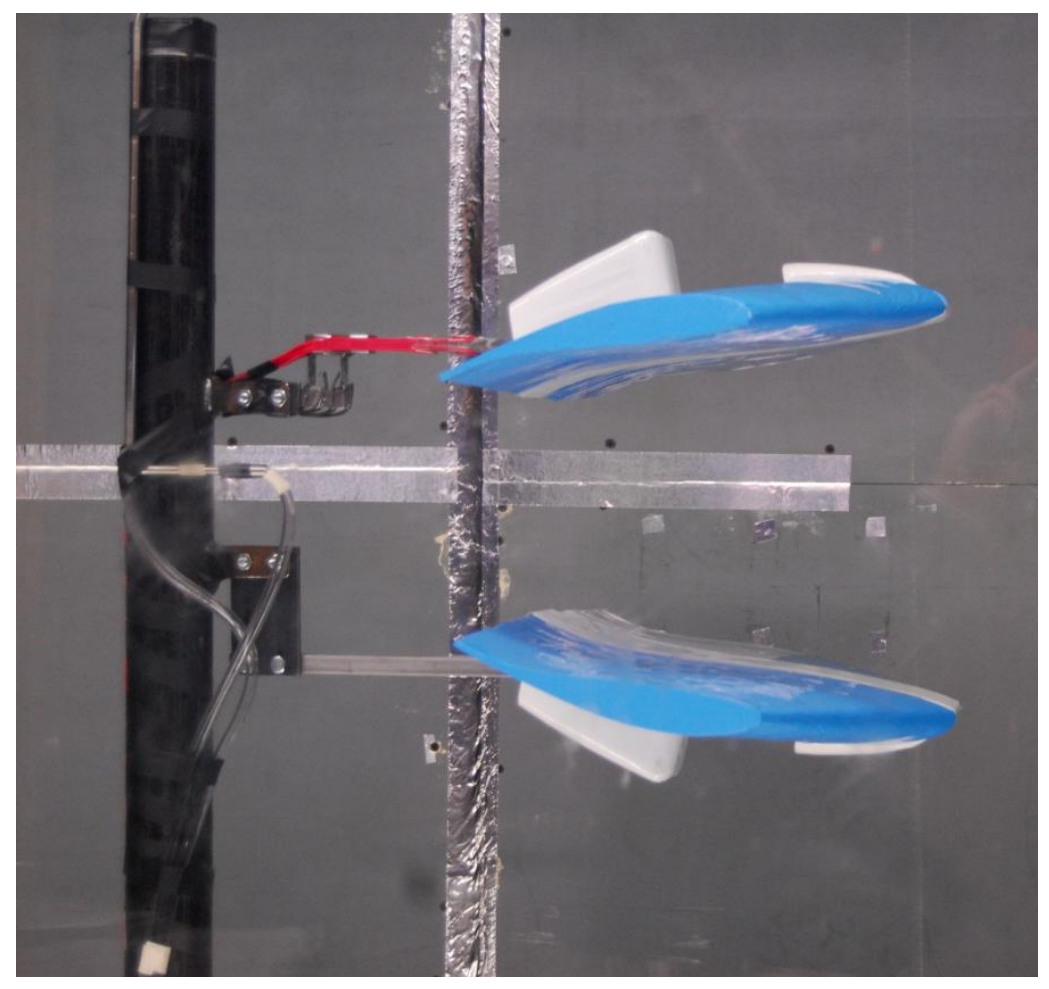

Figure 66: Symmetric Models Mounted to Test Rig

The pipe was sized based on its ability to resist bending in the beam based on the expected applied forces determined from the CFD models. The bottom section on the pipe was reinforced with a support piece to limit the length of applied bending thus allowing for smaller diameter pipe. This was important because a smaller test rig support structure allows for less flow interference during testing. 


\subsubsection{Sting Design}

In order to measure the forces experienced by the glider model a sting, otherwise known as an internal balance, was designed. This sting was designed to measure pitch, drag and lift since these were the primary characteristics of concern. Pitch and lift are found from similar instrumentation so can be set-up with a similar device for measurement. As shown in Figure 67, a bending beam can be used to determine the lifting force and the pitching moment.

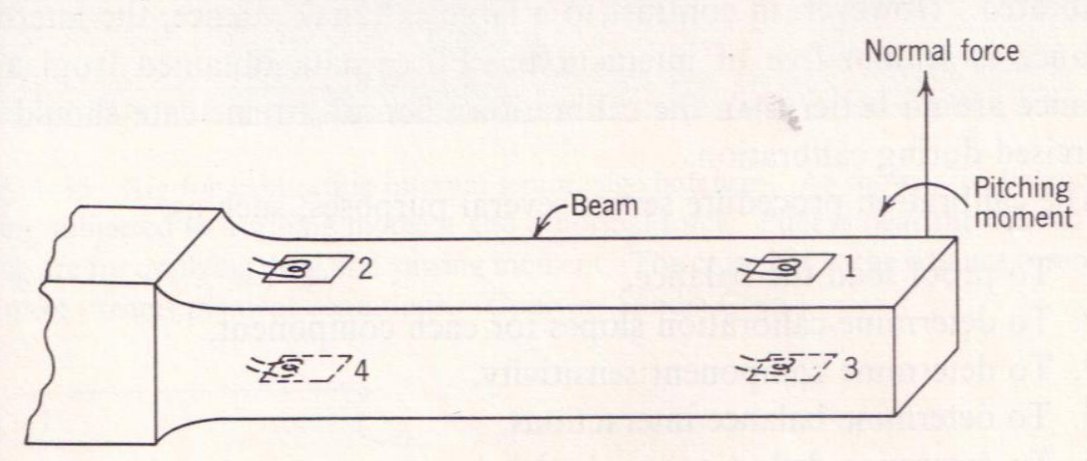

Figure 67: Bending Beam for Pitch and Lift (58)

Both of these characteristics are measured based on deflections experienced by strain gages that are placed along the beam. The strain gages are placed in full Wheatstone bridges as shown in Figure 68. Full Wheatstone bridges are used in order to increase sensitivity and resolution and are capable of compensating for temperature variations between the gage and the mount (59). 


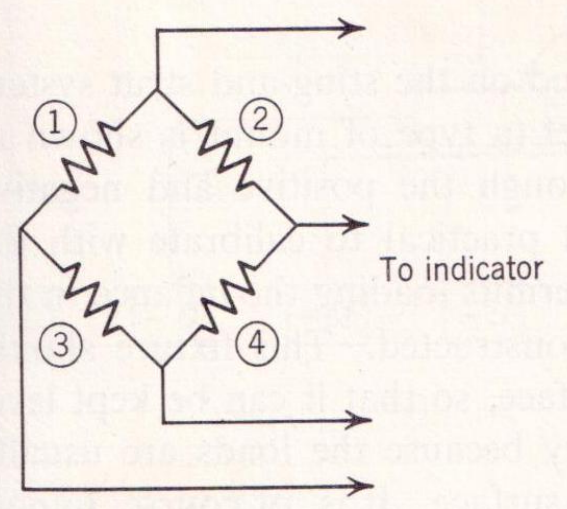

(a) Differential circuit for normal force

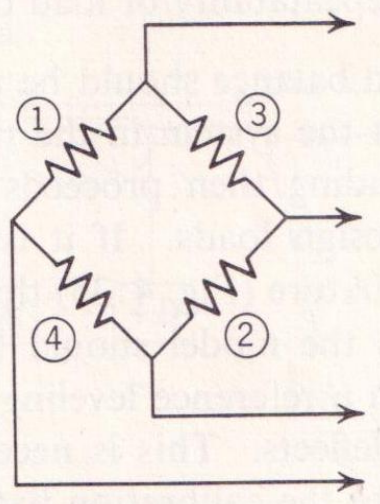

(b) Summing circuit for pitching moment

Figure 68: Wheatstone Bridges for Lift and Pitch (58)

Drag was placed in another location apart from the pitch and lift since it required bending in a separate direction. As shown in Figure 69, the drag was designed to be determined by vertical beams that flexed when an axial force was introduced. While this method can produce interference from the lift force, it is one of the easiest to implement.

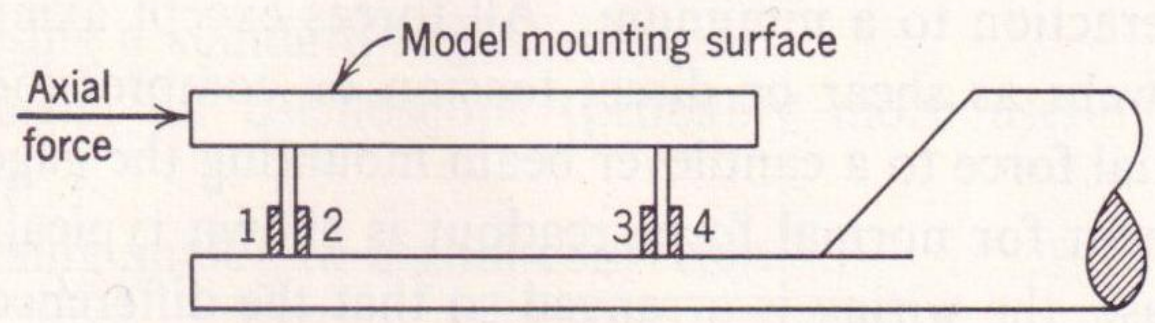

Figure 69: Bending Beam for Drag (58)

Much like the lifting force and pitching moment, the drag force was determined through the use of a full Wheatstone bridge as shown in Figure 70. 


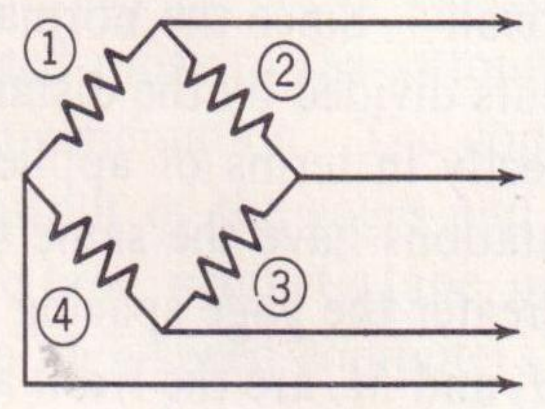

Figure 70: Wheatstone Bridge for Drag (58)

The culmination of the pitch, lift, and drag design theories were developed into a sting capable of measuring three components in combination as shown in Figure 71. This design utilized an adjustable head capability that would allow for an adjustment of the angle of attack without moving the main body containing the strain gages out of the direction of the wind axis. This is an important feature since most stings are held along the body of the model requiring a translation of forces back to the wind axis.

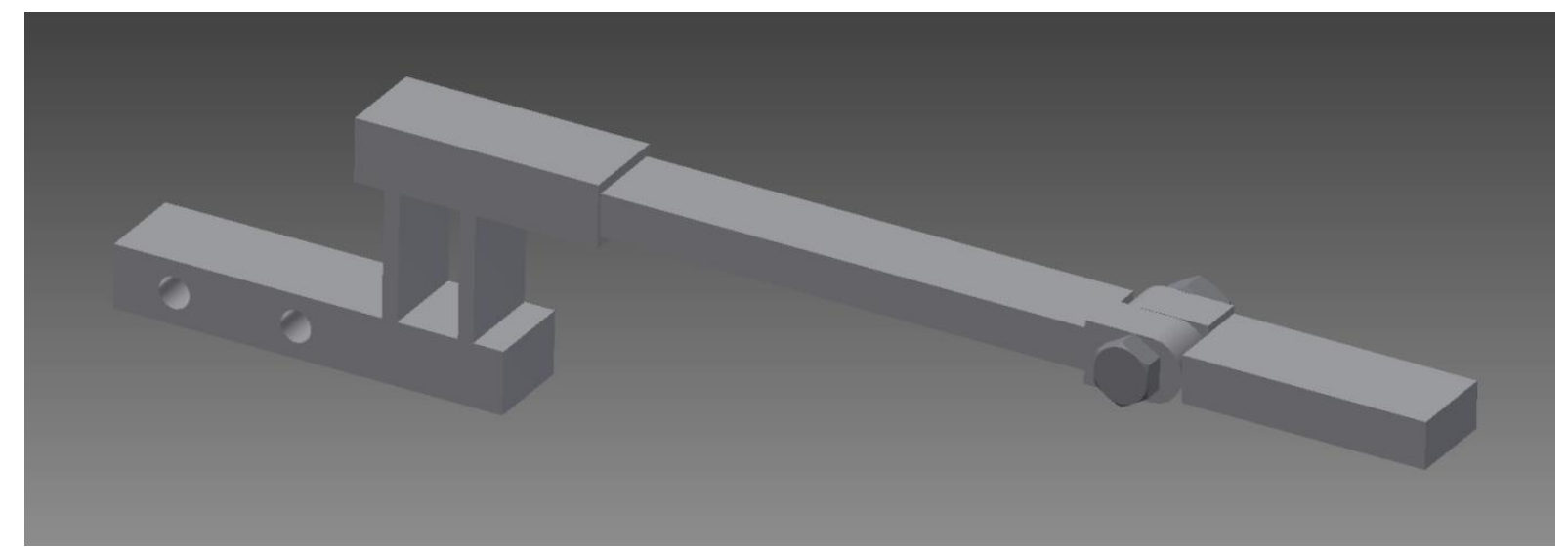

Figure 71: Sting for Gages

Since symmetric modeling took place to mimic ground effect in the wind tunnel, a second sting was constructed that did not require the use of gages, shown in Figure 72. 


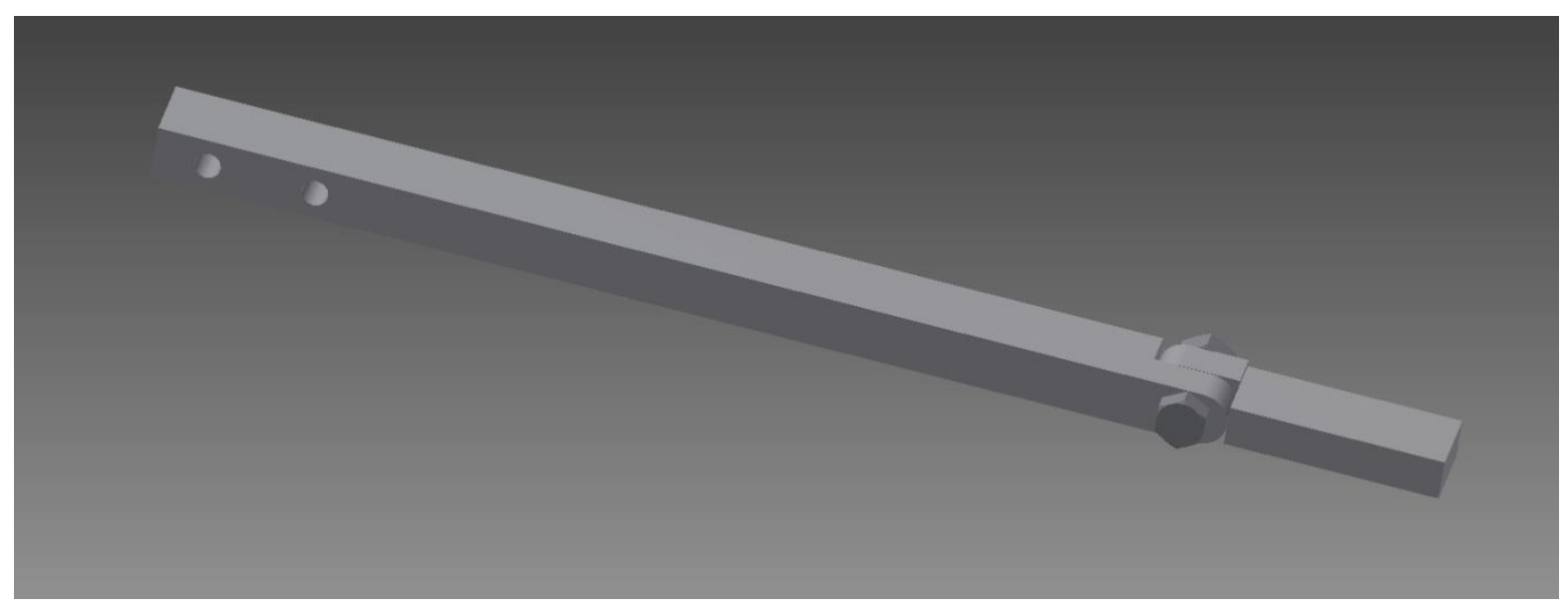

Figure 72: Sting for Symmetric Model

This sting therefore, consisted of a straight beam that could be placed at a given distance from the ground plane. In order to test within the ground effect regime, the models must be located within a chord length to the ground (14). The chord of this model is 12 in and the model distance to the symmetry plane is 3 in, or $25 \%$ of the chord length. When placed as mirror images of each other, Figure 73, each model is 3 in from the ground but 6 in from each other.

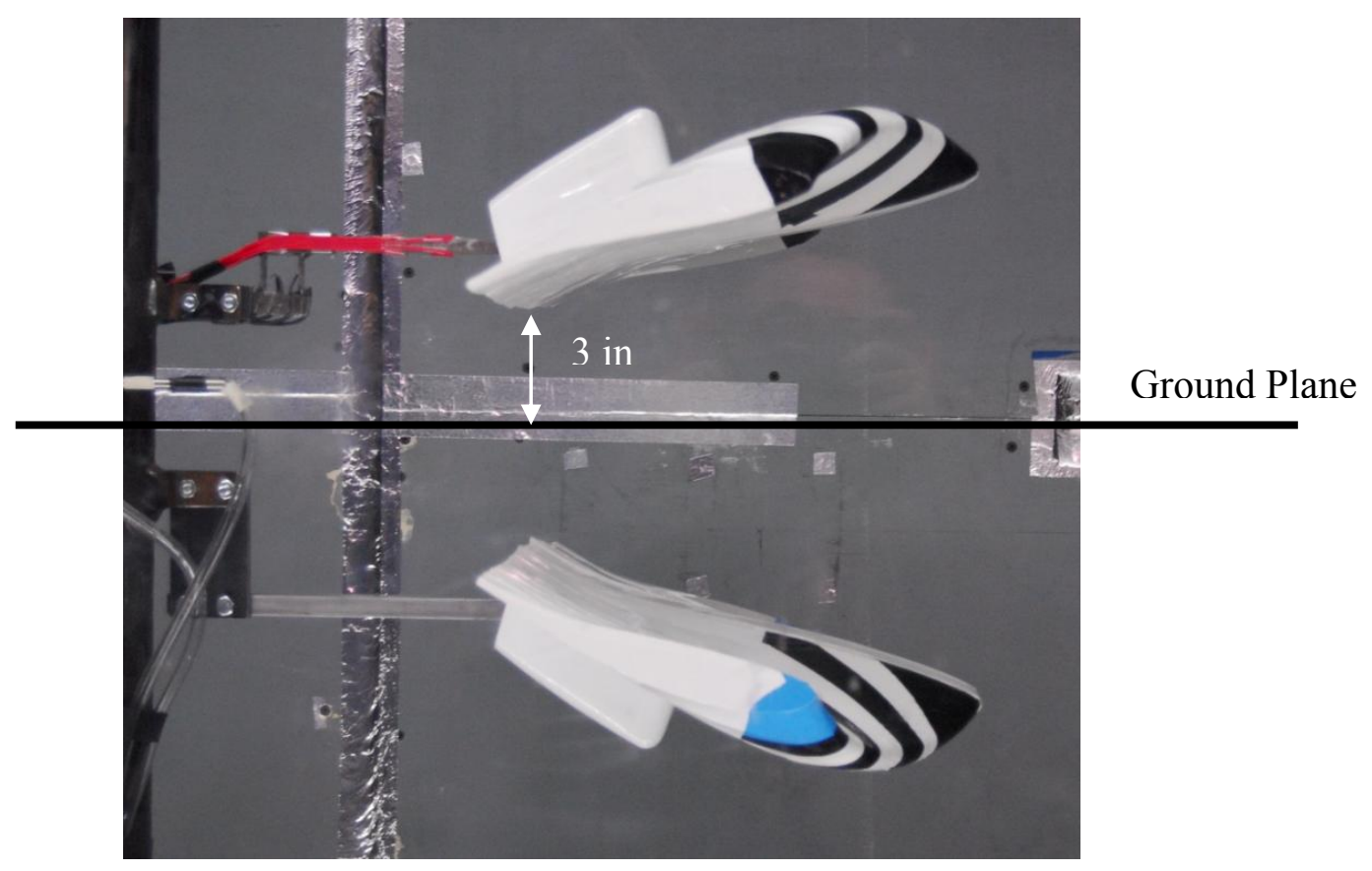

Figure 73: Representation of Ground Plane through Mirror Imaging 


\subsubsection{Sting Calibration}

The sting was calibrated using a block of wood that was representative of the initial weight of the model. Various weights were connected to the block, both in the positive and negative directions, to assess the applied weight versus the indicated weight from the strain gages as shown in Figure 74.

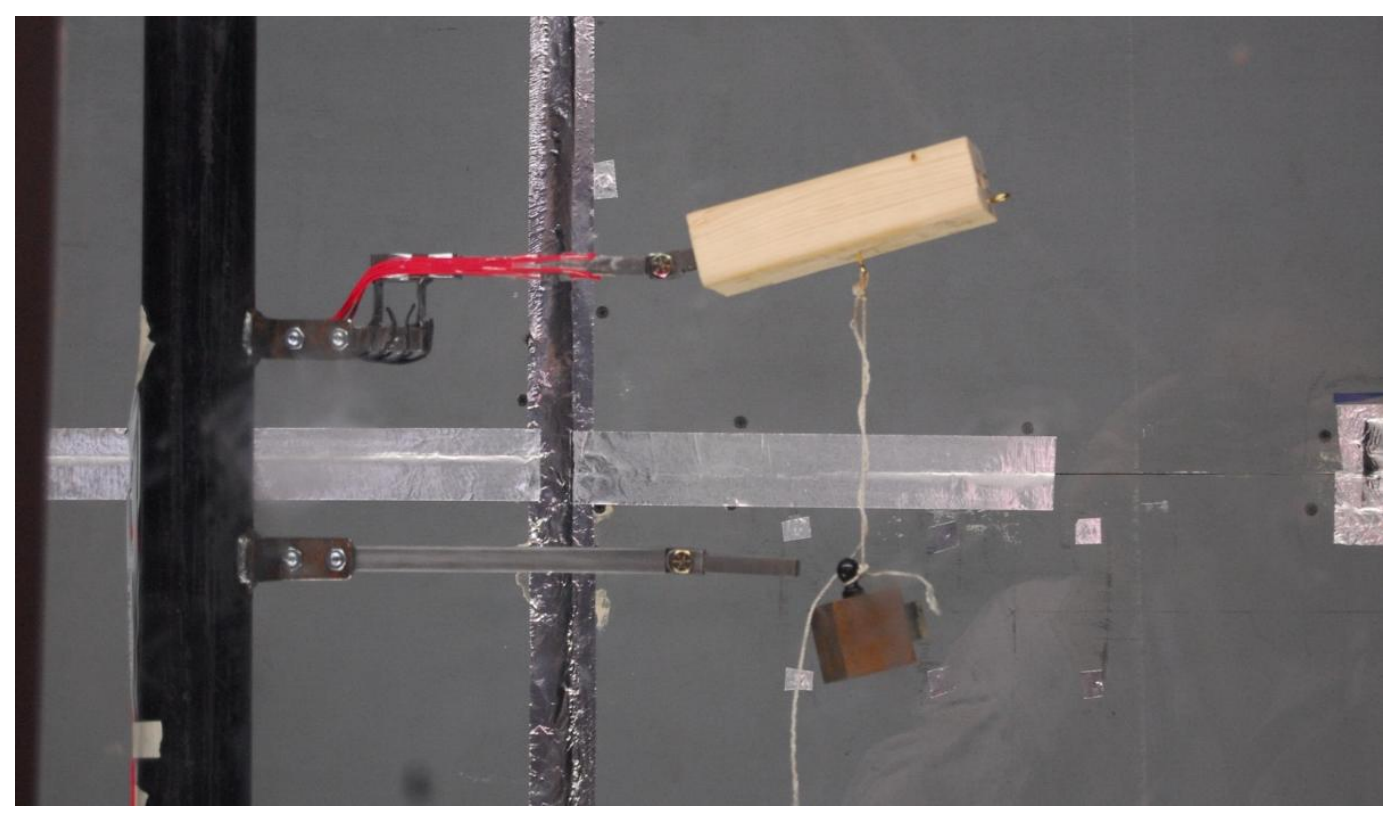

Figure 74: Weights

In this manner, the calibration curves were created that can be applied to future readings from the internal balance. A calibration curve was created for the lift force as shown in Figure 75. 


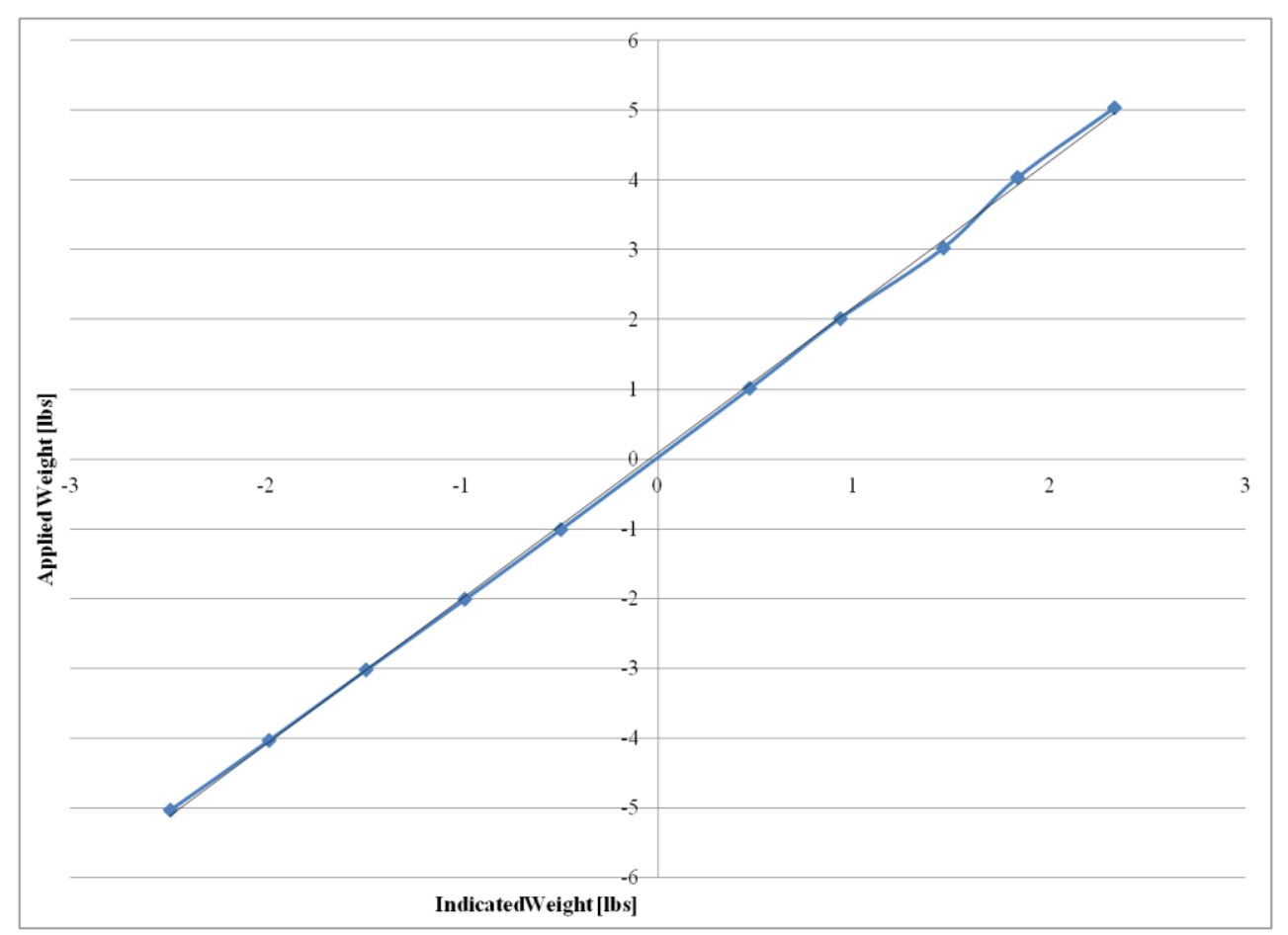

Figure 75: Lift Force Calibration Curve

The calibration curve for the lift force can be expressed as shown in Equation 19. This expresses a relationship between the weight applied to the sting, $y$, and the weight that was indicated by the recording instrumentation, $x$.

$$
y=2.089 x+0.089
$$

The drag calibration curves were more complicated in that the interaction from the lift component needed to be taken into account as created interference in the drag force reading. Therefore measurements were taken at each angle of attack tested to determine the interference created by the varying lifting forces. The interference caused by the lifting force at $0^{\circ}$ angle of attack is shown in Figure 76. 


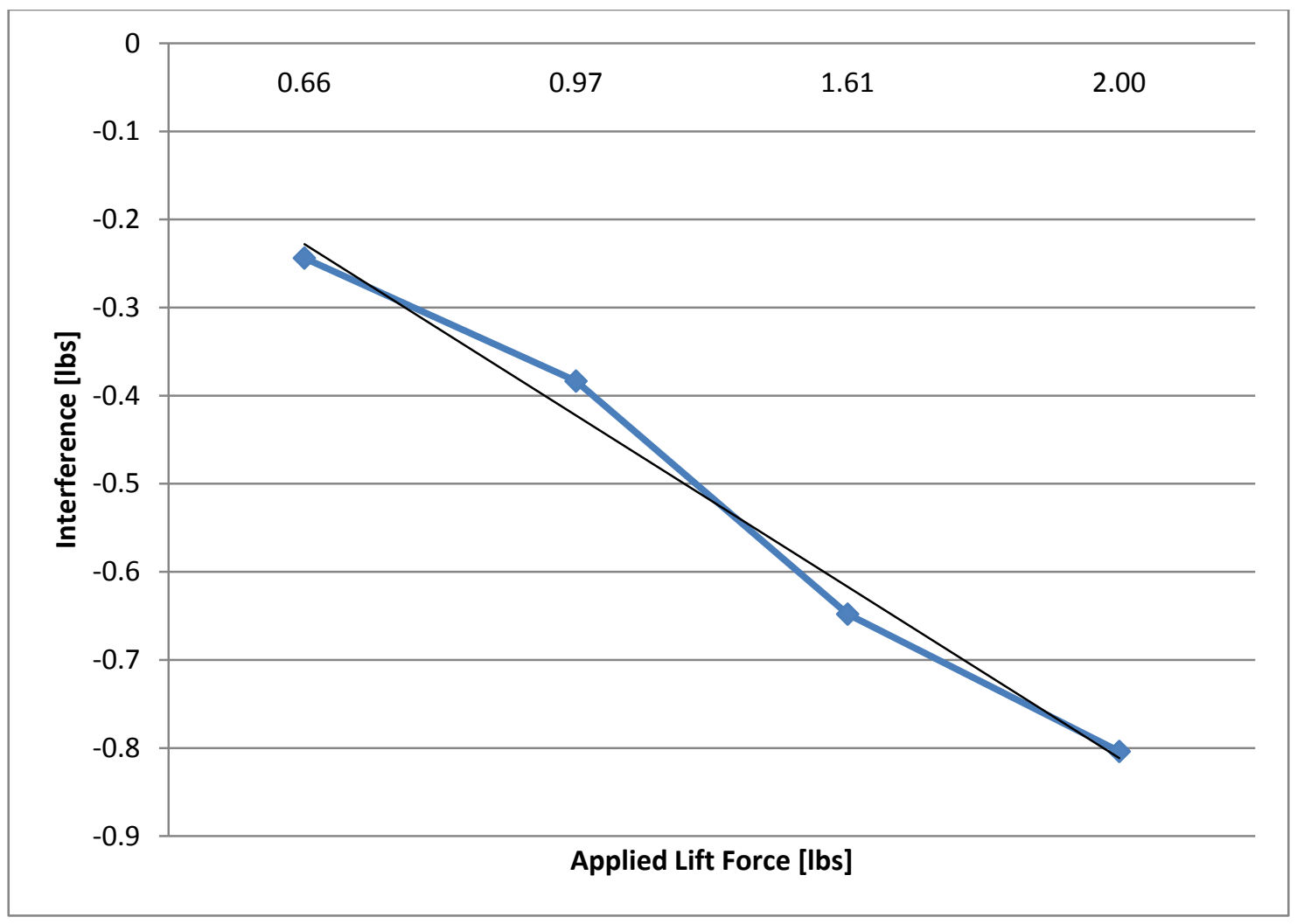

Figure 76: Interference Caused by Lift at $0^{\circ}$ Angle of Attack

An expression for the interference force at $0^{\circ}$ angle of attack can be expressed in Equation 15, where $\mathrm{x}$ represents the applied lifting force and $\mathrm{y}$ represents the interference force as it applies to the drag.

$$
y=-0.416 x+0.0292
$$

The interference factor is determined through the use of the known lifting force. This interference factor is then subtracted from the recorded drag forces to achieve the correct results. The interference curve for $5^{\circ}$ angle of attack is shown in Figure 77. 


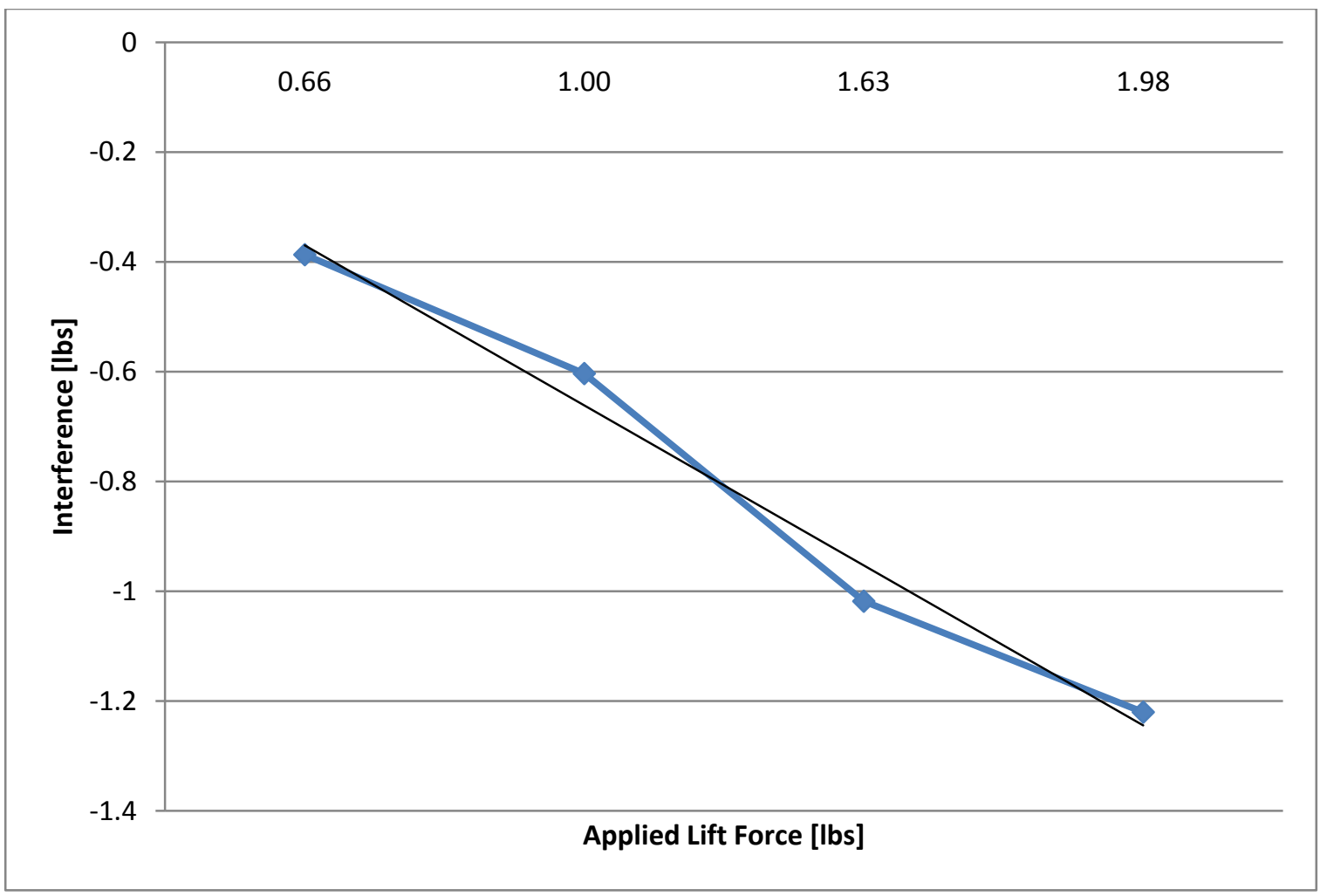

Figure 77: Interference Caused by Lift at $5^{\circ}$ Angle of Attack

Similarly, this figure can be expressed as an equation, shown in Equation 16.

$$
y=-0.49 x+0.0243
$$

Equation 16

The interference curve for $10^{\circ}$ angle of attack is shown in Figure 78 . 


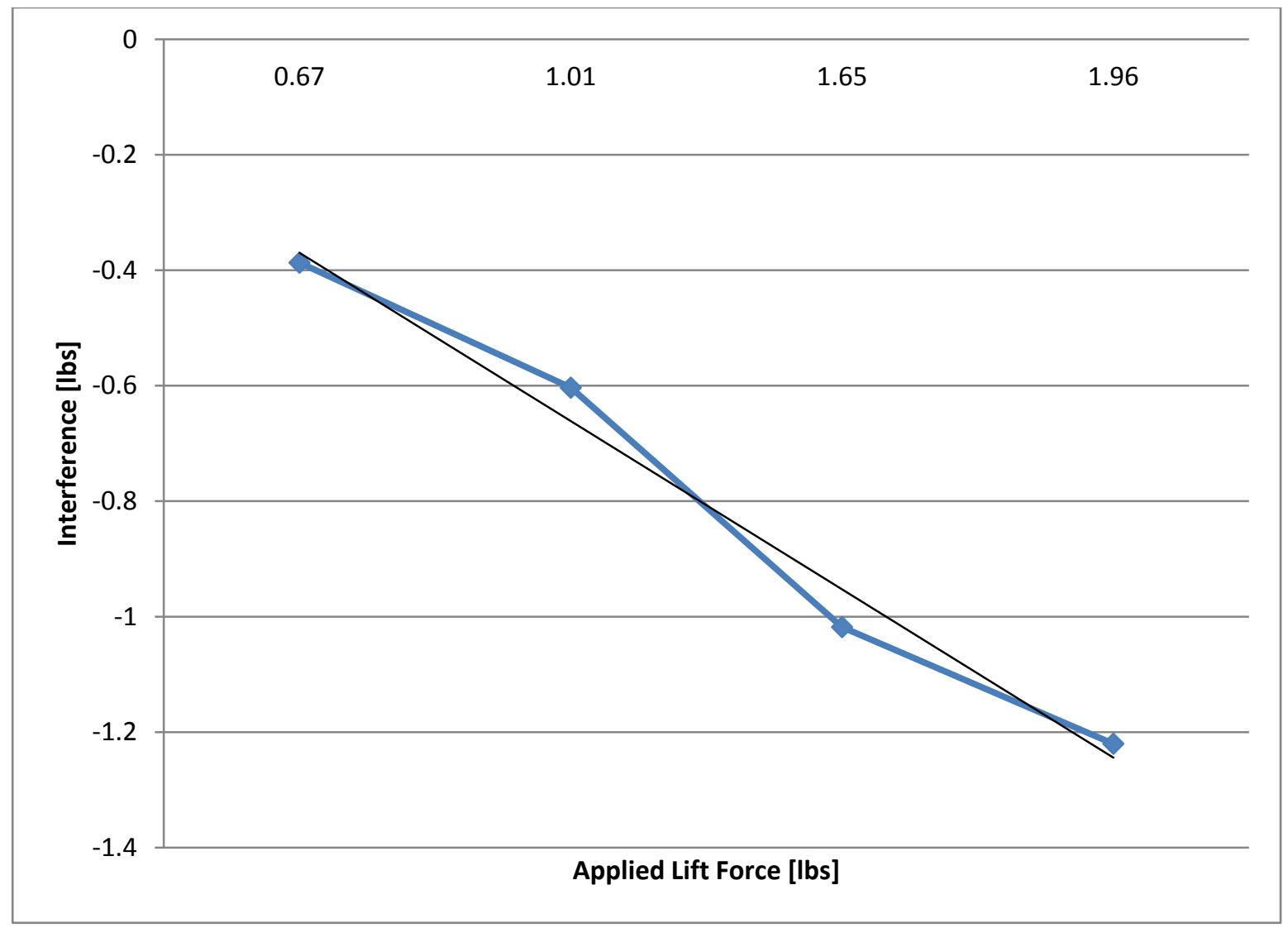

Figure 78: Interference Caused by Lift at $10^{\circ}$ Angle of Attack

This figure can also be expressed through the use of an equation, shown in Equation 17.

$$
y=-0.581 x+0.0413 \quad \text { Equation } 17
$$

And lastly, the interference curve for $15^{\circ}$ angle of attack is shown in Figure 79. It should be noted that while the equations present similar slopes, they are different enough to represent significant changes in correcting the drag force. 


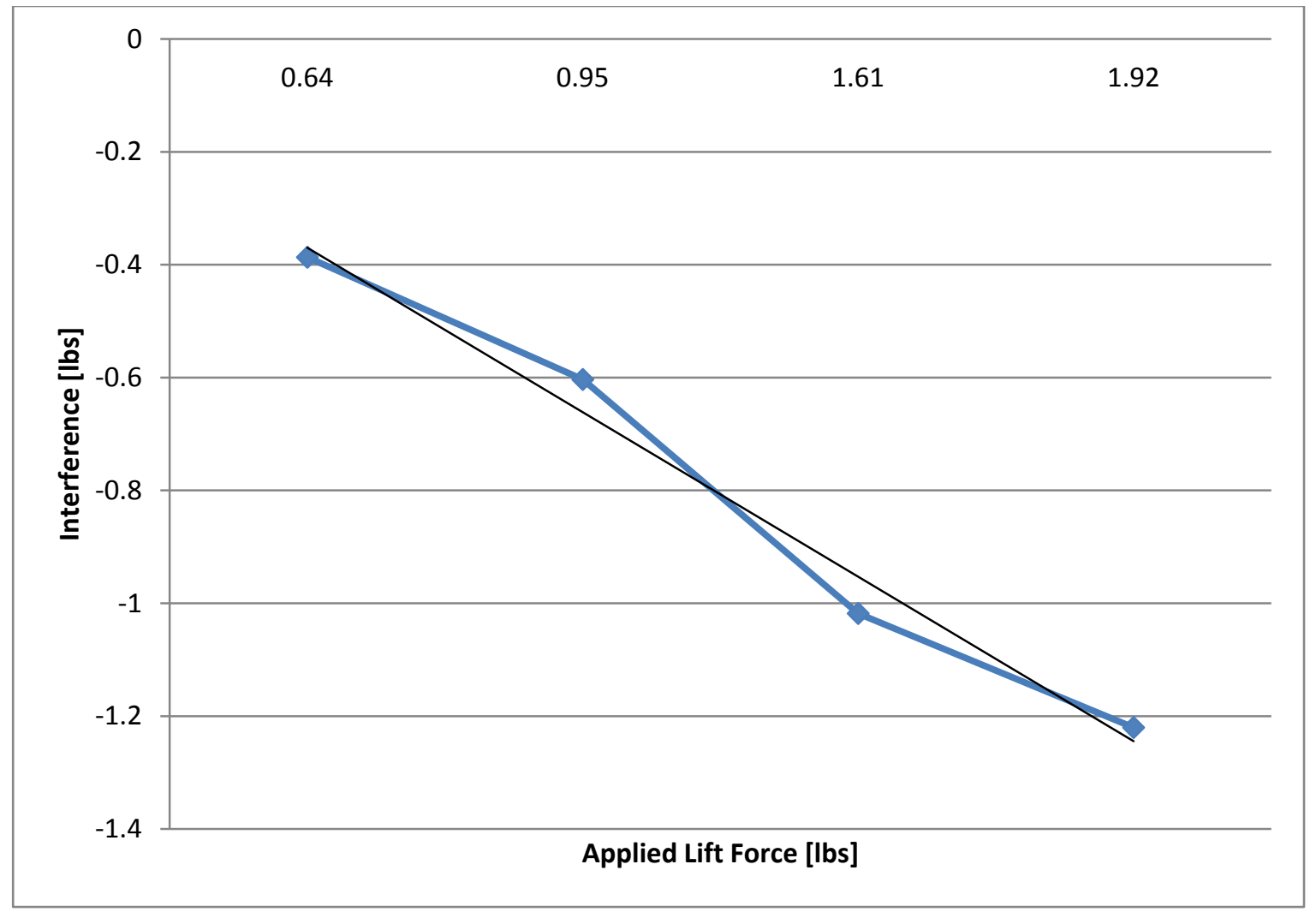

Figure 79: Interference Caused by Lift at $15^{\circ}$ Angle of Attack

The equation representing the interference cause by lift for $15^{\circ}$ angle of attack is shown in Equation 18.

$$
y=-0.649 x+0.0294
$$

Equation 18

\subsubsection{Flow Scaling}

In order to perform experimental testing, scaled models of the wing geometries were constructed. It was necessary to use scaled models as a result of the limited size of the test section in the testing facility. The testing facility in use was the $6 \mathrm{ft} \times 4 \mathrm{ft}$ test section of the WVU Closed Loop Subsonic Wind Tunnel. When working within a given test section, the amount of wind flow blockage that a model creates must be taken into account when sizing the 
model. A blockage factor of $5-10 \%$ is the preferred maximum amount allowable in the wind tunnel before interference effects become considerable. As a result of scaled model geometries, the associated wing speed and ground speed were also scaled.

Froude number scaling was used to relate the full size model operating at $44 \mathrm{ft} / \mathrm{s}$ with a $10 \mathrm{ft}$ root chord, to the $1 \mathrm{ft}$ root chord scaled model. This non-dimensional number relates the chord length to velocity as shown in Equation 19and is used for flow with the free surface (60). In this study, the effective "free surface" is the symmetry plane or ground plane.

$$
F r=\frac{V}{\sqrt{g l}}
$$

From this relationship, a velocity of $13.91 \mathrm{ft} / \mathrm{s}$ was found for the scaled model to be used in experimental testing. In addition, it was necessary to know the Reynolds number in order to categorize the flow around the scaled model. The Reynolds number was calculated using Equation 20 in which the density was taken at sea level to be $0.00238 \mathrm{slugs} / \mathrm{ft}^{3}$ and the viscosity of $3.68 \mathrm{e}-7 \mathrm{lbf}-\mathrm{s} / \mathrm{ft}^{2}$.

$$
\mathrm{Re}=\frac{\rho V L}{\mu}
$$

For the scaled model speed of $13.91 \mathrm{ft} / \mathrm{s}$, the Reynolds number was calculated to be $6.5 \times 10^{4}$ for a chord length of $1 \mathrm{ft}$, which indicates a laminar flow. Laminar flow occurs when the Reynolds number is less than $3 \times 10^{5}(6)$. The speed of this scaled model, found through the use of Froude number, is located inside a Reynolds number regime which has been found to be unstable in previous experimentally tested 3-D airfoils and can cause laminar flow separation to occur as shown in Figure 80 (61). 

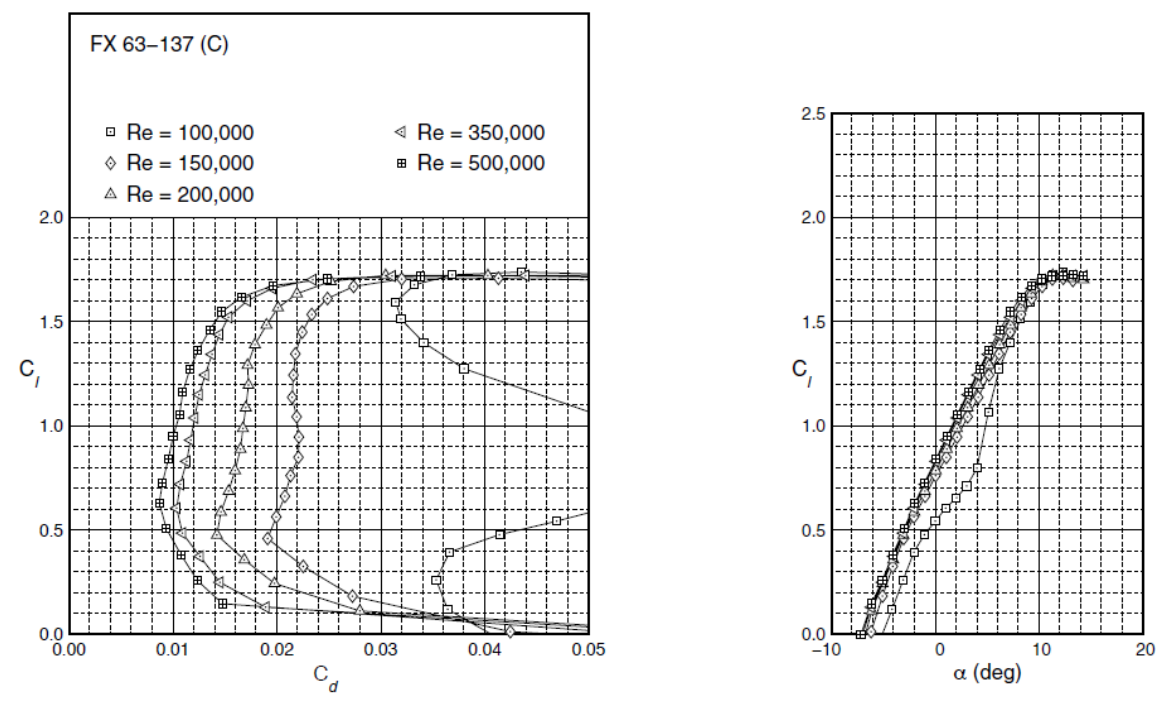

Figure 80: $C_{L}$ vs. $C_{D}$ chart (left) and $C_{L}$ vs. $\alpha$ chart (right) (61)

As a result, the baseline model was tested at $30 \mathrm{ft} / \mathrm{s}, 40 \mathrm{ft} / \mathrm{s}$ and, $50 \mathrm{ft} / \mathrm{s}$, which is approximately equivalent to $\mathrm{Re}=140,000 ; \mathrm{Re}=188,000$; and $\mathrm{Re}=235,000$. This verified concurrence among surrounding Reynolds numbers, and determined a suitably similar testing velocity that avoided the laminar separation that was known to occur below $\mathrm{Re}=100,000$.

\subsection{Experimental Results and Analysis}

This section describes all experimentation that was performed in the wind tunnel, including Reynolds number analysis, boundary layer tripping analysis, and model comparison and analysis.

\subsubsection{Reynolds Number Comparison}

The results for varying Reynolds numbers were compared for low speed velocities in order to determine if higher Reynolds would produce similar aerodynamic results, i.e. force coefficients, without the laminar separation issue that was known to occur at or below $\mathrm{Re}=100,000$. The resulting comparison, Figure 81, was produced for the lift coefficients. This comparison included 
three Reynolds numbers as well as an additional test at $\mathrm{Re}=140,000$ that used boundary layer trips as a method for simulating turbulent flow similar to that anticipated on the full-sized model. A further explanation of boundary layer trips; their styles and effects, are discussed in Section

\subsection{2.}

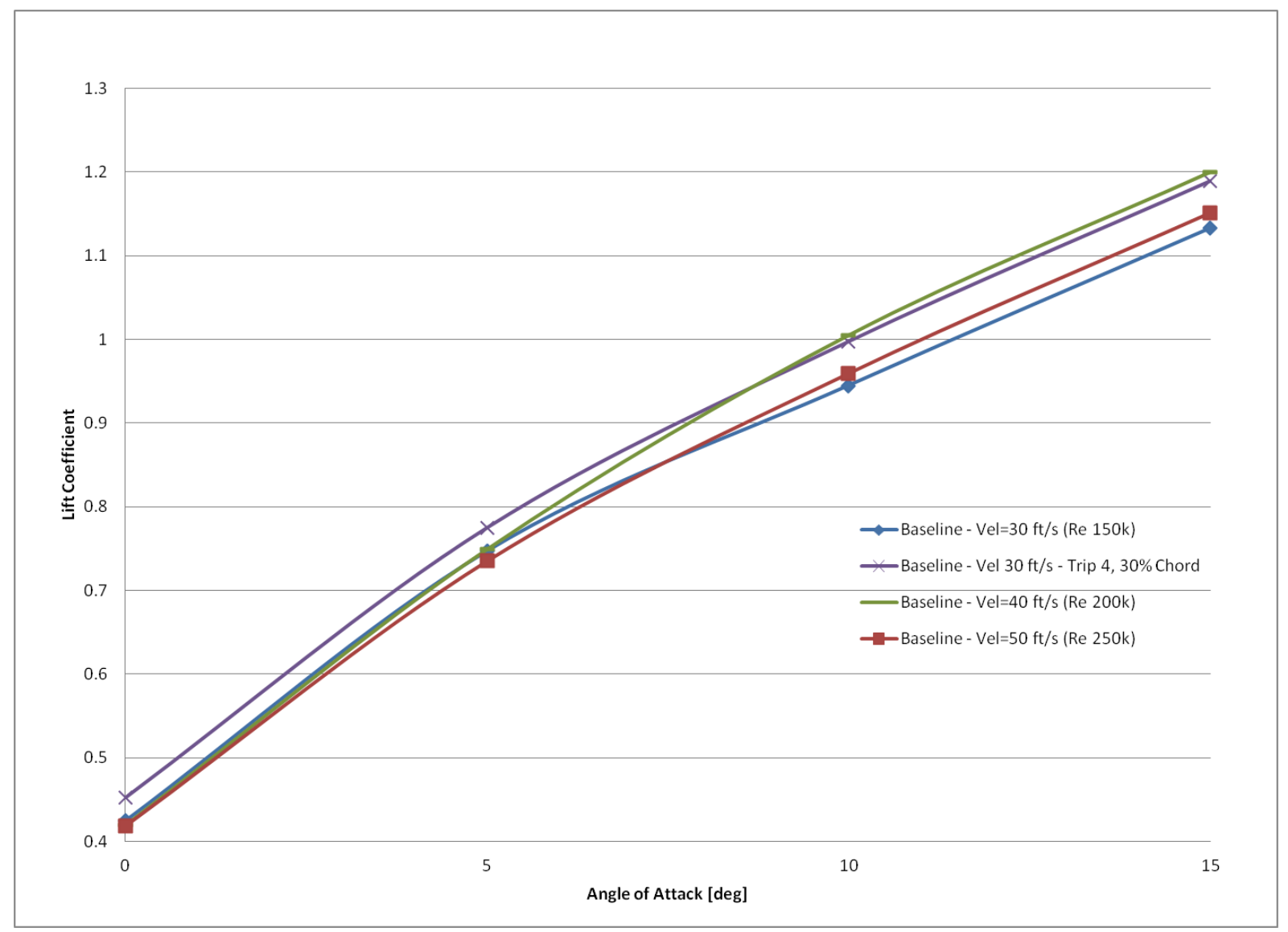

Figure 81: Reynolds number comparison of lift

As shown in Figure 81, the lift slopes of the three Reynolds numbers are closely located near each other with the exception of the $30 \mathrm{ft} / \mathrm{s}$ curve at $10^{\circ}$ and $15^{\circ}$ angle of attack. This lift curve shows substantial improvement at the higher angles of attack with the addition of a boundary layer trip located at a distance of $30 \%$ of the chord from the leading edge. The drag behavior, as shown in Figure 82, is more susceptible to Reynolds number variations than the lift 
shown in Figure 81. This is an expected trend that has been demonstrated repeatedly in various experimental works, including that shown in Figure 80.

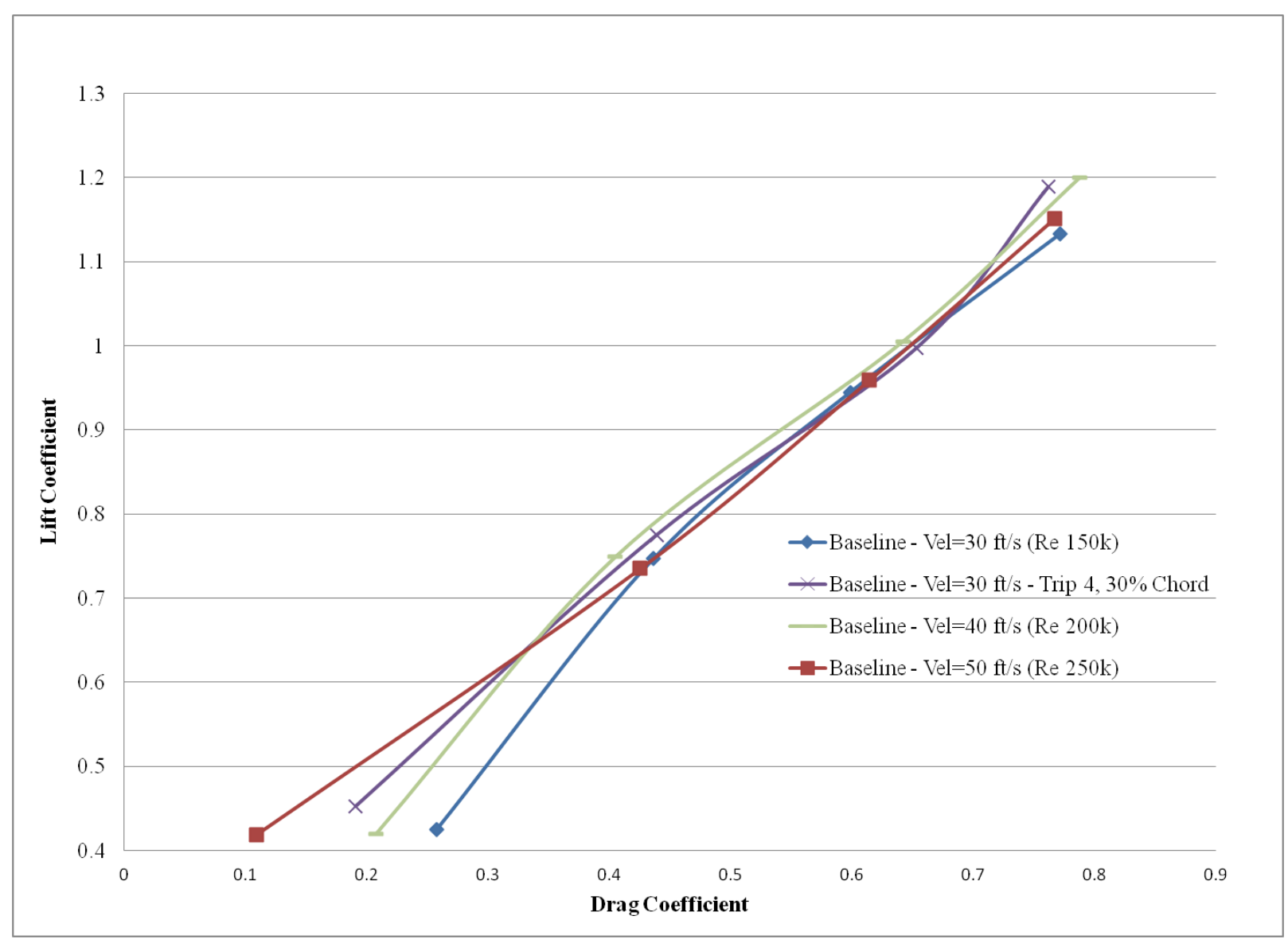

Figure 82: Reynolds number comparison of drag

In order to maintain similarity for comparison and avoid laminar separation, the $30 \mathrm{ft} / \mathrm{s}$ case will be used to measure and compare data across all model types. These results will most closely resemble the expected full-sized results at the $13.91 \mathrm{ft} / \mathrm{s}$ test velocity.

\subsubsection{Boundary Layer Trip Analysis}

An investigation into boundary layer tripping was conducted as part of this research to establish comparable flow characteristics to that of the full-scale model. A boundary layer trip is a device that is laid along the span of the wing at a given distance from the leading edge in an 
attempt to alter the flow located close to the surface of the wing. This device can be constructed of any material but is most commonly created from tape or sand and is located at a distance upstream of the maximum thickness location of the airfoil. (62)(63) For the Wortmann FX 63137 case, the maximum thickness location occurs at a distance approximately $30 \%$ of the chord, from the leading edge.

For this investigation, five types of boundary layer trip styles were examined, located at two locations along the chord-line. These boundary layer trips were chosen for the maximum height and surface roughness that they could provide. Boundary layer trips typically do not exceed the predicted height of the boundary layer. These trip heights were chosen to start at the boundary layer height of 3/16 in and decrease in size in order to establish that flow was moving over the wings at these locations and would produce known effects, namely flow separation. The initial boundary layer height was determined from flat plate boundary layer thickness predictions (4). The trip number, construction material and maximum size is shown in Table 18.

Table 18: Boundary Layer Trip Style

\begin{tabular}{|c|c|c|}
\hline & Material & Size [in] \\
\hline Trip 1 & Aluminum & $3 / 16$ \\
\hline Trip 2 & Aluminum & $1 / 8$ \\
\hline Trip 3 & Sand & $1 / 16$ \\
\hline Trip 4 & Sand & $1 / 32$ \\
\hline Trip 5 & Tape & $1 / 64$ \\
\hline
\end{tabular}

Trips 1 and 2 were constructed of the thin aluminum found in soda cans. The aluminum was cut into strips and folded in half along the length to create a $90^{\circ}$ fold. One edge was then cut into a saw-tooth pattern as shown in Figure 83 and placed along the upper and lower surfaces at the same chord location. 


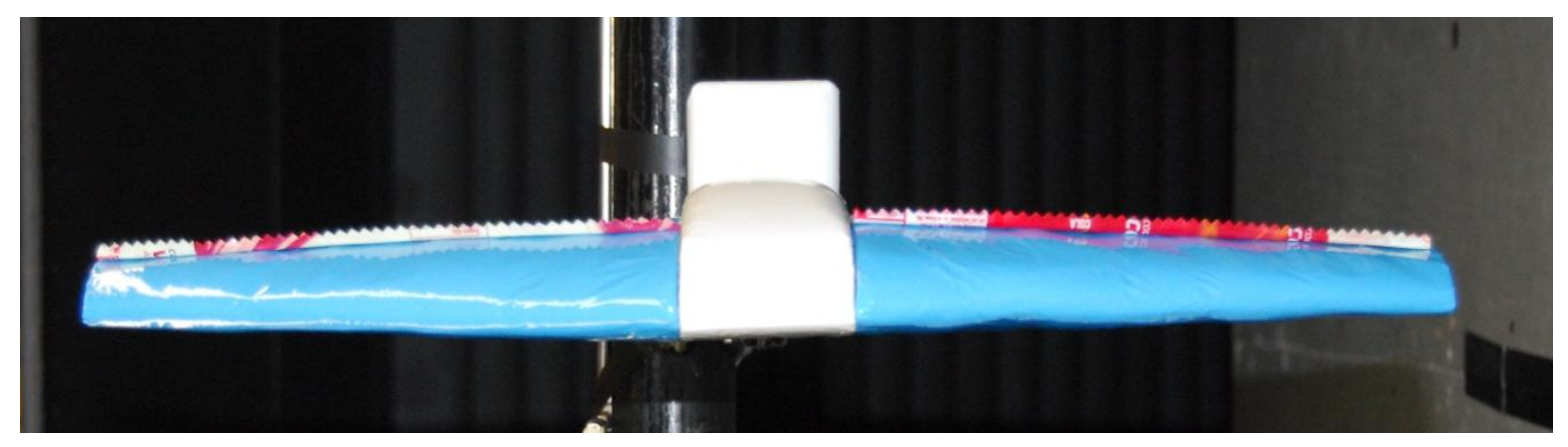

Figure 83: Boundary Layer Trip Style 1 and 2

Trips 3 and 4 were constructed of coarse and medium grain commercially available sand. This sand was attached to the model wings on the upper and lower surface using double sided sticky tape as shown in Figure 84. The double-sided tape was of minimal thickness as it was smaller than the measuring capability of a 1/64 in scale caliper and was therefore ignored.

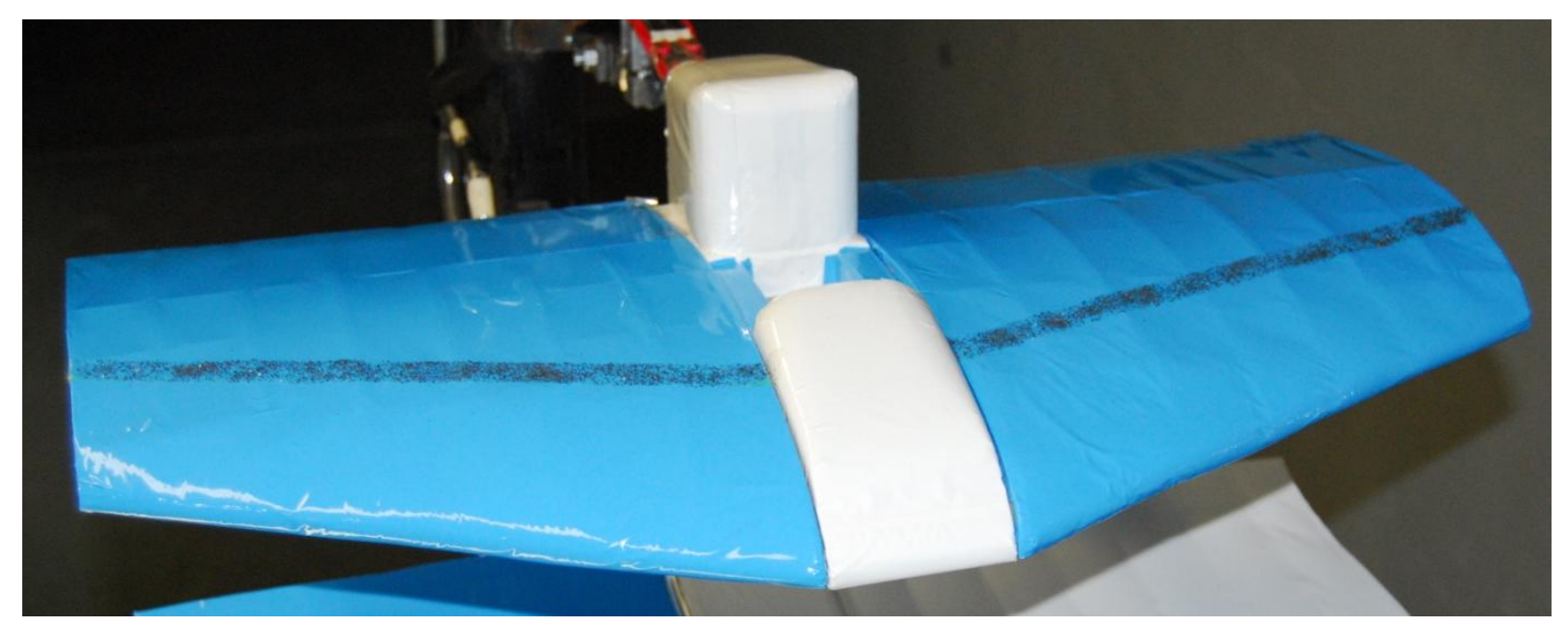

Figure 84: Boundary layer Trip Style 3 and 4

Trip 5 was constructed of commercially available duct tape that was cut in a $1 / 4$ inch wide strip and placed down the length of the wings in the same manner as the previous styles. This tape was chosen due to its high thickness compared to other tapes such as packaging, scotch, etc. 
The boundary layer trips were placed on the baseline model in ground effect and measured against an un-tripped model to determine the effectiveness of each style of the lift coefficient. The results are shown in Figure 85 and Figure 86, and are broken down into smaller groupings in subsequent figures to highlight the effects of certain styles.

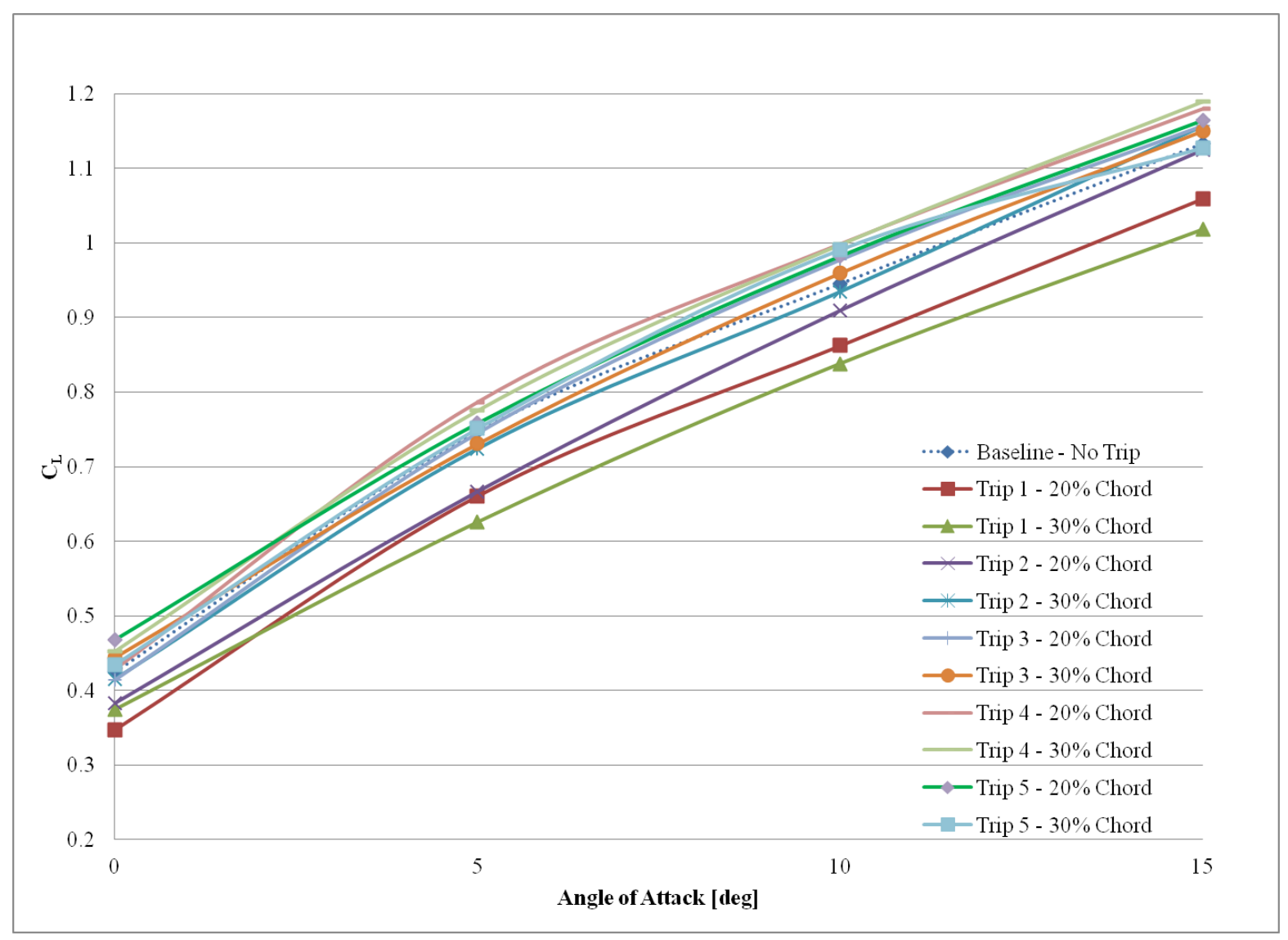

Figure 85: Boundary Layer Trip Lift Comparison (Experimental) 


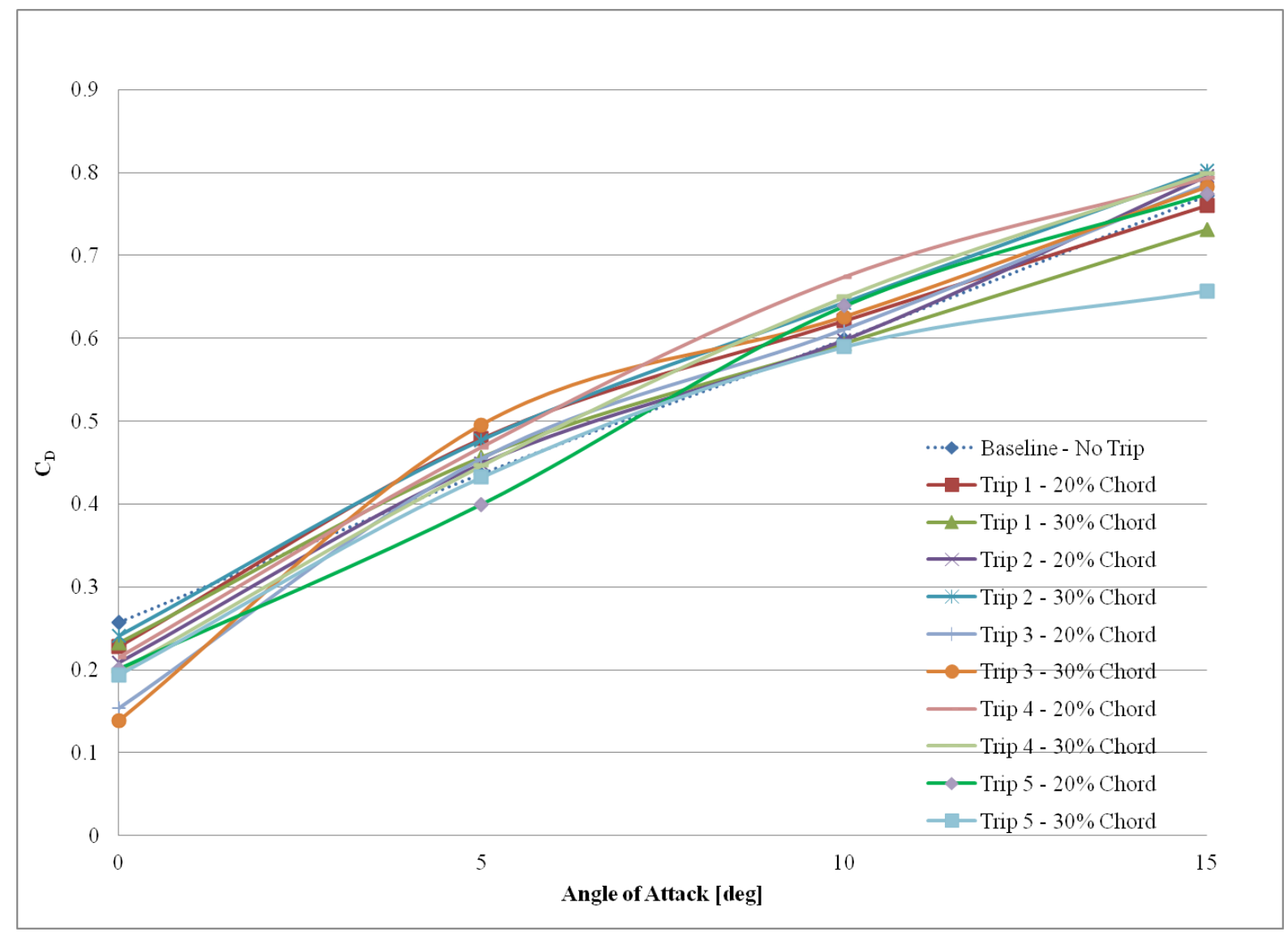

Figure 86: Boundary Layer Trip Drag Comparison (Experimental)

The boundary layer trips shown in Figure 87 were taken from Figure 85 to demonstrate those trips that caused flow separation to occur and thus lower their respective lift coefficients. These trips were the aluminum style trips that were created to intentionally impede the flow and thus verify that flow was passing over the wings and had not already separated. 


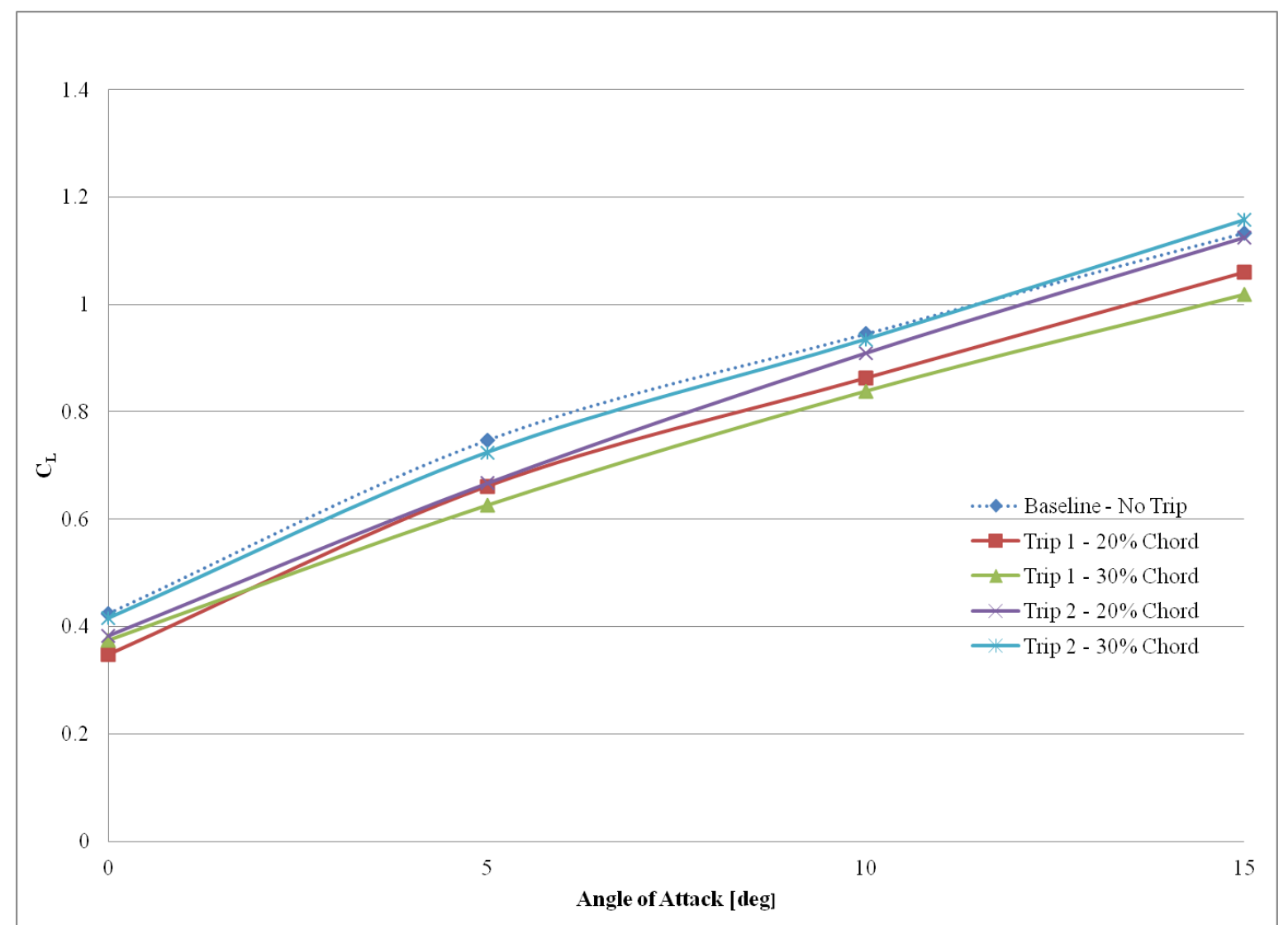

Figure 87: Ineffective Boundary Layer Trips - Lift Coefficients (Experimental)

While, primarily, the lift was examined for its influence on achieving turbulent flow, the drag component was also examined to determine what influence the boundary trips had. Shown in Figure 88 are the boundary layer trips that showed negative benefit for the lift component. The drag coefficients for the various trips have a tendency to move in similar motions, with the greatest decrease in the drag coefficient being shown at $0^{\circ}$ angle of attack. There occurs a peak in the drag increase at $5^{\circ}$ angle of attack, before falling off again towards $15^{\circ}$ angle of attack. 


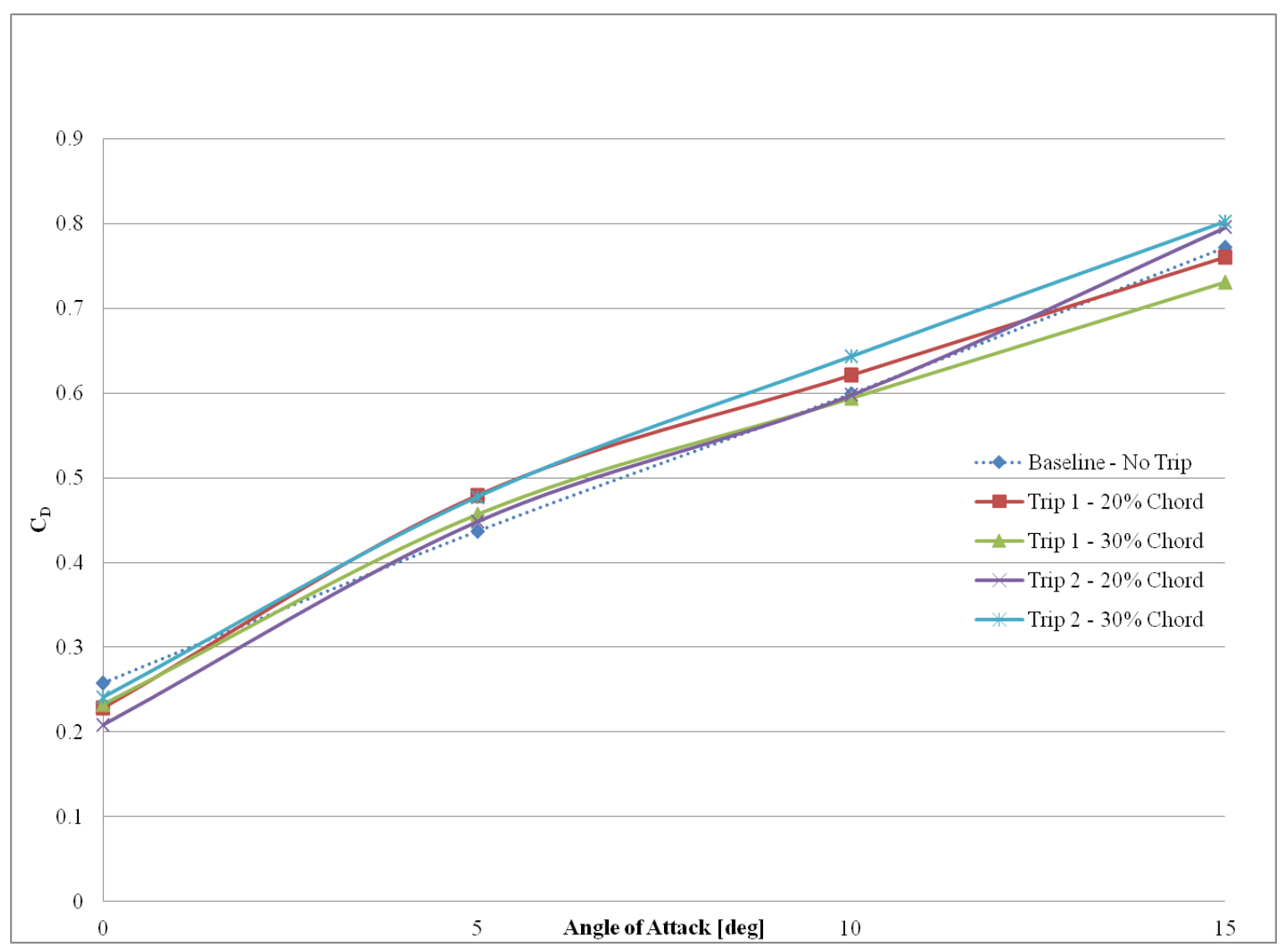

Figure 88: Ineffective Boundary Layer Trips - Drag Coefficients (Experimental)

Figure 89 demonstrates the boundary layer trips that have increased improvement with decreased trip size. These two styles are those of the sand, where the medium sized sand showed an increased improvement at the higher angles of attack than the coarse grain sand. 


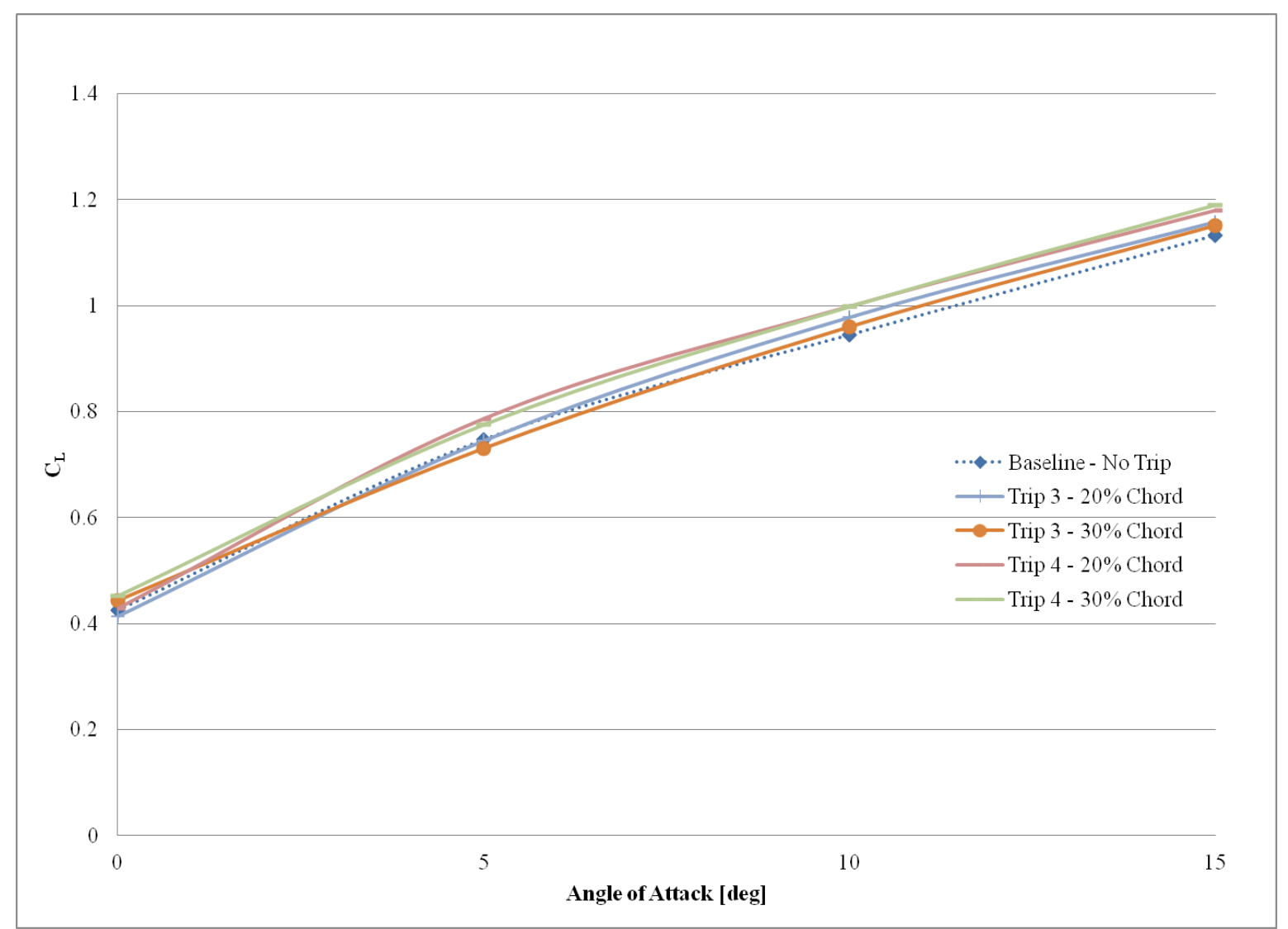

Figure 89: Boundary Layer Trips with Increasing Effectiveness - Lift Coefficients (Experimental)

Figure 90 demonstrates the drag coefficients for those boundary layer trips that were shown to produce effective results in the lift direction. The drag coefficients for these boundary layer trips demonstrate larger variation from the baseline case than those shown in Figure 88. With the exception of the $0^{\circ}$ angle of attack case, the drag coefficients all show an increase over the baseline case. This increase in the drag coefficients was expected given the flow excitation that is occurring at the boundary layer. 


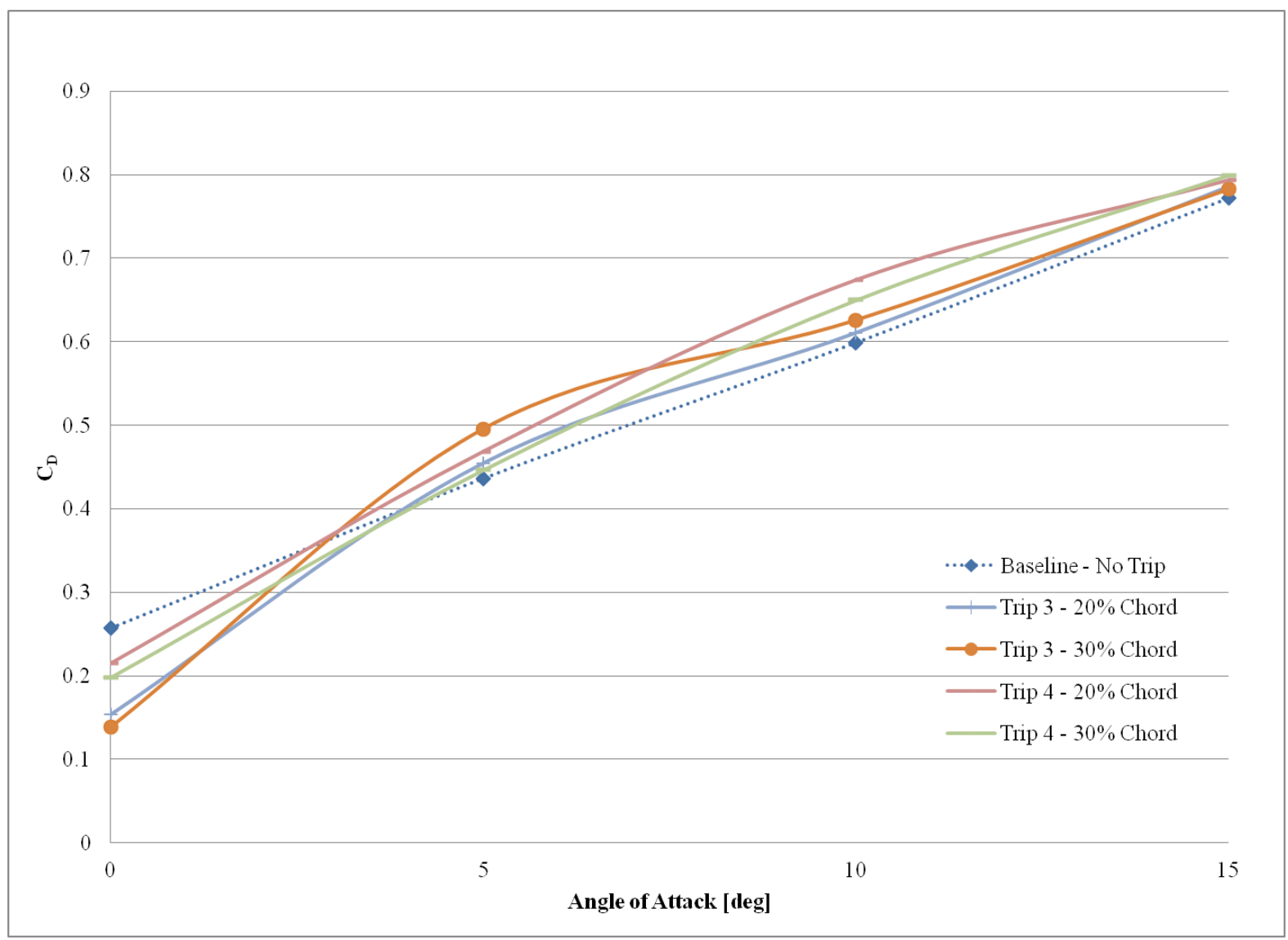

Figure 90: Boundary Layer Trips with Increasing Effectiveness - Drag Coefficients (Experimental)

Figure 91 shows the boundary layer trips that have lost their effectiveness as they have become too small to properly impact the flow at larger angles of attack. Trip 5 is compared to Trip 4 which had the peak performance off all the trip styles. Trip 5 is able to produce an improvement in the lift coefficient at $0^{\circ}$ angle of attack, but at approximately $2.5^{\circ}$ this quickly changes and is unable to out-perform Trip 4. 


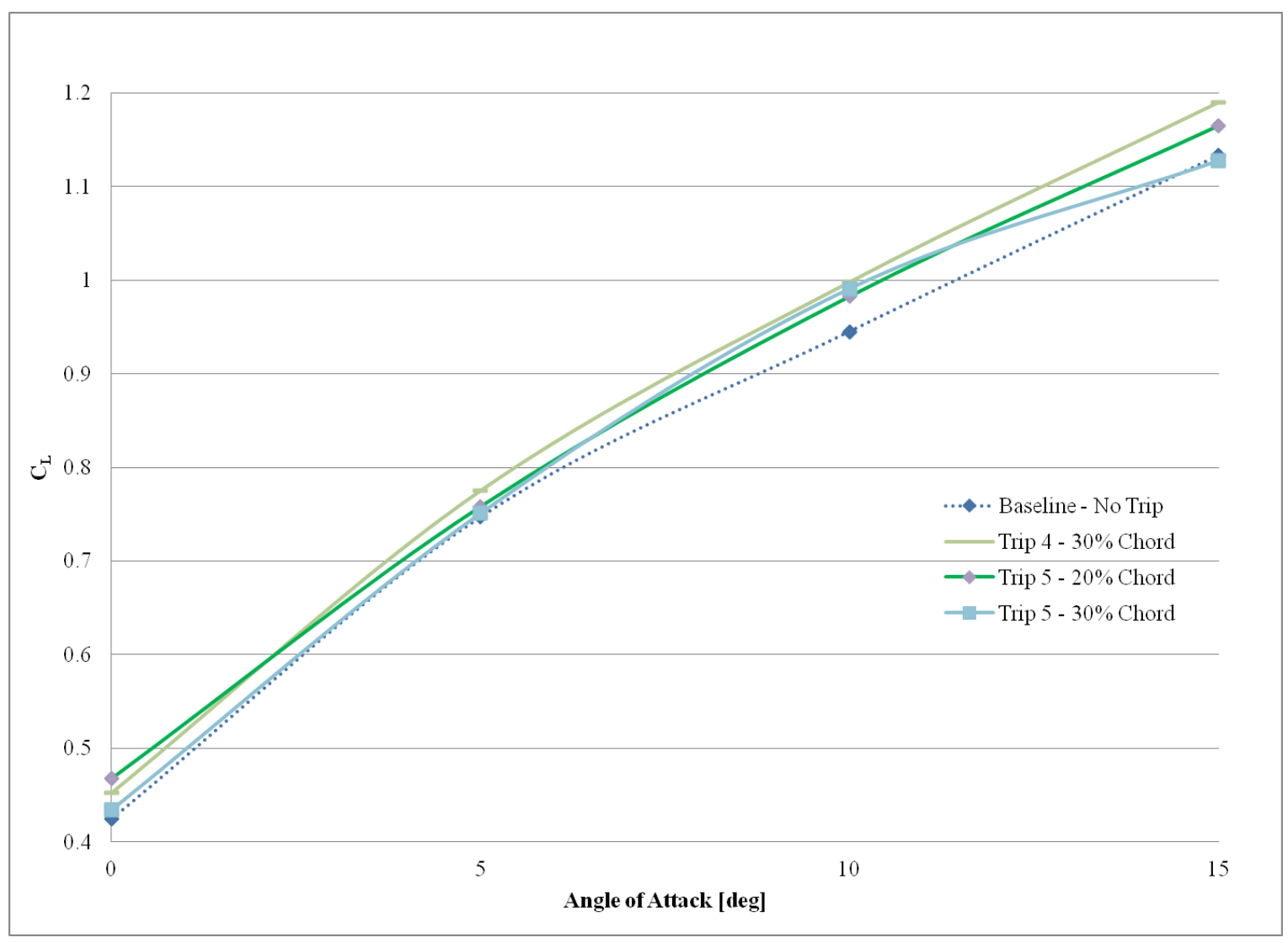

Figure 91: Boundary Layer Trips with Decreasing Effectiveness - Lift Coefficients (Experimental)

In Figure 92, the drag coefficients for the decreasingly effective boundary layer trips are shown. These shown an overall decrease in the variation of the drag coefficients as compared to Figure 90 with the exception of Trip 5 located at $30 \%$ of the chord at $15^{\circ}$ angle of attack. Given that this trip is the smallest height with which to transition the flow, it is interesting to note its influence at this location. 


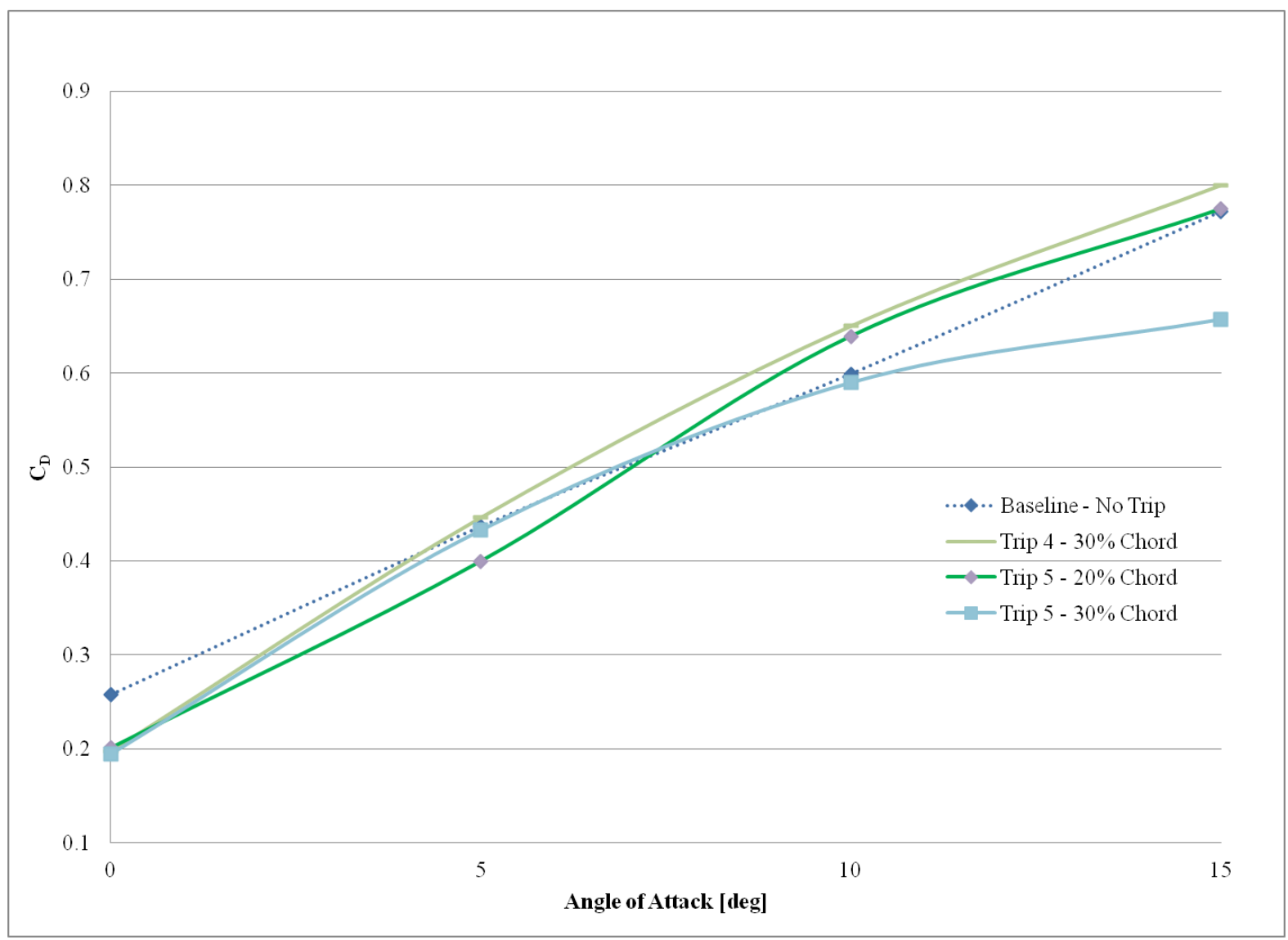

Figure 92: Boundary Layer Trips with Decreasing Effectiveness - Drag Coefficients (Experimental)

Figure 93 compares Trip 4, placed at a location 30\% of the chord from the leading edge, with an un-tripped model. There is approximately a 5\% increase that occurs over the range of angles of attack for the tripped curve as compared to the un-tripped curve. This boundary layer trip resulted in a lift slope which more closely matches with those of higher Reynolds numbers as shown previously in Figure 81. 


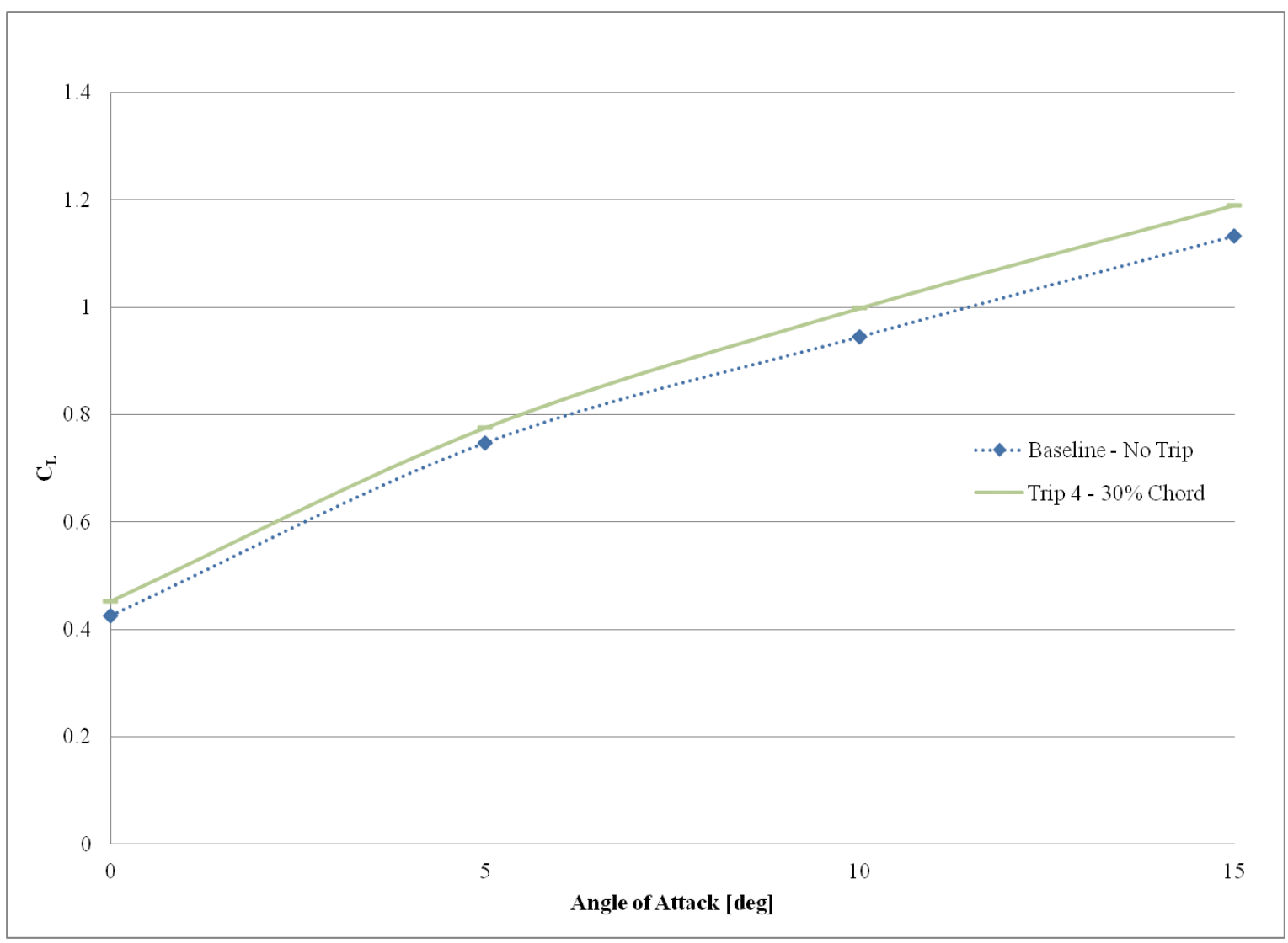

Figure 93: Most Effective Trip - Lift Coefficient (Experimental)

Figure 94 shows the drag coefficients for the boundary layer trip that was decided to have the most benefit in tripping the boundary layer flow and simulating turbulence. The drag coefficients for this trip, with the exception of $0^{\circ}$ angle of attack, show an increase over the baseline, non-tripped, case. Overall, there is a general increase in the slope of the drag coefficient line, indicating a uniform change to the body flow at varying angles of attack. 


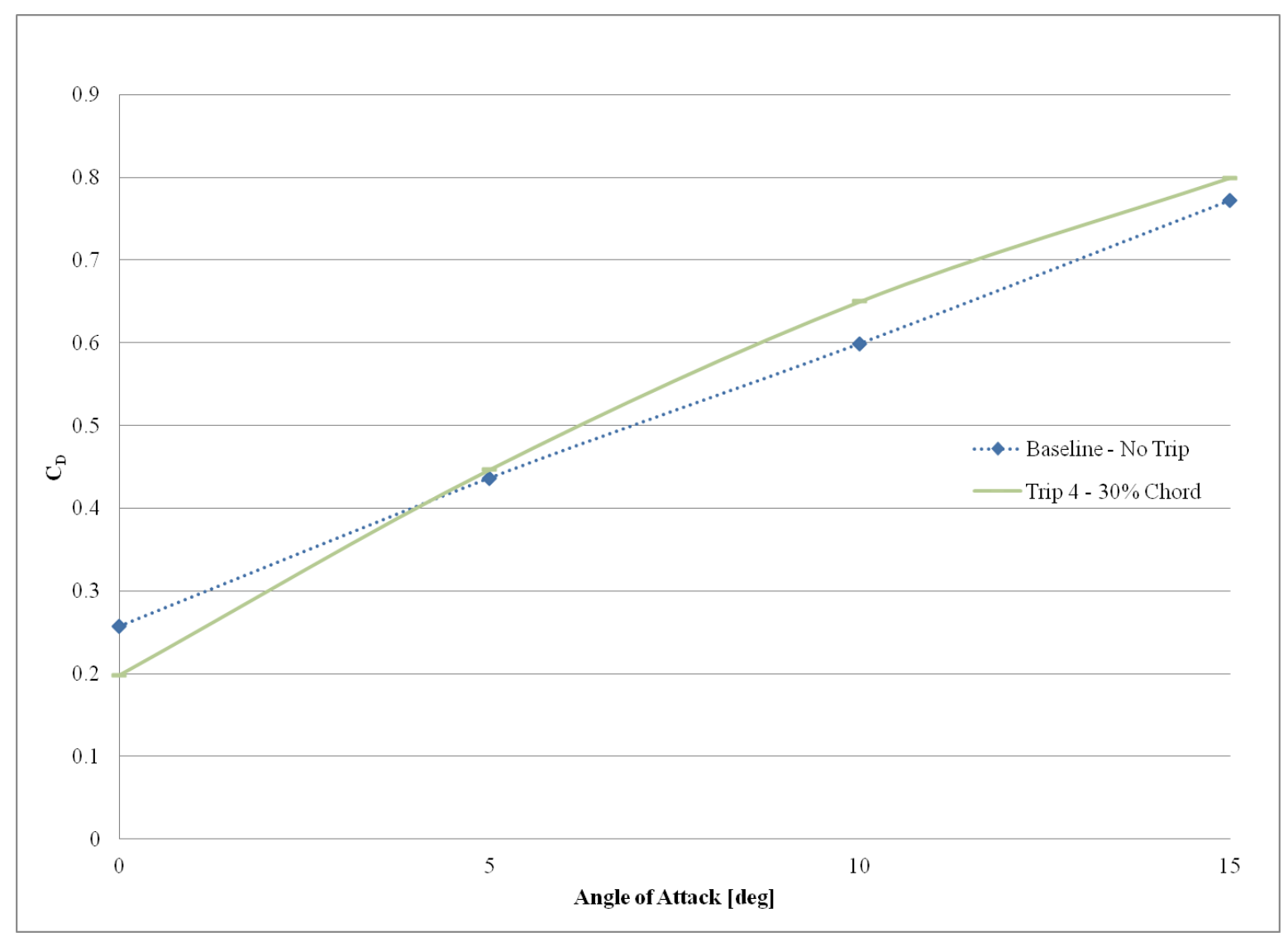

Figure 94: Most Effective Trip - Drag Coefficient (Experimental)

Overall, the use of trips is an effective means of altering the boundary layer. Through the application of various trips, a relationship was shown that developed between the height of the trip and the interaction with the boundary layer. The large aluminum trips caused flow separation to occur as a result of the height rivaling that of the boundary layer itself and therefore impeding the flow. The sand was $1 / 3$ to $1 / 6$ the size of the boundary layer height and caused an increase in the performance of the wing. The tape was $1 / 12$ the boundary layer height and showed decreases in the performance as compared to previous trips indicating a peak performance around $1 / 6$ the boundary layer height. 


\subsubsection{Baseline Model Testing}

In order to determine the accuracy of the results, the experimental values of the baseline model need to be compared to existing data from computational analysis and analytical data. For the purpose of this verification, the results were compared to computational analysis that was performed on the full scale design from which this scaled experimental model was built. In addition, analytical data was also used for lift comparison which was adapted from 2-D experimental data as demonstrated in Section 3.3. This analytical data is representative of a 3-D wing out-of-ground effect, therefore the provided lift coefficients can be up to $20 \%$ less than the experimental and computational ground effect counter-parts shown in Figure 95.

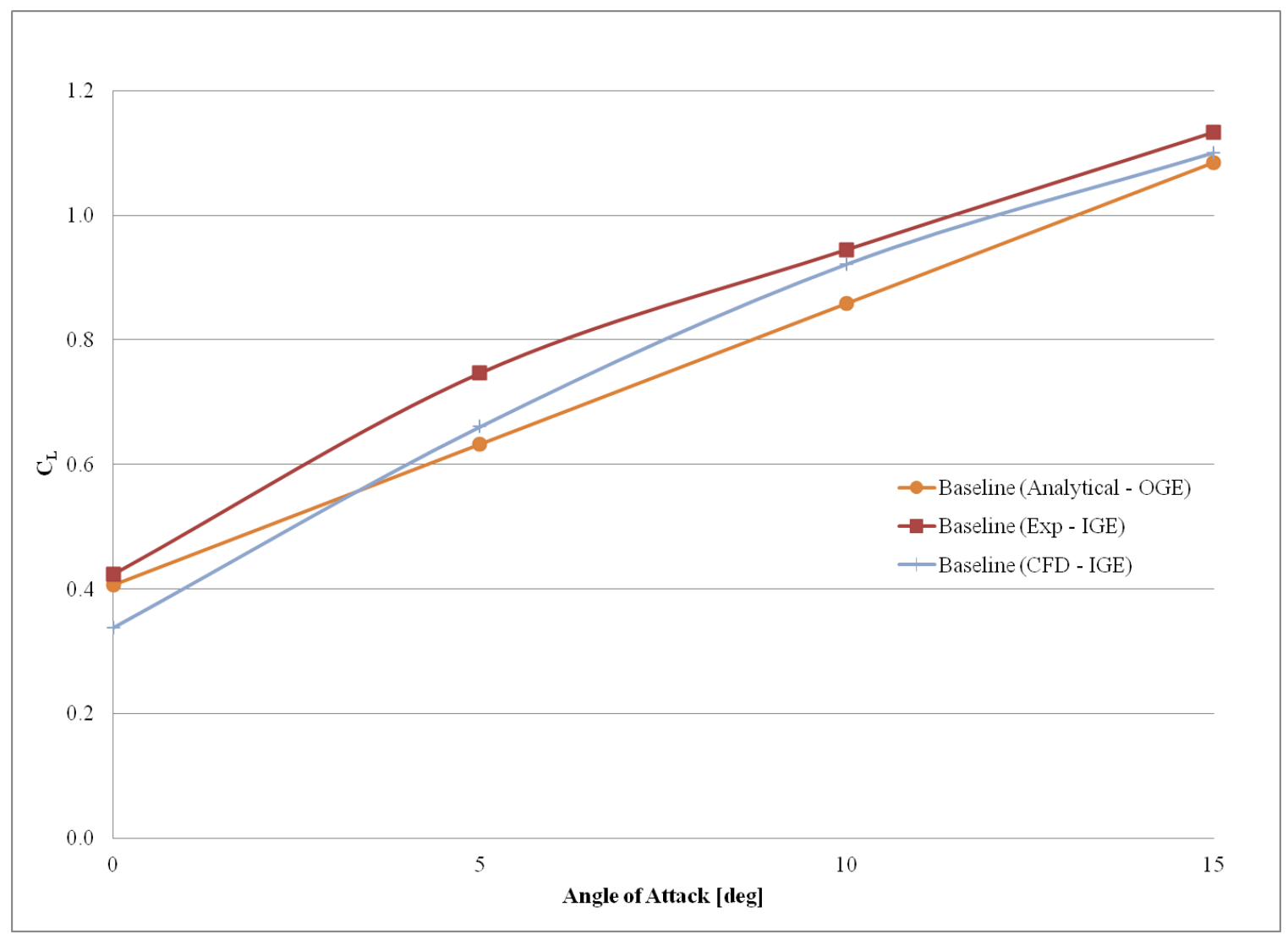

Figure 95: Lift Coefficient Comparison for Baseline Configuration 
In Figure 96, the drag coefficients are plotted against the lift coefficients which show a higher drag coefficient for the experimental wind tunnel testing. This could be in part to the physical nature of the wing containing imperfections, such as where the material overlaps itself and creates an edge, resulting in an increase of drag. This could also be a result of a significant increase in the configuration base drag over the theoretical predictions due to the relatively low aspect ratio fuselage. The analytical drag coefficients were found in the same manner described previously in Section 3.4 and are representative of out-of-ground effect values. The use of the ground effect regime for flight allows for a potential decrease in the induced drag up to $10 \%$, however due to the type of ground-effect generated (i.e. chord-wise dominated); this reduction is perceived to not occur.

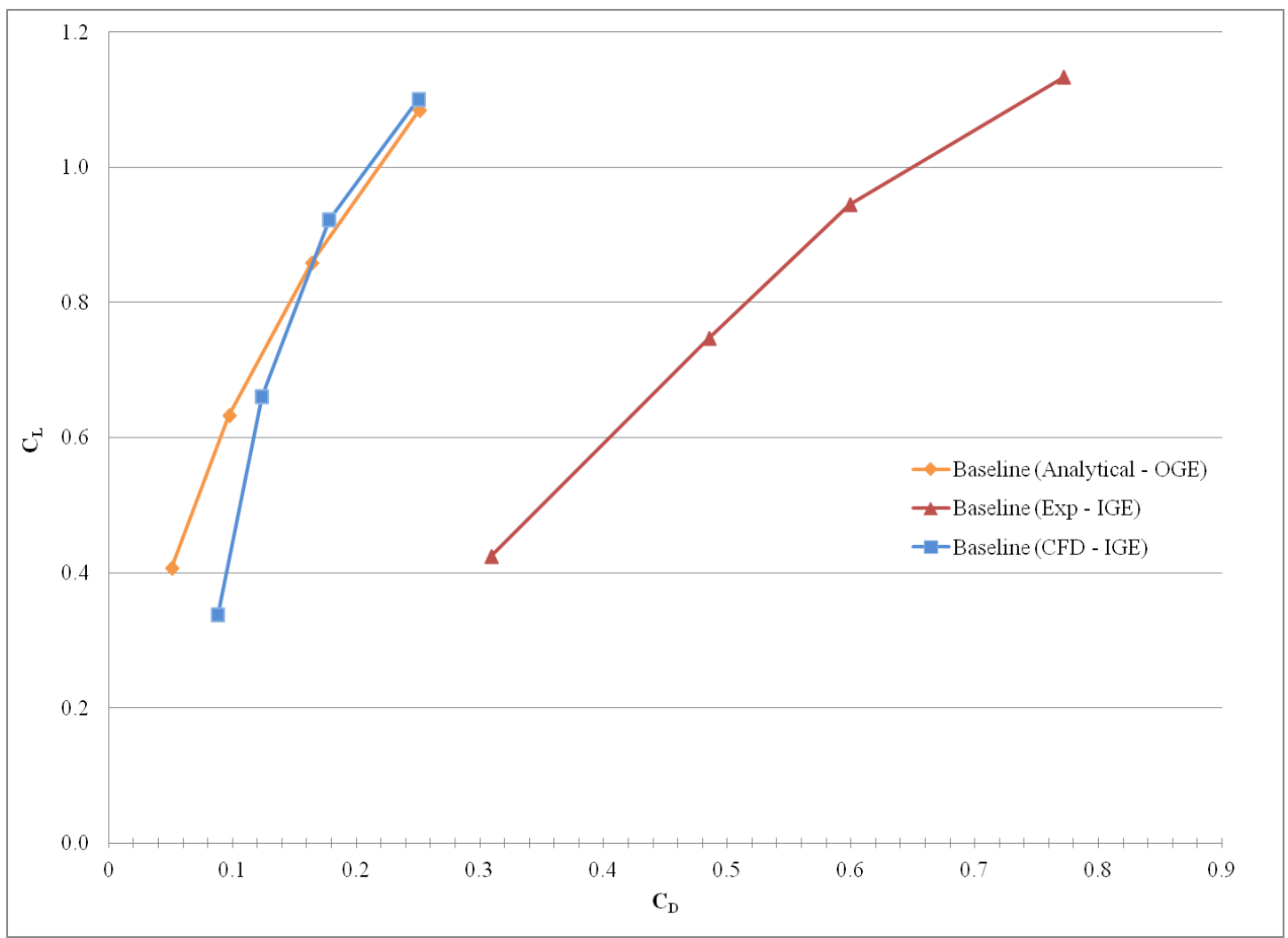

Figure 96: Drag Coefficient Comparison 


\subsubsection{Twisted Model Testing}

Variations in the classical wing form were examined in ground effect, including the configuration with a twist that peaked in the center of each wing wherein the trailing edge remained flat and the leading edge contained a curve. The lift benefit of two amounts of twist, were examined experimentally and compared to work that was performed computationally as shown in Figure 97.

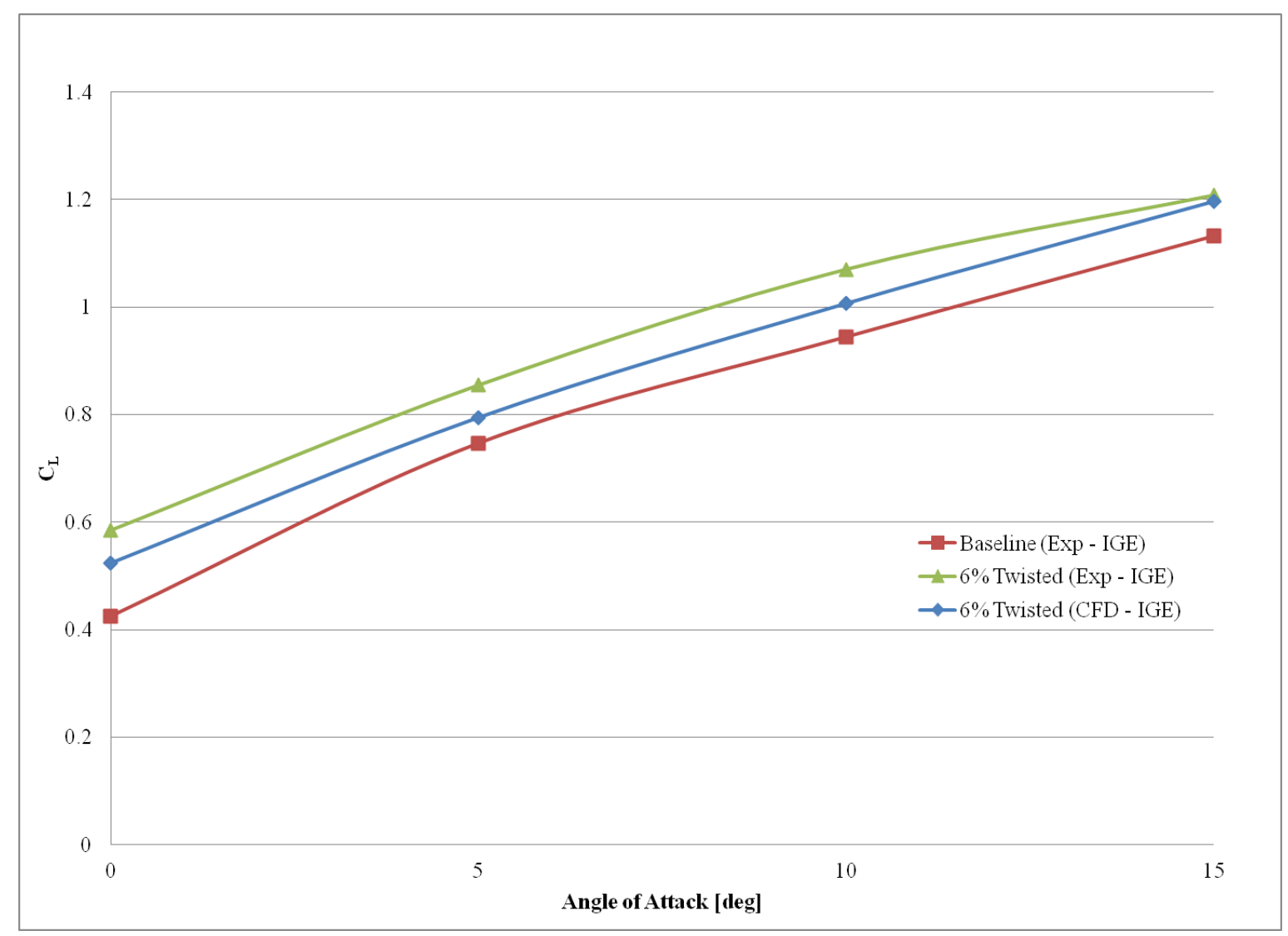

Figure 97: Comparison of Lift for 6\% Twisted Model

Figure 97 shows a distinct improvement of the twisted models both experimentally and in CFD as compared to the in-ground-effect experimental baseline. The improvements are more dramatic in the wind tunnel testing reaching as high as $38 \%$ improvement over the baseline 
model at $0^{\circ}$ angle of attack as shown in Table 19. The experimental data showed a small increase over the CFD as well with as much as a $12 \%$ increase at $0^{\circ}$ angle of attack, tapering off to $1 \%$ at $15^{\circ}$ angle of attack. The improvement of twisted wings is the most beneficial at lower angles of attack which for this particular application, is where the benefit is needed the most.

Table 19: Lift Analysis from 6\% Twisted Mo
\begin{tabular}{|c|c|c|}
\hline & $6 \%$ Twisted as Compared to: \\
\hline AoA & CFD & Baseline \\
\hline 0 & $12 \%$ & $38 \%$ \\
\hline 5 & $8 \%$ & $14 \%$ \\
\hline 10 & $6 \%$ & $13 \%$ \\
\hline 15 & $1 \%$ & $7 \%$ \\
\hline
\end{tabular}

For the $6 \%$ twisted model, the drag coefficient was also shown experimentally to be higher than the CFD prediction at similar lift coefficients. The shape of the drag curve is respective of being in the drag bucket, with the decrease shown experimentally for decreasing $\mathrm{C}_{\mathrm{L}}$ shaping the one side of the bucket. The bucket side is reflected by the solitary experimental data point that was shown to demonstrate the bucket edge. Further investigation should occur to round out the drag bucket and fill in additional points. This was outside the scope of the current work. The $\mathrm{C}_{\mathrm{D}}$ of the experimental $6 \%$ twisted shape shows a decrease as compared to the experimental baseline which is known to occur in ground effect from induced drag reduction. This primarily occurs when the wing tip and/or trailing edge vortices are unable to develop as a result of ground proximity. In this case, the trailing edge of the twisted wing is channeling the flow from the body and forcing it through a narrow opening created by the trailing edge with respect to the ground. This is creating a higher pressure location on the underside of the trailing edge, than what would be seen with the spanwise curvature wing. This in turn is changing the formation of the vortex generation and presumably reducing its effects. 


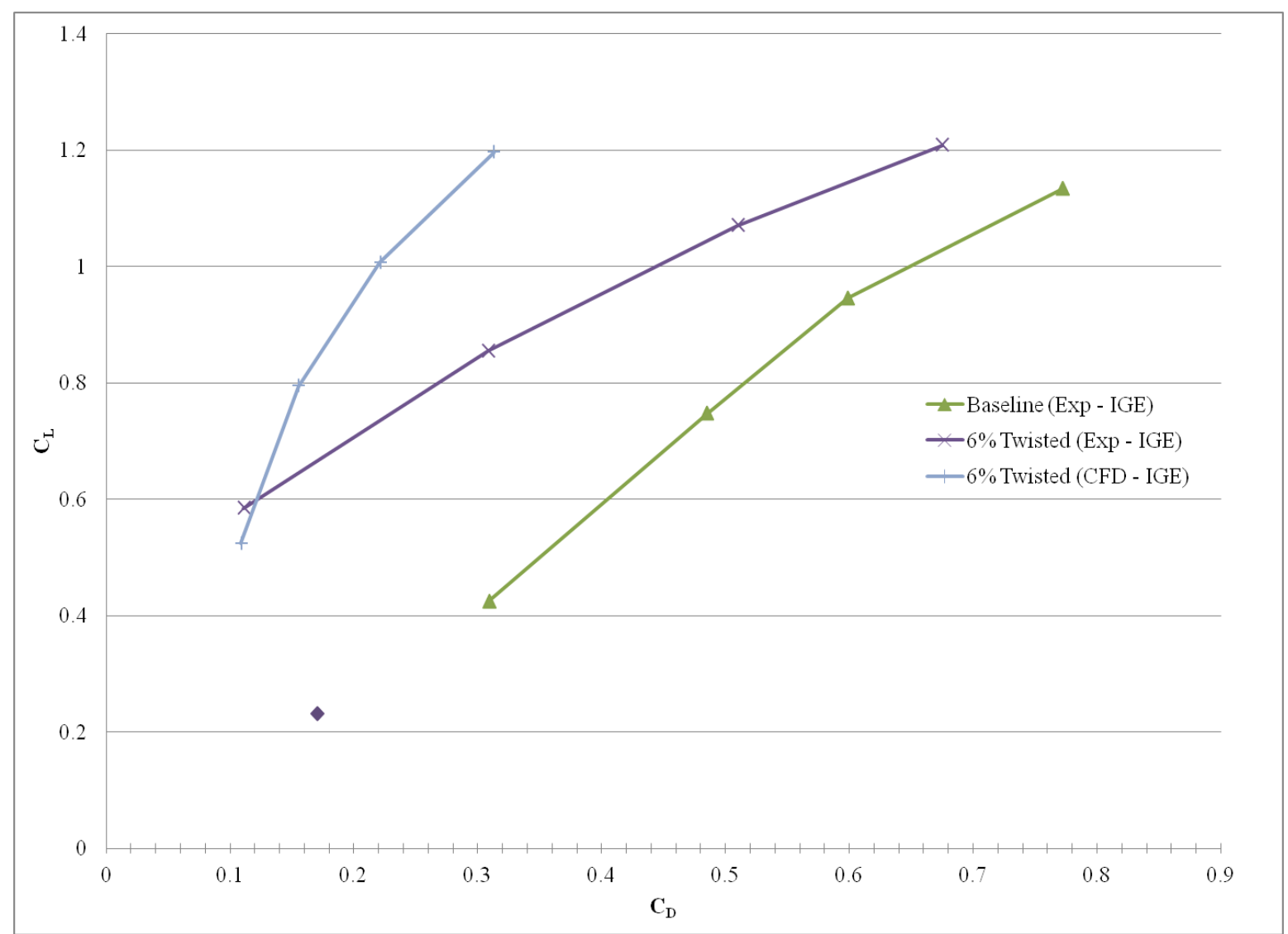

Figure 98: Comparison of Drag for 6\% Twisted Model

The $10 \%$ twist model was also tested experimentally to indentify whether a gradual improvement in lift was present as twist increased, which was predicted in the CFD. As shown in Figure 99, the experimental model is within $10 \%$ of the CFD model, demonstrating concurrence with the prediction, which both show a marked improvement over the experimental baseline. 


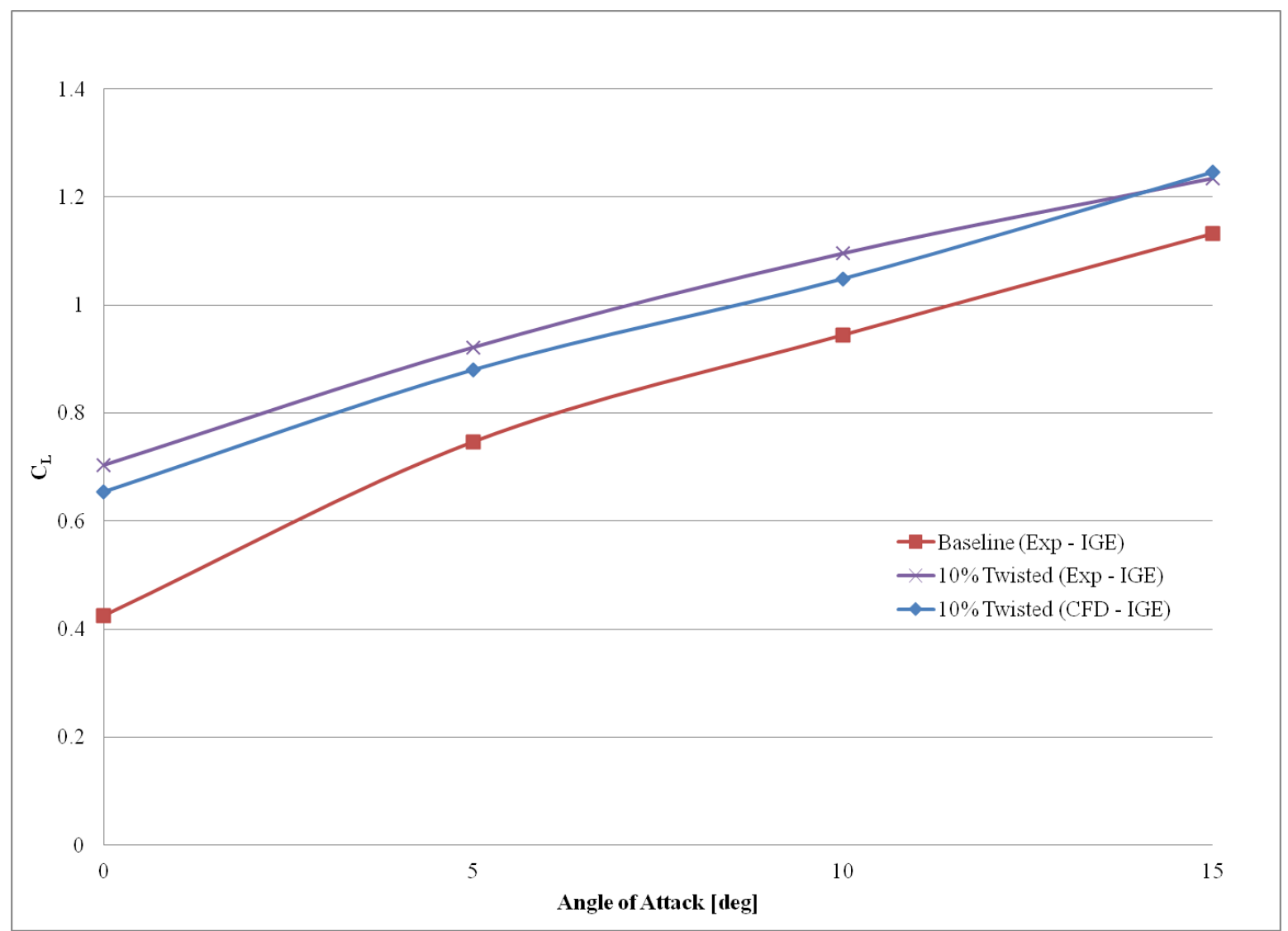

Figure 99: Comparison of Lift for 10\% Twisted Model

The amount of improvement is shown in Table 20, which compares the experimental twisted model to the baseline as well as the CFD model. The experimental $10 \%$ twisted model has almost doubled the amount of improvement of the experimental $6 \%$ twisted model case at lower angles of attack. At $15^{\circ}$ angle of attack, the CFD actually predicts a slightly higher lift coefficient than what was found in the wind tunnel testing, however this could be a result of either experimental or computational error as will be discussed in Section 5.2.6. 
Table 20: Lift Analysis from 10\% Twisted Model

\begin{tabular}{|c|c|c|}
\hline & \multicolumn{2}{|c|}{$10 \%$ Twisted as Compared to: } \\
\hline AoA & CFD & Baseline \\
\hline 0 & $8 \%$ & $66 \%$ \\
\hline 5 & $5 \%$ & $23 \%$ \\
\hline 10 & $5 \%$ & $16 \%$ \\
\hline 15 & $-1 \%$ & $9 \%$ \\
\hline
\end{tabular}

The $10 \%$ twisted drag model, like the $6 \%$ twisted drag model, shows the characteristic slope that is present with being in the drag bucket with one end of the drag bucket being shown in the experimental data for the twisted model only. This end of the drag bucket was found through additional testing at $-5^{\circ}$ angle of attack as is shown as a solitary point.

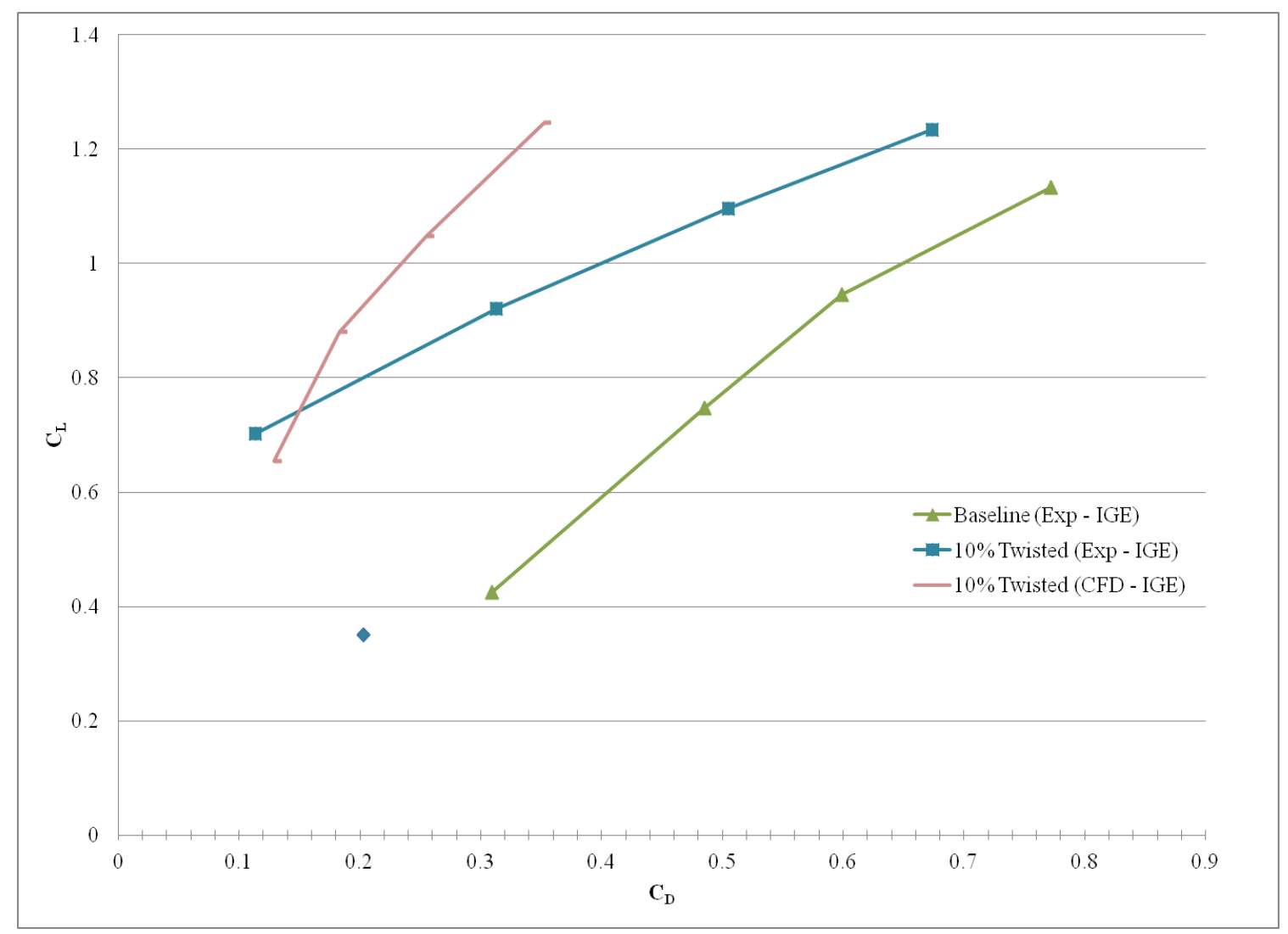

Figure 100: Comparison of Drag for 10\% Twisted Model 


\subsubsection{Spanwise Curvature Model Testing}

Another variation in the classic wing form is the use of dihedral spanwise wing curvature. This method, unlike the twisted approach, does not increase the capture area, but simply relocates the cross-sectional airfoil shape to a different location along the span. As shown in Figure 101, experimentally the curved model does not perform as well as the baseline model which was also found in the CFD predictions of performance.

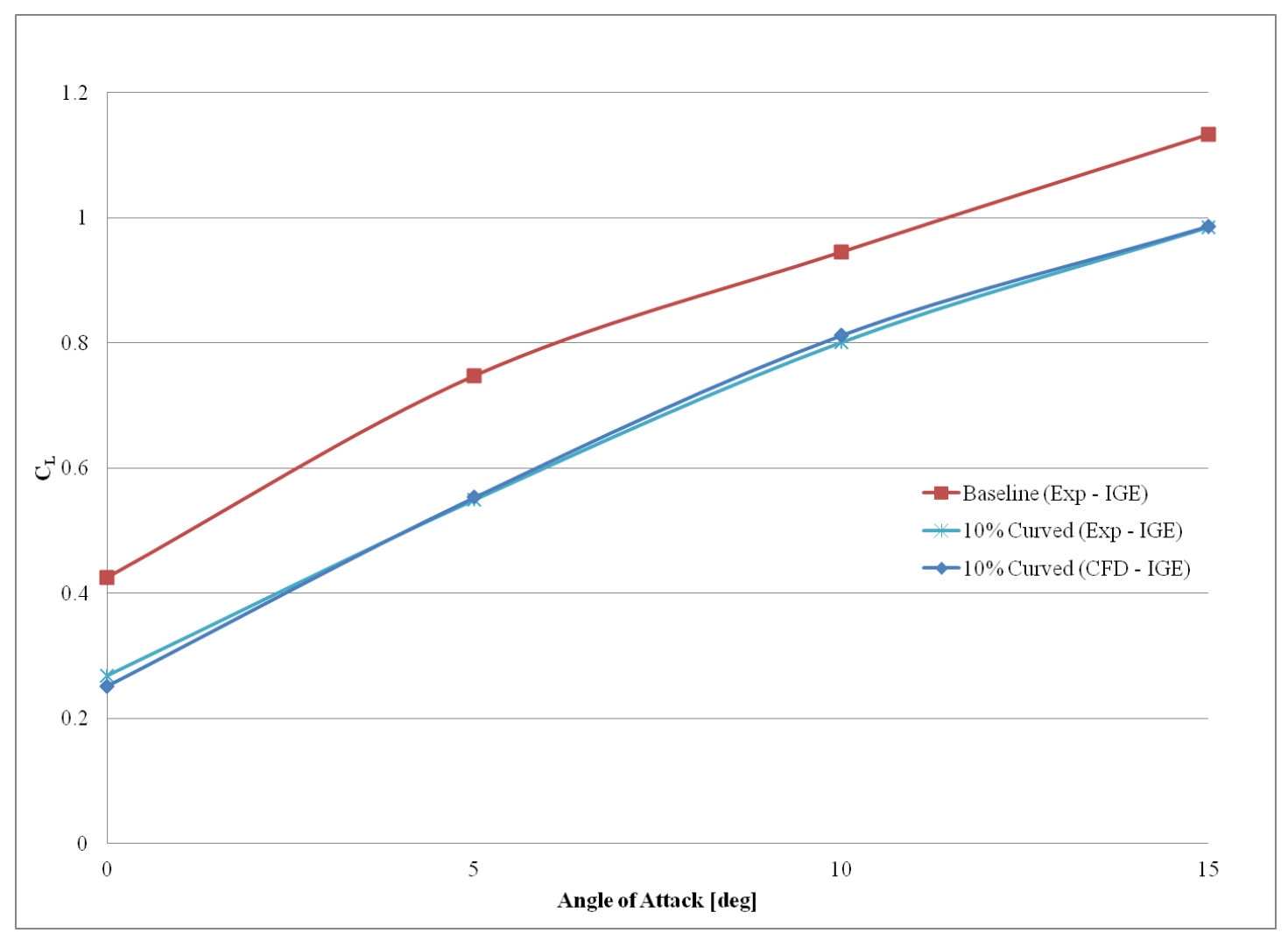

Figure 101: Comparison of Lift for 10\% Curved Model

With the exception of some minor variation at $0^{\circ}$ angle of attack, the CFD and experimental curved models are within a few percentage points of each other as shown in Table 21. 
Table 21: Lift Analysis from 10\% Curved Model

\begin{tabular}{|c|c|c|}
\hline & \multicolumn{2}{|c|}{$10 \%$ Curved as Compared to: } \\
\hline AoA & CFD & Baseline \\
\hline 0 & $6 \%$ & $-37 \%$ \\
\hline 5 & $-1 \%$ & $-27 \%$ \\
\hline 10 & $-1 \%$ & $-15 \%$ \\
\hline 15 & $0 \%$ & $-13 \%$ \\
\hline
\end{tabular}

The drag coefficients for the experimental curved model are shown in Figure 102 as compared to the CFD curved model and the experimental baseline model. The curved drag values are similar to those of the baseline with little variation. The similarity is due to the likeness in the frontal areas and general profiles of the wings. The curved model has a slightly larger wing area, accounting for the increase in the drag on the skin.

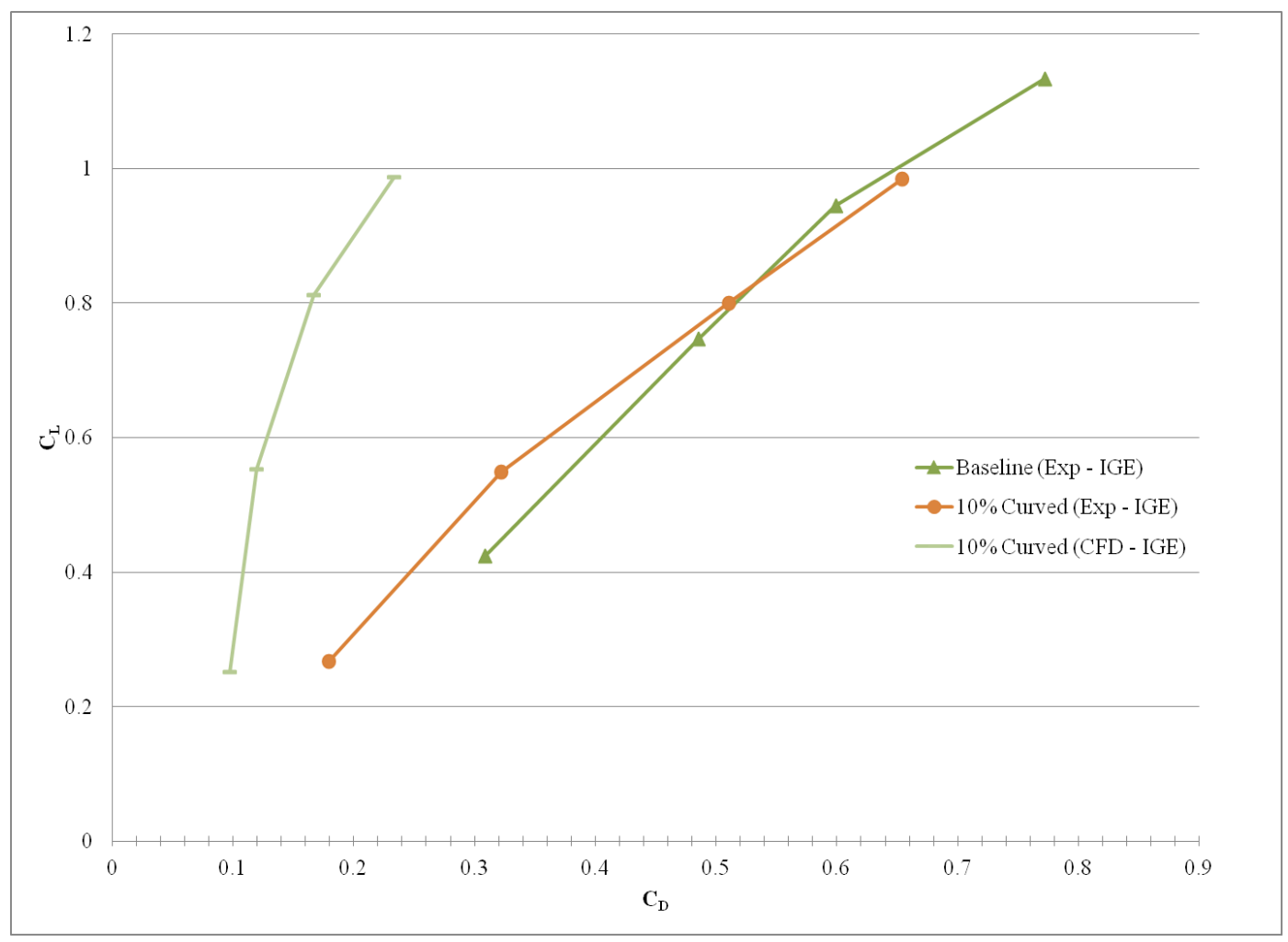

Figure 102: Comparison of Drag for 10\% Curved Model 


\subsubsection{Error Analysis}

The instrumentation error was examined for the measured forces taken during the experimental tests. Equation 21 shows the formula for determining the uncertainty created by the instruments, both electronic and hand-held.

$$
u_{R}=\left[\left(\frac{\partial R}{\partial x_{1}} u_{1}\right)^{2}+\left(\frac{\partial R}{\partial x_{2}} u_{2}\right)^{2}+\cdots+\left(\frac{\partial R}{\partial x_{i}} u_{i}\right)^{2}\right]^{2}
$$

The resultant uncertainty, $u_{R}$, is a measurement corresponding to a measured result, $R$, and the measure quantities, $x_{i}$, from which $\mathrm{R}$ is a function. The measured quantities $x$, in which $i$ indicates a variety of quantities, each have a component of uncertainty as shown in Equation 22.

$$
x_{i}=x_{\text {measured }, i} \pm u_{i}
$$

Equation 22

The two measured experimental resultants were the lift and drag forces which were equated to lift and drag coefficients. Each of these has uncertainty in the measured value as a result of error introduced through the calibration equipment, measuring devices, etc. In the case of the lift coefficient, $\mathrm{C}_{\mathrm{L}}=\mathrm{f}(\mathrm{T}, \mathrm{P}, \rho, \mathrm{L}, \mathrm{V})$. Therefore, partial derivates will need to be taken of all these quantities, with the exception of density, since it is a function of pressure and temperature. The resulting partial derivatives are shown in Equation 23 through Equation 26.

$$
\begin{gathered}
\frac{\partial C_{L}}{\partial T}=\frac{2 L R}{P V^{2} A} \\
\frac{\partial C_{L}}{\partial P}=\frac{-2 L R T}{P^{2} V^{2} A} \\
\frac{\partial C_{L}}{\partial L}=\frac{2 R T}{P V^{2} A}
\end{gathered}
$$




$$
\frac{\partial C_{L}}{\partial V}=\frac{-4 R T}{P V^{3} A}
$$

The partial derivates can then be applied to Equation 21, as shown in Equation 27, where $u_{1}$ through $u_{4}$ are uncertainties of each measuring device, shown in Table 22.

$$
u_{R}=\left[\left(\frac{2 L R}{P V^{2} A} u_{1}\right)^{2}+\left(\frac{-2 L R T}{P^{2} V^{2} A} u_{2}\right)^{2}+\left(\frac{2 R T}{P V^{2} A} u_{3}\right)^{2}+\left(\frac{-4 R T}{P V^{3} A} u_{4}\right)^{2}\right]^{2}
$$

These devices were used to take the data and will produce an uncertainty for each lift coefficient calculated. As an example of the resulting error, a calculation was performed for the free-stream (OGE) baseline case at $0^{\circ}$ angle of attack, and resulted in an error of approximately $\pm 0.0034 \%$.

Table 22: Uncertainties of Measurement Device as Percent of Reading

\begin{tabular}{|l|r|}
\hline Bridge Balance & $0.10 \%$ \\
\hline Barometer & $0.03 \%$ \\
\hline Thermometer & $1.43 \%$ \\
\hline Manometer & $11.11 \%$ \\
\hline
\end{tabular}

For the drag coefficient case, $\mathrm{C}_{\mathrm{D}}=\mathrm{f}\left(\mathrm{T}, \mathrm{P}, \rho, \mathrm{L}, \mathrm{V}, \mathrm{C}_{\mathrm{L}}\right)$, where $\mathrm{C}_{\mathrm{L}}$ is now included as a result of the interference it provides in the $C_{D}$ calculation that must be taken into account. Therefore, the uncertainty calculation for $C_{D}$ will include all terms previously mentioned in the $C_{L}$ calculation and shown in Equation 23 through Equation 26. The new terms used for the $C_{D}$ are shown in Equation 28 through Equation 31.

$$
\begin{gathered}
\frac{\partial C_{D}}{\partial T}=\frac{2 D R}{P V^{2} A} \\
\frac{\partial C_{D}}{\partial P}=\frac{-2 D R T}{P^{2} V^{2} A}
\end{gathered}
$$

Equation 28

Equation 29 


$$
\begin{gathered}
\frac{\partial C_{D}}{\partial L}=\frac{2 R T}{P V^{2} A} \\
\frac{\partial C_{D}}{\partial V}=\frac{-4 R T}{P V^{3} A}
\end{gathered}
$$

Once the terms have been placed in the uncertainty equation, as shown in Equation 32, then the error as a result of instrumentation can be known. An example of this error for the free-stream (OGE) baseline case at $0^{\circ}$ angle of attack is $0.0035 \%$.

$$
\begin{gathered}
u_{R}=\left[\left(\frac{2 L R}{P V^{2} A} u_{1}\right)^{2}+\left(\frac{-2 L R T}{P^{2} V^{2} A} u_{2}\right)^{2}+\left(\frac{2 R T}{P V^{2} A} u_{3}\right)^{2}+\left(\frac{-4 R T}{P V^{3} A} u_{4}\right)^{2}\right. \\
\left.+\left(\frac{2 D R}{P V^{2} A} u_{5}\right)^{2}+\left(\frac{-2 D R T}{P^{2} V^{2} A} u_{6}\right)^{2}+\left(\frac{2 R T}{P V^{2} A} u_{7}\right)^{2}+\left(\frac{-4 R T}{P V^{3} A} u_{8}\right)^{2}\right]^{2}
\end{gathered}
$$

\subsubsection{Results Summary}

Overall the variation in wing planform shape produced interesting results in the aerodynamic performance of the glider. As shown comparatively in Figure 103, the twisted wing creates the most lift enhancement as a result of the increase in the capture area. The spanwise curvature wing, due to its lack of increased capture area and variation in airfoil position along the span, caused a noticeable decrease in the lift performance. 


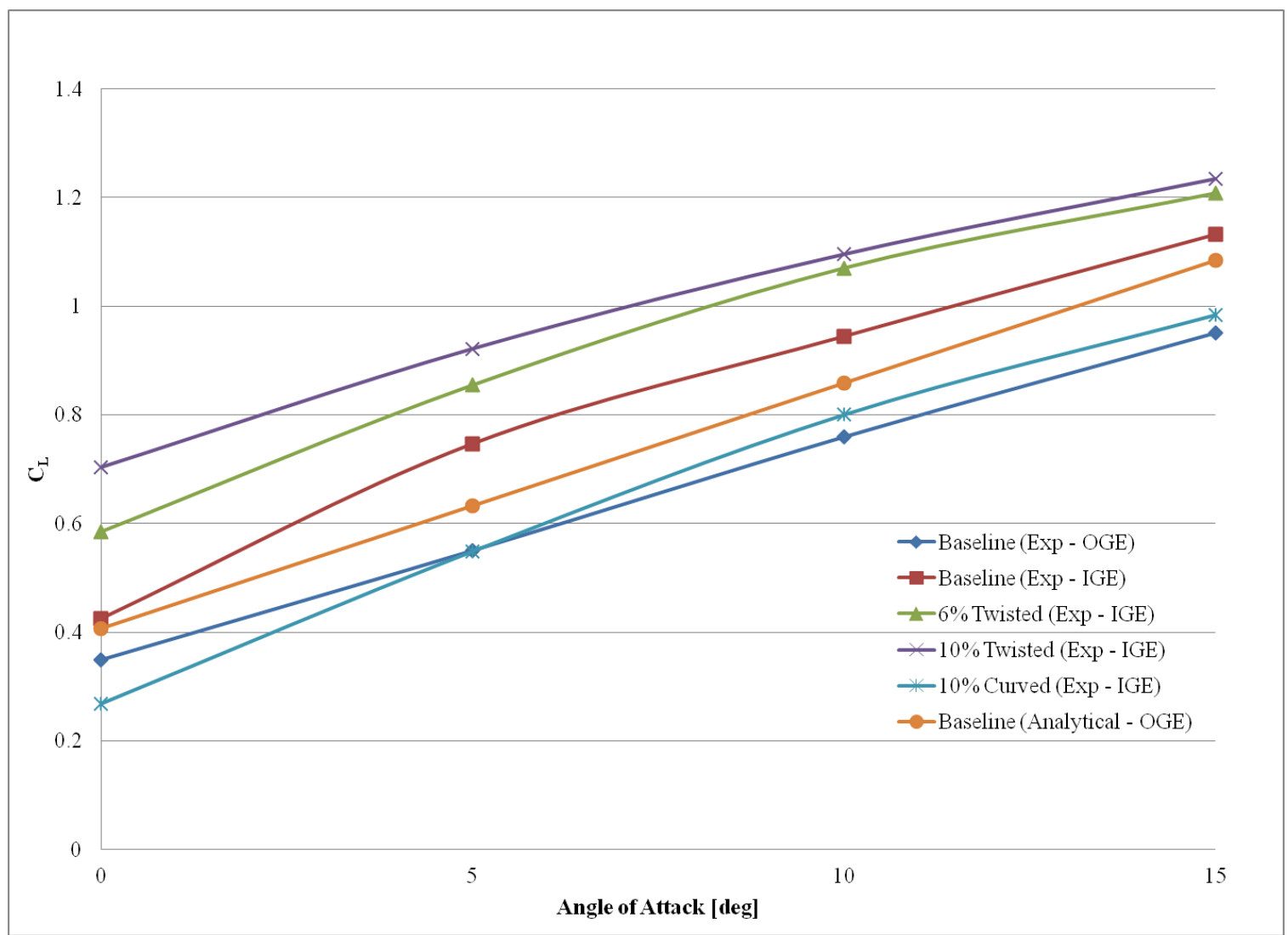

Figure 103: Overall Lift Comparison

The drag values are split among the two groupings of styles; group 1 is the baseline and spanwise curvature styles which have similar frontal profiles, and group 2 contains the twisted styles which have a larger frontal profiles. Group 1, as shown in Figure 104, is bunched together and has similar amounts of drag acting on the models. Group 2, the two twisted cases, demonstrated a substantial shift from the drag polars shown in the baseline and spanwise curvature cases. The variation in the wing structure allows for an increase in the capture area and thus a large increase in lifting force, while maintaining similar amounts of drag. 


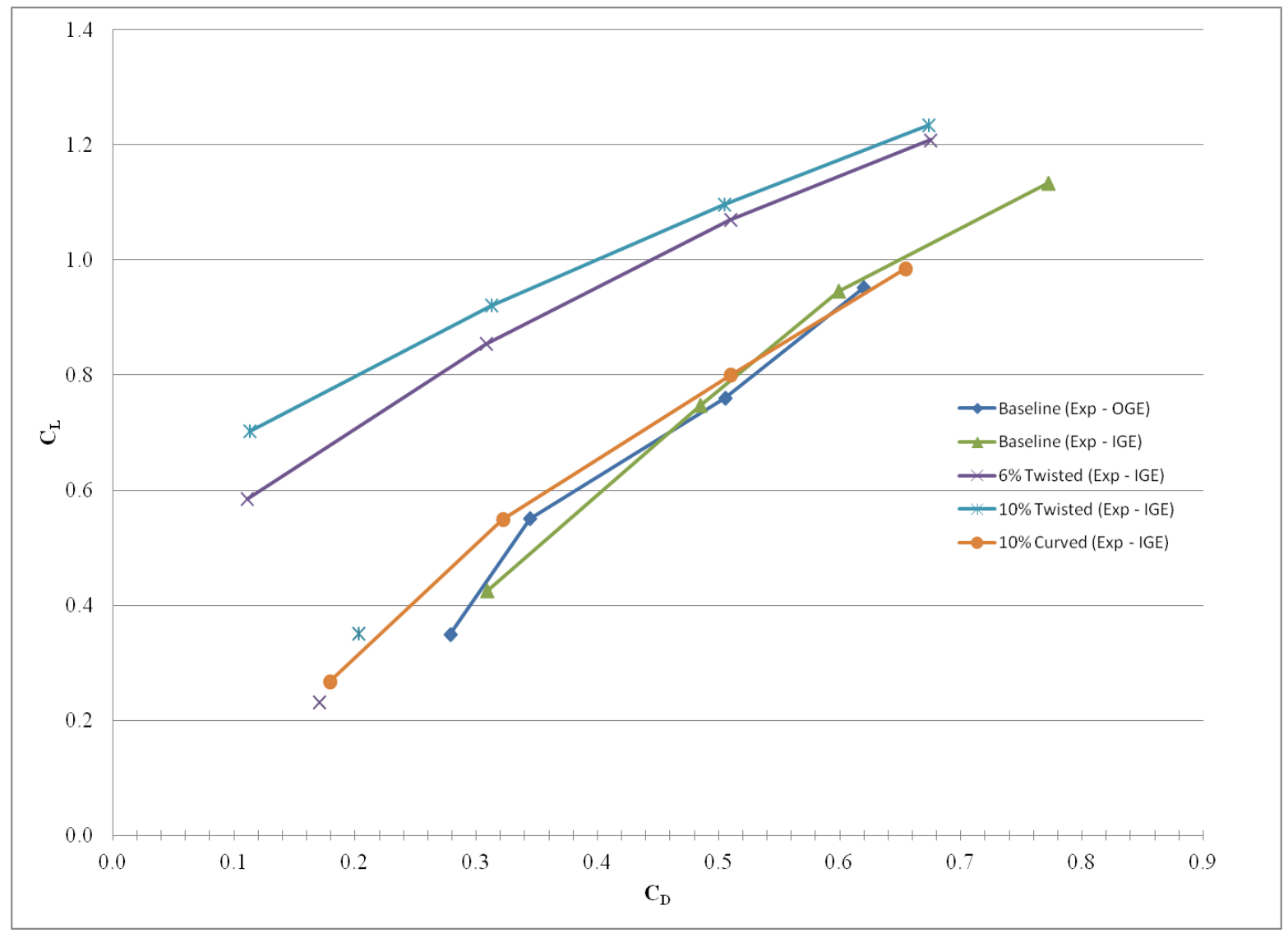

Figure 104: Overall Drag Comparison 


\section{Chapter 6.0 Conclusions}

The main objective of this research was to correctly size the wing and minimize the planform shape in order to maintain flight and prevent leaving the ground effect regime. This reduction in span, caused by an increase in the lift performance, would also increase the maneuvering capability of the glider by allowing smaller banking angles and turning radii.

The improvement in the lift capabilities presented through the use of the twisted wings allows for improvements to be made on the overall design and size of the glider. With a $\mathrm{C}_{\mathrm{L}}=0.92$, at $5^{\circ}$ angle of incidence, this allows for a $4.5 \%$ reduction in the overall size of the glider. This lift coefficient is approximately $7 \%$ improved over the lift coefficient that was used to design the baseline straight wing model analytically which was adapted from 2-D data and then adjusted by $20 \%$ to account for the predicted ground effect benefit. The reduction in the overall size also allows for a $0.5^{\circ}$ increase in the banking angle of the glider. While not widely improving its maneuverability, this will increase the rate at which it turns. In addition, there is a drag reduction that occurs with this style of wing. In the current application, drag is necessary in order to restrict the safe maximum speed and to minimize the rider's ability to exceed this.

The final design included a $4.5 \%$ reduction in the overall size which resulted in a wing span of $17.4 \mathrm{ft}$ and a root chord length of $10.23 \mathrm{ft}$. The front view of the final design is shown in Figure 105 and reflects the use of the $10 \%$ twisted wings with a rounded seat back section and a flattened canopy. 


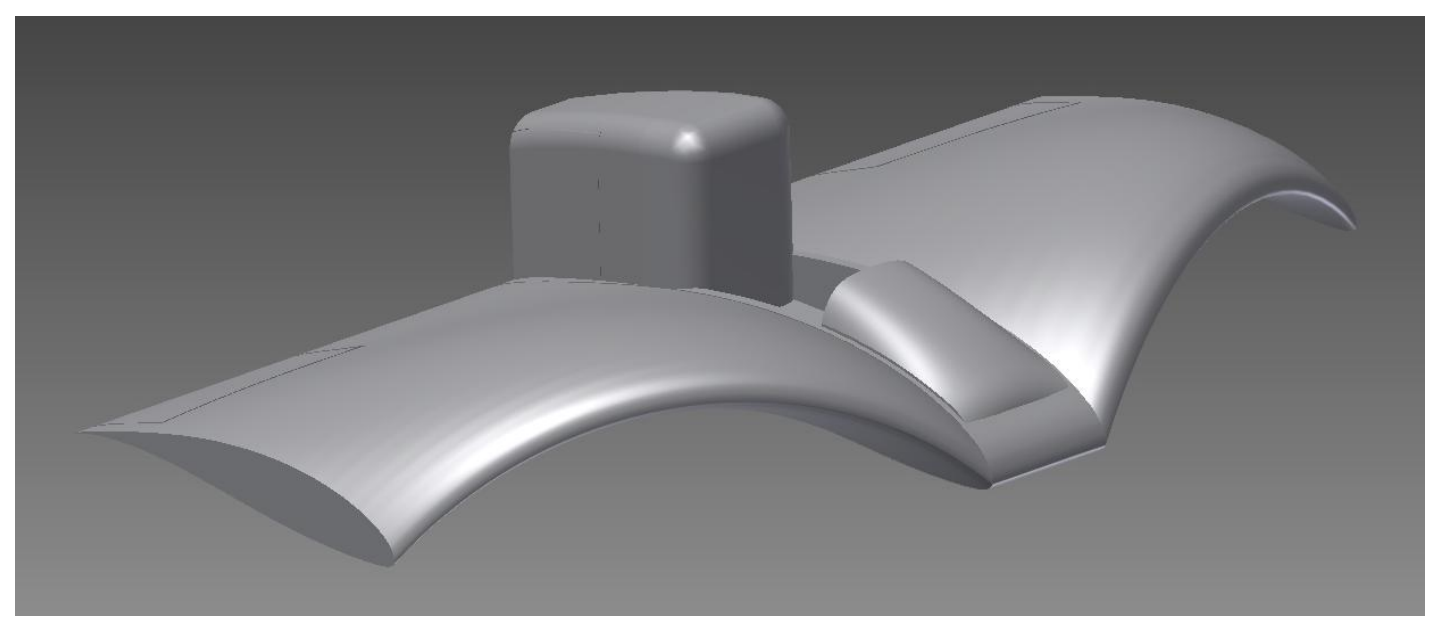

Figure 105: Final Design (front view)

The back view of the final design is shown in Figure 106, showing the split tail sections with vertical rudders on each side and flaperon placement.

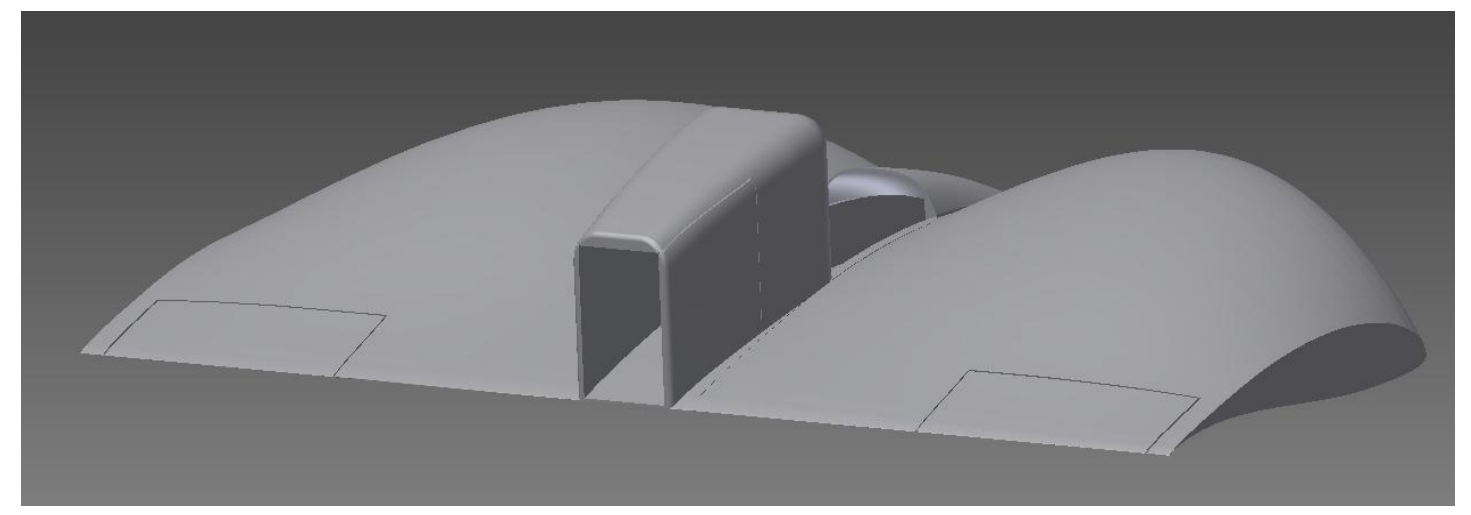

Figure 106: Final Design (back view)

The use of ground effect has been around for over a century with many contributions being added over time. The application of ground effect to a low speed, gravity propelled glider is a unique addition to this field. The use of biomimicry to alter the wing structure and enhance the flight performance of this glider in the ground-effect regime is also another novel addition. The data gained from this research into the flight characteristics of arc dihedral/anhedral and twist in-ground-effect provides a useful contribution to the understanding of flight over the 
ground. This research can be applied not only to AirRay, as a gravity propelled aircraft, but to any powered aircraft that operates in ground proximity flight. This could lead to new avenues of low-speed, single or multi, rider aircraft that would have commercial and military applications such as scout vehicles, border patrol, or for towing vehicles which are capable of flying over minefields.

\subsection{Recommendations}

The next step in the progression of this research would be to examine the effects of moving the location of maximum curvature and twist along the semi-span. For this case, the effects were examined with the flexure point located at half the semi-span, however, bird wings vary this location demonstrating additional flexure points ranging from a quarter the distance of the semi-span from the root to a quarter the distance of the semi-span from the tip of the wing.

As a step further to this, the drag characteristics could be examined on a broad range of twist profiles in-ground-effect, from varying flexure points to a range of maximum heights to further explore the change in drag seen in 5.2.4.

Another step in this research could include examining the integration of passive pitch slots, from previous 2-D AirRay research, into the twisted wing design to test overall performance. This work would determine if additional benefits were present or if these concepts were even compatible.

The eventual progression of this research will be to build a full-scale prototype and test in real-world scenario. This will ensure all functionality has been met to specified requirements. 


\section{Chapter 7.0 References}

1. Williams, Kenneth. Concept of AirRay. 2007.

2. The Main Research Problems Solved in Designing Russian Ekranoplans and which are Necessary to be Solved for Wide Practical Realization of Ekranoplans. Mashalik, A.I. Toulouse, France : s.n., June 2001. EAGES 2001 International Ground Effect Symposium.

3. History of Flight. [Online] 2003. http://www.century-of-flight.net/index.htm.

4. Anderson, John D. Fundamentals of Aerodynamics. NewYork, NY : McGraw-Hill, 2007.

5. Corke, Thomas C. Design of Aircraft. Upper Saddle River, NJ : Prentice Hall, 2003.

6. Bertin, John J. Aerodynamics for Engineers. Upper Saddle River, NJ : Prentice Hall, 2002.

7. Raymer, Daniel P. Aircraft Design: A Conceptual Approach. Reston, VA : AIAA Education Series, 1999.

8. Langevin, Gail S. Office of External Affairs - NASA Langley Research Center. [Online] October 7, 2003. http://oea.larc.nasa.gov/PAIS/Concept2Reality/winglets.html.

9. Demonstration of an in situ morphing hyperelliptical cambered span wing mechanism.

Manzo, Justin and Ephrahim Garcia. 2, 2010, Smart Materials and Structures, Vol. 19.

10. Wing design and scaling of flying fish with regard to flight performance. Fish, F.E. 1990, Journal of Zoology, Vol. 221, pp. 391-403.

11. On an Extension of Prandtl's Lifting Line Theory of Curved Wings. Prossdorf, S. and D. Tordella. 1991, Impact of Computing in Science and Engineering, Vol. 3.

12. Experimental Investigation of Nose-Mounted Controls for a Hypersonic Missile. Landers, M.G. and L.M. Auman. Anaheim, CA : AIAA-2001-2433, 2001. AIAA Applied Aerodynamics Conference.

13. Aerodynamic Effects of Body Slots on a Guided Projectile with Cruciform Surfaces. Appich, W.H. and J.R. Wittmeyer. Boulder, CO : AIAA-1979-1658, 1979. Atmospheric Flight Mechanics Conference.

14. Rozhdestvensky, K.V. Aerodynamics of a Lifting System in Extreme Ground Effect. Berlin : Springer, 2000.

15. Historical Review of WIG Vehicles. Ollila, R.G. Baltimore MD : AIAA-1979-2033, 1979. Advanced Marine Vehicles Conference. 
16. Scott, Jeff. http://www.aerospaceweb.org/qurtion/aerodynamics/q0130.shtml. [Online] June 29, 2003.

17. Raymond, A.E. Ground Influence on Aerofoils. 1921. NACA Technical Note - 67.

18. Rozhdestvensky, K.V. Wing-in-Ground-Effect Vehicles. Progress in Aerospace Sciences. May 2006. Vol. 2, 3.

19. Lifting Line In Extreme Ground Effect. Rozhdestvensky, K.V. EuroAvia, Toulouse : s.n., 2001. Proceedings of the EuroAvia Ground Effect Symposium.

20. Cole, W. The Pelican: A Big Bird for the Long Haul. Boeing Frontiers Online. September 2002, Vol. 1, 5.

21. Paulson, John W. and Scott O. Kjelgaard. An Experimental and Theoretical Investigation of Thick Wings at Various Sweep Angles In and Out of Ground Effect. s.1. : NASA, 1982. Technical Paper 2068.

22. Stoen, Hal. Cross Wind Landings. Stoenworks. [Online] February 22, 2011. [Cited: December 5, 2011.] http://stoenworks.com/tutorials/Crosswind\%20Landings.html.

23. Experimental Investigation of Various Winglet Designs for a Wing in Ground Effect. Ogurek, David J. and Jeff Ashowrth. Providence, RI : s.n., August 2004. 22nd Applied Aerodynamics Conference and Exhibit.

24. Performance and Stability of a Winged Vehicle in Ground Effect. De Divitiis, N. 1, February 2005, Journal of Aircraft, Vol. 42.

25. Aerofoil Ground Effect Revisited. Coulliette, C. and A. Plotkin. February 1996, Aeronautical Journal.

26. Some Aerodynamic Aspects of Wings Near Ground. Steinbach, Dieter and Jacob Klaus. 1991, ransactions of the Japan Society for Aeronautical and Space Sciences, pp. 56-70.

27. Aerodynamic Characteristics of a Two-Dimensional Airfoil with Ground Effect. Hsuin, C.H and C.K. Chen. 2, March 1996, Journal of Aircraft, Vol. 33.

28. Wind-Tunnel Invesitigation of Wings-in-Ground Effects. Chawla, M.D., L.C. Edwards and M.E Franks. 4, April 1990, Journal of Aircraft, Vol. 27.

29. Turbulence Flow Simulation for Wings in Ground Effect with Two Ground Conditions: Fixed and Moving Ground. Chun, H.H. and R.H. Chang. 2003, International Journal of Maritime Engineering.

30. Analysis of Vehicles with Wings Operating in Ground Effect. Borst, H.V. Baltimore, MD : AIAA, 1979. Advanced Marine Vehicles Conference. 
31. Configuration Effects on the Lift of a Body in Close Ground Proximity. Ailor, W.H. and W.R. Eberle. 4, August 1976, Journal of Aircraft, Vol. 27.

32. Cambered Airfoil in Ground Effect - An Experimental and Computational Study.

Ranzenbach, R. and J. Barlow. Detroit, MI : SAE International, April 1996. SAE International Congress and Exposition.

33. Abbot, I.H. and A.E. Von Doenhoff. Theory of Wing Sections Including a Summary of Airfoil Data. Dover, N.Y. : s.n., 1959.

34. Aerodynamics of a NACA 4412 Airfoil in Ground Effect. Ahmed, M.R., Y. Kohama and T. Takasaki. 1, January 2007, AIAA Journal, Vol. 45.

35. A Technical Note on the Appropriate CFD Boundary Conditions for the Prediction of Ground Effect Aerodynamics. Barber, T.J., E. Leronardi and R.D. Archer. November 1999, The Aeronautical Journal.

36. Easy Ways to Study Ground Effects. Monchaux, Jan and Stephan Aubin. Toulouse, France : s.n., 2001. EAGES 2001 International Ground Effect Symposium.

37. McClearn, Sandy. Haze Gray and Underway . [Online] 2007. [Cited: April 27, 2010.] http://www.hazegray.org/navhist/canada/postwar/brasdor/.

38. Dunbar, Jill. The Physics of a Race Care: Ground Effects. [Online] August 27, 2001. http://www.nas.nasa.giv/About/Education/Racecar/physics_groundeffect.html.

39. Encyclopaedia Britannica. Encyclopaedia Britannica Online. Ornithopter. [Online] January 21, 2010. http://www.britannica.com/EBchecked/topic/432999/ornithopter.

40. Ross, Rachel. Robotic Insect Takes Off. MIT Review. July 2007.

http://www.technologyreview.com/infotech/19068/?a=f.

41. Aerodynamic Modeling of Morphing Wings Using an Extended Lifting Line Analysis.

Wickenheiser, Adam and Ephrahim Garcia. 1, February 2005, Journal of Aircraft, Vol. 44.

42. Avian Wings. Liu, Tianshu, K. Kuykendoll, R. Rhew and S. Jones. Portland, OR : AIAA 2004-2186, 2004. 24th AIAA Aerodynamic Measurement Technology and Ground Testing Conference.

43. Scientific Literature Digital Library. Wortmann Airfoil. August 2008. http://www.aerodesign.ufsc.br/teoria/perfis/wort/wortmann.htm\#.

44. Malcolm. FX 63-137 Characteristics. [Online] http://hpagcd.propdesigner.co.uk/html/fx_63-137_characteristics.html. 
45. Validation of an Airfoil in the Ground Effect Regime Using 2-D CFD Analysis. Smith, J. Seattle, WA : AIAA, 2008. AIAA Aerodynamic Measurment Technology and Ground Testing Conference.

46. Hubbell, Meagan. Computational Analysis of Pitch Stability for a Slotted Airfoil in Ground Effect. Morgantown, WV : Master's Thesis, 2008.

47. Pitch Stability Analysis of an Airfoil in Ground Effect. Angle, Gerald, Brian O' Hara, Franz Pertl and James Smith. 3, 2009, Journal of Aircraft, Vol. 46.

48. McDowell, Margaret and Cynthia Ogden. Anthropometric Reference Data for Children and Adults: United States, 2003-2006. 2008.

49. Machinist Materials, Inc. Machinist Materials. [Online] [Cited: March 3, 2010.]

http://www.machinist-materials.com/comparison_table_for_plastics.htm.

50. Kroo, Ilan. Aircraft Design:Synthesis and Analysis. Stanford, CA : Desktop Aeronautics, Inc., 2006. http://adg.stanford.edu/aa241/AircraftDesign.html.

51. How Fast Do Winter Sport Participants Travel on Alpine Slopes? Shealy, J.E., C.F.

Ettlinger and R.J. Johnson. July 2005, Journal of ASTM International, pp. Vol.2, No.7.

52. USDA. Timberline Mountain Specification Summary. US Forest Service. [Online] March 2005. http://www.fs.fed.us/r6/mthood/projects/timberline-

express/Appendices/Appendix\%20G\%20-

\%20Timberline\%20Mountain\%20Specifications\%20Summary/Appendix\%20G\%20-

\%20Timberline\%20Mountain\%20Specifications\%20Summary.pdf.

53. Van Opstal, Edwin. The WIG Page. SE Technology. [Online] November 16, 2009.

http://www.se-technology.com/wig/index.php.

54. Howe, Denis. Aircraft Coneptual Design Synthesis. s.1. : John Wiley \& Sons, 2005.

http://www.knovel.com/web/portal/browse/display?_EXT_KNOVEL_DISPLAY_bookid=1408.

55. Ansys Fluent. Fluent 6.3 User's Guide. 2006.

56. Procedure for Estimation and Reporting of Discretization Error in CFD Applications. Celik, I.B. 2005. ASME Journal of Fluids Engineering.

57. Guiler, Richard W. Control of a Swept Wing Tailless Aircraft Through Wing Morphing. Morgantown, WV : s.n., 2007.

58. Pope, Alan and John Harper. Low-Speed Wind Tunnel Testing. New York, NY : John Wiley \& Sons, Inc., 1966. 
59. Omega Engineering, Inc. Positioning Strain Gages to Monitor Bending, Axial, Shear, and Torsional Loads. Omega Engineering. [Online]

http://www.omega.com/techref/pdf/Positioning_Strain_Gages.pdf.

60. Young, Donald, Bruce Munson, and Theodore Okiishi. A Brief Introduction to Fluid Mechanics. s.1. : John Wiley \& Sons Inc, 2004.

61. Selig, M.S. and B.D McGranaham. Wind Tunnel Aerodynamic Tests of Six Airfoils for Use on Small Wind Turbines. s.1. : National Renewable Energy Laboratory, 2004. NREL/SR-50034515.

62. Bounary Layer Trips for Low Reynolds Number Wind Tunnel Tests. Rona, Aldo and Houssam Soueid. Orlando, FL : AIAA-2010-399, 2010. 48th AIAA Aerospace Sciences Meeting Including the New Horizons Forum and Aerospace Exposition.

63. Experimental Investigation of the Effect of Trip Strips at Low Reynolds Number. Traub, Lance. 5, 2011, Journal of Aircraft, Vol. 48.

64. Aerodynamic Coefficients for a Parafoil Wing with Arc Anhedral. Jann, Thomas. Monterey, CA : AIAA, May 2003. 17th AIAA Aerodynamic DecleratorSystems Technology Conference and Seminar. 


\section{Chapter 8.0 Appendix}

\subsection{Computational Data}

Table 23: CFD Data Baseline

\begin{tabular}{|r|r|r|r|r|r|}
\hline & \multicolumn{1}{|l|}{ Cl } & \multicolumn{1}{l|}{ Cd } & \multicolumn{1}{l|}{ LE } & Cm-TE & Xcp-X-Calc \\
\hline 0 & 0.3379 & 0.0879 & -0.1373 & -0.0600 & 4.0630 \\
\hline 5 & 0.6606 & 0.1236 & -0.2607 & -0.2647 & 3.9465 \\
\hline 10 & 0.9218 & 0.1780 & -0.7325 & -0.4301 & 7.9462 \\
\hline 15 & 1.1007 & 0.2501 & -0.4276 & -0.4276 & 3.8853 \\
\hline$\%$ Change & & & & & $1.78 \%$ \\
\hline
\end{tabular}

Table 24: CFD Data - 2\% Twist

\begin{tabular}{|c|c|c|c|c|c|}
\hline 2P & $\mathrm{Cl}$ & $\mathrm{Cd}$ & $\mathrm{Cm}-\mathrm{LE}$ & $\mathrm{Cm}-\mathrm{TE}$ & $\mathrm{Xcp}$ \\
\hline 0 & 0.4059 & 0.0937 & -0.1642 & -0.1120 & 4.045 \\
\hline 5 & 0.7264 & 0.1309 & -0.2865 & -0.3132 & 3.945 \\
\hline 10 & 0.9385 & 0.1901 & -0.3700 & -0.4488 & 3.943 \\
\hline 15 & 1.1278 & 0.2587 & -0.4408 & -0.5671 & 3.908 \\
\hline \% Change & & & & & $1.37 \%$ \\
\hline
\end{tabular}

Table 25: CFD Data - 4\% Twist

\begin{tabular}{|c|c|c|c|c|c|}
\hline 4P & $\mathrm{Cl}$ & $\mathrm{Cd}$ & $\mathrm{Cm}-\mathrm{LE}$ & $\mathrm{Cm}-\mathrm{TE}$ & $\mathrm{Xcp}$ \\
\hline 0 & 0.4694 & 0.1007 & -0.1885 & -0.1607 & 4.016 \\
\hline 5 & 0.7665 & 0.1424 & -0.3037 & -0.3492 & 3.962 \\
\hline 10 & 0.9669 & 0.2142 & -0.3848 & -0.4651 & 3.980 \\
\hline 15 & 1.1592 & 0.2774 & -0.4520 & -0.5901 & 3.900 \\
\hline \% Change & & & & & $1.16 \%$ \\
\hline
\end{tabular}

Table 26: CFD Data - 6\% Twist

\begin{tabular}{|c|c|c|c|c|c|}
\hline 6P & $\mathrm{Cl}$ & $\mathrm{Cd}$ & $\mathrm{Cm}-\mathrm{LE}$ & $\mathrm{Cm}-\mathrm{TE}$ & $\mathrm{Xcp}$ \\
\hline 0 & 0.5240 & 0.1088 & -0.2118 & -0.2059 & 4.042 \\
\hline 5 & 0.7945 & 0.1553 & -0.3170 & -0.3761 & 3.989 \\
\hline 10 & 1.0066 & 0.2212 & -0.3991 & -0.5052 & 3.965 \\
\hline 15 & 1.1962 & 0.3128 & -0.4656 & -0.6127 & 3.892 \\
\hline \% Change & & & & & $1.50 \%$ \\
\hline
\end{tabular}

Table 27: CFD Data - 8\% Twist

\begin{tabular}{|c|c|c|c|c|c|}
\hline 8P & $\mathrm{Cl}$ & $\mathrm{Cd}$ & $\mathrm{Cm}-\mathrm{LE}$ & $\mathrm{Cm}-\mathrm{TE}$ & $\mathrm{Xcp}$ \\
\hline 0 & 0.5505 & 0.1512 & -0.2253 & -0.5042 & 4.093 \\
\hline 5 & 0.8294 & 0.1690 & -0.3317 & -0.4065 & 3.999 \\
\hline 10 & 1.0173 & 0.2362 & -0.4068 & -0.5203 & 3.999 \\
\hline 15 & 1.1180 & 0.3175 & -0.4383 & -0.5781 & 3.920 \\
\hline \% Change & & & & & $1.73 \%$ \\
\hline
\end{tabular}

Table 28: CFD Data - 10\% Twist

\begin{tabular}{|c|c|c|c|c|c|}
\hline $10 P$ & $\mathrm{Cl}$ & $\mathrm{Cd}$ & $\mathrm{Cm}-\mathrm{LE}$ & $\mathrm{Cm}-\mathrm{TE}$ & $\mathrm{Xcp}$ \\
\hline 0 & 0.6539 & 0.1290 & -0.2631 & -0.3065 & 4.024 \\
\hline 5 & 0.8800 & 0.1835 & -0.3537 & -0.4491 & 4.019 \\
\hline 10 & 1.0483 & 0.2552 & -0.4185 & -0.5454 & 3.992 \\
\hline 15 & 1.2456 & 0.3522 & -0.4875 & -0.6587 & 3.914 \\
\hline$\%$ Change & & & & & $1.10 \%$ \\
\hline
\end{tabular}


Table 29: CFD Data - 2\% Curve

\begin{tabular}{|r|r|r|r|r|r|}
\hline 2P & \multicolumn{1}{l|}{ Cl } & \multicolumn{1}{l|}{ Cd } & Cm-LE & Cm-TE & Xcp \\
\hline 0 & 0.3099 & 0.0944 & -0.1266 & -0.0551 & 4.085 \\
\hline 5 & 0.6196 & 0.1241 & -0.2470 & -0.2514 & 3.986 \\
\hline 10 & 0.8522 & 0.1771 & -0.3384 & -0.3986 & 3.971 \\
\hline 15 & 1.0556 & 0.2574 & -0.4131 & -0.5204 & 3.914 \\
\hline \% Change & & & & & $1.71 \%$ \\
\hline
\end{tabular}

Table 30: CFD Data - 4\% Curve

\begin{tabular}{|r|r|r|r|r|r|}
\hline 4P & \multicolumn{1}{|l|}{ Cl } & \multicolumn{1}{l|}{ Cd } & \multicolumn{1}{l|}{ Cm-LE } & Cm-TE & Xcp \\
\hline 0 & 0.2887 & 0.0951 & -0.1206 & -0.0451 & 4.177 \\
\hline 5 & 0.6131 & 0.1213 & -0.2456 & -0.2493 & 4.006 \\
\hline 10 & 0.8223 & 0.1751 & -0.3297 & -0.3815 & 4.010 \\
\hline 15 & 1.0457 & 0.2542 & -0.4136 & -0.5067 & 3.955 \\
\hline \% Change & & & & & $2.22 \%$ \\
\hline
\end{tabular}

Table 31: CFD Data - 6\% Curve

\begin{tabular}{|r|r|r|r|r|r|}
\hline 6P & \multicolumn{1}{|l|}{ Cl } & \multicolumn{1}{l|}{ Cd } & Cm-LE & Cm-TE & Xcp \\
\hline 0 & 0.2849 & 0.0935 & -0.1194 & -0.0464 & 4.193 \\
\hline 5 & 0.5937 & 0.1233 & -0.2413 & -0.2385 & 4.065 \\
\hline 10 & 0.8219 & 0.1712 & -0.3324 & -0.3826 & 4.044 \\
\hline 15 & 0.9999 & 0.2416 & -0.3990 & -0.4903 & 3.990 \\
\hline \% Change & & & & & $2.02 \%$ \\
\hline
\end{tabular}

Table 32: CFD Data -8\% Curve

\begin{tabular}{|r|r|r|r|r|r|}
\hline 8P & \multicolumn{1}{|l|}{ Cl } & \multicolumn{1}{l|}{ Cd } & \multicolumn{1}{l|}{ Cm-LE } & \multicolumn{1}{l|}{ Cm-TE } & Xcp \\
\hline 0 & 0.2704 & 0.0946 & -0.1153 & -0.0387 & 4.262 \\
\hline 5 & 0.5723 & 0.1192 & -0.2340 & -0.2292 & 4.090 \\
\hline 10 & 0.8283 & 0.1711 & -0.3368 & -0.3869 & 4.067 \\
\hline 15 & 1.0011 & 0.2430 & -0.4015 & -0.4882 & 4.010 \\
\hline
\end{tabular}

Table 33: CFD Data - 10\% Curve

\begin{tabular}{|r|r|r|r|r|r|}
\hline $10 P$ & \multicolumn{1}{l|}{ Cl } & \multicolumn{1}{l|}{ ld } & \multicolumn{1}{l|}{ Cm-LE } & \multicolumn{1}{l|}{ Cm-TE } & Xcp \\
\hline 0 & 0.2517 & 0.0974 & -0.1092 & -0.0294 & 4.339 \\
\hline 5 & 0.5530 & 0.1194 & -0.2283 & -0.2181 & 4.129 \\
\hline 10 & 0.8121 & 0.1668 & -0.3325 & -0.3779 & 4.094 \\
\hline 15 & 0.9866 & 0.2330 & -0.3806 & -0.4821 & 3.858 \\
\hline$\%$ Change & & & & & $4.81 \%$ \\
\hline
\end{tabular}




\subsection{Experimental Data - Freestream Model (not-in-ground effect)}

Table 34: Experimental Data Runs - Baseline Model (OGE) - $0^{\circ}$ Angle of Attack

\begin{tabular}{|c|c|c|c|c|c|c|c|c|c|c|c|c|c|c|c|}
\hline \multicolumn{16}{|c|}{ Single Model $-0 \mathrm{AoA}-\mathrm{Vel}=30 \mathrm{ft} / \mathrm{s}$} \\
\hline & Input V & Pitch V & \begin{tabular}{|l|} 
Lift V \\
\end{tabular} & Drag V & Pitch Moment & Lift Force & Drag Force & Act. Lift & Drag Interf. & Act. Drag & $\mathrm{P}$ [in Hg] & $\mathrm{T}[\mathrm{R}]$ & rho $[\mathrm{lb} / \mathrm{ft} 3]$ & $\mathrm{CL}$ & $C D$ \\
\hline Test 1 & 4.9976 & 0.13603 & 0.08498 & -0.015 & 2.415323 & 0.215565 & -0.131258 & 0.518129 & -0.186505875 & 0.055248 & 28.66 & 531 & 0.07151507 & 0.360642 & 0.285091 \\
\hline Test 2 & 4.9976 & 0.14224 & 0.087064 & -0.01435 & 2.525646 & 0.22084 & -0.125628 & 0.52956 & -0.191247309 & 0.065619 & 28.66 & 531 & 0.07151507 & 0.368598 & 0.33861 \\
\hline Test 3 & 4.9976 & 0.12768 & 0.08265 & -0.01398 & 2.267093 & 0.209645 & -0.122383 & 0.505301 & -0.181184684 & 0.058802 & 28.66 & 535 & 0.07098037 & 0.354362 & 0.305715 \\
\hline Test 4 & 4.9976 & 0.12082 & 0.078176 & -0.01207 & 2.145176 & \begin{tabular}{|l|}
0.198296 \\
\end{tabular} & -0.105668 & 0.480707 & -0.170983636 & 0.065316 & 28.66 & 535 & 0.07098037 & 0.337115 & 0.339582 \\
\hline Test 5 & 4.9976 & 0.13865 & 0.084342 & -0.01631 & 2.461894 & 0.213937 & -0.142725 & 0.514601 & -0.185042547 & 0.042318 & 28.65 & 535 & 0.07095561 & 0.36101 & 0.220089 \\
\hline Test 6 & 4.9976 & 0.13854 & 0.084955 & -0.01592 & 2.459877 & 0.215491 & -0.139295 & 0.517969 & -0.18643936 & \begin{tabular}{|l|}
0.047144 \\
\end{tabular} & 28.65 & 535 & 0.07095561 & 0.363373 & 0.245193 \\
\hline Test 7 & 4.9976 & 0.10905 & 0.073093 & -0.01315 & 1.936177 & \begin{tabular}{|l|}
0.185403 \\
\end{tabular} & -0.115078 & 0.452768 & -0.159394764 & \begin{tabular}{|l|}
0.044317 \\
\end{tabular} & 28.65 & 537 & 0.07069134 & 0.31882 & 0.231349 \\
\hline Test 8 & 4.9976 & 0.11677 & 0.076163 & -0.01326 & 2.07327 & 0.19319 & -0.116088 & 0.469643 & -0.166394108 & \begin{tabular}{|l|}
0.050306 \\
\end{tabular} & 28.65 & 537 & 0.07069134 & 0.330702 & 0.262615 \\
\hline Average & 4.9976 & 0.128723 & \begin{tabular}{|l|}
0.081428 \\
\end{tabular} & -0.01426 & 2.285557 & \begin{tabular}{|l|}
0.206546 \\
\end{tabular} & -0.124765 & 0.498585 & -0.178399035 & \begin{tabular}{|l|}
0.053634 \\
\end{tabular} & 28.655 & 534.5 & 0.0710356 & 0.349328 & 0.278531 \\
\hline Std & & & & & & & & & & & & & & 0.018068 & 0.018344 \\
\hline Percent & & & & & & & & & & & & & & $5.17 \%$ & $6.59 \%$ \\
\hline
\end{tabular}

Table 35: Experimental Data Runs - Baseline Model (OGE) - $5^{\circ}$ Angle of Attack

\begin{tabular}{|c|c|c|c|c|c|c|c|c|c|c|c|c|c|c|c|}
\hline \multicolumn{16}{|c|}{ Single Model $-5 \mathrm{AoA}-\mathrm{Vel}=30 \mathrm{ft} / \mathrm{s}$} \\
\hline & Input V & Pitch V & Lift V & Drag V & Pitch Moment & Lift Force & Drag Force & Act. Lift & Drag Interf. & Act. Drag & $\mathrm{P}$ [in $\mathrm{Hg}]$ & $T[R]$ & rho $[\mathrm{lb} / \mathrm{ft} 3]$ & $\mathrm{CL}$ & $C D$ \\
\hline Test 1 & 4.9976 & 0.23426 & 0.13372 & -0.05835 & 4.159377 & 0.339176 & -0.510645 & 0.785994 & -0.360892151 & -0.14975 & 28.66 & 531 & 0.07151507 & 0.547088 & -0.57563 \\
\hline Test 2 & 4.9976 & 0.23637 & 0.13458 & -0.05754 & 4.196934 & 0.341356 & -0.503586 & 0.790718 & -0.363207649 & -0.14038 & 28.66 & 531 & 0.07151507 & 0.550376 & -0.5396 \\
\hline Test 3 & 4.9976 & 0.24217 & 0.13598 & -0.0312 & 4.299909 & 0.344912 & -0.273078 & 0.798424 & -0.366984673 & 0.093907 & 28.65 & 535 & 0.07095561 & 0.560122 & 0.363814 \\
\hline Test 4 & 4.9976 & 0.26113 & 0.14549 & -0.03421 & 4.636458 & 0.369031 & -0.2994 & 0.85069 & -0.39260279 & 0.093203 & 28.65 & 535 & 0.07095561 & 0.596788 & 0.361087 \\
\hline Test 5 & 4.9976 & 0.23312 & 0.13417 & -0.03029 & 4.139118 & 0.340332 & -0.26514 & 0.788499 & -0.362120002 & 0.09698 & 28.65 & 536 & 0.07082323 & 0.554193 & 0.376423 \\
\hline Test 6 & 4.9976 & 0.22845 & 0.13064 & -0.02999 & 4.056325 & 0.331374 & -0.262475 & 0.769087 & -0.352605218 & 0.09013 & 28.65 & 536 & 0.07082323 & 0.54055 & 0.349836 \\
\hline Test 7 & 4.9976 & 0.22051 & 0.12182 & -0.02688 & 3.915224 & 0.309002 & -0.235266 & 0.720607 & -0.328842685 & 0.093577 & 28.65 & 538 & 0.07055994 & 0.508365 & 0.364568 \\
\hline Test 8 & 4.9976 & 0.24139 & 0.13213 & -0.03343 & 4.285994 & 0.335154 & -0.292554 & 0.777279 & -0.356620164 & 0.064066 & 28.65 & 538 & 0.07055994 & 0.548345 & 0.249597 \\
\hline Average & 4.9976 & 0.237175 & 0.133566 & -0.03774 & 4.211167375 & 0.338792 & -0.271319 & 0.785163 & -0.359962589 & 0.088644 & 28.6525 & 535 & 0.07096346 & 0.550729 & 0.344221 \\
\hline Std & & & & & & & & & & & & & & 0.024316 & 0.047126 \\
\hline Percent & & & & & & & & & & & & & & $4.42 \%$ & $13.69 \%$ \\
\hline
\end{tabular}

*Note: Any value denoted in red was removed from data set due to it being an outlier 
Table 36: Experimental Data Runs - Baseline Model (OGE) - $10^{\circ}$ Angle of Attack Single Model $-10 \mathrm{AoA}-\mathrm{Vel}=30 \mathrm{ft} / \mathrm{s}$

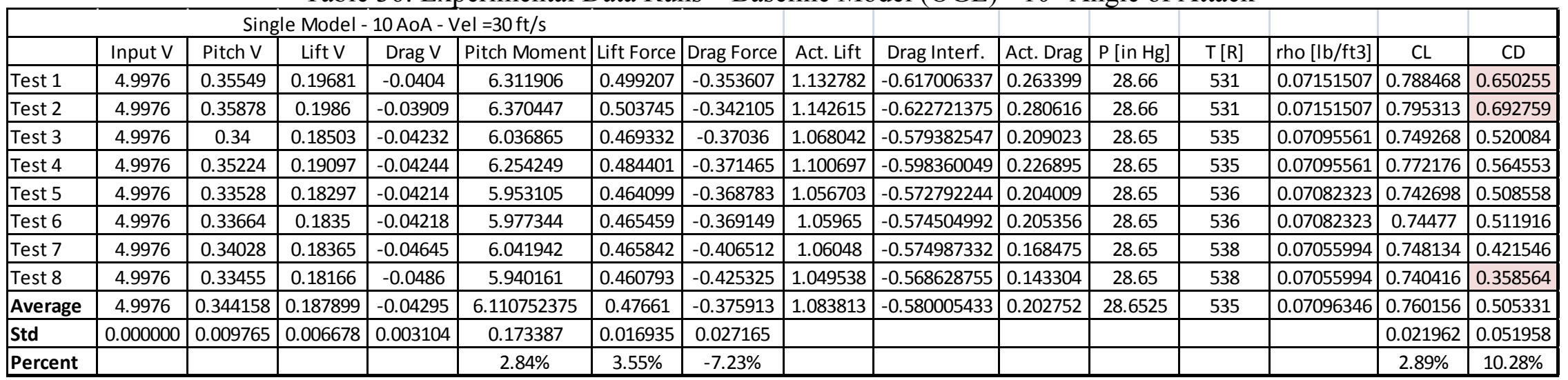

Table 37: Experimental Data Runs - Baseline Model (OGE) - $15^{\circ}$ Angle of Attack

\begin{tabular}{|c|c|c|c|c|c|c|c|c|c|c|c|c|c|c|c|}
\hline \multicolumn{8}{|c|}{ Single Model $-15 \mathrm{AoA}-\mathrm{Vel}=30 \mathrm{ft} / \mathrm{s}$} & & & & & & & & \\
\hline & Input V & Pitch V & Lift V & Drag V & Pitch Moment & Lift Force & Drag Force & Act. Lift & Drag Interf. & Act. Drag & $P$ [in $\mathrm{Hg}]$ & $T[R]$ & rho [lb/ft3] & $\mathrm{CL}$ & $C D$ \\
\hline Test 1 & 4.9976 & 0.45108 & 0.24154 & -0.06011 & 8.009246 & 0.612662 & -0.526095 & 1.378639 & -0.866480837 & 0.340386 & 28.66 & 532 & 0.07138064 & 0.961403 & 0.612933 \\
\hline Test 2 & 4.9976 & 0.45952 & 0.2453 & -0.07026 & 8.159057 & 0.622216 & -0.614965 & 1.399342 & -0.879935432 & 0.26497 & 28.66 & 532 & 0.07138064 & 0.975841 & 0.477133 \\
\hline Test 3 & 4.9976 & 0.43824 & 0.23556 & -0.05738 & 7.781304 & 0.597512 & -0.5022 & 1.345809 & -0.845145572 & 0.342946 & 28.65 & 535 & 0.07095561 & 0.944131 & 0.621242 \\
\hline Test 4 & 4.9976 & 0.45989 & 0.2471 & -0.06198 & 8.16565 & 0.626769 & -0.542455 & 1.409208 & -0.886347278 & 0.343892 & 28.65 & 535 & 0.07095561 & 0.988608 & 0.622957 \\
\hline Test 5 & 4.9976 & 0.45276 & 0.24269 & -0.05395 & 8.039007 & 0.6156 & -0.472153 & 1.385005 & -0.870618329 & 0.398465 & 28.65 & 537 & 0.07069134 & 0.975261 & 0.724513 \\
\hline Test 6 & 4.9976 & 0.43962 & 0.23476 & -0.05146 & 7.805674 & 0.595483 & -0.450358 & 1.341412 & -0.842288196 & 0.39193 & 28.65 & 537 & 0.07069134 & 0.944564 & 0.712631 \\
\hline Test 7 & 4.9976 & 0.41524 & 0.22295 & -0.05571 & 7.372881 & 0.565507 & -0.487571 & 1.276454 & -0.800073946 & 0.312503 & 28.65 & 537 & 0.07069134 & 0.898823 & 0.568212 \\
\hline Test 8 & 4.9976 & 0.4292 & 0.22973 & -0.07235 & 7.620787 & 0.582707 & -0.633227 & 1.313726 & \begin{tabular}{|l|}
-0.82429616 \\
\end{tabular} & 0.191069 & 28.65 & 537 & 0.07069134 & 0.925069 & 0.347413 \\
\hline Average & 4.9976 & 0.443194 & 0.237454 & -0.0604 & 7.86920075 & 0.602307 & -0.528628 & 1.356199 & 2.809489526 & 0.35502 & 28.6525 & 535.25 & 0.07092973 & 0.951712 & 0.619946 \\
\hline Std & & & & & & & & & & & & & & 0.029779 & 0.084318 \\
\hline Percent & & & & & & & & & & & & & & $3.13 \%$ & $13.60 \%$ \\
\hline
\end{tabular}




\subsection{Experimental Data - Baseline Model (in-ground effect)}

Table 38: Experimental Data Runs - Baseline Model (IGE) - $0^{\circ}$ Angle of Attack

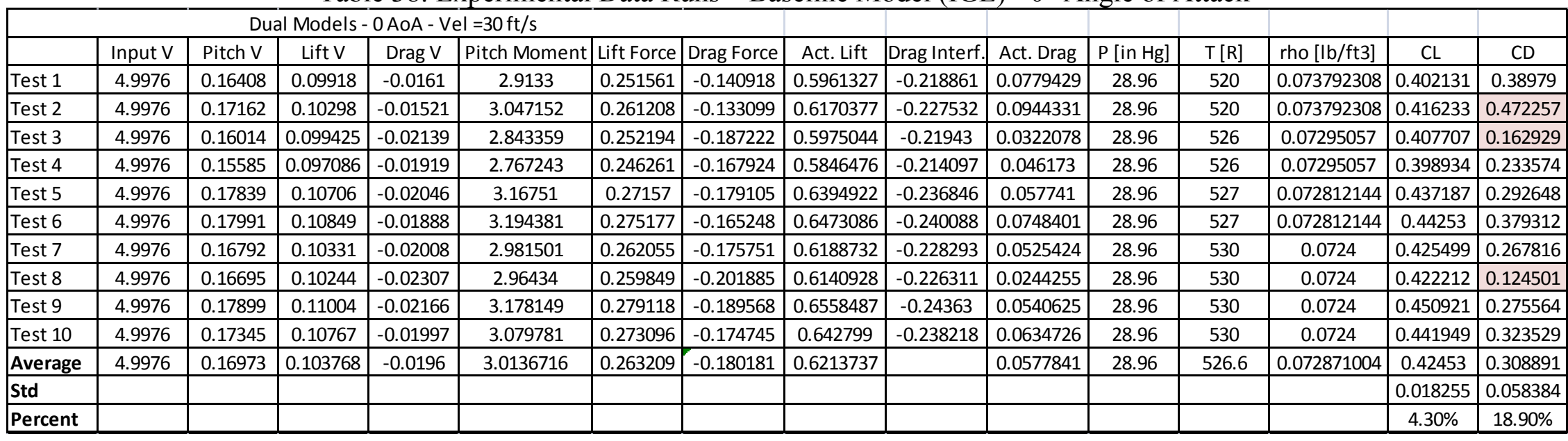

Table 39: Experimental Data Runs - Baseline Model (IGE) - $5^{\circ}$ Angle of Attack

\begin{tabular}{|c|c|c|c|c|c|c|c|c|c|c|c|c|c|c|c|}
\hline \multicolumn{8}{|c|}{ Dual Models $-5 \mathrm{AoA}-\mathrm{Vel}=30 \mathrm{ft} / \mathrm{s}$} & \multirow[b]{2}{*}{ Act. Lift } & \multirow[b]{2}{*}{ Drag Interf. } & \multirow[b]{2}{*}{ Act. Drag } & \multirow[b]{2}{*}{$\mathrm{P}$ [in $\mathrm{Hg}]$} & \multirow[b]{2}{*}{$T[R]$} & \multirow[b]{2}{*}{ rho $[\mathrm{lb} / \mathrm{ft} 3]$} & \multirow[b]{2}{*}{$\mathrm{CL}$} & \multirow[b]{2}{*}{$C D$} \\
\hline & Input V & Pitch V & Lift V & Drag V & Pitch Moment & Lift Force & Drag Force & & & & & & & & \\
\hline Test 1 & 4.9976 & 0.34435 & 0.19036 & -0.04459 & 6.114094 & 0.482842 & -0.390237 & 1.0973186 & -0.513488 & 0.1232507 & 28.96 & 524 & 0.073229008 & 0.745908 & 0.462674 \\
\hline Test 2 & 4.9976 & 0.33737 & 0.18593 & -0.04357 & 5.990254 & 0.471626 & -0.381309 & 1.0730135 & -0.501575 & 0.1202656 & 28.96 & 524 & 0.073229008 & 0.729386 & 0.451468 \\
\hline Test 3 & 4.9976 & 0.34526 & 0.19211 & -0.04624 & 6.130376 & 0.487284 & -0.404681 & 1.1069444 & -0.518206 & 0.1135248 & 28.96 & 526 & 0.07295057 & 0.755323 & 0.427791 \\
\hline Test 4 & 4.9976 & 0.35217 & 0.19581 & -0.04682 & 6.253028 & 0.496673 & -0.409781 & 1.1272904 & -0.528178 & 0.1183974 & 28.96 & 526 & 0.07295057 & 0.769206 & 0.446152 \\
\hline Test 5 & 4.9976 & 0.35297 & 0.19371 & -0.04489 & 6.267171 & 0.49136 & -0.392918 & 1.1157771 & -0.522535 & 0.1296172 & 28.96 & 527 & 0.072812144 & 0.762797 & 0.489359 \\
\hline Test 6 & 4.9976 & 0.34965 & 0.19187 & -0.04371 & 6.208223 & 0.486672 & -0.382527 & 1.1056182 & -0.517556 & 0.1350288 & 28.96 & 527 & 0.072812144 & 0.755852 & 0.50979 \\
\hline Test 7 & 4.9976 & 0.3222 & 0.17932 & -0.05382 & 5.720889 & 0.454844 & -0.471053 & 1.0366469 & -0.48375 & 0.0126965 & 28.96 & 530 & 0.0724 & 0.712735 & 0.048208 \\
\hline Test 8 & 4.9976 & 0.33002 & 0.18371 & -0.05352 & 5.859761 & 0.465975 & -0.468443 & 1.0607678 & -0.495572 & 0.0271293 & 28.96 & 530 & 0.0724 & 0.729319 & 0.103008 \\
\hline Test 9 & 4.9976 & 0.33341 & 0.18868 & -0.04237 & 5.919874 & 0.478583 & -0.370857 & 1.0880894 & -0.508964 & 0.138107 & 28.96 & 530 & 0.0724 & 0.748103 & 0.52438 \\
\hline Test 10 & 4.9976 & 0.34028 & 0.1922 & -0.04211 & 6.041877 & 0.487531 & -0.368521 & 1.1074797 & -0.518468 & 0.1499472 & 28.96 & 530 & 0.0724 & 0.761435 & 0.569336 \\
\hline Average & 4.9976 & 0.340768 & 0.18937 & -0.04616 & 6.0505547 & 0.480339 & -0.387604 & 1.0918946 & -0.511654 & & 28.96 & 527.4 & 0.072758344 & 0.747006 & 0.485119 \\
\hline Std & & & & & & & & & & & & & & 0.017945 & 0.047361 \\
\hline Percent & & & & & & & & & & & & & & $2.40 \%$ & $9.76 \%$ \\
\hline
\end{tabular}


Table 40: Experimental Data Runs - Baseline Model (IGE) - $10^{\circ}$ Angle of Attack Dual Models $-10 \mathrm{AoA}-\mathrm{Vel}=30 \mathrm{ft} / \mathrm{s}$

\begin{tabular}{|c|c|c|c|c|c|c|c|c|c|c|c|c|c|c|c|}
\hline \multicolumn{8}{|c|}{ Dual Models $-10 \mathrm{AoA}-\mathrm{Vel}=30 \mathrm{ft} / \mathrm{s}$} & & & & & & & & \\
\hline & Input V & Pitch V & Lift V & Drag V & Pitch Moment & Lift Force & Drag Force & Act. Lift & Drag Interf. & Act. Drag & $\mathrm{P}$ [in $\mathrm{Hg}]$ & $\mathrm{T}[\mathrm{R}]$ & rho $[\mathrm{lb} / \mathrm{ft} 3]$ & $\mathrm{CL}$ & $C D$ \\
\hline Test 1 & 4.9976 & 0.44958 & 0.24078 & -0.05858 & 7.982662 & 0.610747 & -0.512677 & 1.3744887 & -0.757477 & 0.2447999 & 28.96 & 524 & 0.073229008 & 0.934315 & 0.590194 \\
\hline Test 2 & 4.9976 & 0.4645 & 0.24862 & -0.06022 & 8.24743 & 0.630619 & -0.527039 & 1.4175514 & -0.782503 & 0.2554642 & 28.96 & 524 & 0.073229008 & 0.963588 & 0.615905 \\
\hline Test 3 & 4.9976 & 0.45129 & 0.24471 & -0.05743 & 8.012877 & 0.620722 & -0.502622 & 1.3961046 & -0.770039 & 0.2674171 & 28.96 & 527 & 0.072812144 & 0.954442 & 0.648414 \\
\hline Test 4 & 4.9976 & 0.44463 & 0.24114 & -0.05587 & 7.894649 & 0.61166 & -0.488976 & 1.3764672 & -0.758627 & 0.2696507 & 28.96 & 527 & 0.072812144 & 0.941017 & 0.653829 \\
\hline Test 5 & 4.9976 & 0.43949 & 0.23753 & -0.04003 & 7.803474 & 0.602496 & -0.350306 & 1.3566088 & -0.747086 & 0.3967798 & 28.96 & 529 & 0.072536862 & 0.930961 & 0.965734 \\
\hline Test 6 & 4.9976 & 0.45408 & 0.2442 & -0.03668 & 8.062475 & 0.61943 & -0.321016 & 1.3933048 & -0.768412 & 0.447396 & 28.96 & 529 & 0.072536862 & 0.956143 & 1.08893 \\
\hline Test 7 & 4.9976 & 0.44995 & 0.24676 & -0.06393 & 7.989224 & 0.625908 & -0.5595 & 1.4073426 & -0.77657 & 0.2170702 & 28.96 & 530 & 0.0724 & 0.967602 & 0.529332 \\
\hline Test 8 & 4.9976 & 0.43208 & 0.23617 & -0.06114 & 7.671953 & 0.599053 & -0.535108 & 1.3491479 & -0.74275 & 0.2076418 & 28.96 & 530 & 0.0724 & 0.927591 & 0.506341 \\
\hline Test 9 & 4.9976 & 0.4289 & 0.23583 & -0.05621 & 7.615495 & 0.598181 & -0.491991 & 1.3472582 & -0.741652 & 0.2496606 & 28.96 & 530 & 0.0724 & 0.926292 & 0.608805 \\
\hline Test 10 & 4.9976 & 0.44091 & 0.24163 & -0.05693 & 7.828627 & 0.612888 & -0.498292 & 1.3791283 & -0.760173 & 0.2618812 & 28.96 & 530 & 0.0724 & 0.948204 & 0.638605 \\
\hline Average & 4.9976 & 0.445541 & 0.241737 & -0.0547 & 7.9108866 & 0.61317 & -0.514526 & 1.3797403 & & & 28.96 & 528 & 0.072675603 & 0.945015 & 0.598928 \\
\hline Std & & & & & & & & & & & & & & 0.015130 & 0.054662 \\
\hline Percent & & & & & & & & & & & & & & $1.60 \%$ & $9.13 \%$ \\
\hline
\end{tabular}

Table 41: Experimental Data Runs - Baseline Model (IGE) - $15^{\circ}$ Angle of Attack

\begin{tabular}{|c|c|c|c|c|c|c|c|c|c|c|c|c|c|c|c|}
\hline \multicolumn{16}{|c|}{ Dual Models $-15 \mathrm{AoA}-\mathrm{Vel}=30 \mathrm{ft} / \mathrm{s}$} \\
\hline & Input V & Pitch V & Lift V & Drag V & Pitch Moment & Lift Force & Drag Force & Act. Lift & Drag Interf. & Act. Drag & $\mathrm{P}$ [in $\mathrm{Hg}]$ & $\mathrm{T}[\mathrm{R}]$ & rho $[\mathrm{lb} / \mathrm{ft} 3]$ & $\mathrm{CL}$ & $C D$ \\
\hline Test 1 & 4.9976 & 0.54412 & 0.28576 & -0.06864 & 9.661139 & 0.724839 & -0.600757 & 1.6217261 & -1.024456 & 0.4236991 & 28.96 & 526 & 0.07295057 & 1.106584 & 0.746536 \\
\hline Test 2 & 4.9976 & 0.56206 & 0.29489 & -0.0707 & 9.979732 & 0.747999 & -0.618778 & 1.6719138 & -1.057072 & 0.4382936 & 28.96 & 526 & 0.07295057 & 1.140829 & 0.772251 \\
\hline Test 3 & 4.9976 & 0.55198 & 0.29301 & -0.07276 & 9.800736 & 0.743238 & -0.636827 & 1.6615967 & -1.050367 & 0.4135399 & 28.96 & 527 & 0.072812144 & 1.135945 & 0.730022 \\
\hline Test 4 & 4.9976 & 0.55706 & 0.29492 & -0.07296 & 9.890951 & 0.748061 & -0.6386 & 1.6720482 & -1.057159 & 0.418559 & 28.96 & 527 & 0.072812144 & 1.14309 & 0.738882 \\
\hline Test 5 & 4.9976 & 0.53062 & 0.28244 & -0.07519 & 9.421445 & 0.716423 & -0.658046 & 1.6034886 & -1.012604 & 0.3545582 & 28.96 & 530 & 0.0724 & 1.10246 & 0.629464 \\
\hline Test 6 & 4.9976 & 0.53584 & 0.28473 & -0.09056 & 9.514184 & 0.722216 & -0.792577 & 1.6160421 & -1.020762 & 0.2281853 & 28.96 & 530 & 0.0724 & 1.111091 & 0.405108 \\
\hline Test 7 & 4.9976 & 0.54688 & 0.29418 & -0.0705 & 9.710201 & 0.746203 & -0.617016 & 1.6680219 & -1.054542 & 0.4375264 & 28.96 & 530 & 0.0724 & 1.146829 & 0.776762 \\
\hline Test 8 & 4.9976 & 0.55233 & 0.2974 & -0.07071 & 9.806935 & 0.754373 & -0.618839 & 1.6857263 & -1.066048 & 0.4472089 & 28.96 & 530 & 0.0724 & 1.159002 & 0.793952 \\
\hline Test 9 & 4.9976 & 0.5477 & 0.29297 & -0.06834 & 9.724766 & 0.743122 & -0.5981 & 1.6613454 & -1.050204 & 0.4521035 & 28.96 & 530 & 0.0724 & 1.142239 & 0.802641 \\
\hline Test 10 & 4.9976 & 0.54752 & 0.29276 & -0.06757 & 9.721584 & 0.742593 & -0.591423 & 1.660199 & -1.049459 & 0.4580355 & 28.96 & 530 & 0.0724 & 1.141451 & 0.813173 \\
\hline Average & 4.9976 & 0.547611 & 0.291306 & -0.07279 & 9.7231673 & 0.738907 & -0.619821 & 1.6522108 & & & 28.96 & 528.6 & 0.072592543 & 1.132952 & 0.771777 \\
\hline Std & & & & & & & & & & & & & & 0.019167 & 0.030812 \\
\hline Percent & & & & & & & & & & & & & & $1.69 \%$ & $3.99 \%$ \\
\hline
\end{tabular}




\subsection{Experimental Data - 6\% Twist (in-ground effect)}

Table 42: Experimental Data Runs - 6\% Twist Model (IGE) - $(-5)^{\circ}$ Angle of Attack

\begin{tabular}{|c|c|c|c|c|c|c|c|c|c|c|c|c|c|c|c|c|}
\hline \multicolumn{17}{|c|}{$6 \mathrm{P}$ Twisted Models $-(-5)$ AoA $-\mathrm{Vel}=30 \mathrm{ft} / \mathrm{s}$} \\
\hline & Input V & Pitch V & \begin{tabular}{|l|} 
Lift V \\
\end{tabular} & Drag V & Pitch Moment & Lift Force & Drag Force & Act. Pitch & Act. Lift & Drag Interf. & Act. Drag & $\mathrm{P}[\mathrm{in} \mathrm{Hg}]$ & $\mathrm{T}[\mathrm{R}]$ & rho $[\mathrm{lb} / \mathrm{ft} 3]$ & $\mathrm{CL}$ & $C D$ \\
\hline Test 1 & 4.9976 & 0.09371 & 0.062543 & -0.01103 & 1.663894 & 0.158642 & -0.096534 & & 0.3947772 & -0.227099 & 0.1305649 & 28.82 & 530 & 0.07205 & 0.272743 & 0.185199 \\
\hline Test 2 & 4.9976 & 0.079615 & \begin{tabular}{|l|}
0.053724 \\
\end{tabular} & -0.01036 & 1.413621 & 0.136271 & -0.090688 & & 0.3462993 & -0.195594 & 0.1049065 & 28.82 & 530 & 0.07205 & 0.239251 & 0.148804 \\
\hline Test 3 & 4.9976 & 0.066829 & 0.04755 & -0.00423 & 1.186591 & 0.120612 & -0.037014 & & 0.3123662 & -0.173542 & 0.1365284 & 28.82 & 530 & 0.07205 & 0.215807 & 0.193658 \\
\hline Test 4 & 4.9976 & 0.082532 & 0.057377 & -0.00441 & 1.465419 & 0.145539 & -0.038565 & & 0.366383 & -0.208646 & 0.1700813 & 28.82 & 530 & 0.07205 & 0.253126 & 0.241251 \\
\hline Test 5 & 4.9976 & 0.068974 & 0.050892 & -0.00874 & 1.224676 & 0.129088 & -0.07651 & & 0.3307337 & -0.185479 & 0.1089689 & 28.82 & 530 & 0.07205 & 0.228497 & 0.154566 \\
\hline Test 6 & 4.9976 & 0.064018 & \begin{tabular}{|l|}
0.048235 \\
\end{tabular} & -0.00362 & 1.136687 & 0.122349 & -0.031666 & & 0.3161303 & -0.175989 & 0.1443226 & 28.82 & 530 & 0.07205 & 0.218408 & 0.204713 \\
\hline Test 7 & 4.9976 & 0.046403 & 0.041186 & -0.00651 & 0.823909 & 0.104468 & -0.05696 & & 0.2773822 & -0.150807 & 0.0938473 & 28.71 & 530 & 0.071775 & 0.192372 & 0.133627 \\
\hline Average & 4.9976 & 0.071726 & 0.051644 & -0.00699 & 1.273542429 & 0.130996 & -0.061134 & & 0.299384 & -0.165106 & 0.1116135 & 28.7925 & 530.25 & 0.071947313 & 0.231457 & 0.170094 \\
\hline Std & & & & & & & & & & & & & & & 0.026415 & 0.028306 \\
\hline Percent & & & & & & & & & & & & & & & $11.41 \%$ & $16.64 \%$ \\
\hline
\end{tabular}

Table 43: Experimental Data Runs - 6\% Twist Model (IGE) - $0^{\circ}$ Angle of Attack

\begin{tabular}{|c|c|c|c|c|c|c|c|c|c|c|c|c|c|c|c|c|}
\hline \multicolumn{17}{|c|}{$6 \mathrm{P}$ Twisted $-0 \mathrm{AoA}-\mathrm{Vel}=30 \mathrm{ft} / \mathrm{s}$} \\
\hline & Input V & Pitch V & Lift V & Drag V & Pitch Moment & Lift Force & Drag Force & Act. Pitch & Act. Lift & Drag Interf. & Act. Drag & $\mathrm{P}$ [in $\mathrm{Hg}]$ & $\mathrm{T}[\mathrm{R}]$ & rho $[\mathrm{lb} / \mathrm{ft} 3]$ & $\mathrm{CL}$ & $C D$ \\
\hline Test 1 & 6 & 0.2619 & 0.14489 & -0.03165 & 4.650129 & 0.367519 & \begin{tabular}{|l|}
-0.277 \\
\end{tabular} & & 0.8474137 & \begin{tabular}{|c|}
-0.32309 \\
\end{tabular} & 0.0460897 & 29.2 & 530 & 0.073 & 0.577841 & 0.170936 \\
\hline Test 2 & 6 & 0.25291 & 0.13939 & -0.03086 & 4.490558 & 0.35357 & -0.270061 & & 0.8171862 & -0.310552 & 0.0404907 & 29.2 & 530 & 0.073 & 0.557229 & 0.150171 \\
\hline Test 3 & 6 & 0.25375 & 0.14474 & -0.03265 & 4.505495 & 0.367143 & -0.28573 & & 0.8465989 & -0.322752 & 0.0370217 & 29.2 & 535 & 0.072317757 & 0.582731 & 0.1386 \\
\hline Test 4 & 6 & 0.25527 & 0.14452 & -0.03251 & 4.532533 & 0.36659 & -0.28454 & & 0.8454005 & -0.322255 & 0.0377147 & 29.2 & 535 & 0.072317757 & 0.581906 & 0.141195 \\
\hline Test 5 & 6 & 0.25227 & 0.1423 & -0.03349 & 4.479146 & 0.360952 & -0.293067 & & 0.833183 & -0.317187 & 0.02412 & 29.18 & 537 & 0.071999069 & 0.576035 & 0.090699 \\
\hline Test 6 & 6 & 0.24722 & 0.1392 & -0.03235 & 4.389547 & 0.35309 & -0.283103 & & 0.816146 & -0.31012 & 0.0270172 & 29.18 & 537 & 0.071999069 & 0.564256 & 0.101594 \\
\hline Test 7 & 6 & 0.26572 & 0.15058 & -0.03576 & 4.718058 & 0.381945 & -0.313013 & & 0.8786748 & -0.336057 & 0.0230435 & 29.18 & 538 & 0.071865242 & 0.608618 & 0.086813 \\
\hline Test 8 & 6 & 0.26759 & 0.15123 & -0.03559 & 4.751259 & 0.383609 & -0.311482 & & 0.8822807 & -0.337552 & 0.0260702 & 29.18 & 538 & 0.071865242 & 0.611116 & 0.098215 \\
\hline Test 9 & 6 & 0.25802 & 0.14876 & -0.03461 & 4.581238 & 0.377333 & -0.30287 & & 0.8686806 & -0.331911 & 0.029041 & 29.18 & 539 & 0.071731911 & 0.602814 & 0.109611 \\
\hline Test 10 & 6 & 0.24916 & 0.14299 & -0.03273 & 4.424094 & 0.362696 & -0.286412 & & 0.8369622 & -0.318755 & 0.0323426 & 29.18 & 539 & 0.071731911 & 0.580803 & 0.122072 \\
\hline Average & 6 & 0.256381 & 0.14486 & -0.03322 & 4.5522057 & 0.367445 & -0.290728 & & & & & 29.14455 & 535.8 & 0.072182796 & 0.584335 & 0.1111 \\
\hline Std & & & & & & & & & & & & & & & \begin{tabular}{|l|}
0.018007 \\
\end{tabular} & 0.020864 \\
\hline Percent & & & & & & & & & & & & & & & $3.08 \%$ & $18.78 \%$ \\
\hline
\end{tabular}


Table 44: Experimental Data Runs - 6\% Twist Model (IGE) - $5^{\circ}$ Angle of Attack

\begin{tabular}{|c|c|c|c|c|c|c|c|c|c|c|c|c|c|c|c|c|}
\hline \multicolumn{17}{|c|}{$6 \mathrm{P}$ Twisted Models $-5 \mathrm{AoA}-\mathrm{Vel}=30 \mathrm{ft} / \mathrm{s}$} \\
\hline & Input V & Pitch V & Lift V & Drag V & Pitch Moment & Lift Force & Drag Force & Act. Pitch & Act. Lift & Drag Interf. & Act. Drag & $\mathrm{P}$ [in $\mathrm{Hg}]$ & $T[R]$ & rho $[\mathrm{lb} / \mathrm{ft} 3]$ & $\mathrm{CL}$ & $C D$ \\
\hline Test 1 & 4.9976 & 0.40816 & 0.22578 & -0.0544 & 7.247073 & 0.572703 & -0.476089 & & 1.2920474 & -0.608934 & 0.132845 & 29.2 & 532 & 0.072725564 & 0.884355 & 0.320491 \\
\hline Test 2 & 4.9976 & 0.39832 & 0.21988 & -0.05327 & 7.072403 & 0.557724 & -0.466246 & & 1.2595879 & \begin{tabular}{|l|}
-0.593024 \\
\end{tabular} & 0.126778 & 29.2 & 532 & 0.072725564 & 0.862138 & 0.305855 \\
\hline Test 3 & 4.9976 & 0.36899 & 0.20654 & -0.04941 & 6.551698 & 0.523886 & -0.432443 & & 1.186261 & -0.557083 & 0.1246398 & 29.18 & 536 & 0.072133396 & 0.818614 & 0.303165 \\
\hline Test 4 & 4.9976 & 0.38218 & 0.21401 & -0.05101 & 6.785844 & 0.542842 & -0.446452 & & 1.2273386 & -0.577217 & 0.130765 & 29.18 & 536 & 0.072133396 & 0.846961 & 0.318063 \\
\hline Test 5 & 4.9976 & 0.41029 & 0.223 & -0.05391 & 7.284923 & 0.565634 & -0.471869 & & 1.2767289 & -0.601426 & 0.1295567 & 29.18 & 537 & 0.071999069 & 0.882688 & 0.315712 \\
\hline Test 6 & 4.9976 & 0.41898 & 0.22698 & -0.05537 & 7.439303 & 0.575743 & -0.484614 & & 1.2986351 & -0.612163 & 0.127549 & 29.18 & 537 & 0.071999069 & 0.897833 & 0.31082 \\
\hline Test 7 & 4.9976 & 0.38256 & 0.21136 & -0.05123 & 6.792697 & 0.536126 & -0.448412 & & 1.212785 & -0.570084 & 0.1216716 & 29.18 & 539 & 0.071731911 & 0.841602 & 0.297601 \\
\hline Test 8 & 4.9976 & 0.38599 & 0.21302 & -0.05132 & 6.853541 & 0.540325 & -0.449121 & & 1.2218843 & -0.574544 & 0.1254226 & 29.18 & 539 & 0.071731911 & 0.847917 & 0.306776 \\
\hline Test 9 & 4.9976 & 0.38225 & 0.21211 & -0.0508 & 6.787168 & 0.538029 & -0.444614 & & 1.2169088 & -0.572105 & 0.1274909 & 29.18 & 539 & 0.071731911 & 0.844464 & 0.311835 \\
\hline Test 10 & 4.9976 & 0.37041 & 0.2055 & -0.04905 & 6.576839 & 0.521258 & -0.429335 & & 1.1805661 & -0.554291 & 0.1249565 & 29.18 & 539 & 0.071731911 & 0.819244 & 0.305636 \\
\hline Average & 4.9976 & 0.390813 & 0.215818 & -0.05198 & 6.9391489 & 0.547427 & -0.45492 & & 1.2311884 & & & & & & 0.854582 & 0.308385 \\
\hline Std & & & & & & & & & & & & & & & 0.026915 & 0.006376 \\
\hline Percent & & & & & & & & & & & & & & & $3.15 \%$ & $2.07 \%$ \\
\hline
\end{tabular}

Table 45: Experimental Data Runs - 6\% Twist Model (IGE) - $10^{\circ}$ Angle of Attack

\begin{tabular}{|c|c|c|c|c|c|c|c|c|c|c|c|c|c|c|c|c|}
\hline \multicolumn{17}{|c|}{$6 \mathrm{P}$ Twisted Models $-10 \mathrm{AoA}-\mathrm{Vel}=30 \mathrm{ft} / \mathrm{s}$} \\
\hline & Input V & Pitch V & Lift V & Drag V & Pitch Moment & Lift Force & Drag Force & Act. Pitch & Act. Lift & Drag Interf. & Act. Drag & $P$ [in $\mathrm{Hg}]$ & $\mathrm{T}[\mathrm{R}]$ & rho [lb/ft3] & $\mathrm{CL}$ & $C D$ \\
\hline Test 1 & 4.9976 & 0.51966 & 0.28023 & -0.06645 & 9.226903 & 0.710809 & -0.58156 & & 1.5913231 & -0.883492 & 0.3019323 & 29.2 & 533 & 0.072589118 & 1.091245 & 0.541711 \\
\hline Test 2 & 4.9976 & 0.51381 & 0.27705 & -0.06588 & 9.123023 & 0.702747 & -0.57656 & & 1.5738527 & -0.873339 & 0.2967793 & 29.2 & 533 & 0.072589118 & 1.079265 & 0.532466 \\
\hline Test 3 & 4.9976 & 0.48861 & 0.26315 & -0.06301 & 8.675626 & 0.66749 & -0.551498 & & 1.4974508 & -0.828938 & 0.2774395 & 29.18 & 536 & 0.072133396 & 1.03336 & 0.500912 \\
\hline Test 4 & 4.9976 & 0.50144 & 0.27046 & -0.0643 & 8.903366 & 0.686025 & -0.562733 & & 1.5376162 & -0.85228 & 0.289547 & 29.18 & 536 & 0.072133396 & 1.061077 & 0.522772 \\
\hline Test 5 & 4.9976 & 0.50128 & 0.2729 & -0.06582 & 8.900585 & 0.692208 & -0.576035 & & 1.5510147 & -0.860067 & 0.2840317 & 29.18 & 537 & 0.071999069 & 1.07232 & 0.513771 \\
\hline Test 6 & 4.9976 & 0.49301 & 0.26765 & -0.06443 & 8.753703 & 0.6789 & -0.563937 & & 1.5221763 & -0.843307 & 0.27937 & 29.18 & 537 & 0.071999069 & 1.052382 & 0.505339 \\
\hline Test 7 & 4.9976 & 0.519 & 0.2773 & -0.06815 & 9.215285 & 0.70339 & -0.596462 & & 1.5752461 & -0.874149 & 0.277687 & 29.18 & 539 & 0.071731911 & 1.093129 & 0.504165 \\
\hline Test 8 & 4.9976 & 0.50149 & 0.26739 & -0.0656 & 8.904276 & 0.678231 & -0.574165 & & 1.5207266 & -0.842464 & 0.2682995 & 29.18 & 539 & 0.071731911 & 1.055296 & \begin{tabular}{|l}
0.487121 \\
\end{tabular} \\
\hline Test 9 & 4.9976 & 0.49708 & 0.27082 & -0.06506 & 8.825964 & 0.686941 & -0.569377 & & 1.5396011 & -0.853434 & 0.2840566 & 29.18 & 539 & 0.071731911 & 1.068394 & 0.51573 \\
\hline Test 10 & 4.9976 & 0.51079 & 0.27831 & -0.06701 & 9.069483 & 0.705944 & -0.586467 & & 1.5807806 & -0.877365 & 0.2908985 & 29.18 & 539 & 0.071731911 & 1.09697 & 0.528152 \\
\hline Average & 4.9976 & 0.504617 & 0.272526 & -0.06557 & 8.9598214 & 0.691269 & -0.573879 & & 1.5489788 & & & 29.184 & 536.8 & 0.072037081 & 1.070344 & \begin{tabular}{|l}
0.509745 \\
\end{tabular} \\
\hline Std & & & & & & & & & & & & & & & 0.020426 & \begin{tabular}{|l}
0.016465 \\
\end{tabular} \\
\hline Percent & & & & & & & & & & & & & & & $1.91 \%$ & $3.23 \%$ \\
\hline
\end{tabular}


Table 46: Experimental Data Runs - 6\% Twist Model (IGE) - $15^{\circ}$ Angle of Attack

\begin{tabular}{|c|c|c|c|c|c|c|c|c|c|c|c|c|c|c|c|c|}
\hline \multicolumn{17}{|c|}{$6 \mathrm{P}$ Twisted Models $-15 \mathrm{AoA}-\mathrm{Vel}=30 \mathrm{ft} / \mathrm{s}$} \\
\hline & Input V & Pitch V & Lift V & \begin{tabular}{|l|} 
Drag V \\
\end{tabular} & \begin{tabular}{|l|} 
Pitch Moment \\
\end{tabular} & Lift Force & Drag Force & Act. Pitch & Act. Lift & Drag Interf. & Act. Drag & $\mathrm{P}$ [in $\mathrm{Hg}]$ & $\mathrm{T}[\mathrm{R}]$ & rho $[\mathrm{lb} / \mathrm{ft} 3]$ & \begin{tabular}{l|l}
$\mathrm{CL}$ & \\
\end{tabular} & $\mathrm{CD}$ \\
\hline Test 1 & 4.9976 & 0.56816 & 0.30583 & -0.07236 & 10.088089 & 0.775739 & -0.63334 & & 1.7320264 & -1.096137 & 0.462797 & 29.2 & 533 & 0.072589118 & 1.187732 & 0.651575 \\
\hline Test 2 & 4.9976 & 0.57813 & 0.3116 & -0.07321 & 10.265118 & 0.790382 & -0.640735 & & 1.7637578 & -1.116758 & 0.4760233 & 29.2 & 533 & 0.072589118 & 1.209492 & 0.670197 \\
\hline Test 3 & 4.9976 & 0.56138 & 0.30329 & -0.07213 & 9.967611 & 0.769298 & -0.631328 & & 1.7180688 & -1.087066 & 0.4557383 & 29.18 & 536 & 0.072133396 & 1.185604 & 0.645691 \\
\hline Test 4 & 4.9976 & 0.5609 & 0.30442 & -0.07188 & 9.959198 & 0.772172 & -0.629119 & & 1.7242967 & -1.091114 & 0.4619947 & 29.18 & 536 & 0.072133396 & 1.189902 & 0.654555 \\
\hline Test 5 & 4.9976 & 0.58313 & 0.31675 & -0.07471 & 10.353797 & 0.803453 & -0.653838 & & 1.7920827 & -1.135166 & 0.4813278 & 29.18 & 538 & 0.071865242 & 1.241294 & 0.684491 \\
\hline Test 6 & 4.9976 & 0.56935 & 0.30855 & -0.07305 & 10.109125 & 0.782652 & -0.639354 & & 1.7470069 & -1.105872 & 0.4665184 & 29.18 & 538 & 0.071865242 & 1.210072 & 0.663431 \\
\hline Test 7 & 4.9976 & 0.56165 & 0.30234 & -0.06966 & 9.9725 & 0.7669 & -0.609664 & & 1.7128723 & -1.083689 & 0.4740253 & 29.18 & 539 & 0.071731911 & 1.188634 & 0.675359 \\
\hline Test 8 & 4.9976 & 0.57337 & 0.30808 & -0.07076 & 10.180541 & 0.781457 & -0.619289 & & 1.7444173 & -1.104189 & 0.4849005 & 29.18 & 539 & 0.071731911 & 1.210524 & 0.690853 \\
\hline Test 9 & 4.9976 & 0.56054 & 0.30618 & -0.06992 & 9.952858 & 0.776631 & -0.611919 & & 1.7339594 & -1.097393 & 0.4854742 & 29.18 & 540 & 0.071599074 & 1.205499 & 0.692954 \\
\hline Test 10 & 4.9976 & 0.58454 & 0.31898 & -0.07277 & 10.378952 & 0.809089 & -0.636896 & & 1.8042959 & -1.143103 & 0.5062068 & 29.18 & 540 & 0.071599074 & 1.254399 & 0.722547 \\
\hline Average & 4.9976 & 0.570115 & 0.308602 & -0.07204 & 10.1227789 & 0.782777 & -0.630548 & & 1.7472784 & & & 29.184 & 537.2 & 0.071983748 & 1.208315 & 0.675165 \\
\hline Std & & & & & & & & & & & & & & & 0.023320 & 0.023350 \\
\hline Percent & & & & & & & & & & & & & & & $1.93 \%$ & $3.46 \%$ \\
\hline
\end{tabular}




\subsection{Experimental Data $-10 \%$ Twist (in-ground effect)}

Table 47: Experimental Data Runs - 10\% Twist Model (IGE) - $(-5)^{\circ}$ Angle of Attack

\begin{tabular}{|c|c|c|c|c|c|c|c|c|c|c|c|c|c|c|c|c|}
\hline \multicolumn{17}{|c|}{ 10P Twisted Models $-(-5)$ AoA $-\mathrm{Vel}=30 \mathrm{ft} / \mathrm{s}$} \\
\hline & Input V & Pitch V & Lift V & Drag V & Pitch Moment & Lift Force & Drag Force & Act. Pitch & Act. Lift & Drag Interf. & Act. Drag & $P[$ in $\mathrm{Hg}]$ & $T[R]$ & rho $[\mathrm{lb} / \mathrm{ft} 3]$ & $\mathrm{CL}$ & $C D$ \\
\hline Test 1 & 4.9976 & 0.128 & 0.079761 & -0.02221 & 2.272677 & 0.202315 & -0.19441 & & 0.4894166 & -0.288602 & 0.0941922 & 28.82 & 526 & 0.072597909 & 0.335575 & 0.123910601 \\
\hline Test 2 & 4.9976 & 0.12828 & 0.08078 & -0.01636 & 2.277679 & 0.204901 & -0.143202 & & 0.4950205 & -0.292244 & 0.149042 & 28.82 & 528 & 0.072322917 & 0.340708 & 0.196811455 \\
\hline Test 3 & 4.9976 & 0.12256 & 0.077051 & -0.01655 & 2.17608 & 0.195442 & -0.144826 & & 0.4745228 & -0.278923 & 0.1340971 & 28.82 & 528 & 0.072322917 & 0.3266 & 0.177076677 \\
\hline Test 4 & 4.9976 & 0.14105 & 0.086539 & -0.01741 & 2.50445 & 0.219508 & -0.152415 & & 0.5266738 & -0.312815 & 0.1603995 & 28.82 & 528 & 0.072322917 & 0.362494 & 0.211809251 \\
\hline Test 5 & 4.9976 & 0.15674 & 0.094962 & -0.01894 & 2.783097 & 0.240873 & -0.165759 & & 0.5729718 & -0.342902 & 0.1771432 & 28.82 & 530 & 0.07205 & 0.395854 & 0.234805477 \\
\hline Test 6 & 4.9976 & 0.13673 & 0.080401 & -0.01729 & 2.427737 & 0.203938 & -0.151351 & & 0.4929336 & -0.290888 & 0.1395368 & 28.82 & 530 & 0.07205 & 0.340557 & 0.184957742 \\
\hline Test 7 & 4.9976 & 0.14048 & 0.082788 & -0.0162 & 2.494358 & 0.209995 & -0.141742 & & 0.5060592 & -0.299418 & 0.1576757 & 28.82 & 532 & 0.071779135 & 0.350945 & 0.209789737 \\
\hline Test 8 & 4.9976 & 0.13366 & 0.082565 & -0.01674 & 2.373228 & 0.209428 & -0.146492 & & 0.5048305 & -0.298619 & 0.1521272 & 28.82 & 532 & 0.071779135 & 0.350093 & 0.202407394 \\
\hline Average & 4.9976 & 0.135938 & 0.083106 & -0.01771 & 2.41366325 & 0.2108 & -0.149398 & & 0.4164429 & -0.241179 & 0.117159 & 28.82 & 530.2 & 0.072024553 & 0.350353 & 0.202522533 \\
\hline Std & & & & & & & & & & & & & & & 0.021346 & 0.019017 \\
\hline Percent & & & & & & & & & & & & & & & $6.09 \%$ & $9.39 \%$ \\
\hline
\end{tabular}

Table 48: Experimental Data Runs - 10\% Twist Model (IGE) - $0^{\circ}$ Angle of Attack

\begin{tabular}{|c|c|c|c|c|c|c|c|c|c|c|c|c|c|c|c|c|}
\hline & Input V & Pitch V & Lift V & Drag V & Pitch Moment & Lift Force & Drag Force & Act. Pitch & Act. Lift & Drag Interf. & Act. Drag & $\mathrm{P}$ [in $\mathrm{Hg}]$ & $T[R]$ & rho $[\mathrm{lb} / \mathrm{ft} 3]$ & $\mathrm{CL}$ & $C D$ \\
\hline Test 1 & 6 & 0.33164 & 0.18407 & -0.04334 & 5.888478 & 0.466889 & \begin{tabular}{|l|}
-0.379337 \\
\end{tabular} & & 1.0627485 & -0.412408 & 0.0330714 & 29.29 & 522 & 0.074347222 & 0.711543 & 0.101567712 \\
\hline Test 2 & 6 & 0.32825 & 0.18207 & -0.04309 & 5.828315 & 0.461826 & -0.377088 & & 1.0517769 & -0.407858 & 0.0307696 & 29.29 & 522 & 0.074347222 & 0.704197 & 0.094498275 \\
\hline Test 3 & 6 & 0.3297 & 0.18479 & -0.04235 & 5.854061 & 0.468714 & -0.370638 & & 1.0667032 & -0.414049 & 0.0434108 & 29.29 & 528 & 0.073502367 & 0.7224 & 0.134854113 \\
\hline Test 4 & 6 & 0.31479 & 0.17636 & -0.03998 & 5.589339 & 0.447344 & -0.349899 & & 1.0203944 & -0.39484 & 0.0449414 & 29.29 & 528 & 0.073502367 & 0.691039 & 0.139608793 \\
\hline Test 5 & 6 & 0.32606 & 0.1839 & -0.04336 & 5.789351 & 0.466476 & -0.379513 & & 1.0618535 & -0.412037 & 0.0325242 & 29.29 & 530 & 0.073225 & 0.72184 & 0.101417932 \\
\hline Test 6 & 6 & 0.30264 & 0.17118 & -0.03992 & 5.373514 & 0.434209 & -0.349414 & & 0.9919309 & -0.383034 & 0.03362 & 29.29 & 530 & 0.073225 & 0.674307 & 0.104834916 \\
\hline Test 7 & 6 & 0.31023 & 0.17443 & -0.04178 & 5.508427 & 0.442435 & -0.365666 & & 1.0097566 & -0.390428 & 0.024762 & 29.29 & 532 & 0.072949718 & 0.689015 & 0.077504827 \\
\hline Test 8 & 6 & 0.31519 & 0.17684 & -0.04242 & 5.596367 & 0.448547 & -0.371301 & & 1.0230013 & -0.395922 & 0.0246207 & 29.29 & 532 & 0.072949718 & 0.698053 & 0.077062781 \\
\hline Test 9 & 6 & 0.32282 & 0.18191 & -0.04238 & 5.731903 & 0.461429 & -0.370881 & & 1.0509166 & -0.407501 & 0.0366197 & 29.29 & 534 & 0.072676498 & 0.719797 & 0.115050453 \\
\hline Test 10 & 6 & 0.31318 & 0.1764 & -0.04098 & 5.560667 & 0.447454 & -0.358689 & & 1.0206328 & -0.394939 & 0.0362503 & 29.29 & 534 & 0.072676498 & 0.699055 & 0.113889799 \\
\hline Average & 6 & 0.31945 & 0.179195 & \begin{tabular}{|l|}
-0.04196 \\
\end{tabular} & 5.6720422 & 0.454532 & -0.367243 & & & & & & & 0.073340161 & 0.703124 & 0.113215249 \\
\hline Std & & & & & & & & & & & & & & & 0.015950 & 0.016319 \\
\hline Percent & & & & & & & & & & & & & & & $2.27 \%$ & $14.41 \%$ \\
\hline
\end{tabular}


Table 49: Experimental Data Runs - 10\% Twist Model (IGE) - $5^{\circ}$ Angle of Attack

\begin{tabular}{|c|c|c|c|c|c|c|c|c|c|c|c|c|c|c|c|c|}
\hline \multicolumn{17}{|c|}{ 10P Twisted Models $-5 \mathrm{AoA}-\mathrm{Vel}=30 \mathrm{ft} / \mathrm{s}$} \\
\hline & Input V & Pitch V & Lift V & Drag V & Pitch Moment & Lift Force & Drag Force & Act. Pitch & Act. Lift & Drag Interf. & Act. Drag & $P$ [in $\mathrm{Hg}]$ & $T[R]$ & rho $[\mathrm{lb} / \mathrm{ft} 3]$ & $\mathrm{CL}$ & $C D$ \\
\hline Test 1 & 4.9976 & 0.44262 & 0.24027 & -0.05475 & 7.858979 & 0.609443 & -0.479184 & & 1.371663 & -0.647958 & 0.1687736 & 29.29 & 522 & 0.074347222 & 0.918371 & 0.355500447 \\
\hline Test 2 & 4.9976 & 0.43928 & 0.23815 & -0.05442 & 7.799771 & 0.604072 & -0.476298 & & 1.360024 & -0.642253 & 0.1659548 & 29.29 & 522 & 0.074347222 & 0.910578 & 0.349562925 \\
\hline Test 3 & 4.9976 & 0.44713 & 0.24345 & -0.05753 & 7.939066 & 0.617512 & -0.503547 & & 1.3891485 & -0.656528 & 0.1529811 & 29.29 & 528 & 0.073502367 & 0.940769 & 0.325939444 \\
\hline Test 4 & 4.9976 & 0.42057 & 0.22931 & -0.05336 & 7.467557 & 0.581654 & -0.467038 & & 1.3114442 & -0.618441 & 0.1514034 & 29.29 & 528 & 0.073502367 & 0.888145 & 0.3225779 \\
\hline Test 5 & 4.9976 & 0.43764 & 0.23977 & -0.05602 & 7.770518 & 0.608184 & -0.490258 & & 1.3689347 & -0.64662 & 0.1563624 & 29.29 & 531 & 0.0730871 & 0.932347 & 0.335036279 \\
\hline Test 6 & 4.9976 & 0.42628 & 0.23302 & -0.05414 & 7.568884 & 0.591058 & -0.473801 & & 1.3318227 & -0.62843 & 0.1546289 & 29.29 & 531 & 0.0730871 & 0.907071 & 0.331321993 \\
\hline Test 7 & 4.9976 & 0.43553 & 0.23912 & -0.05805 & 7.733049 & 0.60654 & -0.508065 & & 1.3653722 & -0.644874 & 0.1368092 & 29.29 & 532 & 0.072949718 & 0.931672 & 0.293691895 \\
\hline Test 8 & 4.9976 & 0.43113 & 0.237 & -0.05768 & 7.654989 & 0.601165 & -0.50484 & & 1.3537246 & -0.639165 & 0.1343251 & 29.29 & 532 & 0.072949718 & 0.923724 & 0.288359247 \\
\hline Test 9 & 4.9976 & 0.42792 & 0.23242 & -0.05616 & 7.597933 & 0.589531 & -0.491493 & & 1.3285137 & -0.626808 & 0.135315 & 29.29 & 534 & 0.072676498 & 0.909929 & 0.291576312 \\
\hline Test 10 & 4.9976 & 0.45037 & 0.24359 & -0.05843 & 7.996661 & 0.617877 & -0.511396 & & 1.3899395 & -0.656916 & 0.1455198 & 29.29 & 534 & 0.072676498 & 0.952001 & 0.313565686 \\
\hline Average & 4.9976 & 0.435847 & 0.23761 & -0.05605 & 7.7387407 & 0.602704 & -0.490592 & & 1.355436 & & & & & & 0.921461 & 0.312758595 \\
\hline Std & & & & & & & & & & & & & & & 0.018593 & 0.018971 \\
\hline Percent & & & & & & & & & & & & & & & $2.02 \%$ & $6.07 \%$ \\
\hline
\end{tabular}

Table 50: Experimental Data Runs - 10\% Twist Model (IGE) - $10^{\circ}$ Angle of Attack

\begin{tabular}{|c|c|c|c|c|c|c|c|c|c|c|c|c|c|c|c|c|}
\hline \multicolumn{17}{|c|}{ 10P Twisted Models $-10 \mathrm{AoA}-\mathrm{Vel}=30 \mathrm{ft} / \mathrm{s}$} \\
\hline & Input V & Pitch V & Lift V & Drag V & Pitch Moment & Lift Force & Drag Force & Act. Pitch & Act. Lift & Drag Interf. & Act. Drag & $P$ [in $\mathrm{Hg}]$ & $T[R]$ & rho $[\mathrm{lb} / \mathrm{ft} 3]$ & $\mathrm{CL}$ & $C D$ \\
\hline Test 1 & 4.9976 & 0.52501 & 0.28404 & -0.06739 & 9.321909 & 0.720483 & -0.58978 & & 1.6122867 & -0.895676 & 0.3058955 & 29.29 & 526 & 0.073781844 & 1.087748 & 0.495666031 \\
\hline Test 2 & 4.9976 & 0.54071 & 0.29198 & -0.0697 & 9.600612 & 0.740626 & -0.609993 & & 1.6559365 & -0.921043 & 0.3110501 & 29.29 & 526 & 0.073781844 & 1.117197 & 0.504018369 \\
\hline Test 3 & 4.9976 & 0.53376 & 0.28928 & -0.06762 & 9.477327 & 0.733774 & -0.591792 & & 1.6410883 & -0.912414 & 0.3206219 & 29.29 & 530 & 0.073225 & 1.115599 & 0.523479031 \\
\hline Test 4 & 4.9976 & 0.51421 & 0.27898 & -0.06536 & 9.130231 & 0.707649 & -0.57203 & & 1.5844754 & -0.879513 & 0.3074827 & 29.29 & 530 & 0.073225 & 1.077114 & 0.502026771 \\
\hline Test 5 & 4.9976 & 0.50516 & 0.27464 & -0.06602 & 8.969473 & 0.696622 & -0.577822 & & 1.5605799 & -0.865626 & 0.2878036 & 29.29 & 531 & 0.0730871 & 1.062872 & 0.470783295 \\
\hline Test 6 & 4.9976 & 0.52737 & 0.28584 & -0.06841 & 9.36385 & 0.725051 & -0.598732 & & 1.6221855 & -0.901428 & 0.3026963 & 29.29 & 531 & 0.0730871 & 1.10483 & 0.49514453 \\
\hline Test 7 & 4.9976 & 0.53631 & 0.28873 & -0.06752 & 9.522514 & 0.732373 & -0.590976 & & 1.6380523 & -0.910649 & 0.3196735 & 29.29 & 531 & 0.0730871 & 1.115636 & 0.522915382 \\
\hline Test 8 & 4.9976 & 0.52139 & 0.2795 & -0.06521 & 9.257682 & 0.708948 & -0.570742 & & 1.5872903 & -0.881149 & 0.3104066 & 29.29 & 531 & 0.0730871 & 1.081063 & 0.507756891 \\
\hline Test 9 & 4.9976 & 0.52705 & 0.28365 & -0.0666 & 9.358115 & 0.719496 & -0.582865 & & 1.6101478 & -0.894433 & 0.3115675 & 29.29 & 534 & 0.072676498 & \begin{tabular}{|l|}
1.102827 \\
\end{tabular} & 0.512535236 \\
\hline Test 10 & 4.9976 & 0.52157 & 0.28048 & -0.06557 & 9.260879 & 0.711442 & -0.573845 & & 1.5926948 & -0.88429 & 0.3104445 & 29.29 & 534 & 0.072676498 & 1.090873 & 0.510687884 \\
\hline Average & 4.9976 & 0.525254 & 0.283712 & -0.06694 & 9.3262592 & 0.719646 & -0.585858 & & 1.6104737 & -0.894622 & 0.3087642 & 29.29 & 530.4 & 0.073171508 & 1.095576 & 0.504501342 \\
\hline Std & & & & & & & & & & & & & & & 0.018599 & 0.015353 \\
\hline Percent & & & & & & & & & & & & & & & $1.70 \%$ & $3.04 \%$ \\
\hline
\end{tabular}


Table 51: Experimental Data Runs - 10\% Twist Model (IGE) - $15^{\circ}$ Angle of Attack

\begin{tabular}{|c|c|c|c|c|c|c|c|c|c|c|c|c|c|c|c|c|}
\hline \multicolumn{17}{|c|}{ 10P Twisted Models $-15 \mathrm{AoA}-\mathrm{Vel}=30 \mathrm{ft} / \mathrm{s}$} \\
\hline & Input V & Pitch V & Lift V & Drag V & Pitch Moment & Lift Force & Drag Force & Act. Pitch & Act. Lift & Drag Interf. & Act. Drag & $P$ [in $\mathrm{Hg}]$ & $T[R]$ & rho $[\mathrm{lb} / \mathrm{ft} 3]$ & $\mathrm{CL}$ & $C D$ \\
\hline Test 1 & 4.9976 & 0.60815 & 0.32889 & -0.07478 & 10.798101 & 0.834246 & -0.654495 & & 1.8588111 & -1.178531 & 0.5240356 & 29.29 & 526 & 0.073781844 & 1.254068 & 0.678311263 \\
\hline Test 2 & 4.9976 & 0.58754 & 0.31789 & -0.07179 & 10.43226 & 0.806329 & -0.628298 & & 1.7983149 & -1.139216 & 0.5109179 & 29.29 & 526 & 0.073781844 & 1.213254 & 0.661331817 \\
\hline Test 3 & 4.9976 & 0.61256 & 0.33209 & -0.07525 & 10.876478 & 0.842346 & -0.658593 & & 1.8763638 & -1.189938 & 0.5313445 & 29.29 & 530 & 0.073225 & 1.275537 & 0.693002198 \\
\hline Test 4 & 4.9976 & 0.5993 & 0.32377 & -0.0735 & 10.640919 & 0.821249 & -0.643257 & & 1.8306466 & -1.160227 & 0.5169703 & 29.29 & 530 & 0.073225 & 1.244459 & 0.674254706 \\
\hline Test 5 & 4.9976 & 0.59215 & 0.32292 & -0.07195 & 10.513982 & 0.819099 & -0.629714 & & 1.8259875 & -1.1572 & 0.5274855 & 29.29 & 531 & 0.0730871 & 1.243634 & 0.689267163 \\
\hline Test 6 & 4.9976 & 0.56464 & 0.30774 & -0.06895 & 10.025616 & 0.780581 & -0.603461 & & 1.742519 & -1.102956 & 0.4994948 & 29.29 & 531 & 0.0730871 & 1.186786 & 0.652691647 \\
\hline Test 7 & 4.9976 & 0.60356 & 0.32928 & -0.07451 & 10.716626 & 0.835239 & -0.652125 & & 1.8609629 & -1.179929 & 0.527804 & 29.29 & 532 & 0.072949718 & 1.269842 & 0.690982122 \\
\hline Test 8 & 4.9976 & 0.58086 & 0.31837 & -0.07148 & 10.313592 & 0.807557 & -0.625639 & & 1.800976 & -1.140945 & 0.5153063 & 29.29 & 532 & 0.072949718 & 1.228909 & 0.674620601 \\
\hline Test 9 & 4.9976 & 0.57938 & 0.314 & -0.07134 & 10.287248 & 0.796468 & -0.624374 & & 1.7769462 & -1.125329 & 0.500955 & 29.29 & 534 & 0.072676498 & 1.217071 & 0.658297944 \\
\hline Test 10 & 4.9976 & 0.57575 & 0.31231 & -0.07062 & 10.222865 & 0.792192 & -0.618063 & & 1.7676801 & -1.119307 & 0.5012442 & 29.29 & 534 & 0.072676498 & 1.210724 & 0.658678036 \\
\hline Average & 4.9976 & 0.590389 & 0.320726 & -0.07242 & 10.4827687 & 0.813531 & -0.633802 & & 1.8139208 & -1.149358 & 0.5155558 & 29.29 & 530.6 & 0.073144032 & 1.234428 & 0.67314375 \\
\hline Std & & & & & & & & & & & & & & & 0.028140 & 0.014870 \\
\hline Percent & & & & & & & & & & & & & & & $2.28 \%$ & $2.21 \%$ \\
\hline
\end{tabular}




\subsection{Experimental Data - 10\% Spanwise Curve (in-ground effect)}

Table 52: Experimental Data Runs - 10\% Spanwise Curve Model (IGE) - $0^{\circ}$ Angle of Attack

\begin{tabular}{|c|c|c|c|c|c|c|c|c|c|c|c|c|c|c|c|}
\hline \multicolumn{16}{|c|}{ 10P Curved - $0 \mathrm{AoA}-\mathrm{Vel}=30 \mathrm{ft} / \mathrm{s}(\mathrm{Vel} 2)$} \\
\hline & Input V & Pitch V & Lift V & Drag V & Pitch Moment & Lift Force & Drag Force & Act. Lift & Drag Interf. & Act. Drag & $\mathrm{P}$ [in $\mathrm{Hg}]$ & $\mathrm{T}[\mathrm{R}]$ & rho $[\mathrm{lb} / \mathrm{ft} 3]$ & $\mathrm{CL}$ & $C D$ \\
\hline Test 1 & 4.9976 & 0.096627 & 0.06778 & -0.01315 & 1.715683 & 0.171922 & -0.115093 & 0.423555 & -0.147277 & 0.0321844 & 29.14 & 524 & 0.07368416 & 0.286135 & 0.161093 \\
\hline Test 2 & 4.9976 & 0.08993 & 0.060805 & -0.01089 & 1.59676 & 0.154234 & -0.095341 & 0.3852251 & -0.131379 & 0.0360375 & 29.14 & 524 & 0.07368416 & 0.260241 & 0.180379 \\
\hline Test 3 & 4.9976 & 0.08829 & 0.064562 & -0.01266 & 1.567653 & 0.163762 & -0.110837 & 0.4058723 & -0.139943 & 0.0291058 & 29.14 & 528 & 0.073125947 & 0.276282 & 0.146795 \\
\hline Test 4 & 4.9976 & 0.080394 & 0.059573 & -0.01103 & 1.427448 & 0.151108 & -0.096544 & 0.378451 & -0.128569 & 0.0320247 & 29.14 & 528 & 0.073125947 & \begin{tabular}{|l|}
0.257617 \\
\end{tabular} & 0.161517 \\
\hline Test 5 & 4.9976 & 0.095737 & \begin{tabular}{|l|}
0.069098 \\
\end{tabular} & -0.01313 & 1.69987 & 0.175268 & -0.114872 & 0.4308058 & -0.150285 & 0.0354129 & 29.14 & 530 & 0.07285 & \begin{tabular}{|l|}
0.294366 \\
\end{tabular} & 0.179282 \\
\hline Test 6 & 4.9976 & 0.097886 & 0.070163 & -0.01355 & 1.738031 & \begin{tabular}{|l|}
0.177969 \\
\end{tabular} & -0.118605 & 0.4366588 & -0.152713 & 0.0341077 & 29.14 & 530 & 0.07285 & \begin{tabular}{|l|}
0.298365 \\
\end{tabular} & 0.172674 \\
\hline Test 7 & 4.9976 & 0.079658 & 0.059306 & -0.01121 & 1.414376 & \begin{tabular}{|l|}
0.150432 \\
\end{tabular} & -0.098117 & 0.3769861 & -0.127961 & 0.0298441 & 29.14 & 531 & 0.072712806 & \begin{tabular}{|l|}
0.258077 \\
\end{tabular} & 0.151374 \\
\hline Test 8 & 4.9976 & 0.084407 & \begin{tabular}{|l|}
0.061591 \\
\end{tabular} & -0.01058 & 1.498697 & \begin{tabular}{|l|}
0.156227 \\
\end{tabular} & -0.092598 & 0.3895439 & -0.13317 & 0.0405719 & 29.14 & 531 & 0.072712806 & \begin{tabular}{|l|}
0.266674 \\
\end{tabular} & 0.205788 \\
\hline Test 9 & 4.9976 & 0.083443 & 0.06069 & -0.01079 & 1.481594 & 0.153942 & -0.094399 & 0.3845923 & -0.131116 & 0.036717 & 29.14 & 532 & 0.072576128 & 0.26378 & 0.186586 \\
\hline Test 10 & 4.9976 & 0.08772 & 0.063313 & -0.01084 & 1.557521 & 0.160594 & -0.094879 & 0.3990072 & -0.137095 & 0.0422162 & 29.14 & 532 & 0.072576128 & 0.273667 & 0.214531 \\
\hline Average & 4.9976 & 0.088409 & 0.063688 & -0.01178 & 1.5697633 & 0.161546 & -0.103129 & 0.4010697 & -0.137951 & 0.0348222 & 29.14 & 529 & 0.072989808 & 0.267809 & 0.179247 \\
\hline Std & & & & & & & & & & & & & & 0.010109 & \begin{tabular}{|l|l|}
0.019631 \\
\end{tabular} \\
\hline Percent & & & & & & & & & & & & & & $3.77 \%$ & $10.95 \%$ \\
\hline
\end{tabular}

Table 53: Experimental Data Runs - 10\% Spanwise Curve Model (IGE) - $5^{\circ}$ Angle of Attack

\begin{tabular}{|c|c|c|c|c|c|c|c|c|c|c|c|c|c|c|c|}
\hline \multicolumn{16}{|c|}{ 10P Curved Models $-5 \mathrm{AoA}-\mathrm{Vel}=30 \mathrm{ft} / \mathrm{s}$} \\
\hline & Input V & Pitch V & Lift V & Drag V & Pitch Moment & Lift Force & Drag Force & Act. Lift & Drag Interf. & Act. Drag & $P$ [in $\mathrm{Hg}]$ & $\mathrm{T}[\mathrm{R}]$ & rho $[\mathrm{lb} / \mathrm{ft} 3]$ & $\mathrm{CL}$ & $C D$ \\
\hline Test 1 & 4.9976 & 0.21493 & 0.12881 & -0.02748 & \begin{tabular}{|l|}
3.81627 \\
\end{tabular} & 0.326738 & -0.240526 & 0.7590412 & -0.347681 & 0.1071551 & 29.14 & 526 & 0.073403992 & 0.514732 & 0.332449 \\
\hline Test 2 & 4.9976 & 0.23459 & 0.13953 & -0.03044 & 4.165334 & 0.353927 & -0.266371 & 0.8179598 & -0.37656 & 0.110189 & 29.14 & 526 & 0.073403992 & 0.554687 & 0.341862 \\
\hline Test 3 & 4.9976 & 0.24863 & 0.14801 & -0.03381 & 4.414548 & 0.375439 & -0.295899 & 0.8645763 & -0.399409 & 0.1035101 & 29.14 & 530 & 0.07285 & 0.590758 & 0.323583 \\
\hline Test 4 & 4.9976 & 0.24129 & 0.1428 & -0.0325 & 4.284236 & 0.362214 & -0.284401 & 0.8359177 & -0.385362 & 0.1009611 & 29.14 & 530 & 0.07285 & 0.571175 & 0.315615 \\
\hline Test 5 & 4.9976 & 0.2276 & 0.13527 & -0.02996 & 4.041267 & 0.343114 & -0.26219 & 0.794528 & -0.365075 & 0.1028849 & 29.14 & 530 & 0.07285 & 0.542894 & 0.321629 \\
\hline Test 6 & 4.9976 & 0.2291 & 0.13748 & -0.02944 & 4.067816 & 0.348726 & -0.257653 & 0.8066892 & -0.371036 & \begin{tabular}{|l|l|}
0.1133827 \\
\end{tabular} & 29.14 & 530 & 0.07285 & 0.551204 & 0.354446 \\
\hline Test 7 & 4.9976 & 0.22084 & 0.13367 & -0.03014 & 3.921113 & 0.339068 & -0.263794 & \begin{tabular}{|l|l|}
0.7857604 \\
\end{tabular} & -0.360777 & 0.0969834 & 29.14 & 532 & 0.072576128 & 0.538929 & 0.304324 \\
\hline Test 8 & 4.9976 & 0.21959 & 0.13176 & -0.02949 & 3.899019 & 0.334208 & -0.258092 & 0.7752287 & -0.355615 & 0.0975234 & 29.14 & 532 & 0.072576128 & 0.531706 & 0.306018 \\
\hline Test 9 & 4.9976 & 0.22383 & 0.1348 & -0.03044 & 3.974249 & 0.341911 & -0.266382 & 0.7919211 & -0.363797 & 0.0974151 & 29.14 & 534 & 0.072304307 & 0.545197 & 0.306828 \\
\hline Test 10 & 4.9976 & 0.2259 & 0.13477 & -0.03024 & 4.010966 & 0.341851 & -0.26466 & 0.7917911 & \begin{tabular}{|c|}
-0.363733 \\
\end{tabular} & \begin{tabular}{|l|l|}
0.0990734 \\
\end{tabular} & 29.14 & 534 & 0.072304307 & 0.545107 & 0.312051 \\
\hline Average & 4.9976 & 0.22863 & 0.13669 & -0.03039 & 4.0594818 & 0.34672 & -0.265997 & 0.8071525 & & & & & & 0.548639 & 0.321881 \\
\hline Std & & & & & & & & & & & & & & \begin{tabular}{|l|l|}
0.020851 \\
\end{tabular} & 0.016656 \\
\hline Percent & & & & & & & & & & & & & & $3.80 \%$ & $5.17 \%$ \\
\hline
\end{tabular}


Table 54: Experimental Data Runs - 10\% Spanwise Curve Model (IGE) - $10^{\circ}$ Angle of Attack

\begin{tabular}{|c|c|c|c|c|c|c|c|c|c|c|c|c|c|c|c|}
\hline \multicolumn{16}{|c|}{ 10P Curved Models $-10 \mathrm{AoA}-\mathrm{Vel}=30 \mathrm{ft} / \mathrm{s}$} \\
\hline & Input V & Pitch V & Lift V & Drag V & Pitch Moment & Lift Force & Drag Force & Act. Lift & Drag Interf. & Act. Drag & $\mathrm{P}$ [in $\mathrm{Hg}$ ] & $\mathrm{T}[\mathrm{R}]$ & rho $[\mathrm{lb} / \mathrm{ft} 3]$ & $\mathrm{CL}$ & $C D$ \\
\hline Test 1 & 4.9976 & 0.36061 & 0.2037 & -0.04626 & 6.40289 & 0.516693 & -0.404888 & 1.1706737 & -0.639028 & 0.2341397 & 29.14 & 527 & 0.073264706 & 0.795383 & 0.531382 \\
\hline Test 2 & 4.9976 & 0.36074 & 0.20432 & -0.04602 & 6.405173 & 0.518272 & -0.402785 & 1.1740954 & -0.641016 & 0.2382313 & 29.14 & 527 & 0.073264706 & 0.797708 & 0.540668 \\
\hline Test 3 & 4.9976 & 0.36191 & 0.20577 & -0.04791 & 6.426021 & 0.521951 & -0.419345 & 1.1820678 & -0.64565 & 0.2263045 & 29.14 & 530 & 0.07285 & 0.807697 & 0.516524 \\
\hline Test 4 & 4.9976 & 0.35557 & 0.20118 & -0.04664 & 6.31346 & 0.51029 & -0.408228 & 1.1567984 & -0.630964 & 0.222736 & 29.14 & 530 & 0.07285 & 0.79043 & \begin{tabular}{|l|}
0.508379 \\
\end{tabular} \\
\hline Test 5 & 4.9976 & 0.37103 & 0.20851 & -0.04872 & 6.587859 & 0.528903 & -0.426445 & 1.1971328 & -0.654405 & 0.2279597 & 29.14 & 530 & 0.07285 & 0.817991 & 0.520301 \\
\hline Test 6 & 4.9976 & 0.364 & 0.20501 & -0.04739 & 6.463111 & 0.520012 & -0.414802 & 1.177866 & -0.643208 & 0.2284056 & 29.14 & 530 & 0.07285 & 0.804826 & \begin{tabular}{|l|}
0.521319 \\
\end{tabular} \\
\hline Test 7 & 4.9976 & 0.35329 & 0.19972 & -0.04853 & 6.27292 & 0.506588 & -0.424705 & 1.1487762 & -0.626302 & 0.2015968 & 29.14 & 532 & 0.072576128 & \begin{tabular}{|l|}
0.787911 \\
\end{tabular} & 0.461866 \\
\hline Test 8 & 4.9976 & 0.35633 & 0.19864 & -0.04806 & 6.326916 & 0.503866 & -0.420628 & 1.1428776 & -0.622874 & 0.2022458 & 29.14 & 532 & 0.072576128 & \begin{tabular}{|l|}
0.783865 \\
\end{tabular} & 0.463353 \\
\hline Test 9 & 4.9976 & 0.35827 & 0.20382 & -0.04745 & 6.361341 & 0.516987 & -0.415315 & 1.1713108 & -0.639398 & 0.224083 & 29.14 & 534 & 0.072304307 & 0.806387 & 0.515313 \\
\hline Test 10 & 4.9976 & 0.36233 & 0.20543 & -0.0477 & 6.433485 & \begin{tabular}{|l|}
0.521075 \\
\end{tabular} & -0.417433 & 1.1801695 & -0.644546 & 0.2271133 & 29.14 & 534 & 0.072304307 & \begin{tabular}{|l|}
0.812486 \\
\end{tabular} & \begin{tabular}{|l|}
0.522282 \\
\end{tabular} \\
\hline Average & 4.9976 & 0.360408 & 0.20361 & -0.04747 & 6.3993176 & 0.516464 & -0.415457 & 1.1701768 & & & 29.14 & 530.6 & 0.072769028 & 0.800468 & 0.510139 \\
\hline Std & & & & & & & & & & & & & & 0.011182 & 0.026560 \\
\hline Percent & & & & & & & & & & & & & & $1.40 \%$ & $5.21 \%$ \\
\hline
\end{tabular}

Table 55: Experimental Data Runs - 10\% Spanwise Curve Model (IGE) - $15^{\circ}$ Angle of Attack

\begin{tabular}{|c|c|c|c|c|c|c|c|c|c|c|c|c|c|c|c|}
\hline \multicolumn{8}{|c|}{ 10P Curved Models $-15 \mathrm{AoA}-\mathrm{Vel}=30 \mathrm{ft} / \mathrm{s}$} & & & & & & & & \\
\hline & Input V & Pitch V & Lift V & Drag V & Pitch Moment & Lift Force & Drag Force & Act. Lift & Drag Interf. & Act. Drag & $\mathrm{P}[$ in $\mathrm{Hg}]$ & $\mathrm{T}[\mathrm{R}]$ & rho $[\mathrm{lb} / \mathrm{ft} 3]$ & $\mathrm{CL}$ & $C D$ \\
\hline Test 1 & 4.9976 & 0.466 & 0.25966 & -0.06013 & 8.274116 & 0.658642 & -0.526232 & 1.4782772 & -0.931233 & 0.405001 & 29.14 & 528 & 0.073125947 & 1.006282 & 0.6753 \\
\hline Test 2 & 4.9976 & 0.4586 & 0.25485 & -0.05875 & 8.142832 & 0.646437 & -0.514188 & 1.451829 & -0.914045 & 0.3998571 & 29.14 & 528 & 0.073125947 & 0.988279 & 0.666723 \\
\hline Test 3 & 4.9976 & 0.47226 & 0.26258 & -0.06185 & 8.385246 & 0.666053 & -0.541283 & 1.4943369 & -0.94167 & 0.4003867 & 29.14 & 530 & 0.07285 & \begin{tabular}{|l|}
1.021068 \\
\end{tabular} & 0.670134 \\
\hline Test 4 & 4.9976 & 0.46299 & 0.25745 & -0.06041 & 8.220676 & 0.653025 & -0.528692 & 1.4661052 & -0.923323 & 0.3946308 & 29.14 & 530 & 0.07285 & 1.001777 & \begin{tabular}{|l|}
0.660501 \\
\end{tabular} \\
\hline Test 5 & 4.9976 & 0.44105 & 0.24666 & -0.05862 & 7.831148 & 0.625652 & -0.513018 & 1.4067879 & -0.884774 & 0.3717562 & 29.14 & 531 & 0.072712806 & 0.96306 & 0.623389 \\
\hline Test 6 & 4.9976 & 0.44047 & 0.24591 & -0.05809 & 7.820809 & 0.623768 & -0.508428 & 1.4027053 & -0.882121 & 0.3736931 & 29.14 & 531 & 0.072712806 & 0.960265 & \begin{tabular}{|l|}
0.626637 \\
\end{tabular} \\
\hline Test 7 & 4.9976 & 0.45642 & 0.25415 & -0.05946 & 8.104016 & \begin{tabular}{|l|}
0.644669 \\
\end{tabular} & -0.520402 & 1.4479977 & -0.911555 & 0.3911533 & 29.14 & 532 & 0.072576128 & \begin{tabular}{|l|}
0.993138 \\
\end{tabular} & \begin{tabular}{|l|}
0.657151 \\
\end{tabular} \\
\hline Test 8 & 4.9976 & 0.44497 & 0.24704 & -0.05713 & 7.900782 & \begin{tabular}{|l|}
0.626614 \\
\end{tabular} & -0.50001 & 1.4088725 & -0.886129 & 0.386119 & 29.14 & 532 & 0.072576128 & \begin{tabular}{|l|}
0.966303 \\
\end{tabular} & 0.648693 \\
\hline Test 9 & 4.9976 & 0.44667 & 0.24809 & -0.05733 & 7.930967 & 0.629288 & -0.501776 & 1.4146671 & -0.889895 & 0.3881187 & 29.14 & 534 & 0.072304307 & 0.973925 & 0.654504 \\
\hline Test 10 & 4.9976 & 0.44554 & 0.24704 & -0.05677 & 7.910827 & 0.626635 & -0.496893 & 1.408918 & -0.886159 & 0.3892656 & 29.14 & 534 & 0.072304307 & \begin{tabular}{|l|}
0.969967 \\
\end{tabular} & 0.656438 \\
\hline Average & 4.9976 & 0.453497 & 0.252343 & -0.05885 & 8.0521419 & \begin{tabular}{|l|}
0.640078 \\
\end{tabular} & -0.515092 & 1.4380497 & -0.90509 & 0.3899981 & 29.14 & 531 & 0.072713838 & 0.984406 & 0.653947 \\
\hline Std & & & & & & & & & & & & & & \begin{tabular}{|l|}
0.020817 \\
\end{tabular} & 0.017153 \\
\hline Percent & & & & & & & & & & & & & & \begin{tabular}{|l|}
$2.11 \%$ \\
\end{tabular} & $2.62 \%$ \\
\hline
\end{tabular}




\subsection{Experimental Data Variance}

Table 56: Variation in the Experimental Data Set across Test Runs

\begin{tabular}{|c|c|c|c|c|c|c|c|c|c|c|}
\hline \multicolumn{10}{|c|}{ Preestream } & \multicolumn{2}{c|}{ Baseline } & \multicolumn{2}{c|}{$6 \%$ Twisted } & \multicolumn{2}{c|}{$10 \%$ Twisted } & \multicolumn{2}{c|}{$10 \%$ Curved } \\
\hline & \multicolumn{1}{|c|}{ Freercent Variation } \\
\hline & $\mathrm{CL}$ & $\mathrm{CD}$ & $\mathrm{CL}$ & $\mathrm{CD}$ & $\mathrm{CL}$ & $\mathrm{CD}$ & $\mathrm{CL}$ & $\mathrm{CD}$ & $\mathrm{CL}$ & $\mathrm{CD}$ \\
\hline 0 & $5.17 \%$ & $6.59 \%$ & $4.30 \%$ & $18.90 \%$ & $3.08 \%$ & $18.78 \%$ & $2.27 \%$ & $14.41 \%$ & $3.77 \%$ & $10.95 \%$ \\
\hline 5 & $4.42 \%$ & $13.69 \%$ & $2.40 \%$ & $9.76 \%$ & $3.15 \%$ & $2.07 \%$ & $2.02 \%$ & $6.07 \%$ & $3.80 \%$ & $5.17 \%$ \\
\hline 10 & $2.89 \%$ & $10.28 \%$ & $1.60 \%$ & $9.13 \%$ & $1.91 \%$ & $3.23 \%$ & $1.70 \%$ & $3.04 \%$ & $1.40 \%$ & $5.21 \%$ \\
\hline 15 & $3.13 \%$ & $13.60 \%$ & $1.69 \%$ & $3.99 \%$ & $1.93 \%$ & $3.46 \%$ & $2.28 \%$ & $2.21 \%$ & $2.11 \%$ & $2.62 \%$ \\
\hline
\end{tabular}

Table 57: Standard Deviation in the Experimental Data Set across Test Runs

\begin{tabular}{|c|c|c|c|c|c|c|c|c|c|c|}
\hline \multicolumn{10}{|c|}{ Standard Deviation } \\
\hline & \multicolumn{2}{|c|}{ Freestream } & \multicolumn{2}{c|}{ Baseline } & \multicolumn{2}{c|}{$6 \%$ Twisted } & \multicolumn{2}{c|}{$10 \%$ Twisted } & \multicolumn{2}{c|}{$10 \%$ Curved } \\
\hline & $\mathrm{CL}$ & $\mathrm{CD}$ & $\mathrm{CL}$ & $\mathrm{CD}$ & $\mathrm{CL}$ & $\mathrm{CD}$ & $\mathrm{CL}$ & $\mathrm{CD}$ & $\mathrm{CL}$ & $\mathrm{CD}$ \\
\hline 0 & 0.0181 & 0.0183 & 0.0183 & 0.0584 & 0.0180 & 0.0209 & 0.0160 & 0.0163 & 0.0101 & 0.0196 \\
\hline 5 & 0.0243 & 0.0471 & 0.0179 & 0.0474 & 0.0269 & 0.0064 & 0.0186 & 0.0190 & 0.0209 & 0.0167 \\
\hline 10 & 0.0220 & 0.0520 & 0.0151 & 0.0547 & 0.0204 & 0.0165 & 0.0186 & 0.0154 & 0.0112 & 0.0266 \\
\hline 15 & 0.0298 & 0.0843 & 0.0192 & 0.0308 & 0.0233 & 0.0233 & 0.0281 & 0.0149 & 0.0208 & 0.0172 \\
\hline
\end{tabular}

